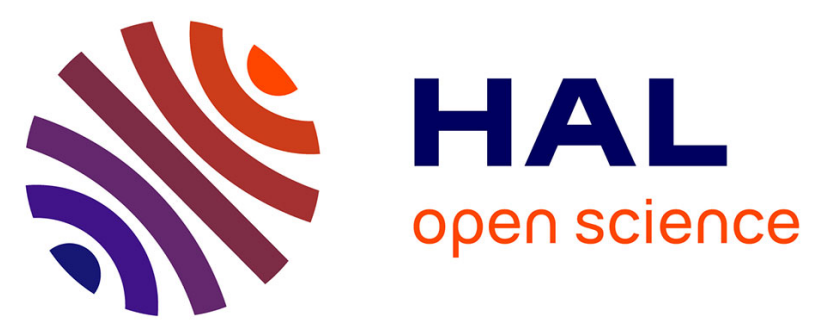

\title{
Molecular and morphological recognition of species boundaries in the neglected ant genus Brachymyrmex (Hymenoptera: Formicidae): toward a taxonomic revision
}

Claudia M Ortiz-Sepulveda, Bert Van Bocxlaer, Andrés D Meneses, Fernando Fernandez

\section{To cite this version:}

Claudia M Ortiz-Sepulveda, Bert Van Bocxlaer, Andrés D Meneses, Fernando Fernandez. Molecular and morphological recognition of species boundaries in the neglected ant genus Brachymyrmex (Hymenoptera: Formicidae): toward a taxonomic revision. Organisms Diversity and Evolution, 2019, 19 (3), pp.447-542. 10.1007/s13127-019-00406-2 . hal-02323851

\section{HAL Id: hal-02323851 https://hal.science/hal-02323851}

Submitted on 16 Aug 2021

HAL is a multi-disciplinary open access archive for the deposit and dissemination of scientific research documents, whether they are published or not. The documents may come from teaching and research institutions in France or abroad, or from public or private research centers.
L'archive ouverte pluridisciplinaire HAL, est destinée au dépôt et à la diffusion de documents scientifiques de niveau recherche, publiés ou non, émanant des établissements d'enseignement et de recherche français ou étrangers, des laboratoires publics ou privés. 
1 Molecular and morphological recognition of species boundaries in the

2 neglected ant genus Brachymyrmex (Hymenoptera: Formicidae): towards a

\section{3 taxonomic revision}

5 Claudia M. Ortiz-Sepulveda ${ }^{1,2, *}$, Bert Van Bocxlaer ${ }^{1}$, Andrés D. Meneses ${ }^{2}$, Fernando Fernández ${ }^{2}$

$7 \quad{ }^{1}$ Université de Lille, CNRS, UMR 8198 - Evo-Eco-Paleo, F-59000 Lille, France.

$8 \quad{ }^{2}$ Instituto de Ciencias Naturales, Universidad Nacional de Colombia, Carrera 30 \# 45 - 03, Bogotá,

9 Colombia.

ORCID: CMOS: 0000-0003-0072-719X; BVB: 0000-0003-2033-326X.

11 *Corresponding author. E-mail: claudia.ortiz-sepulveda@univ-lille.fr; Tel.: +33 320434015.

\section{ABSTRACT}

Brachymyrmex is a neglected genus of Formicinae because of its small body size, soft mesosoma and superficially monotonous external morphology. These features have complicated the documentation of morphological variation, resulting in poorly-defined and incompletely described species. Consequently, the taxonomy of the genus is complex and problematic, which

18 has impeded research and conservation efforts. Here we integrate molecular and morphological data to recognize species boundaries in Brachymyrmex and to guide its long-overdue revision. Specifically, we (1) redefine the limits of all described species, subspecies and varieties based on intra- and interspecific morphological variation in workers; (2) document this variation quantitatively by constructing morphospace occupation and statistically analyzing measurements; 
and (4) examine the significance of our morphological identification system with molecular evidence from four genes (EF1aEF1, EF1aEF2, WG and COI). We recognize 40 species, of which four are new to science: B. bahamensis, B. bicolor, B. iridescens and B. sosai.

Furthermore, Brachymyrmex attenuatus and B. bonariensis are raised to species, and we propose 25 new synonyms. Morphometrics indicated that even poorly distinguishable species pairs show statistically significant differences in some traits, and that taxonomically problematic cases relate monophyly of the genus based on increased taxon sampling, and of the 19 species that were

to taxa that demonstrate large intraspecific trait variance. Our molecular analysis supports the included 18 were retrieved as monophyletic. The single case of incongruence was also flagged in morphological analyses and requires extended geographic sampling before it can be resolved. In conclusion, the molecular work corroborates the morphologically-recognized species boundaries. We also document the presence of worker dimorphism and putative worker-queen intercastes in several Brachymyrmex species, which indicates that the genus may present a promising study system to understand caste evolution in ants.

Keywords. Brachymyrmex, Formicinae, phylogeny, taxonomy, neotropics, morphometrics.

\section{INTRODUCTION}

Brachymyrmex is a neglected genus of Formicinae that consists of minute ants (maximum length

$\sim 3 \mathrm{~mm}$ ), which are morphologically diagnosed by the presence of an acidopore and antennae with 9 segments lacking a club (Bolton 2003). The combination of their small body size, soft metasoma, and at least superficially monotonous external morphology complicate the observation and interpretation of morphological variation. Brachymyrmex is native to America and predominantly Neotropical. It ranges from the south of Canada to Argentina and Chile, including 

pointed out that these tiny ants are easily transported with living plants, and beyond the native distribution some species have been introduced to, among others, various places in Africa (Forel 1895a; Dejean et al. 2010), Europe (Forel 1874), and Asia (Guénard 2018; Yoshimura pers. comm.). Brachymyrmex heeri and B. longicornis, for example, were described by Forel (1874; 1907) from ant colonies in European greenhouses and B. cordemoyi was described from Réunion are considered pests in the southern United States (MacGown et al. 2007) and probably beyond.

(Forel 1895a). Some Brachymyrmex species, like B. patagonicus, are notorious invaders which

The only complete taxonomic treatment of Brachymyrmex was published by Santschi (1923a) and included 27 species and 15 subspecies and varieties. The work was based on worker morphology, but unfortunately the identification key is difficult to use because it includes polytomous steps with strongly overlapping character suites. Furthermore, character descriptions are regularly ambiguous and contain contradictions. As a result, species, subspecies and varieties are often poorly defined and incompletely described (De Zolessi et al. 1978). The small size and taxonomic ambiguity prompted Creighton (1950) to label Brachymyrmex as a "miserable little genus" in his treatment of the ants of North America, and for more than a century colleagues (Wheeler 1903; Kusnezov 1959; Wilson and Taylor 1967) have raised warnings on the taxonomic challenges in this genus. Since Santschi (1923a), Alayo (1974) examined the species from Cuba and Wheeler and Wheeler (1978) those from the United States. More recently, Quirán and collaborators (Quirán et al. 2004; Quirán 2005, 2007) reported on the Brachymyrmex species from Argentina, and Ortiz and Fernández (2014) reviewed the species with tumuliform metathoracic spiracles. Additionally, Wilson et al. (2016) documented the male genitalia of Brachymyrmex. Currently 44 species with 17 subspecies and varieties are attributed to the genus 
in the online catalog of the ants of the world (Bolton 2018). However, the biology, diversity and phylogeny of the genus remain poorly understood and a comprehensive revision is long-overdue (see Wilson and Taylor 1967).

A detailed account of opinions on the phylogenetic position of Brachymyrmex within Formicinae is provided by Wilson et al. (2016). Agosti (1991) divided the subfamily in four groups based on morphological characters, with Brachymyrmex included in the 'Pseudolasius genus group' based on the widely separated hind coxae, the petiole that is ventrally u-shaped and the simple helcium that is antero-ventrally often concealed by the anteriorly-fused sternite and tergite, which meet laterally. Bolton (2003), also based on morphology, assigned Brachymyrmex (and Pseudolasius) to the Plagiolepidini, which is one of three tribes of the lasiine group. More recently, Blaimer et al. (2015) obtained strong support for a sister group relationship between Brachymyrmex and Myrmelachista upon analysis of ultraconserved elements (UCEs), and these genera form a wellsupported sister group to all other formicines. Therefore, Ward et al. (2016) resurrected the tribe Myrmelachistini (= Brachymyrmicini) for these two genera. This tribe is morphologically characterized by 9-10 antennal segments, five mandibular teeth, an anteriorly inclined petiole with a long posterior peduncle, and an anterior tergosternal fusion of the third abdominal segment.

Here, we work towards a comprehensive revision of Brachymymex by 1) redefining the limits of all of the described species, subspecies and varieties in light of intra- and interspecific morphological variation in workers; 2) documenting this variation both qualitatively and quantiatively; 3) summarizing these findings on diagnostic traits with a new, dichotomous, illustrated identification key to increase reproducibility and to make the diversity of 
118 (Ortiz and Fernández 2014).
Brachymyrmex more accessible for future research; and 4) examining the significance of our morphological identification system and the monophyly of the genus in light of molecular evidence. Finally, we also report on the biogeographical distribution of the recognized species and how our taxonomic framework compares with previous studies.

In summary, we recognize a total of 40 species, four of which are newly described here. We also synonymize 25 previously described species/subspecies and raise two former subspecies to species status. The proposed species delimitations follow a new, dichotomous identification key that is supported by quantitative morphological studies. More importantly, we tested our morphological identification system with molecular data for half of the recognized species and found strong congruence (18 of the 19 included species were retrieved as monophyletic), indicating its overall validity. During our studies, it also became clear that several samples contain specimens that presumably belong to undescribed species, but we prefer to await more material before formal description. This remark includes, but is not limited to, several potentially new species from Central America. We also observed that some species have dimorphic workers and others a possible intercaste between worker and queen. However, confirming the presence of an intercaste necessitates distinguishing it from ergatoid queens, which requires dissections of the ovaries and demographic data (Peeters 1991). Unfortunately, such confirmation is not usually possible based on the museum specimens studied here, but we discuss the issue where relevant. In general, it warrants further study and for now, we highlight such specimens as putative intercastes. If intercastes would be confirmed in the future beyond dimorphic workers, Brachymyrmex would present a promising study system to understand caste evolution in ants 
123 Authors of previous taxonomic studies of Brachymyrmex (e.g. Santschi 1923a; Creighton 1950;

124 Quirán et al. 2004; Quirán 2005, 2007) have mainly or exclusively focused on the morphology of 125 workers, for which abundant material is available in existing museum collections. Consequently, we adopt the same focus here. A comparative framework is largely lacking for queens and males, because they are not available for all species, and even when collections exist they are often poorly preserved. Nevertheless, we provide a genus-level diagnosis of queens and males with selected pictures for illustrative purposes. The morphological terminology used follows Bolton

130 (1994), that for hair inclination Kugler (1994), and for sculpture Harris (1979).

131 We examined a total of 1303 Brachymyrmex samples. This material belongs to the following 132 institutions, and it includes all relevant types and many additional specimens; most collection acronyms follow Ward (1989). In some collections not all specimens have individual voucher numbers. In such cases, we assigned an identifier (either a personal code or number, such as

135 CMOS 000032, or a Smithsonian database reference number, such as USNMENT00757197) to 136 the relevant specimen, preceded by the acronym of the proprietary institution. These unique 137 identifiers are used here for traceability. 
Manuscript submitted to: Organisms Diversity \& Evolution

Published version available; DOI: 10.1007/s13127-019-00406-2

144 ICN Instituto de Ciencias Naturales, Universidad Nacional de Colombia, Bogotá D.C., Colombia.

146 INBC Instituto Nacional de Biodiversidad, Santo Domingo de Heredia, Costa Rica.

147 INSUE Instituto Superior de Entomología, Universidad Nacional de Tucumán, San Miguel de Tucumán, Argentina.

149 JTLC John Longino Collection, the University of Utah, Salt Lake City, UT, USA.

MACN

Museo Argentino de Ciencias Naturales Bernardino Rivadavia, Buenos Aires, Argentina.

MCZC Museum of Comparative Zoology, Harvard University, Cambridge, MA, USA.

MCSN Museo Civico di Storia Naturale "Giacomo Doria”, Genoa, Italy.

MfNB Museum für Naturkunde, Berlin, Germany.

MLP Museo de La Plata, Buenos Aires, Argentina.

MHNG Muséum d'Histoire Naturelle, Genève, Switzerland.

MPEG Museu Paraense "Emílio Goeldi”. Belém, Pará, Brazil.

MZSP Museu de Zoologia da Universidade de São Paulo, São Paulo, Brazil.

NHMB Naturhistorisches Museum, Basel, Switzerland.

NHMW Naturhistorisches Museum, Wien, Austria.

PSWC Philip S. Ward Collection, University of California, Davis, CA USA.

RBINS Royal Belgium Institution of Natural Sciences, Bruxelles, Belgium.

UFUC Universidade Federal de Uberlândia, Uberlândia, Minas Gerais, Brazil.

UNMSM Museo de Historia Natural, Universidad Nacional Mayor de San Marcos, Lima, Peru.

USNM Department of Entomology, National Museum of Natural History Smithsonian Institution, Washington DC, USA. 
Manuscript submitted to: Organisms Diversity \& Evolution

Published version available; DOI: 10.1007/s13127-019-00406-2

WEMC William and Emma MacKay, Personal Collection, El Paso Texas, TX, USA.

\section{Georeferencing and mapping.}

171 Although we tried to georeference all studied samples, some were excluded because locality

172 information was too ambiguous for georeferencing (e.g., when only a country name was

173 available). Furthermore, specimens from the same collecting event were sometimes separated

174 over replicate samples. After removing such 'duplicates', 747 georeferenced localities remained,

175 of which 736 represented specimens from the native range. These were mapped in $\mathrm{R} v 3.2 .1$. ( $\mathrm{R}$

176 Core Team 2015) using the packages maps v3.0.1. (Brownrigg et al. 2015) and mapdata v2.2-5

177 (Brownrigg 2015), and subsequently projected on the ETOPO1 global topographic map of

178 Amante and Eakins (2009).

\section{Images.}

Photographs were taken in dorsal, lateral and full-face view. At the MCZC we used an imaging system that consisted of a Leica MZ16 stereomicroscope equipped with a Leica DCF 420 digital camera, software from Leica Application Suite 3.7 and Helicon Focus 5.1 for auto-montage; at the USNM the imaging system consisted of a Leica Z16APO stereomicroscope with a JVC KYF75U digital camera mounted to the Leica motor-focus system. Composite images made with this system were assembled using Auto-Montage Pro Version 5.03.0018 BETA (Synoptics Ltd.); at the MZSP the imaging system consisted of a Leica M250c stereomicroscope and Auto-Montage Professional software LAS3.6.0. Some images were obtained from www.antweb.org, which is specified in the figure captions. Images were processed with Adobe Photoshop CS5.

\section{Analysis of measurements and indices.}


192 Measurements were made using an Advanced Optical microscope, a Leica Z16 APO microscope, 193 and a Zeiss StereoDiscovery V20 in combination with an ocular micrometer. All measurements 194 were taken at 80-120 $\times$ magnification and are reported in $\mathrm{mm}$ to an accuracy of 2 decimal places. 195 Indices were calculated from these measurements following Ortiz and Fernández (2014) (Fig. 1).

197 Head Length $\left(\mathrm{HL}_{1}\right)$ : The maximum length of the head excluding the mandibles in full-face view. $198 \mathrm{HL}_{1}$ is measured as the straight-line distance from the mid-point of the anterior margin of the 199 clypeus to the mid-point of the posterior (= vertexal) margin of the head (for major workers the 200 posterior mid-point is located at the middle of the virtual line between the posterior apices of the 201 head).

Head Length $\left(\mathrm{HL}_{2}\right)$ : Distance from the posterior margin of the frontal triangle (see Bolton, 1994, p. 192) to the vertexal margin in full-face view.

Head Length ${ }_{3}\left(\mathrm{HL}_{3}\right)$ : Measurement of the gena in lateral view; this measurement equals the 207 distance from the anterior margin of the eye to the posterior edge of the clypeus, parallel to the longest axis of the eye.

Head Width (HW): The maximum width of the head measured in full-face view. Eyes are

211 included in the measurement if they project laterally from the head.

213 Scape Length (SL): The maximum length of the scape, excluding the basal constriction just distal 214 to the condylar bulb. 
Manuscript submitted to: Organisms Diversity \& Evolution

Published version available; DOI: 10.1007/s13127-019-00406-2

216 Eye Length (EL): Maximum diameter of the compound eye.

218 Weber's Length (WL): The diagonal length of the mesosoma in lateral view, i.e. from the

219 anterior-most point of the pronotum to the posterior-most basal angle of the metapleuron (this

220 measurement excludes the cervical neck of the pronotum).

221

222 Pronotum Length $(\mathrm{PnL})$ : The length along the midline between the anterior and posterior edges

223 of the pronotum in dorsal view (this measurement excludes the cervical neck of the pronotum).

Pronotum Width (PnW): The maximum width of the pronotum in dorsal view.

Mesonotum Length (ML): The length between the anterior edge of the mesonotum and the mesometanotal suture in dorsal view.

Mesonotum Width (MW): The maximum width of the mesonotum in dorsal view.

232 Cephalic Index (CI): (HW/HL 1$)$ x 100.

233 Scape Index $\left(\mathrm{SI}_{1}\right):(\mathrm{SL} / \mathrm{HW}) \times 100$.

234 Scape Index2 (SI $):\left(\mathrm{SL} / \mathrm{HL}_{2}\right) \times 100$.

235 Ocular Index $\left(\mathrm{OI}_{1}\right):(\mathrm{EL} / \mathrm{HW})$ x 100.

236 Ocular Index $\left(\mathrm{OI}_{2}\right):\left(\mathrm{HL}_{3} / \mathrm{HL}_{1}\right) \times 100$.

Ommatidia: The number of facets in the compound eye along its maximal diameter. 
In total 347 specimens of 38 species were measured. In some cases, it was not possible to reliably measure all features, e.g. because of the preservation of the specimen or the way it was mounted. The ranges of the obtained mesurements are described in the systematic treatment, but we also performed a statistical analysis of morphometric variables.

244 First, we ordinated these data with non-metric multidimensional scaling (nmMDS) using 245 functions of vegan v2.3-0 (Oksanen et al. 2015) and MASS v7.3-41 (Venables and Ripley 2002). 246 As this rank-based method does not allow missing data, we selected only specimens for which all

measurements were taken, i.e. a subset of 240 individuals for 38 species. We converted this dataset into a Euclidean distance matrix and ordinated it in two dimensions using 1,000 random starting configurations to find the solution with minimal stress without getting trapped in local minima. The resulting stress value obtained, i.e. the goodness-of-fit, was multiplied by 100 and evaluated using the criteria of Kruskal (1964) and Clarke (1993). We also examined how individual morphometric variables (i.e. the measurements, indices and counts) contributed to the morphospace occupation with the 'envfit' function of vegan using 1,000 permutations.

Subsequently, we conducted statistical tests for the univariate morphometric variables on all species that were represented with at least 5 specimens, resulting in a subset of 286 specimens for 20 species. (Specimens with missing data were allowed for these tests.) Given that the data of several species differed significantly from a normal distribution, we used non-parametric Dunn's tests to test pairwise differences between species for each measurement and index. These tests were performed in R using functions of the package dunn.test v1.3.4. (Dinno 2017), and the resulting $p$-values were adjusted with a Benjamini-Hochberg correction, i.e. using the false discovery rate (Benjamini and Hochberg 1995). These results were represented with boxplots, featuring letters to indicate significance levels of comparisons. 
Manuscript submitted to: Organisms Diversity \& Evolution

Published version available; DOI: 10.1007/s13127-019-00406-2

\section{Molecular phylogenetics.}

We examined the monophyly of the genus with a dataset that has substantially enhanced taxon sampling compared to previous efforts (Brady et al. 2006; Moreau et al. 2006; Blaimer et al. 2015), and we examined the molecular support of the here proposed morphological identification system. The specimens used for genetics are indicated in Supplementary material table S1, i.e. 82 specimens covering 19 Brachymyrmex species and 6 specimens of 5 Myrmelachista species (the sister-genus of Brachymyrmex [Blaimer et al. 2015]). Acanthoponera minor, Manica rubida and Rhytidoponera metallica were used as outgroups.

DNA extraction, amplification, and sequencing were carried out at the Laboratories of Analytical Biology (LAB) of the Smithsonian National Museum of Natural History, Washington, DC. Genomic DNA was extracted using the Qiagen DNEasy Tissue Kit. Fragments of four proteincoding genes were amplified, i.e. one fragment for each of the nuclear genes elongation factor 1alpha paralog F1 (EF1 $\alpha$ F1), elongation factor 1-alpha paralog F2 (EF1 $\alpha$ F2) and wingless (wg), and two of the mitochondrial gene cytochrome oxidase subunit 1 (COI). Primer sequences used for polymerase chain reaction (PCR) amplification are those used by LaPolla et al. (2010). PCR products were sequenced on an ABI sequencer (ABI 377 or ABI 3100) using Big Dye Cycle Sequencing chemistry. Fragments were sequenced bidirectionally, and the resulting chronograms were assembled and edited with SEQUENCHER v.4.8.

Furthermore, our dataset includes unpublished sequences that are available in GenBank by the International Barcode of Life Consortium. These sequences are provided without species identification, but they are linked to an image database, and we included specimens for which 
Manuscript submitted to: Organisms Diversity \& Evolution

Published version available; DOI: 10.1007/s13127-019-00406-2

unambiguous identification was possible based on the available images. Additional sequences with specimen images were kindly provided by David Donoso and John Longino, and we used the same criteria for inclusion as for GenBank sequences.

Sequences for each gene fragment were aligned using MAFFT v.7 (Katoh and Standley 2013) and results were visually inspected in MESQUITE v.2.10 (Maddison and Maddison 2017) to determine codon positions. We tested for substitutional saturation using DAMBE v.5.5.9 (Xia 2013) but none of the gene fragments used were saturated. Models of sequence evolution were fit with PARTITION FINDER v.1.1.1 (Lanfear et al. 2012) to individual gene fragments accounting for potential differences between codon positions. The resulting model fit was examined with a corrected Akaike Information Criterion (AICc). Subsequently, the data for the individual fragments was concatenated into a total dataset with seven partitions (Supplementary material table S2) and phylogenetically analysed with maximum parsimony (MP), maximum likelihood (ML) and Bayesian inference (BI). MP analyses were performed in PAUP* v.4.0b0.10 for Windows (Swofford 2002) with gaps treated as fifth state, 10000 bootstrap replicates and treebisection-reconnection branch swapping. ML analyses were performed with the RAxML BlackBox (Stamatakis et al. 2008) with 100 replicates and the implemented GTR $+\Gamma$ model, individually parameterized for each of the 7 partitions. BI analyses were executed in MrBayes v.3.2.6 (Ronquist et al. 2012) as implemented in CYPRES v.3.3 (Miller et al. 2010). Two independent Markov chain Monte Carlo (MCMC) runs were conducted for 20 million generations and sampled every 1,000 generations. Each run was distributed across four chains with a heating parameter of 0.2 and $25 \%$ of the samples were discard as burnin. Convergence between runs was examined using the sump command and by inspecting effective sample sizes for the parameters in TRACER v.1.6 (Rambaut et al. 2013). The maximum clade credibility tree 
312 was visualized with FigTree v.1.4.0 (Rambaut 2012) and the bootstrap support for clades

313 retrieved under MP and ML was added. Sequences are deposited in GenBank and accession

314 numbers are indicated in Supplementary table S1.

316 Automated species delimitation.

317 We identified hypothetical species entities from sequence data with an automated procedure. Our

318 specific aim was to evaluate the congruence of automated species delimitation and our

319 morphological identification system, and thus to test the reliability of that identification system.

320 Multiple such methods exist (Pons et al. 2006; Leliaert et al. 2014; Da Silva et al. 2018) and

321 results may vary considerably among methods (Da Silva et al. 2018) related to the size of the

322 dataset, the methodological procedures adopted, variation in underlying population genetic

323 parameters and evolutionary processes. Many of the potentially influencing biological factors are

324 poorly known for Brachymyrmex. We used the automatic barcode gap discovery method (ABGD;

325 Puillandre et al. 2011), i.e. a fast single-locus method, on the barcoding fragment of COI, because

326 of the exceptional suitability of this fragment for species identification as well as species

327 delimitation and discovery in Metazoa (Hebert et al. 2003). The ABGD method is generally

328 considered to be conservative as to the number of hypothetical species lineages it detects (Da

329 Silva et al. 2018). We performed the analysis on the ABGD website

330 (http://wwwabi.snv.jussieu.fr/public/abgd/abgdweb.html, accessed 8 October 2018) using default

331 parameters except for relative gap width, which was set to 1.0. 
Manuscript submitted to: Organisms Diversity \& Evolution

Published version available; DOI: 10.1007/s13127-019-00406-2

Plagiolepis (in part): Roger (1863: 162).

Brachymyrmex Mayr, 1868: 163. Type species: B. patagonicus, by monotypy.

Brachymyrmex subgenus Bryscha Santschi, 1923a: 652.

Brachymyrmex senior synonym of Bryscha: Smith (1979: 1424).

Brachymyrmex: Kempf (1972), Bolton (1995; 2003; 2018).

Worker. Head. Usually longer than wide, cordate in some species, with sparse to dense pubescence and hairs in variable orientation (appressed, decumbent, erect). Mandibles with five teeth, of which intercalar (central) and basal teeth are smaller than the others and the apical tooth is largest. Maxillary palps and labial palps with 6 and 4 segments, respectively. Maxillary palps usually reach the occiput and bear several long ventral hairs. The clypeus has a rounded anterior margin or in some taxa, notably B. nebulosus, its medio-anterior portion forms a "lip". In monomorphic species the clypeus bears five long, erect hairs of which one usually conspicuous hair is near the anterior margin, two are in mediolateral position and the other two close to the toruli; other hairs are markedly shorter and appressed or decumbent. In dimorphic species the clypeus is larger and with a row of long thick hairs near the anterior margin. Toruli either touch 
Manuscript submitted to: Organisms Diversity \& Evolution

Published version available; DOI: 10.1007/s13127-019-00406-2

the posterior clypeal margin in oblique anterodorsal view or surpass it. Compound eye conspicuous, positioned usually on the cephalic midline or anterior to it; with 3-14 ommatidia along its maximal diameter. Number of ocelli either 0,1 or 3 , but when present often inconspicuous. Antennae with 9 segments, without antennal club; flagelomeres sometimes gradually increasing apically in diameter; scapes variable in length, with appressed, decumbent or erect hairs.

Mesosoma. With sparse or dense pubescence and hairs in variable orientation. The pronotum and mesonotum typically bear two erect hairs each, but sometimes additional suberect hairs on one or both are present, or erect hairs may be absent from the mesonotum. The pronotum is slightly to strongly convex, and the promesonotal suture, i.e. the line of junction between the pronotum and mesonotum, is always present. The mesonotum may bulge dorsally above the propodeum, and the mesometanotal suture, i.e. the line of junction between the mesonotum and the metanotum, is usually conspicuous, although the mesonotum and metanotum appear fused in some species. The metanotum is reduced to a transverse groove, the metanotal groove, which separates the mesonotum from the propodeum on the mesosomal dorsum. The metanotal groove is variable, from absent to wide and deep. The metathoracic spiracles are dorsal near the midline or dorsolateral, and not, slightly or very strongly protruding, i.e. tumiliform. The propodeal suture, i.e. the line of junction between either the mesonotum (if the metanotal groove is absent) or the metanotal groove anteriorly and the propodeum posteriorly, is present as a dorsal fold with variable lateral extension. Dorsum of the propodeum flat or convex and usually shorter than the propodeal slope. Propodeal spiracles circular and positioned near the posterior propodeal margin. Petiole usually with a low scale, reduced to a narrow subcylindrical segment that is overhung from behind by the gaster, but in dimorphic species the scale of the petiole may be high and visible in dorsal view. Hairs on the legs may be appressed, decumbent or erect. 
Gaster. Of variable size, with five segments that bear sparse or dense pubescence and usually erect hairs, mainly but not exclusively along the posterior edges of the segments.

Color and sculpture. Body color ranges from light yellow to dark brown and black; most often it is uniform, but some species display markedly contrasting patterns, e.g. with the head and/or the gaster darker than the rest of the body. Body usually smooth and shiny, but in some species the head and/or mesonotum bear microsculpture.

Queen (Fig. 2) Head wider than long, with abundant, fine pubescence, and with long erect hairs; eyes large, located laterally along the cephalic midline; 3 ocelli present; frontal lobes welldeveloped; scapes usually extending beyond the posterior margin of the head; palpal formula: 6,4. Mesosoma with moderately dense, fine pubescence and several erect hairs; anepisternum and katepisternum separated by a distinct suture. Anterior wing with a single dark brown cell, i.e. pterostigma, the first submarginal cell is closed, others open. Posterior wing with five to seven hammuli. Gaster with moderately dense, fine pubescence, and erect hairs along the posterior edges of the segments. Body color ranges from yellow to dark brown, and it is uniform or sometimes with the head and/or gaster darker than the rest of the body.

Male (Fig. 3). Head wider than long, with fine, sparse pubescence, lacking erect hairs except on mouthparts, and with smooth, shiny integument; maxillary palps with four segments, labial palps with two; mandibles unidentate; frontal lobes reduced; ocelli and eyes well-developed; antennae with 10 segments. Mesosoma with sparse pubescence and shiny integument, without erect hairs. Gaster shiny, lacking pubescence, with scattered erect hairs on the last few segments. Head dark 405 brown to almost black, rest of body, including appendages, very light brown or concolorous. Wilson et al. (2016) described the morphology of the male genitalia in detail. 
Manuscript submitted to: Organisms Diversity \& Evolution

Published version available; DOI: 10.1007/s13127-019-00406-2

Distribution. Neotropical and Nearctic, with introductions elsewhere. The native distribution of Brachymyrmex is illustrated in Fig. 4.

Biology. Brachymyrmex is commonly collected from leaf-litter and some species occur in

412 association with epiphytes; nests are found under stones, among plant roots, in trees, in rotten

413 wood (Wheeler 1942; LaPolla and Longino 2006), and in urban buildings (MacGown et al.

414 2007). The biology and natural history of the genus are poorly known although habitat

415 information exists for some species, such as the arboreal B. nebulosus (LaPolla and Longino

416 2006). As mentioned, some Brachymyrmex species are notorious invaders which are considered

417 pests (MacGown et al. 2007).

418 Interestingly, Brachymyrmex species occur sometimes in association with other insects. Santschi

419 (1923a) mentioned associations of Brachymyrmex depilis, B. giardi and B. heeri with mealybugs

420 (Hemiptera: Coccidae) and observed that some species live in or very close to termite nests $(B$.

421 fiebrigi, B. modestus, B. myops, B. termitophilus). Moretti et al. (2011), suggested a possible

422 association between B. cordemoyi and the cockroach Pycnoscelus surinamensis (Blaberoidea:

423 Blaberidae), whereas Delssine (pers. comm.) found a staphylinid beetle in a nest of $B$. modestus

424 in Ecuador.

426 Synonymy of species.

427 B. admotus Mayr, 1887

$428=$ B. longicornis var. immunis Forel, 1908 n. syn.

429 B. antennatus Santschi, 1929

$430 \quad$ B. aphidicola Forel, 1909 
Manuscript submitted to: Organisms Diversity \& Evolution

Published version available; DOI: 10.1007/s13127-019-00406-2

$431=$ B. heeri var. fallax Santschi, 1923a

$432=$ B. longicornis var. hemiops Santschi, 1923a n. syn.

433 B. attenuatus Santschi, 1929 n. st.

$434 \quad$ B. australis Forel, 1901

$435=$ B. australis var. curta Santschi, 1922 n. syn.

$436=$ B. longicornis Forel, 1907 n. syn.

437 B. bahamensis n. sp.

$438 \quad$ B. bicolor n. sp.

439 B. bonariensis Santschi, 1933 n. st.

$440 \quad$ B. brasiliensis Ortiz \& Fernández, 2014

$441 \quad$ B. bruchi Forel, 1912a

$442=$ B. bruchi var. rufipes Forel, 1912a

$443=$ B. giardi var. nitida Santschi, 1922 n. syn.

$444=$ B. laevis var. andina Santschi, 1923a n. syn.

445 B. cavernicola Wheeler, 1938

446 B. coactus Mayr, 1887

$447=$ B. coactus var. nictitans Emery, 1906 n. syn.

$448=$ B. constrictus Santschi, 1923a n. syn.

$449=$ B. coactus var. robustus Santschi, 1923b n. syn.

$450 \quad$ B. cordemoyi Forel, 1895a

$451=$ B. laevis var. fuscula Emery, 1906 n. syn.

$452=$ B. brevicornis Emery, 1906 n. syn.

$453=$ B. patagonicus var. brevicornoeides Forel, 1914 n. syn.

$454=$ B. cordemoyi var. nigricans Santschi, 1916 
Manuscript submitted to: Organisms Diversity \& Evolution

Published version available; DOI: 10.1007/s13127-019-00406-2

$455=$ B. cordemoyi var. distinctus Santschi, 1923a n. syn.

$456 \quad$ B. degener Emery, 1906

$457=$ B. admotus r. niger Forel, 1912a n. syn.

$458=B$. incisus Forel, 1912a n. syn.

$459=$ B. luederwaldti Santschi, 1923a n. syn.

$460 \quad$ B. delabiei Ortiz \& Fernández, 2014

$461 \quad$ B. depilis Emery, 1893

$462=$ B. depilis subsp. flavescens Grundmann, 1952

$463=$ B. nanellus Wheeler, 1903.

$464 \quad$ B. donisthorpei Santschi, 1939

465 B. feitosai Ortiz \& Fernández, 2014

466 B. fiebrigi Forel, 1908

$467=$ B. fiebrigi var. funicularis Santschi, 1922 n. syn.

$468=$ B. fiebrigi var. fumida Santschi, 1923a n. syn.

469 B. flavidulus Roger, 1863

$470 \quad$ B. gagates Wheeler, 1934

471 B. gaucho Santschi, 1917

$472 \quad$ B. giardi Emery, 1895

$473=$ B. melensis De Zolessi, Abenante \& Gonzalez, 1978 n. syn.

$474 \quad$ B. heeri Forel, 1874

$475=$ B. goeldii Forel, 1912a n. syn

$476=$ B. giardi var. cordobensis Santschi, 1929 n. syn.

$477=$ B. physogaster Kusnezov, 1960 n. syn.

$478 \quad$ B. iridescens n.sp. 
Manuscript submitted to: Organisms Diversity \& Evolution

Published version available; DOI: 10.1007/s13127-019-00406-2

479 B. micromegas Emery in Santschi, 1923a

$480 \quad$ B. minutus Forel, 1893

$481 \quad$ B. modestus Santschi, 1923b

$482 \quad$ B. musculus Forel, 1899

483 B. myops Emery, 1906

484 B. nebulosus LaPolla \& Longino, 2006

485 B. obscurior Forel, 1893

$486 \quad$ B. oculatus Santschi, 1919

487 B. patagonicus Mayr, 1868

$488=$ B. laevis Emery, 1895 n. syn.

$489=$ B. patagonicus var. atratula Santschi, 1923a

$490 \quad$ B. pictus Mayr, 1887

$491=$ B. heeri var. basalis Wheeler, 1921. n. syn.

$492=$ B. pictus subsp. balboae Wheeler, 1942 n. syn.

$493 \quad$ B. pilipes Mayr, 1887

494 B. santschii Menozzi, 1927

495 B. sosai n. sp.

496 B. termitophilus Forel, 1895b

497 B. tristis Mayr, 1870

498

499 Identification key to Brachymyrmex species.

5001 Clypeus with a single long apical hair near the anterior margin, two lateral hairs medially and

501 two hairs near the toruli (Fig. 5.a1); monomorphic 2 

with the body color. from Brazil

2(1) Metathoracic spiracles tumuliform (i.e. strongly protruding dorsally) (Fig. 6a1); known only

- Metathoracic spiracles not (Fig. 6.a2) or slightly protruding but not tumiliform (Fig. 6.a3); naturally occurring throughout the Neotropics 5

3(2) Toruli surpassing the posterior clypeal margin in oblique anterodorsal view (Fig. 5.a3); head and mesosoma smooth and shiny

- Toruli touching the posterior clypeal margin but never surpassing it in oblique anterodorsal view (Fig. 5.a2); head and mesosoma finely punctate and opaque B. brasiliensis

4(3) Mesosoma without erect hairs; gaster with scattered long erect hairs, except for the first segment which has dense yellowish pubescence

B. feitosai

- Mesosoma with two erect hairs on pronotum and two on mesonotum; gaster with scattered long erect hairs, also on the first segment

B. delabiei

5(2) Dorsum of the head, mesosoma and gaster with thick erect black hairs (as in Nylanderia) that contrast with the body color (head and gaster may be darker than mesosoma)

\section{B. cavernicola}

- Dorsum of the head, mesosoma and gaster without hairs, or with thin hairs that do not contrast 
6(5) Eyes positioned below the cephalic midline (Fig. 5.b1), with 3 or 4 ommatidia along the

- Eyes usually positioned on the cephalic midline (Fig. 5.b2), with more than 4 ommatidia along

- Mesonotum bulging dorsally above the pronotum in lateral view (Fig. 6.b2)

8(7) Scapes short, just reaching the posterior margin of the head or surpassing it by a length shorter than the maximal diameter of the eye (Fig.5.d1,d2)

- Scapes long, surpassing the posterior margin of the head by a length approximately equal to the maximal diameter of the eye (Fig. 5.d3)

B. myops

10(9) Scapes surpass the posterior cephalic margin by a length of approximately $1.5 \times$ the maximal diameter of the eye (Fig. 5.d3: 2A $\leq$ B); hairs on scapes decumbent; body uniform in color (usually dark brown)

B. admotus

- Scapes surpass the posterior cephalic margin by a length of approximately $1.0 \times$ the maximal diameter of the eye (Fig. 5.d3: 2A>B); hairs on scapes appressed; head and mesosoma light brown, gaster darker .

B. bonariensis n. st. 
- Dorsal margin of the mesosoma not sinusoidal or only of sub-sinusoidal shape (Figs.

12(11) Clypeus with its medial anterior portion forming a "lip" (Fig. 5.e1); head and mesosoma partially or completely alveolate (sometimes alveolate-strigate); dorsum of the mesosoma with

-Clypeus without anteromedial "lip" (Fig. 5.e2); entire body non-alveolate; dorsum of the mesosoma without erect hairs; head and gaster black; mesosoma yellowish

14(13) Metanotal groove wider than the diameter of the metathoracic spiracles (Fig. 6.f1: $A \leq B)$; scapes surpassing the posterior margin of the head by approximately $1.0 \times$ the maximal diameter of

- Metanotal groove narrower than the diameter of the metathoracic spiracles (Fig. 6.f2: A > B); scapes just reaching the posterior margin of the head (Fig. 5.d2); gaster with dense pubescence 
Manuscript submitted to: Organisms Diversity \& Evolution

Published version available; DOI: 10.1007/s13127-019-00406-2

16(15) Pronotum without erect hairs; scapes short or reaching the posterior margin of the head

(Fig. 5.d1,d2); gaster with dense pubescence (Fig. 6.g2)

B. flavidulus

- Pronotum with two erect hairs (Fig. 6.d1); scapes surpassing the posterior margin of the head

(Fig. 5.d3); gaster without dense pubescence, but with scattered appressed hairs (Fig. 6.g1) ..

18(17) Metanotal groove absent or when present shallow and narrower than the diameter of the

- Metanotal groove deep and wider than the diameter of the metathoracic spiracles (Fig. 6.f1: A $\leq$

B).

20(19) Scapes just reaching the posterior margin of the head or surpassing it by a length of less

592 than $1.0 \times$ the maximal diameter of the eye (Fig. 5.d2,d3: A $>$ B)

- Scapes surpassing the posterior margin of the head by a length of approximately $1.0 \times$ the maximal 
21(20) Body usually dark brown; eye with on average 9 ommatidia along its maximal diameter;

- Body yellowish; eye with on average 6 ommatidia along its maximal diameter; scapes on average

$599<0.5 \mathrm{~mm}$; known only from Canada, Mexico, USA

\section{B. depilis}

600

601

22(19) Body yellowish

602 - Body dark brown

23(22) Scapes not or barely reaching the posterior margin of the head (Fig. 5.d1,d2)

\section{B. fiebrigi}

- Scapes surpassing the posterior margin of the head (Fig. 5.d3).

24(23) About 6 erect hairs on the pronotum and two on the mesonotum, each hair with a length of about $2.0 \times$ the maximal diameter of the eye; known only from the Bahamas..B. bahamensis n. sp. - Two erect hairs on the pronotum and two on the mesonotum, each with a length shorter than the maximal diameter of the eye; widespread

B. termitophilus

25(22) Dorsum of the head and mesosoma with light-colored, dense pubescence; gaster with dense appressed pubescence; eye with on average 11 ommatidia along its maximal diameter, head on average long $(\mathrm{HL} 1>0.5 \mathrm{~mm})$ and wide $(\mathrm{HW}>0.4 \mathrm{~mm})$

B. cordemoyi

616 - Dorsum of the head and mesosoma with less conspicuous dense pubescence; gaster with dense 617 decumbent pubescence; eye with on average 9 ommatidia along its maximal diameter, head on average short $(\mathrm{HL} 1<0.5 \mathrm{~mm})$ and narrow $(\mathrm{HW}<0.4 \mathrm{~mm})$

\section{B. obscurior}


Manuscript submitted to: Organisms Diversity \& Evolution

Published version available; DOI: 10.1007/s13127-019-00406-2

26(18) Dorsum of the mesosoma without conspicuous sculpture; metathoracic spiracles fully dorsal in position; dorsal margin of the mesonotum strongly antero-posteriorly inclined (Fig. 6.e1) B.

\section{sosai n.sp.}

- Dorsum of the mesosoma with imbricate sculpture; metathoracic spiracles in dorsolateral position; dorsal margin of the mesonotum not or slightly antero-posteriorly inclined (Fig. 6.e2)

27(26) Second segment of the antennal funiculus shorter than the first antennal segment (Fig. 5.g1: $\mathrm{S} 2<\mathrm{S} 1$ ); scapes with appressed hairs; metathoracic spiracles protruding slightly dorsally, but not tumiliform (Fig. 6.a3); hairs lighter in color than the body, which is brownish

\section{B. attenuatus n.st}

- Second segment of the antennal funiculus as long or longer than the first antennal segment (Fig. 6.g2: $\mathrm{S} 2 \geq \mathrm{S} 1$ ); scapes with decumbent hairs; methatoracic spiracles not protruding (Fig. 6.a2) hairs darker in color than the body, which is yellowish

B. antennatus

28(17) Eyes large, with a maximal diameter $>1 / 4$ th of the length of the head (HL 1$)$, usually with $>14$ ommatidia along their maximal diameter

B. oculatus

- Eyes small, with a maximal diameter of approximately $1 / 4$ th the length of $\mathrm{HL}_{1}$, typically with $<14$ ommatidia along their maximal diameter 29

29(28) Metanotal groove absent, or, when present, shallow and narrower than the diameter of the metathoracic spiracles (Fig. 6.f2: A > B)

- Metanotal groove deep and wider than the diameter of the metathoracic spiracles (Fig. 6.f1: A $\leq$

B.) 
Manuscript submitted to: Organisms Diversity \& Evolution

Published version available; DOI: 10.1007/s13127-019-00406-2

30(29) Head and thorax yellowish; gaster black or yellowish with a black spot, $\mathrm{OI}_{2}$ usually $>27$

646

647

648

649

650

651

\section{B. pictus}

- Body of uniform color, $\mathrm{OI}_{2}$ usually $<25$

31(30) Body yellowish, usually with a narrow mesonotum (MW 16) and 8-9 ommatids along the maximum diameter of the eye.

- Body brownish or dark brown, usually with a wide mesonotum (MW 20 or more) and 10 or more ommatids along the maximum diameter of the eye

32(31) Scapes surpassing the posterior margin of the head by a length exceeding the maximal diameter of the eye (Fig. 5.d3: $A<B$ )

B. aphidicola

-Scapes surpassing the posterior margin of the head by a length smaller than or equal to the maximal diameter of the eye (Fig. 5.d3: $A \geq B$ )

B. australis

33(31) Scapes surpassing the posterior margin of the head by a length smaller than the maximal diameter of the eye (Fig. 5.d3: A > B); usually with two erect hairs on the pronotum and two on the mesonotum

\section{B. patagonicus}

- Scapes surpassing the posterior margin of the head by a length approximately equal to the maximal diameter of the eye (Fig. 5.d3: $\mathrm{A} \approx \mathrm{B}$ ); usually with more than two erect or decumbent hairs on the pronotum and two erect hairs on the mesonotum

B. bruchi

34(29) Legs and antennae with erect hairs; second segment of the antennal funiculus as long as or longer than the first (Fig. 5.g2: S2 $\geq \mathrm{S} 1$ )

B. gaucho 
Manuscript submitted to: Organisms Diversity \& Evolution

Published version available; DOI: 10.1007/s13127-019-00406-2

- Legs and antennae with decumbent or appressed hairs; second segment of the antennal funiculus shorter than the first (Fig. 5.g1: S2 $<\mathrm{S} 1$ )

35(34) Mesonotum not bulging dorsally above the pronotum in lateral view (Fig. 6.b2); metathoracic spiracles low, not protruding dorsally (Fig. 6.a2)

B. musculus

- Mesonotum bulging dorsally above the pronotum in lateral view (Fig. 6.b1); metathoracic spiracles protuding slightly in lateral view but not tumiliform in shape (Fig. 6.a3)

36(35) Head and thorax yellow or brown, gaster darker

B. coactus

- Body uniform in color.

37(36) Head with dense decumbent pubescence (Fig. 5.f1)

B. tristis

- Head with sparse decumbent pubescence (Fig. 5.f2). 38

38(37) Mesonotum laterally extended and therefore oval in dorsal view (Fig. 6.h1); body light brown

B. degener

-Mesonotum almost circular in dorsal view (Fig. 6.h2); body dark brown or black

B. gagates

39(1) Mesosoma mostly smooth and shiny, except for longitudinal striations restricted to the metapleura; body uniform light brown

B. micromegas

-Mesosoma entirely covered with fine longitudinal striations; gaster darker than the rest of the body

B. pilipes 


\section{Species accounts.}

\section{Brachymyrmex admotus Mayr}

(Fig. 7, supplementary material Fig. S1)

Brachymyrmex admotus Mayr, 1887: 523 (w.q.). Lectotype worker (NHMW:

USNMENT00757197) and paralectotype workers, queen (NHMW: USNMENT00757196, 00757198-00757200; here designated): 5 workers, 1 queen [examined]. BRAZIL: Santa

Catharina. Other relevant descriptions: Wheeler and Wheeler (1982: 178) (1.). See also: Santschi (1923a: 669); Quirán (2005: 762).

=Brachymyrmex longicornis var. immunis Forel, 1908: 400 (w.q.m.). (MHNG:

USNMENT00757148): 2 workers [examined]. BRAZIL: São Paulo. See also: Forel (1911: 308); Santschi (1923a: 668) n. syn.

Additional material examined. ARGENTINA: Misiones: Est. Ex. Loreto, A.A. Oglobin, 3 workers (NHMB: USNMENT00758065 - 00758067). BRAZIL: Bahia: Itacaré, -14.30917 39.01944, 26 June 1998, Santos, J.R.M. dos, 2 workers (CPDC: USNMENT00757769); Ituberá, 08 May 1994, 4815, J.H.C. Delabie, 3 workers (CPDC: USNMENT00757772); Mato Grosso do Sul: 8 km SE Ponta Pora, 15 Oct. 1989, W.P. MacKay \#12523, 2 workers (WEMC:

USNMENT00759009); Minas Gerais: Alfenas, 05 May 2011, 1 worker (ICN:

USNMENT00759050); Cristina, Luederwaldt, 9 workers (NHMB: USNMENT00758053, 00758059, 00758061); Cristina, MP17192, 2 workers (MZSP: USNMENT00757765, 00757819]; Cocais das Estrelas, -19.73333 -43.41667, 19-22 June 2007, D.L. Braga \#5512, 1 worker (CPDC: USNMENT00757768); Serra Caraça, 1380 m, Nov. 1961, Kloss, Lemko, 2713, Martins \& Silva, 9 workers, 3 males (MCZC: USNMENT00757252, 00757253, 00757764); Viçosa, Mata do 
Paraiso, Dec. 1993-1994, P.S.F. Ferreira, 3 workers (CPDC: USNMENT00757770); Paraná:

Antonina, Parque Estadual do Pauôco, -25.57597 -48.88875, 6-11 May 2002, R.R. Silva \& B.H.

Dietz, 24 workers (ICN: MZSP016, 018, 019); Río Negro, Goeldi, 2 workers (MCZC:

USNMENT00757235); Rio de Janeiro: Reischensperger, 8 workers (NHMB:

USNMENT00758056-00758058); Goeldi, 1 worker (NHMB: USNMENT00758050); Floresta de Tijuca, D. Federal, 16 Dec. 1959, C.A.C Seabra, 5 workers (MZSP: USNMENT00757766); Itatiaia, 17 Oct. 1933, 1 worker (NHMB: USNMENT00758068); Petropolis 77 9, T. Borgmeier, 5 workers, 1 queen (MCZC: USNMENT00757233, 00757234, 00757236); Santa Catarina: Blumenau, Reichensperger, 9 workers (NHMB: USNMENT00758055, 00758060, 00758064); Blumenau, Rev PM Witte, 2 workers (NHMB: USNMENT00758063); Blumenau, Rev Wittz, 19 workers (NHMB: USNMENT00758051, 00758052, 00758062); Palhoça, PE Serra do Tabuleiro, -27.74111 -48.69722, 02-10 June 2003, R.R. Silva, B.H. Dietz \& A. Tavares, 25 workers (ICN: MZP030, 031, 035, 040); São Bento do Sul, APA Rio Vermelho, -26.36417 -49.27111, 30 Mar.04 Apr. 2001, R.R Silva \& Eberhardt, 27 workers (ICN: MZP043, 134, 137); São Bento do Sul, APA Rio Vermelho, -26.36417 -42.27111, 30 Mar.-04 Apr. 2001, R.R. Silva \& R.M. Feitosa, 5 workers (ICN: MZP044); São Paulo: Agudos, 24 Jan. 1955, W.S. Kempf leg 1337, 3 workers (MZSP: USNMENT00757767); Barueri, n 297, 17 Dec. 1957, K. Lenko, 5 workers (MZSP: USNMENT00757775); Iguape, EE Jureia-Itatins, Nucleo Rio Verde, -24.54417 -47.23556, 5-14 Mar. 2001, A.A. Tavares, 13 workers (ICN: MZP157, 158); Ipiranga Ihering, 4 workers (MHNG); Ipiranga (x.60), Ihering, 2 workers (MHNG); Jardim Botanico, Agua Funda, wet Forest, 08 Feb. 1967, W.L. Brown, 5 workers, 1 queen, 1 male (MCZC: USNMENT00757961, 00757771, 00757773, 00757774, CMOS00148, 00153); Jundiai, Serra Do Japi, 03 Jan. 2009, S. Diniz, 4 workers (ICN: USNMENT00759039); Miracatu, Serra do Mar, Clube pesca \& Cia, 0407 Sep. 2004, R.M. Feitosa, 11 workers (ICN: MZP092, 097); Picinguaba, PE Serra do Mar, - 
23.33611 -44.83758, 30 Mar.-04 Apr. 2001, Brandão C.R.F. \& Eq, 52 workers, 1 queen (ICN:

MZP060 - 062, 064); Picinguaba, PE Serra do Mar, -23.33611 -44.83758, 30 Mar.-04 Apr. 2001,

Brandão, Alburquerque \& Silva, 15 workers (ICN: MZP063); Piedade, Floresta Atlantica

"Theomar", Mar 2010, G. Bieber, 1 worker (ICN: USNMENT00759040); Piedade, Floresta

Atlantica, Jurupará, Apr. 2009, G. Bieber, 1 worker (ICN: USNMENT00759041); Serra du

Cantareira, Horto Florestel, 20 Feb. 1967, R. Crozier, 9 workers (MCZC: USNMENT00757774,

CMOS000089, 000090); PANAMA: Colon Province: San Lorenzo Forest, 9-16 Feb. 2004,

Reserva Natural, Bosque Mbaracayú, Jejuimi, -24.10000 -55.50421, 15 Aug. 1996, A. Wild \#AW0295, 3 workers (ALWC: USNMENT00757763).

Diagnosis. Brachymyrmex admotus morphologically resembles B. bonariensis n. st., because both species have long scapes, a conspicuous metanotal groove, a pair of thin erect hairs between the metathoracic spiracles, and a gaster with scarce pubescence. However, B. admotus is usually more uniform brownish in color, it has longer scapes (i.e. the scapes surpass the posterior cephalic margin with a length of approximately $1.5 \times$ the maximal diameter of the eye) with decumbent hairs, and its metathoracic spiracles are positioned more dorsally. Brachymyrmex admotus also resembles B. cavernicola in having a pair of erect hairs between the dorsal metathoracic spiracles, but these hairs are thinner in B. admotus and they are not darker in color than the body. 21.74; $\mathrm{OI}_{2} 23.08$. 
Manuscript submitted to: Organisms Diversity \& Evolution

Published version available; DOI: 10.1007/s13127-019-00406-2

Paralectotypes measurements (mm) $(\mathrm{n}=3) . \mathrm{HL}_{1}$ 0.51-0.57; $\mathrm{HL}_{2} 0.35-0.39 ; \mathrm{HL}_{3} 0.12-0.14 ; \mathrm{HW}$

0.45-0.49; SL 0.55-0.59; EL 0.10; WL 0.53-0.59; PnL 0.14-0.21; PnW 0.31-0.35; ML 0.08-0.12;

MW 0.18-0.21; Indices CI 86.21-92.59; SI 11 12.00-121.74; SI 2 140.00-155.60; OI 20.00-21.74;

$\mathrm{OI}_{2} 23.08-25.93$.

Additional material examined measurements $(\mathrm{mm})(\mathrm{n}=16) . \mathrm{HL}_{1}$ 0.46-0.57; $\mathrm{HL}_{2}$ 0.30-0.43; HL 3

011-0.14; HW 0.43-0.51; SL 0.47-0.57; EL 0.09-0.13; WL 0.46-0.61; PnL 0.16-0.22; PnW 0.29-

0.34; ML 0.09-0.13; MW 0.17-0.21; Indices CI 87.72-96.6; SI 1 105.26-120.00; SI 131.91 -

Description. Head. Slightly longer than wide in full face view, with scattered appresed hairs except for two frontal rows of erect hairs; posterior cephalic border slightly concave. Dorsum of the head with sparse appressed pubescence. Clypeus with a rounded anterior margin and five long, erect hairs of which a single, usually conspicuous apical hair is near the anterior margin, two lateral hairs in medial position and two more near the toruli; other hairs on the clypeus are markedly shorter and appressed or decumbent. Toruli surpassing the posterior clypeal margin in oblique anterodorsal view. Scapes extend beyond the posterior cephalic margin by a length of $\sim 1.5 \times$ the maximum eye diameter or more. The scapes typically have appressed, sometimes decumbent, but never erect hairs. A single central ocellus is present, but sometimes inconspicuous. Eyes are positioned on the cephalic midline and have 7-9 ommatidia along their maximal diameter.

Mesosoma. Usually with two erect hairs on the pronotum and two on the mesonotum; sometimes with additional suberect hairs on both. In lateral view, the mesonotum is not or slightly inflated 
and it does not or only slightly bulge dorsally above the pronotum. Metanotal groove deep and wider than the diameter of the metathoracic spiracles. Metathoracic spiracles fully dorsal and slightly protruding, they are closer to the propodeal than to the mesometanotal suture, but not touching any suture. Between the metathoracic spiracles two simple erect hairs are present, which are shorter than those on the pronotum and mesonotum. Dorsum of the propodeum flat and $\sim 1 / 3$ th of the length of the propodeal slope. Propodeal spiracles circular, positioned ventrally of the posterior propodeal margin slightly posterior of the middle of the propodeal slope. Legs with appressed and scattered hairs. Petiole short and inclined forward.

Gaster. With scattered pubescence and scattered long suberect hairs.

Color and sculpture. Body overall smooth and shiny, except for the sometimes slightly imbricate sculpture on the dorsum of the mesosoma; body typically uniform dark brown in color, although in some specimens the head and mesosoma may be light brownish and the gaster darker brown.

Distribution (Supplementary material Fig, S1). Brachymyrmex admotus is mainly known from Argentina, Brazil, and Paraguay, but we also examined a specimen from Panamá that appears to belong to this species.

Biology. This species makes nests in rotting wood [USNMENT00757763] and it has been collected from below rocks [USNMENT00759009].

Remarks. We synonymize B. longicornis var. immunis Forel, 1908 under B. admotus, because the workers have all morphological characteristics of B. admotus, although they are slightly larger and of somewhat darker color. Forel (1908) did not specify a holotype for B. longicornis var. immunis but considered it to differ from B. longicornis in color, size and the position of the 
metathoracic spiracles. The similarity between B. admotus and B. longicornis var. immunis was previously pointed out by Santschi (1923a) and Quirán (2005), who suggested that the main difference between both relates to the size and position of the metathoracic spiracles. However,

814 these traits appear to be variable among populations and we have not found consistent differences 815 between both taxa. For example, Santschi's collection (MHNB) includes syntype specimens of $B$. 816 longicornis var. immunis that match the diagnostic traits of B. admotus entirely. Hence, synonymization seems appropriate.

Quirán (2005) indicated that B. admotus has 3 small ocelli, but in the samples that we studied we only observed one central ocellus, although this trait is inconspicuous.

Brachymyrmex antennatus Santschi

(Fig. 8, supplementary material Fig. S2)

Brachymyrmex (Bryscha) antennatus Santschi, 1929: 312 (w.q.). Lectotype worker (NHMB:

Negro.

Additional material examined. ARGENTINA: Misiones: loc. IGUAZU: PNI, Garganta, 28 (MACN-Bar-Ins-3120). BRAZIL: Ceará: Meruoca (Baixa, Gnd), \pm 970 m, -3.550 -40.467, July 2003, Y. Quinet, 3 workers (CPDC: USNMENT00757781). São Paulo: Ubatuba, P.E. Serra do Mar, N. Picinguaba, -23.297 -44.789, 800 m, 03-14 Mar. 2008, armadilha subterrânea \#4, F.A. 
Quindio: Génova, Vereda El Cedral, Finca Buenos Aires, 1600 m, 4.235 -75.775, 26 Oct. 1999,

E. Gonzales \& J. Sossa, 1 worker (IAvH-E 74166). ECUADOR: Napo: Carlos Julio Arosemena Tola, -1.150 -77.883, 500 m, 11 Dec. 2003. A. L. Wild \#AW2300, 1 worker (ALWC: USNMENT00757782). FRENCH GUIANA: Petit, Satn Basse vie, June-July 2000, S. Durou, J.

Delabie, A. Dejean \& A. Gibernau, 2 workers (CPDC: USNMENT00757779, 00757780).

PERU: Madre de Dios: Reserva Nacional Tambopata, Centro Sachacavayoc, -12.85583 -

Cuzco Amazónico, 15 km NE Puerto Maldonado, 24 June 1989, 200 m, S.P. Cover \& J.E. Tobin, CA-115, 1 worker, 1 queen (MCZC: USNMENT00757630). SURINAME: Maripahewel, IX1959 14-XX-29 I.v.d. Drift, 1 worker (MZSP: USNMENT00757778).

Diagnosis. Brachymyrmex antennatus morphologically resembles B. gaucho, because both species have legs and antennae with suberect hairs and both have an antennal funiculus with the second segment as long as or longer than the first. However, they differ from one another because B. antennatus has abundant, suberect hairs on the dorsum of the head and mesosoma, its gaster has dense pubescence and its body is lighter and yellowish. Brachymyrmex antennatus also resembles $B$. cavernicola in having suberect hairs on the mesosoma that are generally darker in color than the tegument, but $B$. antennatus has a more elongated head, a longer second segment of the antennal funiculus, as mentioned above, thinner hair on its body and denser pubescence on 854 the gaster. HW 0.68-0.71; SL 0.68-0.80; EL 0.15; WL 0.87; PnL 0.31-0.33; PnW 0.45; ML 0.21; MW 0.27; 
Manuscript submitted to: Organisms Diversity \& Evolution

Published version available; DOI: 10.1007/s13127-019-00406-2

Additional material examined measurements (mm) $(\mathrm{n}=5)$. $\mathrm{HL}_{1}$ 0.54-0.60; HL $20.38-0.41 ; \mathrm{HL}_{3}$

861

862

863

864

865

012-0.16; HW 0.54-0.58; SL 0.52-0.63; EL 0.09-0.14; WL 0.60-0.71; PnL 0.15-0.22; PnW 0.35-

0.40; ML 0.14-0.18; MW 0.20-0.24; Indices CI 92.31-100.00; SI 1 93.33-130.23; $\mathrm{SI}_{2}$ 130.23155.56; $\mathrm{OI}_{1} 15.38-26.67 ; \mathrm{OI}_{2} 21.67-29.03$.

Description. Head. Longer than wide in full face view; posterior cephalic border concave.

Dorsum of the head with scattered decumbent hairs. Clypeus with a rounded anterior margin and five long, erect hairs of which a single, usually conspicuous apical hair is near the anterior margin, two lateral hairs in medial position and two more near the toruli; other hairs on the clypeus are conspicuously shorter and appressed or decumbent. Toruli surpassing the posterior clypeal margin (in oblique anterodorsal view). Scapes surpass the posterior cephalic margin by a length of $1.5 \times$ the maximum eye diameter or more. The second segment of the antennal funiculus is as long as the first or longer. The scapes typically have suberect and erect hairs. Three ocelli present. Eyes are positioned on the cephalic midline and have 7-9 ommatidia along their maximal diameter.

Mesosoma. With conspicuous, thin erect hairs of darker color than the tegument. Pronotum anteroposteriorly elongated. The mesonotum is slightly antero-posteriorly inclined, weakly inflated, and it does not bulge dorsally above the pronotum in lateral view. Metanotal groove deep and wider than the diameter of the metathoracic spiracles. Metathoracic spiracles in dorsolateral position and slightly protruding, closer to the propodeal than to the mesometanotal suture, but not touching any suture. Dorsum of propodeum flat and equal in length to the propodeal slope. Propodeal spiracles circular, situated ventral of the posterior propodeal margin. Legs with suberect and erect hairs. Petiole short and inclined forward. 
Gaster. With dense pubescence and scattered long suberect hairs, mainly at the edges of the segments.

Color and sculpture. Body typically uniformly light brown, although some specimens may be 886 light brownish with the head and gaster darker brown.

Distribution (Supplementary material Fig. S2). Known from Argentina, Brazil, Colombia, Ecuador, French Guiana, Perú and Suriname.

Biology. Unknown.

Remarks. The ant at the top of pin USNMENT00758161 is designated here as lectotype and the one immediately below as paralectotype. Santschi's collection (MHNB) contains three additional pins with four workers from the same locality but they are not considered to be part of the type collection as they have no type label. Santschi (1929) described the queen from a sample that does not contain any workers but expressed confidence that it belongs to B. antennatus; the issue may require verification from independent material. Substantial variation exists in the body size of workers of $B$. antennatus from various locations that were studied here, and the cause of this variation remains uncertain. 
00758121-00718123; here designated): 11 workers [examined]. PARAGUAY: San Bernardino.

908

909

910

911

912

913

914

915

916

917

918
Other relevant descriptions: Forel (1912a: 62) (q.). (MHNG: USNMENT00757128): 1 queen.

BRAZIL: Santa Catarina: Blumenau. Raised to species: Wild (2007: 43).

= B. heeri var. fallax Santschi, 1923a: 665 (w.). (NHMB: USNMENT00757697): 1 worker

[examined]. PARAGUAY. Junior synonym of B. aphidicola: Wild (2007: 43).

= B. longicornis var. hemiops Santschi 1923a: 668 (w.). (NHMB: USNMENT00757188-

00757190) 11 workers, 3 queens [examined]. BRAZIL: São Paulo, Ypiranga. n. syn.

Additional material examined. ARGENTINA: Entre Ríos: $8.63 \mathrm{~km}$ W Concordia, -31.42048 -

58.11700, 16 m, 27 Dec. 2007, W. \& E. MacKay, 1 worker, 1 male (WEMC:

USNMENT00757975). Misiones: Parque Provincial Cañadón de Profundidad, -27.56020 -

55.70988, 160 m, 29 Dec. 2007, W. \& E. MacKay leg \#22710,\#22711,\#22712,\#22724,\#22732,

10 workers (WEMC: USNMENT00757617, 00757897, 00757901, 00757924, 00757925, 00757929, 00757930, 00757956, 00757992). BOLIVIA: Santa Cruz: Parque Nacional Noel Kempff, Mercado, -18.800 -60.383, 700 m, 04 Dec. 1993, P.S. Ward \#12285-46, 2 workers, 1 queen (PSWC: USNMENT00757910). BRAZIL: Amazonas: 61 km N Manaus, om Caracaí Rd, “caatinga”, 10 June 1972, W.L. \& D.E. Brown, 3 workers (MCZC: UNSMENT00757619).

Goias: Anapolis, 12 Feb. 1958, W. Kempf, 2 workers (MZSP: USNMENT00757921). Ouro Verde, Faz Boa Vista, -16.29847 -49.21183, 01-07 Aug. 2005, R.R. Silva \& R.M. Feitosa, 5 workers (ICN: MZSP123). Mato Grosso: Chapada dos Guimarães, -15.43333 -55.44874, 740 m, 03 Sep. 1996, P.S. Ward leg \#13203-7, 3 workers (PSWC: USNMENT00757911). Mato Grosso du Sud: 24 km W Campo Grande, 07 Oct. 1989, W. MacKay, 2 workers (WEMC:

USNMENT00758000). 48 km E Campo Grande, 12 Oct. 1989, S. Porter \#12791, 2 workers (WEMC: USNMENT00759011). 8 km SE Punta Bora, 15 Oct. 1989, W.P. MacKay \#12508, 2 
workers (WEMC: USNMENT00759003). Río de Alegría, 17 Oct. 1989, W.P. MacKay \#12950, 2 workers (WEMC: USNMENT00759022). Pará: Melgaço, Caxiuanã-ECFPn, 27 June-03 Dec. 2001, I. Andrade, 5 workers (MPEG: USNMENT00757674, 00757927, 00758030, 00759030). Melgaço, Caxiuanã-ECFPn, -1.78155 -51.59758, 30 Oct. 2003, A.Y. Harada, E.P. Fagundes, C.J.M. Ribeiro, C.E.D. Sanhudo, C.A.R. Moura, J.L.P. Souza, C. Renato, 2 workers (MPEG: AYH112, 127). Serra Norte, Calderião, 20 Oct. 1980, 2 workers (MPEG: MPEG_HYM11505158, USNMENT00757902). Rio de Janeiro: Teresópolis, P.N. Serra dos Orgãos, -22.45333 -42.99806, 23-28 Nov. 1999, Dietz, Silva \& Rocha, 8 workers (ICN: MZSP130). Rondônia: Ouro Preto do Oeste, 03 Apr. 1985, Linha 212 N$^{\circ} 0375,339$, W. França, 4 workers (MPEG: USNMENT00757899,00757914, 00757915, 00758999,). Ouro Preto do Oeste, 04 May 1985, Linha 212 N$^{\circ} 0375,0413$, W. França, 3 workers (MPEG: USNMENT00757913, 00757938, 00758038). Ouro Preto do Oeste, 25 Mar. 1985, ResINPA0035, J. Dias, 2 workers (MPEG: USNMENT00757914, 00757936). São Paulo: Ipiranga, 2371, 2 workers (MZSP: USNMENT00757926]. Itirapina, Dec. 2008, D.P. Silva, 1 worker (MPEG: AYH008). COLOMBIA: Cundinamarca: Bogotá-Villavicencio Km 88 (Susumuko), 1100 m, 28 June 1976, W.L. \& D.E. Brown, 1 worker, 1 queen (MCZC: USNMENT00757746). Caqueza, 29 Dec. 1975, W. \& E. MacKay \#945, 2 workers (WEMC: USNMENT00757686). Huila: 4 km NE Rivera, 30 Dec. 1986, W. \& E. MacKay, 3 workers (WEMC: USNMENT00757903). La Vega, A280, 14-17 Jul 1975, W. MacKay, 1 worker, 1 male (WEMC: USNMENT00757912). Magdalena: 4 km San Pedro, 10.95 -74.05, 550 m, 14 Aug. 1985, P.S. Ward \#17912-36, 3 workers (PSWC: USNMENT00757585). Meta: San Juan de Arama, RNN La Macarena, Caño La Curía, 580 m, 13 July 1992, Est. U. Nacional, 1 worker (ICN: USNMENT00758035). Tolima: Mendez, 15 Nov. 1995, F. Fernández, 1 worker (IAvH: USNMENT00759058). Valle del Cauca: Medio Calima, 24 June 1989, E. MacKay \#11746 
(WEMC: USNMENT00758041). COSTA RICA: Heredia: Estación biológica La Selva, 10.417 -84.000, 50 m, 21 Oct. 1991, J. Longino \#3126-s, 1 worker, 1 queen (JTLC:

INBIOCRI001238064). ECUADOR: Loja: Estación San Francisco, 2200 m, 14 Sep. 2011, 14 workers (ICN: USNMENT00759036, 00759037). Estación San Francisco, 17 sep. 2011, 2 workers (ICN: USNMENT00759034). Napo: 11 km SE Consaga, -0.66667 -77.80000, 1640 m, 09 Dec. 2003, A.L. Wild \#AW2263, 4 workers (ALWC: USNMENT00757586, 00757928).

GUATEMALA: Alta Vera Paz, Parque Nacional Las Victorias, 15.47492 -90.37528, 206 m, 18 July 2004, W. \& E. MacKay, 1 worker (WEMC: USNMENT00758018). GUYANA: Karto: Pt. Mazaruni-Potaru Dist. J. Weintraub, 2 workers, 1 queen (MCZC: USNMENT00757931).

MEXICO: Guanajuato: Highway 57, Km 306, Rancho Jardin, 10 Aug. 1965, Cornell University, 2 workers, 1 queen (MCZC: USNMENT00759002). Yuriria, 03 Feb. 1964, P. Reyes C. \& H. Romero, 1 worker (MZSP: USNMENT00757616). NICARAGUA: Río San Juan: Bartola, 8 km SE El Castillo, 10.97303 -84.33897, 47 m, 12 July 2003, W. \& E. MacKay \#20187, 2 workers (WEMC: USNMENT00758029). PANAMA: San Blas: Nusegandi, 08 June 1992, L.E. Tennant, 1 worker, 1 queen (MZSP: USNMENT00757923). PARAGUAY: Amambay: Parque Nacional Cerro Corá, -22.650 -56.017, 13 May 1997, A. Wild \#AW0563, 1 worker (ALWC: USNMENT00757625). Canindeyu: Reserva Natural del Bosque, Mbacarayù, Jejuimi, 24.1 -55.5, 19 Sep. 1996, A. Wild \#AW0563, 6 workers (ALWC: USNMENT00757584, 00757895). Reserva Natural del Bosque, Mbacarayù, Jejuimi, -24.1 -55.5, 16-23 May 1996, A.C.F. Costa, 1 worker (ALWC: USNMENT00757868). Reserva Natural del Bosque, Mbacarayù, Jejuimi, -24.1 -55.5, 11 Oct 1996, A. Wild \#AW0334, 1 worker (ALWC: USNMENT00757893). Reserva Natural del Bosque, Mbacarayù, Jejuimi, -24.1 -55.5, 28 Jan. 1997, A. Wild \#AW384, 3 workers (ALWC: USNMENT00757894). Reserva Natural del Bosque, Mbacarayù, Jejuimi, -24.1 -55.5, 12 Mar. 1997, A. Wild \#AW0490, 3 workers (ALWC: 
USNMENT00757896). PERU: Huanuco: 42 km E. Tingo Maria, 1100 m, 10 Dec. 1954, 1 worker (CASC: CASENT0196020). Madre de Dios: Reserva Nacional Tambopata, Centro Sachavacayoc, -12.85583 -69.36194, 19-31 July 2012, Curso de hormigas, 7 workers (ICN:

CAB-120725-1). Reserva Nacional Tambopata, Centro Sachavacayoc, casa camping, -12.85583 69.36194, 198 m, 26 July 2012, GSNMBU, 1 worker (ICN: USNMENT00757613). USA:

Lousiana: East Baton Rouge Par. Baton Rouge, Kennilworth \& Perkins Rd. BREC Perkins Park, 03 Apr. 2003, S.T. Dash, 1 worker (WEMC: USNMENT00759023). VENEZUELA: Bolivar: Canaima, Orchid Is, 14 Oct. 1988, W. MacKay \#11159, 1 worker (WEMC: USNMENT00757906).

Diagnosis. Brachymyrmex aphidicola is morphologically similar to B. australis, B. minutus and B. termitophilus, because all of them typically have smooth and shiny yellowish bodies, their mesonotum does not bulge dorsally above the pronotum, their eyes are positioned on the cephalic midline, and the metanotal groove is either absent or narrower than the diameter of the metathoracic spiracles. However, B. aphidicola differs from B. australis by having scapes that surpass the posterior margin of the head by a length longer than the maximal diameter of the eye; from B. minutus by having a well-differentiated mesometanotal suture and by the presence of two erect hairs on the pronotum and two on the mesonotum; and from B. termitophilus by having scattered pubescence on the gaster.

Lectotype measurements (mm). $\mathrm{HL}_{1}$ 0.41; $\mathrm{HL}_{2}$ 0.29; HL 0.10 ; HW 0.37; SL 0.39; EL 0.10; WL 0.41; PnL 0.10; PnW 0.25; ML 0.08; MW 0.18; Indices CI 90.48; SI1 105.26; SI 2 133.33; $\mathrm{OI}_{1}$ 26.32; $\mathrm{OI}_{2} 23.81$. 
Additional material examined measurements $(\mathrm{mm})(\mathrm{n}=20) . \mathrm{HL}_{1}$ 0.36-0.55; HL $20.26-0.37$; $\mathrm{HL}_{3}$ 0.36; ML 0.07-0.12; MW 0.14-0.20; Indices CI 84.21-95.65; SI 194.74-112.5; SI 2 117.14-157.89;

Description. Head. Slightly longer than wide in full face view; posterior cephalic margin flat or

1013 slightly concave. Dorsum of the head with scattered appressed hairs. Clypeus with a rounded 1014 anterior margin and five long, erect hairs of which a single, usually conspicuous hair is near the anterior margin, two hairs are in mediolateral position and two more near the toruli; other hairs on the clypeus are markedly shorter and appressed or decumbent. Toruli surpassing the posterior clypeal margin in oblique anterodorsal view. The scapes surpass the posterior margin of the head by a length larger than the maximal diameter of the eye, and typically bear appressed, sometimes decumbent, but never erect hairs. Three ocelli usually present, but sometimes inconspicuous.

1020 Eyes are positioned on the cephalic midline and have 7-10 ommatidia along their maximal 1021 diameter.

Mesosoma. Typically with two erect hairs on the pronotum and two on the mesonotum. In lateral 1023 view the mesonotum is not or weakly inflated and does not bulge dorsally above the pronotum.

1024 Metanotal groove absent or shallow and narrower than the diameter of the metathoracic spiracles.

1025 Metathoracic spiracles in dorsolateral position, not protruding, and usually touching the 1026 propodeal suture. Dorsum of propodeum slightly convex and $\sim 1 / 3$ th of the length of the 
propodeal slope. Propodeal spiracles circular, positioned ventrally of the posterior propodeal margin, and slightly posterior of the middle of the propodeal slope. Legs with appressed and scattered hairs. Petiole short and inclined forward.

Gaster. With scattered pubescence and scattered long suberect hairs, especially along the posterior edges of the segments.

Color and sculpture. Body smooth and shiny, yellowish.

\section{Distribution (Supplementary material Fig. S3). Brachymyrmex aphidicola is widely} distributed and known from Argentina, the Bermudas, Bolivia, Brazil, Colombia, Costa Rica, Ecuador, Gutemala, Guyana, Mexico, Nicaragua, Panama, Paraguay, Peru, the United States, and Venezuela.

Biology. Specimens of this species have been found under stones, in rotten wood, on epiphytes (USNMENT00757619), and on Conostegia setosa (USNMENT00757923). Brachymyrmex aphidicola nests underground or in organic litter, and it appears to be abundant in Paraguayan forests (Wild, 2007).

Remarks. Some specimens from Argentina have expanded gasters and Forel (1912a) highlighted a worker identified as B. aphidicola from Santa Catharina (Brazil) that also has a somewhat expanded gaster, but this specimen has not been studied and its identification remains to be confirmed. The original description of Forel (1909) indicates B. aphidicola to occur in both Paraguay and the Bermudas, however, a type locality is not designated. In the type series of Forel's collection (NHMG) only specimens from Paraguay are present. Nevertheless, Santschi's collection (NHMB) contains a decapitated specimen from Bermudas that is labeled as the type of 
1052 here as lectotype and paralectotypes.

1053 We concur with Wild (2007) that B. heeri var. fallax is a junior synonym of B. aphidicola. The 1054 workers of the type series of this variation have all the diagnostic characteristics of B. aphidicola. 1055 The description of B. longicornis var. hemiops (Santschi, 1923a) only specifies color and the 1056 smaller size of the body and eyes of this variation in comparison to B. longicornis, however, 1057 detailed study of the syntype renders it indistinguishable from B. aphidicola.

1058

1059

1060

1061

1062

1063

1064

1065

1066

1067

1068

1069

1070

1071

1072 Lectotype worker measurements (mm) HL1 0.47; HL2 0.28; HL 3 0.11; HW 0.43; SL n.a.; EL

1073 0.12; WL 0.52; PnL 0.09; PnW 0.31; ML 0.12; MW 0.21; Indices CI 90.74; SI1 n.a; SI2 n.a; OI 1

$1074 \quad 28.57 ; \mathrm{OI}_{2} 23.15$.

\section{Brachymyrmex attenuatus Santschi NEW STATUS}

(Fig. 10, supplementary material Fig. S4)

Brachymyrmex luederwaldti st. attenuatus Santschi, 1929: 310 (w.). Lectotype worker (NHMB:

USNMENT00757177) and Paralectotype worker (NHMB: USNMENT00757177; here

designated) 2 workers [examined]. BRAZIL, Santa Catarina, Blumenau.

Diagnosis. Brachymyrmex attenuatus n. st. morphologically resembles Brachymyrmex degener, because both have long scapes that extend beyond the posterior margin of the head, they have faint sculpture on the mesosomal dorsum, and dorsally positioned, slightly protruding metathoracic spiracles. Brachymyrmex attenuatus n. st. differs from B. degener, however, by having a gaster with dense pubescence. 
Manuscript submitted to: Organisms Diversity \& Evolution

Published version available; DOI: 10.1007/s13127-019-00406-2

1075

1076

Paralectotype worker measurements (mm) HL $10.43 ; \mathrm{HL}_{2} 0.31 ; \mathrm{HL}_{3} 0.11$;W 0.39; SL 0.45; EL

1077

0.13; WL 0.46; PnL 0.14; PnW 0.29; ML 0.11; MW 0.15; Indices CI 91.84; SI 113.33; SI 2

1078

145.71; $\mathrm{OI}_{1} 33.33 ; \mathrm{OI}_{2} 25.51$.

1079

1080 Description. Head. Slightly longer than wide in full face view; posterior cephalic margin slightly concave. Dorsum of head with scattered appressed hairs. Clypeus with a rounded anterior margin and five long, erect hairs of which a single, usually conspicuous hair is near the anterior margin, two hairs are in mediolateral position and two more near the toruli; other hairs on the clypeus are substantially shorter and appressed or decumbent. Toruli surpassing the posterior clypeal margin in oblique anterodorsal view. The scapes extend beyond the posterior cephalic margin by a length approximately equal to the maximum diameter of the eye (and not more than $1.5 \times$ this diameter), and have decumbent hairs. A single central ocellus seems to be present but is inconspicuous. Eyes are positioned on the cephalic midline and have 7-9 ommatidia along their maximal diameter.

Mesosoma. Typically with two erect hairs on the pronotum and two on the mesonotum, sometimes with additional suberect hairs, mainly on pronotum. In lateral view, the mesonotum is

1092 inflated, but it does not bulge dorsally above the pronotum. Metanotal groove deep and wider 1093 than the diameter of the metathoracic spiracles. Metathoracic spiracles fully dorsal in position, 1094 slightly protruding and not touching the mesometanotal or propodeal sutures. Dorsum of propodeum slightly convex and shorter than the propodeal slope. Propodeal spiracles circular, positioned ventrally of the posterior propodeal margin, and slightly posteriorly of the middle of

1097 the propodeal slope. Legs with appressed and scattered hairs. Petiole short and inclined forward.

1098 Gaster. With appressed dense pubescence and several scattered long erect hairs. 
1099 Color and sculpture. Body overall smooth and shiny, with faint sculpture on mesosomal dorsum.

1100 Body uniformly light or dark brownish, but the legs and antennae are yellowish.

1101

1102 Distribution (Supplementary material Fig. S4). Brachymyrmex attenuatus is currently only

1103 known from Brazil.

1104

1105

Biology. Unknown.

1106

1107 Remarks. Here we designate the lectotype as the specimen closest to the pin

1108 (USNMENT00757177); the paralectotype has lighter brownish color in comparison with the

1109 lectotype. This species was described by Santschi (1929) as a subspecies of B. luederwaldti that

1110 has a smaller body size in comparison with B. luederwaldti. Additionally, B. attenuatus has

1111 weaker sculpture, a shinier body, especially on pronotum, a more concave posterior cephalic

1112 border, smaller eyes and a more convex mesonotum than B. luederwaldti. All these

1113 characteristics are somewhat subjective, because they represent differences in intensity rather

1114 than state and as such it is difficult to determine clear boundaries. A more marked difference is

1115 the presence of pubescence on the gaster, which is clearly present in B. attenatus $\mathbf{n}$. st., but absent

1116 in B. luederwaldti. The presence or absence of pubescence is an important trait to delimit other

1117 Brachymyrmex species, and hence we raise B. attenatus n. st. to species level.

1118

1119 
1123 Brachymyrmex minutus r. australis Forel, 1901b: 302 (w.). Lectotype worker (MHNG:

1124 USNMENT00757156) and paralectotype worker (MHNG: USNMENT00758102; here

1125 designated): 2 workers [examined]. BRAZIL, Rio Grande do sul, Pelotas. Raised to species:

1126 Santschi (1922: 260). See also: Santschi (1923a: 662).

1127 = Brachymyrmex australis var. curta Santschi, 1922: 260 (w.q.m.). (NHMB:

1128 USNMENT00757700 - 00757703, 00758069 - 00758071): 17 workers, 2 queens, 7 males

1129 [examined]. ARGENTINA: Cordoba, Alta Gracia [Also described as a new variety in Santschi

1130 (1923a: 663)]. n. syn.

1131 = Brachymyrmex longicornis Forel, 1907: 9 (w.). (MHNG: USNMENT00757144): 2 workers

1132 [examined]. BRAZIL: Porto Alegre. Other relevant descriptions: Forel (1912a: 62) (q.).

1133 (MHNG: USNMENT00757145): 1 queen [examined]. BRAZIL: São Paulo. n. syn.

1134

1135 Additional material examined. ARGENTINA: Santa Cruz: O. Bondensköld, 3 workers

1136 (MCZC: USNMENT00759000). Tucumán: 11 km N Tafi Viejo, -26.63333 -65.23333, 820 m,

1137 01 Feb. 1995, P.S. Ward \#12826-25, 3 workers (PSWC: USNMENT00757628). BAHAMAS:

1138 Exumas: unnamed cay, 175 m N of NW tips of Obrien's Cay, 05 May 1995, J. W. Morrison 321-

1139 92, 2 workers (PSWC: USNMENT00758991). BRAZIL: Bahia: Ilheus, CEPEC, Antonio 455E,

11402 workers, 2 queens (CPDC: USNMENT00757922). Lençois, Chap. Diamantina, -12.55 -41.38,

114125 Mar. 2001, Santos, J.R.M. dos, 2 workers, 1 queen (CPDC: USNMENT00757909). Goias:

1142 Ouro verde, Faz Boa Vista, -16.29847 -49.21183, 01-07 July 2005, R.R. Silva \& R.M. Feitosa, 4

1143 workers (ICN: MZSP122). Minas Gerais: Alfenas, Porto, 06 Oct. 2011, I.A. Dos Santos, 6

1144 workers (ICN: USNMENT00759048, 00759049). Pará: Melgaço, Caxiuanã, ECFPn, -1.73584 -

1145 51.48762, II: transecto (4-600), 23-25 Oct. 2005, Equipe A.Y. Harada, 3 workers (MPEG:

1146 AYH036). Rio de Janeiro: Teresópolis, P.N. Serra dos Orgãos, -22.45333 -42.99806, 23-28 
Nov. 1999, Dietz, Silva \& Rocha, 6 workers (ICN: MZSP130). Santa Catarina: São Bento do Sul, APA Rio Vermelho, -26.36417 -42.99806, 30 Mar.-04 Apr. 2001, R. Silva \& Eberhardt, 5 workers (ICN: MZSP134 135). São Paulo: Ilha da Vitória, 16-27 Mar. 1964, Exp. Dep. Zool. 3592, 5 workers, 1 queen (MCZC: USNMENT00757932); Itirapina, 10 Feb. 2009, S. Sendoya, 20 workers (ICN: USNMENT00759046); Jundiai, Sierra Do Japi, Apr. 2009, S. Diniz, 3 workers (ICN: USNMENT00759043); Piedade, Floresta Atlantica, "Cristo", Mar. 2010, G. Bieber, 3 workers (ICN: USNMENT00759045); Tapirai, -24.03208 -47.46556, 08-14 Jan. 2001, R. Silva \& Eberhard, 4 workers (ICN: MZSP170). COLOMBIA: Bolivar: Zambrano, Hacienda Monterrey, 9.617 -74.900, 9-75 m, 04 Aug. 1992, A. Molano, 3 workers (ICN:

USNMENT00757898). Caldas: Municipio Aranzazu, Vereda Alegrias, Finca Betania, La Esperanza, 5.29811 -75.49047, 1990 m, L.E. Franco \& J. Cruz, 2 workers (IAvH: IAvH27305); Municipio Aranzazu, Vereda Alegrias, Finca Villa Rosita, 5.30603 -75.48492, 1825 m, 06-08 Aug. 2003, L.E. Franco \& J. Cruz, 1 worker (IAvH: IAvH25467). Caquetá: PNN Serranía de Chiribiquete, Cuñané-Anui, 26 Feb. 2001, 2 workers (IAvH: IAvH-E71471). Cauca: El Hortigal, Holanda, Mar. 2002, Valderrama, 1 worker (ICN: USNMENT00757937).

Cundinamarca: Fusagasugá, 08 Dec. 1975, W. \& E. MacKay, 2 workers (WEMC: USNMENT00757907). Guajira: Serrania de Macuira, 6-8 km S Nazareth, 70-200 m, 13 June 1957, W.L. Brown \& Kugler, 2 workers (IAvH: IAvH-E74171). Huila: 21 Km W La Plata Gallego, 03 Jan. 1984, W.P. MacKay \#7153, 6 workers (WEMC: USNMENT00757623, 00757624, 00759014); Neiva, 05 Dec 1975, W. \& E. MacKay, 2 workers (WEMC: USNMENT00757620). Magdalena: PNN Tayrona, Cañaveral, 11.33 -74.03, 30 m, 20-27 Apr. 2000, C. Sarmiento, 1 worker (IAvH: USNMENT00759056). Meta and Cundinamarca border: 28 Dec. 1975, W. \& E. Mackay, 4 workers (WEMC: USNMENT00757917, 00757939). Meta: Puerto Gaitán, 21 Dec. 1975, W. \& E. MacKay \#783, 2 workers (WEMC: 
1171 USNMENT00757672). Quindío: Buenavista, Vereda El Infierno, Finca Guadalajara, 4.3767 -75.

11727694,1160 m, 16 Nov. 1999, E. Gonzalez, 2 workers (IAvH: IAvH-E74165); Municipio

1173 Filandia, Vereda Cruces, Finca Los Micos, 4.70424 75.65917, 12-13 July 2002, E. Jimenez \&

1174 L.E. Franco, 1 worker (IAvH: IAvH27232). Risaralda: Apia La Felisa, Cafetal de sol (S-I), 5.13

$1175-75.95,1480$ m, 29 Oct. 2001, 1 worker (IAvH: IAvH-E74174). Valle del Cauca: Dagua, 07 Jan.

1176 1976, W. \& E. MacKay, 5 workers (WEMC: USNMENT00758993); Medio Calima, 24 June

1177 1989, E. MacKay \#11740 \#11743 \#11744, 2 workers (WEMC: USNMENT00757738, 00759005,

1178 00757908, 00759012). Vichada: Municipio Cumaribo, Corregimiento Santa Rita, PNN El

1179 Tuparro, 5.3075 -67.9500, 135 m, 14-16 Feb. 2004, I. Quintero \& E. Gonzalez, 2 workers (IAvH:

1180 USNMENT00759057). COSTA RICA: Guanacaste: Provincia Maritza field Station, 03 May

1181 1995, R. Anderson \#17716, 3 workers (WEMC: USNMENT00757671). Puntarenas: Pen. Osa.

1182 Par. Nat. Corcovado, Llorona, 8.58 -83.70, 5 m, 30 Dec. 1981, J. Longino, 1 worker (JTLC:

1183 JTLC000005948). CUBA: Holguín: 6 km S Yamaniguey, 20.55 -74.73, 25 m, 23 Aug. 2001,

1184 P.S. Ward \#14437-19, 3 workers (PSWC: USNMENT00757919). DOMINICAN REPUBLIC:

118516 km ENE Pedernales, 18.11667 -71.62361, 800 m, 9 Sep. 1992, P.S. Ward \#11726-22, 3

1186 workers (PSWC: USNMENT00757959); Prov. La Vega, Jarabacoa to El Rio, shady ravine, 80-

11871500 m, Feb. 1975, W.L. \& D.E. Brown, 2 workers (MCZC: USNMENT00757736).

1188 ECUADOR: Guayaquil, 10 m, Dec. 1997, Forero, 2 workers (IAvH: USNMENT00759054).

1189 FRENCH GUIANA: Petit Saut Basse Vie II/III, 2001, A. Dejean, 1 worker (CPDC:

1190 USNMENT00757734); Reserve Naturel de Nouragues- Inselbery forest, Oct. 2009, Sara Groc, 4

1191 workers (ICN: USNMENT00759033). GUATEMALA: El progreso: 5 km W El Rancho,

119214.91667 -90.06666, 400 m, 17 Nov. 2003, A.L. Wild \#AW2002, 3 workers (ALWC:

1193 USNMENT00757957). Suchitepéquez: Cocales (Mpio. San Antonio), 14.39206 -91.19347, 242

1194 m, 31 Aug. 2004, W \& E. MacKay \#20820, 1 worker (WEMC: USNMENT00758995). 
1195 GUYANA: Demerara-Mahaica: Wales, 6.67 -58.25, 50 m, 23 Jan. 1981, 2 workers, 1 queen

1196 (JTLC: JTLC000005920); Rupununi, Karanambo, 3.75 -59.3, 100 m, 01 Jan. 1981, 1 worker

1197 (JTLC: JTLC000005926). MAURITIUS: Mgne. Brise Fer, -20.37 57.43, 600 m, 07 May 1989,

1198 P.S. Ward \#10518-2, 3 workers (PSWC: USNMENT00757934). MEXICO: Chiapas: 10 km S

1199 Palenque, 30 May 1988, 31 May 1988, W. MacKay \#10611 \#10613, 8 workers (WEMC:

1200 USNMENT00757588, 00757677, 00757678). Veracruz: Los Tuxtlas, 26 July 1974, R.L. Jeanne, 12011 worker (MCZC: USNMENT00757735). Yucatan: 25.7 km E Progreso, 12 Apr. 1982, Smalley

1202 Thien \& Bradburn, 1 worker (MCZC: USNMENT00757618). PARAGUAY: Boquerón: Enciso, $1203-21.20$-61.67, 03-06 Nov 2001, M. LePonce \& T. Delsinne, 2 workers (ALWC:

1204 USNMENT00757904). Central: Areguá, CHP center, -25.30 -57.38, 01 Oct. 1995, A. Wild 1205 \#AW 0059, 1 worker (ALWC: USNMENT00757905). Presidente Hayes: Monte Lindo, 120623.86667 -58.46667, 800-1500 m, Feb. 1975, W.L. \& D.E. Brown, 2 workers (MCZC:

1207 USNMENT00757736). PERU: Madre de Dios: Reserva Nacional Tambopata, Centro

1208 Sachavacayoc, Centre, -12.85583 -69.36194, 209 m, 19-31 Jul 2012, R. Feitosa, 1 worker (ICN:

1209 USNMENT00757611). URUGUAY: Montevideo, L. Pastre, 1 worker (CPDC:

1210 USNMENT00757684).

1211

1212 Diagnosis. Brachymyrmex australis is very similar in morphology to B. aphidicola, B. minutus 1213 and B. termitophilus, because all these species have a mesonotum that does not bulge dorsally

1214 above the pronotum in lateral view, their bodies are smooth, shiny and yellowish, and their eyes

1215 are positioned on the cephalic midline. However, B. australis differs from B. aphidicola by

1216 somewhat shorter scapes, although they still reach to the posterior margin of the head or surpass

1217 it by a length equal to or smaller than the maximal diameter of the eye; it differs from B. minutus 1218 by having a well-marked mesometanotal suture and two erect hairs on the pronotum and two on 
1219 the mesonotum; finally, it has scattered pubescence on the gaster whereas that of B. termitophilus 1220 is dense.

Lectotype worker measurements (mm) HL $\mathrm{HL}_{1} 0.37$; $\mathrm{HL}_{2}$ 0.27; $\mathrm{HL}_{3}$ 0.10; HW 0.29; SL 0.29; EL 0.10; WL 0.35; PnL n.a.; PnW 0.23; ML 0.08; MW 0.17; Indices CI 78.95; $\mathrm{SI}_{1} 100.00 ; \mathrm{SI}_{2}$ 107.14; $\mathrm{OI}_{1} 33.33 ; \mathrm{OI}_{2} 26.31$. 0.08-0.15; HW 0.29-0.53; SL 0.26-0.48; EL 0.08-0.14; WL 0.29-0.55; PnL 0.08-0.20; PnW 0.21135.29; $\mathrm{OI}_{1} 1$ 15.38-30.91; OI2 19.35-28.33.

Description. Head. Slightly longer than wide in full face view; posterior cephalic margin slightly 1232 concave. Dorsum of the head with scattered appressed hairs. Clypeus with a rounded anterior margin and five long, erect hairs of which a single, usually conspicuous hair is near the anterior

1234 margin, two hairs are in mediolateral position and two more near the toruli; other hairs on the 1235 clypeus are markedly shorter and appressed or decumbent. Toruli surpassing the posterior clypeal 1236 margin in oblique anterodorsal view. The scapes extend beyond the posterior margin of the head 1237 by a length equal to or smaller than the maximal diameter of the eye; they typically have

1238 appressed, sometimes decumbent, but never erect hairs. Three inconspicuous ocelli. Eyes on the 1239 cephalic midline, with 7-14 ommatidia along their maximal diameter.

1240 Mesosoma. Typically with two erect hairs on the pronotum and two on the mesonotum. The 1241 mesonotum is not inflated and it does not bulge dorsally above the pronotum in lateral view. 1242 Metanotal groove absent or shallow and narrower than the diameter of the metathoracic spiracles. 
1243 Metathoracic spiracles in dorsolateral position, not protruding, and usually touching both the

1244 mesometanotal and propodeal sutures. Dorsum of the propodeum flat or weakly convex and

$1245 \sim 1 / 3$ th of the length of the propodeal slope. Propodeal spiracles circular, positioned ventrally of

1246 the posterior propodeal margin slightly posterior of the middle of the propodeal slope. Legs with

1247 appressed and scattered hairs. Petiole short and inclined forward.

1248 Gaster. With scattered pubescence and scattered long suberect hairs.

1249 Color and sculpture. Body smooth and shiny, uniform yellowish in color.

1251 Distribution (Supplementary material Fig. S5). Brachymyrmex australis is known from

1252 Argentina, the Bahamas, Brazil, Colombia, Costa Rica, Cuba, the Dominican Republic, Ecuador,

1253 French Guiana, Guatemala, Guyana, Mexico, Paraguay, Peru and Uruguay. It has also been 1254 introduced in Mauritius.

1256 Biology. Some specimens have been found under stones and among leaf litter. The type material of B. longicornis (here considered a junior synonym of B. australis) was collected from orchids.

1260 diagnostic traits to separate it from typical B. minutus. Subsequently, Santschi (1922) raised B.

1261 australis to species level, described a new variety to it (B. australis var. curta), again without

1262 clear motivation, although he pointed out morphological similarities between the males of $B$. australis and B. fiebrigi. Later, Santschi (1923a) indicated that B. australis has a conspicuous

1264 mesometanotal suture, and B. minutus does not, and that B. australis var. curta is smaller and 1265 shinier than typical B. australis. 
Manuscript submitted to: Organisms Diversity \& Evolution

Published version available; DOI: 10.1007/s13127-019-00406-2

1266

1267

1268

1269

1270

1271

1272

1273

1274

1275

1276

1277

1278

1279

1280

1281

1282

1283

1284

1285

1286

1287

1288

1289

The type material of B. australis var. curta and B. longicornis share the same diagnostic traits and

display only minor variation in body size and the length of the scapes compared with $B$. australis.

Most of the specimens of B. longicornis we studied are yellowish, but one was brownish, and the nature of this variation remains to be documented. In any case, Forel (1907) originally described

B. longicornis as “yellowish brown”. Considering our observations B. australis var. curta and B.

longicornis are synonymized here to $B$. australis.

Santschi (1923a) identified a specimen (1 worker, NHMB) from a termite nest in Sao Leopoldo, Rio Grande do Sul, Brazil, i.e. the type locality of B. termitophilus (which has also been recored from termite nests), as B. australis but this specimen has the diagnosis traits of B. fiebrigi; additional specimens (2 workers, NHMB) from Uruguay, Nueva Helvetia (Mme.v. Steiger) that he identified as $B$. australis var. curta have the diagnostic traits of $B$. termitophilus.

Brachymyrmex bahamensis NEW SPECIES

(Fig. 12, supplementary material S6)

Holotype worker (MCZC: USNMENT00757689) and Paratype workers (MCZC:

USNMENT00757689, PSWC: USNMENT00757726): 5 workers. BAHAMAS: Exuma, unnamed cay, 175 m S of Staniel Cay, 21 May 1990, L.W. Morrison 101-90.

Additional material examined. BAHAMAS, Andros Island, May-June 1904, col. W.M.

Wheeler, 13 workers, 2 queens (MCZC: USNMENT00757690).

Etymology: In reference of the type locality. 
Manuscript submitted to: Organisms Diversity \& Evolution

Published version available; DOI: 10.1007/s13127-019-00406-2

1290 Diagnosis. Brachymyrmex bahamensis resembles B. termitophilus because both species have

1291 scapes that are surpass the posterior margin of the head by a length smaller than the maximal

1292 diameter of the eye, their mesonotum does not bulge dorsally above the pronotum, they have

1293 erect or suberect hairs on the mesosoma, a gaster with dense pubescence, and yellowish body

1294 color. However, the unique feature of B. bahamensis is that it has approximately 6 erect hairs on

1295 the pronotum and two on the mesonotum that are very long, i.e. about twice the length of the

1296 maximal diameter of the eye. Brachymyrmex bahamensis also resembles $B$. heeri, but this latter

1297 species has a mesonotum that bulges out dorsally above the pronotum.

1298

1299 Holotype measurements (mm). HL 1 0.46; HL2 0.31; HL 3 0.13; HW 0.41; SL 0.38; EL 0.09; WL

1300 0.45; PnL 0.13; PnW 0.29; ML 0.09; MW 0.19; Indices CI 88.46; SI 1 91.30; SI2 120.00; OI 1

$1301 \quad 21.74 ; \mathrm{OI}_{2} 28.85$.

1302

1303 Paratype measurements $(\mathrm{mm})(\mathrm{n}=2) . \mathrm{HL}_{1}$ 0.47-0.48; $\mathrm{HL}_{2}$ 0.32; HL 3 0.14; HW 0.43-0.44; SL

1304 0.39-0.40; EL 0.09-0.10; WL 0.47-0.49; PnL 0.13-0.16; PnW 0.30-0.31; ML 0.09-0.12; MW

1305 0.21; Indices CI 90.57-90.74; SI 91.67-91.84; SI 2 122.22-125.00; OI1 22.45-25; OI2 27.78-28.30.

1306

1307 Description. Head. Slightly longer than wide in full face view; posterior cephalic margin slightly

1308 concave. Dorsum of head with appressed hairs and with two rows of erect hairs. Clypeus with a

1309 rounded anterior margin and five long, erect hairs of which a single, usually conspicuous hair is

1310 near the anterior margin, two hairs are in mediolateral position and two more near the toruli;

1311 other hairs on the clypeus are markedly shorter and appressed or decumbent. Toruli surpassing

1312 the posterior clypeal margin in oblique anterodorsal view. The scapes surpass the posterior

1313 cephalic margin by a length smaller than the maximal diameter of the eye; they typically have 
1314 appressed, sometimes decumbent but never erect hairs. Ocelli absent. Eyes are positioned on the

1315 cephalic midline and have $8-9$ ommatidia along their maximal diameter.

1316 Mesosoma. Approximately 6 long, erect hairs on the pronotum and two on the mesonotum, each

1317 having a length of about twice the maximal diameter of the eye. In lateral view, the mesonotum is

1318 not inflated and it does not bulge dorsally above the pronotum. Metanotal groove absent or

1319 shallow and narrower than the diameter of the metathoracic spiracles. Dorsum of the propodeum

1320 is flat and $\sim 1 / 3$ th of the length of the propodeal slope. Metathoracic spiracles in dorsolateral

1321 position, not protruding, and usually touching the propodeal suture, but not the mesometanotal

1322 suture. Propodeal spiracles circular, positioned ventrally of the posterior propodeal margin,

1323 posterior of the middle of the propodeal slope. Legs with appressed and scattered hairs. Petiole

1324 short and inclined forward.

1325 Gaster. With dense pubescence and several scattered conspicuous long erect hairs.

1326 Color and sculpture. Body usually smooth and shiny, yellowish.

Distribution (Supplementary material S6). Currently exclusively known from the Bahamas.

Biology. Unknown.

1332 Remarks. The holotype is located at the top of pin USNMENT00757689, with the two paratypes

1333 below. 
1339 (putative worker-queen intercaste); CASENT0615277, 0615294, 0617077 (destroyed) (3

1340 workers); ANTWEB: CASENT0615273 (putative worker-queen intercaste), 0615276 (1 worker),

13410615292 (1 queen)): 5 workers, 1 queen, 2 putative worker-queen intercastes. HONDURAS:

1342 Comayagua: PN Cerro Azul Meambar, 14.87092, -87.89917, 1120 m, 20 May 2010,

1343 LLAMA\#Wa-C-04-1-31.

1344

1345 Etymology: The epithet bicolor reflects the conspicuous body coloration with black head and 1346 gaster and yellow mesosoma.

1348 Diagnosis. The conspicuous color pattern allows distinguishing $B$. bicolor from any other 1349 Brachymyrmex species.

1350

1351 Holotype measurements (mm). HL 1 0.43; HL $20.30 ; \mathrm{HL}_{3} 0.10$; HW 0.38; SL 0.44; EL 0.11; WL

1352 0.48; PnL 0.12; PnW 0.28; ML 0.10; MW 0.16; Indices CI 88.78; $\mathrm{SI}_{1}$ 114.94; $\mathrm{SI}_{2}$ 147.06; $\mathrm{OI}_{1}$ $1353 \quad 27.59 ; \mathrm{OI}_{2} 22.45$.

1354

Paratype measurements (mm). HL 1 0.43; HL2 n.a.; HL 3 0.10; HW 0.41; SL 0.45; EL 0.11; WL 0.48; PnL 0.12; PnW 0.28; ML 0.11; MW 0.15; Indices CI 94.90; SI 1 109.68; $\mathrm{SI}_{2}$ n.a.; $\mathrm{OI}_{1}$ 25.81;

$1357 \quad \mathrm{OI}_{2} 22.45$.

1358

1359 Worker description. Head. Slightly longer than wide in full face view; posterior cephalic 1360 margin slightly convex. Dorsum of the head with appressed hairs. Clypeus with a rounded 1361 anterior margin and five long, erect hairs of which a single, usually conspicuous hair is near the 
1362 anterior margin, two hairs are in mediolateral position and two more near the toruli; other hairs

1363 on the clypeus are clearly shorter and appressed or decumbent. Toruli surpassing the posterior

1364 clypeal margin in oblique anterodorsal view. The scapes surpass the posterior margin of the head

1365 by a length larger than the maximal diameter of the eye and have appressed pubescence. Three

1366 conspicuous ocelli. Eyes are positioned on the cephalic midline and have 8 ommatidia along their

1367 maximal diameter.

1368 Mesosoma. Without erect hairs and in lateral view approximately hour-glass shaped (this

1369 condition is absent in the presumed intercast) with a constriction between the bulging

1370 promesonotum and propodeum. In lateral view, the mesonotum is anteriorly inclined, but it does

1371 not bulge dorsally above the pronotum. Metanotal groove present and wider than the diameter of

1372 the metathoracic spiracles. Dorsum of the propodeum is convex and shorter than the propodeal

1373 slope. Metathoracic spiracles in dorsal position, not protruding, not touching any sutures.

1374 Propodeal spiracles circular, positioned just ventrally of the posterior propodeal margin slightly

1375 posterior of the middle of the propodeal slope. Legs with appressed and scattered hairs. Petiole

1376 short and inclined forward.

1377 Gaster. With scarce pubescence and several scattered long erect hairs at the edge of the segments.

1378 Color and sculpture. Body smooth and shiny, with a conspicuous bicolored pattern. The head

1379 and gaster are blackish in color, however, the mandibles, the labial and maxillary palps, the bulbi

1380 and bases of the antennae, the terminal antennomeres and hairs are conspicuously yellow in

1381 color. Additionally, the mesosoma and legs are yellowish, with the tibia of the second and third

1382 pairs of legs being dark brownish, like most of the scape.

1384 Intercaste description. The presumed worker-queen intercaste differs from the worker mainly

1385 by its larger body size, the shape of the mesosoma in lateral view, and its dense pubescence on 
1386 the gaster. The dorsum of the head bears two rows of erect hairs. Eyes have around 10 ommatidia

1387 along their maximal diameter; the promesonotum is bluntly angular, with the mesonotum being

1388 not inflated or bulging out dorsally above the pronotum in lateral view, mesonotum in dorsal

1389 view posteriorly extended along the midline. Metanotal groove absent. Dorsum of the propodeum

1390 is flat and shorter than the length of the propodeal slope. Metathoracic spiracles in dorsolateral

1391 position, not protruding, not touching any sutures. Gaster with dense pubescence and several

1392 scattered long erect hairs at the edges of the segments.

1393

1394 Distribution (Supplementary material S7). Currently exclusively known from Honduras.

1395

1396

1397

1398

1399

1400

1401

1402

1403

1404

1405

1406

1407
C. Bruch. n. st.

\section{Brachymyrmex bonariensis Santschi NEW STATUS}

(Fig. 14, supplementary material Fig. S8)

Brachymyrmex constrictus st. bonariensis Santschi, 1933: 122 (w.). Lectotype worker (NHMB:

USNMENT00757706) and paralectotype worker (NHMB: USNMENT00757705; here

designated): 2 workers [examined]. ARGENTINA: Buenos Aires: Buenos Aires, 08 Mar. 1803,

1408 
Manuscript submitted to: Organisms Diversity \& Evolution

Published version available; DOI: 10.1007/s13127-019-00406-2

1409 Diagnosis. Brachymyrmex bonariensis n. st. resembles B. admotus because they both have

1410 scapes that surpass the posterior margin of the head, a pair of simple erect hairs between the

1411 dorsal methathoracic spiracles, a wide metanotal groove, and a gaster with scarce pubescence.

1412 However, in B. bonariensis n. st. the head and mesosoma are light brownish in color, and the

1413 gaster is darker, whereas the body of B. admotus is uniformly colored. The scapes of $B$.

1414 bonariensis are shorter than those of B. admotus and surpass the posterior margin of the head

1415 with a length approximately equal to the maximal diameter of the eyes. The metathoracic

1416 spiracles of $B$. bonariensis are furthermore positioned more laterally and are not protuding. Like

1417 B. admotus, B. bonariensis could be confused with B. cavernicola because this latter species also

1418 has a pair of erect hairs between the methathoracic spiracles, however in B. cavernicola these

1419 hairs are very thick, and they are darker in color than the body.

1420

1421 Lectotype measurements (mm) HL 1 0.53; HL 2 0.36; HL 3 0.15; HW 0.48; SL 0.49; EL 0.13; WL

1422 0.50; PnL 0.14; PnW 0.31; ML 0.12; MW 0.20; Indices CI 90.00; SL 102.78; SL 2 134.55; $\mathrm{OI}_{1}$

$1423 \quad 22.78 ; \mathrm{OI}_{2} 27.50$.

1424

1425

Paralectotypes measurements (mm). HL 10.53 ; $\mathrm{HL}_{2}$ 0.35; HL 3 0.15; HW 0.50; SL 0.50; EL 0.13;

1426 WL 0.53; PnL 0.18; PnW 0.34; ML 0.11; MW 0.18; Indices CI 92.59; SL 1 101.33; SL2 143.40;

$1427 \quad \mathrm{OI}_{1} 26.67 ; \mathrm{OI}_{2} 27.16$.

1428

1429 Description. Head. Slightly longer than wide in full face view; posterior cephalic margin slightly

1430 concave. Dorsum of head with scattered, appressed hairs and usually two rows of erect hairs.

1431 Clypeus with a rounded anterior margin and five long, erect hairs of which a single, usually

1432 conspicuous hair is near the anterior margin, two hairs are in mediolateral position, and two more 
near the toruli; other hairs on the clypeus are markedly shorter and appressed or decumbent.

1434 Toruli surpassing the posterior clypeal margin in oblique anterodorsal view. The scapes surpass

1435 the posterior margin of the head by a length approximately equal to the maximal diameter of the

1436 eyes. Ocelli appear to be present but are inconspicuous. Eyes are positioned on the cephalic

1437 midline and have 8-9 ommatidia along their maximal diameter.

1438 Mesosoma. With two erect hairs on the pronotum and two on the mesonotum. In lateral view, the 1439 mesonotum is somewhat inflated, but it does not bulge dorsally above the pronotum. Metanotal

1440 groove wider than the diameter of the metathoracic spiracles. Metathoracic spiracles in

1441 dorsolateral position, not protuding, but touching the propodeal suture. Between the metathoracic

1442 spiracles two thin erect hairs are present, but they are shorter than those on the pronotum and

1443 mesonotum. Dorsum of the propodeum flat and $\sim 1 / 3$ th of the length of the propodeal slope.

1444 Propodeal spiracles circular, positioned on the posterior propodeal margin slightly posterior of

1445 the middle of the propodeal slope. Legs with appressed and scattered hairs. Petiole short and

1446 inclined forward.

1447 Gaster. With scattered pubescence, and scattered suberect hairs, mainly along the edges of the 1448 segments.

1449 Color and sculpture. Body overall smooth and shiny, except for the slightly imbricate sculpture

1450 on the dorsum of the mesosoma in some specimens. Head and mesosoma light brown, gaster

1451 darker in color.

1452

1453 Distribution (Supplementary material Fig. S8). Exclusively known from Argentina.

1455 Biology. Unknown. 
1457 Remarks. Brachymyrmex bonariensis was first described by Santschi (1933) as a variety of $B$.

1458 constrictus because it has the thorax less strongly strangled, a little wider head and more concave

1459 posterior margin of the head in comparison with B. constrictus. However, in our opinion $B$.

1460 bonariensis is morphologically very different than B. constrictus: it has a mesonotum that does

1461 not bulge dorsally above the pronotum in lateral view whereas that of $B$. constrictus does; $B$.

1462 constrictus does not have erect hairs between the metathoracic spiracles and moreover it has a

1463 uniformly dark brownish body. As mentioned before, B. bonariensis resembles B. admotus more

1464 closely (see diagnosis).

\section{Brachymyrmex brasiliensis Ortiz \& Fernández}

1469 Brachymyrmex brasiliensis Ortiz and Fernández, 2014: 22, Figs. 19, 20, 21 (w). Holotype

14721068 m, 11-12 June 2011, T.M.S. Mesquita worker (RBINS: 4048410). 
Manuscript submitted to: Organisms Diversity \& Evolution

Published version available; DOI: 10.1007/s13127-019-00406-2

1481

1482 Description. See Ortiz and Fernández (2014).

1483

1484

1485

Brachymyrmex bruchi Forel

1486

(Figs. 16, 17, supplementary material Fig. S10)

1487

Brachymyrmex bruchi Forel, 1912a: 64 (w.m.). Lectotype worker (MHNG:

1488

USNMENT00757159), and paralectotype workers, males (MHNG: USNMENT007157-

1489

007159, 00758104, 00758149-00758181; here designated): 21 workers, 3 males [examined].

1490

ARGENTINA: Catamarca: Aconquija, Filo blanco, 4300 m, Bruch. Santschi (1929: 309) (q.).

1491 = Brachymyrmex bruchi var. rufipes Forel, 1912a: 65 (w.). (MHNG: USNMENT00757160,

1492 00757161): 3 workers [examined]. ARGENTINA: Catamarca: Huasan; synonymy by Quirán et

1493 al. (2004: 279). See also: Santschi (1923a: 660).

1494 = Brachymyrmex giardi var. nitida Santschi, 1922: 261 (w.). (NHMB: USNMENT00757182): 1

1495 worker [examined]. CHILE: Los Lagos, Petrohué, 1922, Schiller. Snelling and Hunt (1975: 114)

1496 as junior synonym of Brachymyrmex giardi. n.syn.

1497 = B. laevis var. andina Santschi, 1923a: 659 (w.). (NHMB: USNMENT00758161, 00757186,

1498 00757187; MHNG: USNMENT00758129): 16 workers [examined]. ARGENTINA: Jujuy:

1499 Puna, 4000 m, D. Witter. n. syn.

1500

1501

Additional material examined. ARGENTINA: Entre Ríos: 8.63 km W Concordia, -31.42303 -

1502

58.11672, 16 m, 26 Dec. 2007, W. \& E. MacKay, 7 workers, 1 male, 1 queen (WEMC:

1503

USNMENT00757969, 00757997, 00758001, 00758003, 00758004, 00758013, 00759019) Santa

1504

Fe: 10 km E Santa Fe, -31.6666 -60.5833, 12 Oct. 2002, A.L. Wild \& N. Helle, 1 worker 
1505 (ALWC: USNMENT00757998). Tucumán: Lara, 4000 m, Feb. 2003, G.A. Baer, 2 workers 1506 (MCSN: USNMENT00757709). BOLIVIA: Santa Cruz: Perforación, 68 km ESE Charagua, 19.91667 -62.56667, 470 m, 11 Dec. 1993, P.S. Ward, 3 workers (PSWC:

USNMENT00758008). BRAZIL: Brasilia D.F., Aug. 1996, R.M. Oliveira, 6 workers (CPDC:

1510 USNMENT00758015-00758022). COLOMBIA: Quindío: Génova, Vereda El Cedral, Finca

1511 Venecia, 4.2275 -75.7586, 1800 m, 19 Oct. 1999, E. González \& J. Sossa, 1 worker (IAvH:

1512 IAvH-E74162). COLOMBIA: Risaralda: Apia, La Clarita, 3.13 -75.95, 1550 m, 26 Oct. 2001,

1513 I. Armbrecht, 1 worker (IAvH: IAvH-E74173). DOMINICAN REPUBLIC: 28 km SSE

1514 Constanza, $18.7-70.9,2220$ m, 11 Nov. 1992, P.S. Ward \#11757, 3 workers (PSWC:

1515 USNMENT00758034). La Vega: Reserva Valle Nuevo, 18.81667 -70.68333, 2240 m, 01 Sep.

1516 2001, A.L. Wild \#AW1348, 2 workers, 1 queen (ALWC: USNMENT00757682); Cervantía,

151718.85 -70.70, 1730 m, 01 Sep. 2001, A.L. Wild, 2 workers (ALWC: USNMENT00757988).

1518 ECUADOR: Napo: near Dureno, 0.0780 -76.7307, 287 m, 20 July 2005, W. \& E. MacKay 1519 \#21277, 2 workers (WEMC: USNMENT00759007). GUATEMALA: Sacatepéquez: Finca El

1520 Pilar, near Antigua, 14.55 -90.72, 1700 m, 13 Nov. 2003, A.L. Wild, 3 workers (ALWC:

1521 USNMENT00757963). PARAGUAY: Boquerón: Filadelfía, -22.35 -60.03, 22 Sep. 1994, B.

1522 Garcete, 1 worker (ALWC: USNMENT00758005). Canindeyú: Reserva Natural Bosque

1523 Mbaracayú Lagunita, -24.13 -55.43, 12 Feb. 1997, A. Wild, 3 workers (ALWC:

1524 USNMENT00757999). Concepción: Concepción centro, -23.42 -57.35, 7 Feb. 1998, A. Wild, 3

1525 workers (ALWC: USNMENT00757976). Presidentes Hayes: Villa Hayes, -25.10 -57.57, 21

1526 Sep. 1994, B. Garcete, 2 workers (ALWC: USNMENT00757996). UNITED STATES:

1527 Arizona: Pima Co. Tucson International Airport, 32.11667 -110.93333, 800 m, 07 Aug. 2001, 1528 P.S. Ward \#14412, 2 workers (PSWC: USNMENT00757972). Florida: Florida Gulf Co. 
1530 (MCZC: USNMENT00758014). Lousiana: Audubon Park, New Orleans, 29 Apr. 1995, A.L.

1531

1532

1533

1534

1535

1536

1537

1538

1539

1540

1541

1542

1543

1544

1545

1546

1547

1548

1549

1550

1551

1552

Wild, 2 workers (ALWC: USNMENT00757979); Baton Rouge, 01 Oct. 2000, B. Raphaël, 5 workers (CPDC: USNMENT00757980); E. Baton Rouge Par. Baton Rouge. Kenniloworth \& Perkins Rd. BREC Perkins Park, 03 Apr. 2003, J. Rosson, 1 worker (CPDC:

USNMENT00757967). Plaquemines Co. St. Bernard St. Pk., 22 Aug. 1987, W. MacKay, 22 Aug. 1987, W. MacKay, 2 workers (WEMC: USNMENT00757970). Texas: Austin, Travis Co., 30.25167 -97.76722, 160 m, 21 Nov. 2006, A.L. Wild, 3 workers (ALWC:

USNMENT00757977). URUGUAY: Montevideo, Nov. 2000, L. Pastre, 2 workers (CPDC: USNMENT00757978). Salto: Salto Parque Municipal Benito Solari, 25 Dec. 2007, W. \& E. MacKay, 1 worker (WEMC: USNMENT00758047).

Diagnosis. Brachymyrmex bruchi is morphologically most similar to B. patagonicus and B. oculatus because these species have scapes that surpass the posterior margin of the head, typically two erect hairs on the mesonotum, their metanotal groove is either absent or narrower than the diameter of the metathoracic spiracles, their mesonotum does not bulge dorsally above the pronotum in lateral view, their gaster has several scattered long erect hairs and sparse pubescence, and they have brownish bodies. However, B. bruchi differs from B. patagonicus by having a larger body size, abundant suberect hairs on the dorsum of the pronotum, and scapes that surpass the posterior margin of the head by a length approximately equal to the maximal diameter of the eye. It differs from B. oculatus by having smaller eyes with less than 14 ommatidia along the maximal diameter, which approximately equal only a quarter of the length of the head $\left(\mathrm{HL}_{1}\right)$. 
Manuscript submitted to: Organisms Diversity \& Evolution

Published version available; DOI: 10.1007/s13127-019-00406-2

1553

1554

1555

1556

1557

1558

1559

1560

1561

1562

1563

1564

1565

1566

1567

1568

1569

1570

1571

1572

1573

1574

1575

1576

Lectotype and paralectotypes measurements $(\mathrm{mm})(\mathrm{n}=4)$. HL 1 0.58-0.64; HL2 0.41-0.45; HL 3

0.14-0.18; HW 0.57-0.60; SL 0.55-0.62; EL 0.16-0.18; WL 0.64-0.78; PnL 0.20-0.25; PnW 0.39-

0.45; ML 0.18-0.21; MW 0.27-0.31; Indices CI 90.63-100.00; $\mathrm{SI}_{1}$ 93.33-103.45; $\mathrm{SI}_{2}$ 130.43-

142.86; $\mathrm{OI}_{1} 26.67-31.03 ; \mathrm{OI}_{2} 21.88-28.13$.

Additional material examined measurements $(\mathrm{mm})(\mathrm{n}=25)$. HL 1 0.41-0.61; HL2 0.29-0.42; HL 3

0.09-0.16; HW 0.37-0.60; SL 0.31-0.59; EL 0.10-0.20; WL 0.40-0.72; PnL 0.10-0.20; PnW 0.25-

0.44; ML 0.09-0.20; MW 0.16-0.29; Indices CI 70.98-96.97; $\mathrm{SI}_{1}$ 78.13-136.36; $\mathrm{SI}_{2}$ 106.67-

156.76; $\mathrm{OI}_{1} 23.91-45.45 ; \mathrm{OI}_{2}$ 19.23-28.00.

Description. Head. Slightly longer than wide in full face view; posterior cephalic margin slightly concave. Dorsum of the head with sparse and appressed hairs. Clypeus with a rounded anterior margin and five long, erect hairs of which a single, usually conspicuous hair is near the anterior margin, two hairs are in mediolateral position and two more near the toruli; other hairs on the clypeus are markedly shorter and appressed or decumbent. Toruli surpassing the posterior clypeal margin in oblique anterodorsal view. The scapes surpass the posterior cephalic margin with a length that approximately equals the maximal diameter of the eye; they typically have appressed and decumbent hairs. Three inconspicuous ocelli present. Eyes are positioned on the cephalic midline and have 8-13 ommatidia along their maximal diameter.

Mesosoma. Typically with two erect hairs on the pronotum and two on the mesonotum, sometimes with additional suberect hairs, mainly on the pronotum. The mesonotum is not inflated and does not bulge dorsally above the pronotum in lateral view. Metanotal groove absent or narrower than the diameter of the metathoracic spiracles. Metathoracic spiracles in dorsolateral position, not protruding, but touching the propodeal suture. Dorsum of the propodeum slightly 
convex and shorter than the posterior slope. Propodeal spiracles circular, positioned on the posterior propodeal margin at the middle of the propodeal slope. Legs with appressed and scattered hairs. Petiole short and inclined forward.

Gaster. With sparse pubescence and several scattered long erect hairs.

Color and sculpture. Body overall smooth and shiny, except for the sometimes slightly imbricate sculpture on the dorsum of the mesosoma; typically brownish.

\section{Distribution (supplementary material Fig. S10). Brachymyrmex bruchi is known from} Argentina, Bolivia, Brazil, Chile, Colombia, the Dominican Republic, Ecuador, Guatemala, Paraguay, Uruguay, and the United States.

\section{Biology. Unknown.}

Remarks. The here designated lectotype is the specimen at the top of pin MHNG:

USNMENT00757159, and the ants below are paralectotypes. The type material of B. bruchi, $B$. giardi var. nitida, B. laevis var. andina, and B. bruchi var. rufipes shares a common set of diagnostic characters, i.e. the brownish body color, scapes that surpass the posterior cephalic margin by a length that approximately equals the maximal diameter of the eye, the metanotal groove is lacking or narrow, and scattered pubescence on the gaster. As such, these species and varieties are synonymized here.

Brachymyrmex giardi var. nitida was considered to be a junior synonym of B. giardi by Snelling and Hunt (1975), however we disagree with this synonymization taking in account both the description of Santschi (1922) and our own observations of important differences in diagnostic 
1600 traits: B. giardi var. nitida differs from B. giardi by having erect hairs on the pronotum, a darker

1601 body color and scarce pubescence on the body.

1602 Quirán et al. (2004) suggested B. bruchi var. rufipes to be a junior synonym of B. bruchi based on 1603 the original description by Forel (1912a), which only specifies a difference in body color. Quirán 1604 et al. (2004) argued that this difference is not taxonomically informative and therefore they

1605 proposed synonymization. We agree that body color is variable in several Brachymyrmex species, 1606 and therefore we follow the suggestion of Quirán et al. (2004) here. Nevertheless, it is noteworthy that some individuals of B. bruchi var. rufipes have somewhat denser pubescence on

1608 the gaster than pointed out in our description above (see Fig. 40 d, f). Such moderately dense 1609 pubescence on the gaster has been also observed in some of the examined specimens of B. laevis

1610 var. andina. Future studies on B. bruchi and its geographical variation is required.

1611 Forel (1912a) indicated that B. bruchi and B. patagonicus are very similar as to their mesosoma,

1612 and Santschi (1923a) likewise compared B. laevis var. andina with B. patagonicus var. atratula,

1613 which has been synonymized with B. patagonicus (Quirán et al. 2004). We concur with these

1614 authors that B. bruchi and B. patagonicus, including their type material, are morphologically very

1615 similar, but as noted in the diagnosis above, consistent differences also exist between both

1616 species. Furthermore, our morphometric and phylogenetic analyses tentatively confirm these taxa

1617 to be distinct, although further studies on the morphology and phylogenetics of these species as

1618 well as their ecology and biology are admittedly needed.

1619 Santschi (1929) and Quirán et al. (2004) also referred specimens from Jujuy: Pueblo Viejo

1620 (Weiser), Catamarca: Aconquija and Tucuman (Argentina) to B. bruchi, however, this material 1621 was not studied here. 
Manuscript submitted to: Organisms Diversity \& Evolution

Published version available; DOI: 10.1007/s13127-019-00406-2

1624

1625

1626

1627

1628

1629

1630

1631

1632

1633

1634

1635

1636

1637

1638

1639

1640

1641

1642

1643

1644

1645

1646

1647
Brachymyrmex cavernicola Wheeler

(Figs. 18, supplementary material Fig. S11)

Brachymyrmex cavernicola Wheeler, 1938: 252 (w.m.). Lectotype worker (USNM:

USNMENT00529073) and Paralectotype workers, male (USNM: USNMENT00529073;

MCZC: M.C.Z. Cotype 17-19 22428, M.C.Z. Cotype 11-13 22428, M.C.Z. Cotype 23-25 22428,

M.C.Z. Cotype 14-16 22428, M.C.Z. Cotype 1-3 22428, M.C.Z. Cotype 5-7 22428, M.C.Z.

Cotype 4 22428; here designated): 21 workers, 1 male [examined]. MEXICO: Yucatan,

Chichenitza, Balaam Canche Cave, H.S. Pearse, 13 June 1936.

Additional material examined. BRAZIL: Amazonas: Manaus, BR.174 km 45 EEST-S1, 12

Nov. 1990, Eq. A. Y. Harada, A. G Baindeira, 1 worker (MPEG: USNMENT00757857]. Pará:

Melgaço, Caxiuanã ECFPn, -1.73584 -51.48762, 12-14 Oct. 2006, Equipe A.Y. Harada, 1 worker

(MPEG: AYH051). Melgaço, Caxiuanã ECFPn, -1.75444 -51.52241, 28 Oct. 2003, A.Y. Harada,

E.P. Fagundes, C.J.M. Ribeiro, C.E.D. Sanhudo, C.A.R. Moura, J.L.P. Souza, C. Renato, 1

worker (MPEG: AYH067). Melgaço, Caxiuanã ECFPn, -1.73584 -51.48762, 30 Oct. 2003, A.Y.

Harada, E.P. Fagundes, C.J.M. Ribeiro, C.E.D. Sanhudo, C.A.R. Moura, J.L.P. Souza, C. Renato, 3 workers (MPEG: AYH086, AYH088, AYH126). Serra Norte, Est. Do. Mang, 6 Sep. 1983, 12

Sep. 1983, 29 Feb. 1984, 12 May 1984, 15 May 1984, 22 May 1984, Lote: 2105, 2108, 2195, 2197, 2208, 2213, 2214, 2223, 2227, 2231, 2232, 2235, 11 workers (MPEG:

MEPG_HYM11505683, 11505907, 11505913, 11505945, 11505960, 11505969, 11505999, 11506007, 11506023, 11506030, 11506036). COLOMBIA: Cauca: Isla Gorgona, 17 Sep. 1989, M. Baena \#GQA-05, 1 worker (WEMC: USNMENT00757854). Isla Gorgona, 16 Jan. 1990, M. Baena \#Gacd-19, 2 workers (WEMC: USNMENT00757855, 00757856). Cundinamarca: La Vega, R.N. Natautá, 5.00 -74.33, 1040 m, 10 Nov. 2010, F. Fernández, 2 workers (IAvH: 
USNMENT00757859). Nariño: Barbacoas, Tajadas, 100 m, 1 worker (ICN:

1649

1650

1651

1652

1653

1654

1655

1656

1657

1658

1659

1660

1661

1662

1663

1664

1665

1666

1667

1668

1669

1670

USNMENT00757858). Quindio: Buenavista, Finca Ceilán, Bs., 4.35833 -75.78472, 1100 m, 15

Nov. 1999. E. Gonzalez, 1 worker (IAvH: IAvH-E744170). COSTA RICA: Guanacaste: Prov.

Maritza field, Sta., 800 m, 03 May 1995, R. Anderson \#17714, 4 workers (WEMC:

USNMENT00757844, 00757845). Heredia: Estación Biológica, La Selva, 10.433 -84.017, 50-

150 m, 01 June 1993, INBio-OET, 1 worker (JTLC: INBIOCRI001276875). Puerto Viejo, \#733, 25 June 1979, J. Raich, 7 workers (MCZC: USNMENT00757273, 00757275). ECUADOR:

Endesa: Forest Reserve Pichincha Province, 25 Jan. 1994, L.E. Tennant, 1 worker (MCZC:

USNMENT00757274). Pichincha: La Unión del Río Toachi, -0.31889 -78.95442, 770 m, 15

Jul. 2005, W. \& E. MacKay \#21169, 2 workers (WEMC: USNMENT00757841, 00757842).

MEXICO: Chiapas: 8.8 km SE Salto de Agua, 17.51328 -92.29515, 50 m, 14 July 2007, J.L.

Cozar ANTC\#4225, 1 worker (JTLC: CASENT0600011). 10 km S Palenque, 30 May 1988, A.

Rabeles, 2 workers (WEMC: USNMENT00757848). 10 km S Palenque, 30 May 1988, W.

MacKay \#10563, \#10571, \#10627, \#10674, 15 workers (WEMC: USNMENT00757849,

00757850, 00757851, 00757852, 00757853, 00758028). 10 km S Palenque, 30 May 1988, VIAL,

D. Gonzalez, 1 worker (WEMC: USNMENT00757846,). Veracruz: Los Tuxtlas, 10 km NNW

Sontecomapan, 18.583 -95.083, 500 m, 21 Mar. 1985, P.S. Ward \#7366, 3 workers (PSWC:

USNMENT00757843). PERU: Madre de Dios: Prov. Tambopata, Cuzco Amazónico, 15 km

NE Puerto Maldonado, CA-130, 200 m, 13 June 1989, S.P. Cover \& J.E. Tobin, 6 workers

(MCZC: USNMENT00757260, 00757269, 00757270). Prov. Tambopata, Cuzco Amazónico, 15

km NE Puerto Maldonado, CA-601 JT79, CA-601 JT80, CA-365, CA-659 JT138, CA-116, CA-

141, June 1989, S.P. Cover \& J.E. Tobin, 17 workers (MCZC: USNMENT00757260-00757272). 
Manuscript submitted to: Organisms Diversity \& Evolution

Published version available; DOI: 10.1007/s13127-019-00406-2

1671 Diagnosis. The feature that allows distinguishing B. cavernicola from all other Brachymyrmex

1672 species is the presence of conspicuous thick black hairs on the head, mesosoma and gaster, which

1673 contrast strongly with the yellowish body, a condition reminiscent of Nylanderia. Brachymyrmex

1674 antennatus also has erect hairs on the mesosoma that are darker than the tegument, however these

1675 are not as thick as those of B. cavernicola, and in other features these species are very different.

1676

1677 Additional material examined measurements $(\mathrm{mm})(\mathrm{n}=10) . \mathrm{HL}_{1}$ 0.51-0.57; HL 2 0.35-0.41; HL 3

1678 0.13-0.18; HW 0.45-0.51; SL 0.54-0.63; EL 0.09-0.10; WL 0.51-0.63; PnL 0.19-0.21; PnW 0.29-

1679 0.35; ML 0.10-0.13; MW 0.18-0.22; Indices CI 83.33-91.67; SI 1 118.18-134.62; SI 2 139.53-

$1680 \quad 166.67 ; \mathrm{OI}_{1} 17.54-20.83 ; \mathrm{OI}_{1}$ 25.00-31.25.

1681

1682 Description. Head. Slightly longer than wide in full face view; posterior cephalic margin slightly

1683 concave. Thick hairs cover the front of the head. Clypeus with a rounded anterior margin and five

1684 long, erect hairs of which a single hair is near the anterior margin, two hairs are in mediolateral

1685 position and two more near the toruli; other hairs on the clypeus are markedly shorter and

1686 appressed or decumbent. Toruli surpassing the posterior clypeal margin in oblique anterodorsal

1687 view. The scapes surpass the posterior cephalic margin by a length of approximately $2.0 \times$ the

1688 maximal diameter of the eyes and bear appressed or decumbent hairs. Ocelli are absent or one

1689 central ocellus is present. Eyes are positioned on the cephalic midline and have 7-8 ommatidia

1690 along their maximal diameter.

1691 Mesosoma. With several thick erect hairs on the promesonotum ( $>2)$, and two between the

1692 metathoracic spiracles, but none on the propodeum. The mesonotum is not inflated and does not

1693 bulge dorsally above the pronotum in lateral view. Metanotal groove wider than the diameter of

1694 the metathoracic spiracles. Metathoracic spiracles in dorsolateral position, not protruding, and not 
1695 touching any suture. Dorsum of the propodeum is weakly convex and shorter than the posterior

1696 slope. Propodeal spiracles circular, positioned just ventrally of the posterior propodeal margin

1697 slightly posterior of the middle of the propodeal slope. Legs with appressed and scattered

1698 suberect hairs. Petiole short and inclined forward.

1699 Gaster. With scarce pubescence but densely covered by thick, erect hairs.

1700 Color and sculpture. Body smooth and shiny, except for the dorsum of the mesosoma which

1701 sometimes has slightly imbricate sculpture. The body color is typically yellowish, although the

1702 head and gaster are sometimes darker than the mesosoma. Tegument color contrasts with the

1703 thick black hairs.

1704

1705 Distribution (Supplementary material Fig. S11). Brachymyrmex cavernicola is known from

1706 Argentina, Brazil, Colombia, Costa Rica, Ecuador, Mexico and Peru.

1707

Biology. Nests of this species have been found in the soil under stones.

1709

1710 Remarks. The lectotype is the top specimen on pin USNMENT00759073, whereas the

1711 specimens below are the paralectotypes. As indicated in the diagnosis and pointed out before by

1712 Wheeler (1938), B. cavernicola resembles Nylanderia species by its thick hairs that cover the

1713 entire body.

1714

1715

1716

Brachymyrmex coactus Mayr

1717

(Figs. 19, 20, supplementary material Fig. S12) 
1719 USNMENT00757191) and paralectotype workers, males, queens (NHMW:

1720 USNMENT00757191- 00757195; here designated): 3 workers, 3 males, 2 queens [examined].

1721 BRAZIL: Santa Catharina (Hetscko). See also: Santschi (1923a: 669); Santschi (1923b: 272).

1722 = Brachymyrmex coactus var. nictitans Emery 1906: 178 (w.). (MCSN: USNMENT 00757209):

17231 worker [examined]. COSTA RICA. See also: Santschi (1923a: 670). n. syn.

$1724=$ Brachymyrmex constrictus Santschi 1923a: 671, Figs. 5, 38, 61 (w.). (NHMB:

1725 USNMENT00758087): 1 worker [examined]. BOLIVIA: La Paz: Mapiri. n. syn.

1726 = Brachymyrmex coactus var. robustus Santschi 1923b: 272 (w.). (NHMB:

1727 USNMENT00757224): 4 workers [examined]. BRAZIL: Santa Catharina: Encano alto;

1728 (NHMB: USNMENT00758085, 00758086): 6 workers [examined]. BRAZIL: Santa Catharina: 1729 Blumenau. n. syn.

1730

1731 Additional material examined. ARGENTINA: "Fives Lile", 4 workers, 5 queens, 1 male 1732 (NHMB: USNMENT00758083, 00758084). BRAZIL: Alagoas: Maceió - Emilia Flores, Hm

1733 For 68, For 91, 18 Mar. 2005, 04 June 2005, \#5460, M.C.C. Diniz, 8 workers (CEPLAC:

1734 USNMENT00757552, 00757553, 00757555); Bahia: Barreiras, Serra do Mimo, 24 Apr. 2010 , S.

1735 Souza \& B. Santos, 3 workers (CEPLAC: USNMENT00757564); Esplanada, Baixio, -12.11444 -

1736 37.69944, June- Oct. 2010, M.L.O. Travassos, 1 worker (CEPLAC: USNMENT00757556);

1737 Porto Seguro, Troncoso, 12 June 1991, J. Delabie 4451, 3 workers (CEPLAC:

1738 USNMENT00757559); UNA-ESMAI, Estação Experimental Lemos Maia, Em coqueiro-anão, 1739 Oct. 2005, J.R.M. Santos, 8 workers (CEPLAC: USNMENT00757558, 00757559, 00757562);

1740 Goias: Ouro Verde, Faz Boa Vista, -16.29847 -49.21183, 01-07 July 2005, R.R. Silva \& R.M. 1741 Feitosa, 3 workers (ICN: MZSP123); Santa Catharina: Blumenau, M. Witte \#150, 9 workers 
1742

1743

1744

1745

1746

1747

1748

1749

1750

1751

1752

1753

1754

1755

1756

1757

1758

1759

1760

1761

1762

1763

1764

1765

(MCZC: USNMENT00757238, 00757239, 00757251); Paraiba: Independencia, Mann \& Heath, -7.15194 -34.90556, 3 workers, 1 queen (MZUSP: USNMENT00757240); São Paulo:

ANHEMBI, Faz B. Rio, 14 Feb. 1969, W. Kemf, J.C. Mahalhãres, L.T.F., M. Kulmann, 2

workers, 1 queen (MZUSP: USNMENT00757563); Sete Barras, PE Carlos Bothelo, -24.20833 47.97056, 200 m, 11-15 May 2009, F. Esteves leg, 2 workers (MZUSP: USNMENT00757560).

COSTA RICA: Puntarenas: Sirena, Corcovado National Park, 8.48333 -83.60000, 10 m, 24

Dec. 1981, J. Longino, 1 worker, 1 male (JTLC: JTLC000005905); Peninsula Osa, 8.46667 -

83.58333, 50 m, 24 Dec. 1981, J. Longino, 1 worker, 1 male (MCZC: USNMENT00757243).

ECUADOR: Zamora-Chinchipe: Copalinga, -4.09122 -69.93591, Jacquemin, Col id 5087, 1 worker (RBINS) GUYANA: Rupunini: Kananambo, 16 Jan. 1981, 3.75 -59.3, 100 m, J.

Longino, 1 worker (JTLC: JTLC000005907). PANAMA: Barro Colorado I.: Canal Zone, B50, Jan 1960, W.L. Brown, E.S. McCluskey, 3 workers (MCZC: CMOS0000097). PARAGUAY:

Fortin mayor infante Rd, trans Chaco locality 1, 01 Oct. 2004, T. Delsinne, 1 worker (RBINS: Coll.RIScNB SID SPM_ID 30833); Boquerón: Enciso, -21.20 -61.67, 3-6 Nov. 2001, M.

LePonce \& T. Delsinne, Dry Chaco, Pitfall trap, 3 workers (ALWC: USNMENT00757554);

Boquerón: Enciso, -21.20609 -61.65748, 04-06 Nov. 2001, 23-25 Sep. 2004, M. LePonce, T. Delsinne, Col ID4132, Col ID 13623, 2 workers (RBINS: Coll.RIScNB SID SPM_ID 22607, ID27462); Nueva Asunción, -20.69190 -61.92925, 02-06 Nov 2001, M. Leponce, Col ID 3948, 1 worker (RBINS: Coll.RIScNB SID SPM_ID 30542); Canindeyú: Reserva Natural Bosque Mbaracayú, Jejuimi, -24.10 -61.67, 02 Apr. 1996, A.L. Wild, 3 workers (ALWC:

USNMENT00757561); Cordillera: Caacupé, Camp. J. Noment, -25.36667 -57.08333, 19 Jan. 1994, B. Garcete \#AW0395, 1 worker (ALWC: USNMENT00757567); Misiones: 8 km SE San Juan Bautista, -26.71666 -57.06667, 150 m, 10 Dec. 2002, A.L. Wild \& B. Garcete \#AV1781, 1 worker (ALWC: USNMENT00757570). PERU: Madre de Dios: Reserva Nacional Tambopata, 
1766 Centro Sachavacayoc, -12.85583 -69.36194, 210 m, 19-31 July 2012, R.M. Feitosa, 2 workers

1767 (ICN: USNMENT00757614, 00757612); Reserva Nacional Tambopata, Centro Sachavacayoc, -

176812.82667 -69.37056, 198 m, 26 July 2012, GSNMBU, 2 workers (ICN: USNMENT00757615, 1769 00757838).

1770

1771 Diagnosis. Brachymyrmex coactus is morphologically very similar to B. degener as both species

1772 have scapes that surpass the posterior margin of the head, faint sculpture on the mesosoma, a

1773 mesonotum that is inflated and bulges dorsally above the pronotum in lateral view, a wide

1774 metanotal groove, metathoracic spiracles that are slightly protruding dorsally, and a gaster with

1775 scarce pubescence. However, B. coactus has a brown yellowish head and mesosoma, but a darker

1776 gaster, whereas B. degener has a uniformly brownish body.

1777

1778 Lectotype and paralectotypes measurements $(\mathrm{mm})(\mathrm{n}=3) . \mathrm{HL}_{1}$ 0.72-0.84; $\mathrm{HL}_{2}$ 0.44-0.55; HL 3

1779 0.21-0.25; HW 0.64-0.82; SL 0.68-0.80; EL 0.16-0.21; WL 0.53-0.88; PnL 0.21; PnW 0.43-0.55;

1780 ML 0.14-0.20; MW 0.23-0.35; Indices CI 94.29-97.67; SI 1 97.62-106.06; SI 2 144.00-152.17; $\mathrm{OI}_{1}$

$1781 \quad 24.24-28.57 ; \mathrm{OI}_{2} 29.73-31.43$.

1782

1783 Additional material examined measurements $(\mathrm{mm})(\mathrm{n}=10) . \mathrm{HL}_{1} 0.52-0.88 ; \mathrm{HL}_{2}$ 0.34-0.60; $\mathrm{HL}_{3}$

1784 0.16-0.25; HW 0.50-0.82; SL 0.51-0.82; EL 0.13-0.21; WL 0.53-0.98; PnL 0.18-0.25; PnW 0.36-

1785 0.57; ML 0.13-0.23; MW 0.18-0.35; Indices CI 93.33-101.45; SI 1 92.86-105.36; SI 2 126.67-

$1786 \quad 165.38 ; \mathrm{OI}_{1} 23.53-35.71 ; \mathrm{OI}_{1} 26.67-32.5$.

1788 Description. Head. Slightly longer than wide in full face view; posterior cephalic margin flat or

1789 slightly concave. Dorsum of the head has scattered apressed hairs. Clypeus with a rounded 

anterior margin and five long, erect hairs of which a single, usually conspicuous hair is near the

1791

1792

1793

1794

1795

1796 anterior margin, two hairs are in mediolateral position and two more near the toruli; other hairs on the clypeus are markedly shorter and appressed or decumbent. Toruli surpassing the posterior clypeal margin in oblique anterodorsal view. The scapes extend beyond the posterior margin of the head by a length that is equal to the maximal diameter of the eye or larger, and they bear appressed and decumbent hairs. Three ocelli are present. Eyes are positioned on the cephalic midline and have 10-14 ommatidia along their maximal diameter.

Mesosoma. Typically with two erect hairs on the pronotum and two on the mesonotum; sometimes with additional suberect hairs, mainly on pronotum. Dorsum of the mesosoma with imbricate sculpture. The mesonotum is inflated and bulges dorsally above the pronotum in lateral view. Metanotal groove wider than the diameter of the metathoracic spiracles. Metathoracic spiracles in dorsolateral position, slightly protruding and not touching any sutures. Dorsum of the propodeum strongly convex and shorter than the propodeal slope. Propodeal spiracles conspicuous and circular, positioned on the propodeal margin, anterior of the middle of the propodeal slope. Legs with appressed hairs. Petiole short and inclined forward.

Gaster. With scattered pubescence and several scattered long erect hairs.

Color and sculpture. Head and gaster are smooth and shiny, but the dorsum of the mesosoma usually has imbricate sculpture. Head and mesosoma are brown yellowish, whereas the gaster is darker.

Distribution (Supplementary material Fig. S12). Brachymyrmex coactus occurs in Argentina, Bolivia, Brazil, Costa Rica, Guyana, Panama, Paraguay and Peru. 
1813 Biology. The specimens from UNA-ESMAI in Bahia (Brazil) were found in dwarf coconuts

1814 (CEPLAC: USNMENT00757557, 00757558), those from Canindeyú (Paraguay) on shrubs

1815 (ALWC: USNMENT00757561), and those from St. Catharina underneat bark in association with 1816 a beetle of the genus Claviger (Mayr 1887).

1818 Remarks. The worker on pin USNMENT00757191 is designated here as lectotype. Emery

1819 (1906) considered B. coactus var. nictitans to be a separate variety because it has smaller eyes

1820 than B. coactus, but he also expressed doubt on the level of consistency of this difference.

1821 Santschi (1923a) did not provide a motivation to distinguish B. constrictus from B. coactus but 1822 indicated that B. constrictus has more finely imbricate sculpture on the mesosoma and smaller 1823 metathoracic spiracles. Subsequently, he (Santschi 1923b) reported that his original description 1824 (Santschi 1923a) of B. coactus refers to B. coactus var. robusta. This variety has a larger body 1825 size, more sculpture on the mesosoma, and a somewhat bigger head than the 'typical' form of $B$. 1826 coactus. Both varieties of B. coactus were described from the same type locality, however.

1827 After examining specimens of all these varieties and B. constrictus, we consider the main 1828 morphological differences to relate to variation in body size. This trait is, however, very variable 1829 even within localities (including among specimens mounted on the same pin). As these taxa all 1830 have the same diagnostic features we here synonymize B. coactus var. nictitans, B. coactus var. 1831 robustus, and B. constrictus with B. coactus. 
Brachymyrmex patagonicus var. cordemoyi Forel, 1895a: 49 (w.). (MHNG) [not examined].

1837 REUNION. See also: Emery (1906: 180) (q.m.). Raised to species: Emery (1906: 179).

1838 Subspecies of Brachymyrmex patagonicus: Forel (1908: 399); Forel (1912b: 165); Santschi

1839 (1912: 533). Revived status as species: Wheeler (1922: 1036); Emery (1925: 41). See also Forel

$1840 \quad$ (1912a: 62).

1841 = Brachymyrmex laevis var. fuscula Emery, 1906: 178 (w.q.). (MCSN: USNMENT00757216, 1842 00757217; MHNG00758131 - 00758133): 10 workers, 1 queen [examined]. ARGENTINA:

1843 Mendoza: Mendoza, Punta de vacas; (MCSN: USNMENT00757215): 8 workers [examined].

1844 ARGENTINA: Buenos Aires: Buenos Aires. n. syn.

1845 = Brachymyrmex brevicornis Emery, 1906: 180, Figs. 38, 40, 41 (w.q.m). (MCSN:

1846 USNMENT00757210 - 00757214): 16 workers, 1 queen, 1 male [examined]. ARGENTINA:

1847 Buenos Aires: Santa Catalina. See also Quirán (2005: 765). n. syn.

1848 = Brachymyrmex patagonicus var. brevicornoeides Forel, 1914: 287 (w.q.m). (MHNG:

1849 USNMENT00758141 - 00758143): 4 workers, 3 males [examined]. ARGENTINA: Buenos

1850 Aires: Tapalquén. Junior synonym of Brachymyrmex nigricans: Santschi (1923a: 657).

1851 [Brachymyrmex brevicornoeides has priority as senior name, Brachymyrmex nigricans is its

1852 junior synonym: Bolton (1995: 81)]. n. syn.

1853 = Brachymyrmex cordemoyi var. nigricans Santschi, 1916: 395 (w.). (NHMB:

1854 USNMENT00758081): 3 workers [examined]. ARGENTINA: Río de la plata, Isla Martin

1855 Garcia; (NHMB: USNMENT00758078, 00758080): 10 workers. ARGENTINA: Buenos Aires:

1856 Buenos Aires. [First available use of Brachymyrmex patagonicus cordemoyi nigricans Santschi

1857 (1912: 533) unavailable name]. Raised to species: Santschi (1923a: 657). Junior synonym of

1858 Brachymyrmex nigricans: Santschi (1923a: 657) [As mentioned above Brachymyrmex

1859 brevicorneoides has priority over B. nigricans]. 
1860 = Brachymyrmex cordemoyi var. distincta Santschi, 1923a: 658, Figs. 6, 50,59 (w.q.). (NHMB:

1861 USNMENT00757178, 00757179): 3 workers [examined]. ARGENTINA: Santa Cruz;

1862 (NHMB: USNMENT00758089): 9 workers [examined]. ARGENTINA: Delta del Paraná. n.

1863 syn.

1864

1865

Additional material examined. ARGENTINA: Buenos Aires: Buenos Aires, E.V. Steigen, 3

1866 workers (MZUSP: USNMENT00759023); Buenos Aires, Universidad de Buenos Aires, 18 workers (ICN: USNMENT00759032); La Plata, Silvestri, 4 workers (NHMB: USNMENT00758088), 8 workers (MCZC: USNMENT00757244); Entre Ríos: 8.63 km Concordia, -31.41667 -58.11667, 16 m, 26 Dec. 2007, W. \& E. MacKay \#22670, 1 worker

1870 (WEMC: USNMENT00757638); Isla frente Puerto Victoria, -32.63333 -60.16667, 10 m, 29 Oct. 2002, A.L. Wild \& N. Heller, 1 worker (ALWC: USNMENT00757966); Misiones: 48.93 km N

1872 Campinas de America, -25.8565 -53.9939, 360 m, 03 Jan. 2008, W. \& E. MacKay \#22794, 1 1873 worker (WEMC: USNMENT00757728); San Juan: 8.59 km S Villa Aberastain, -31.72528 1874 68.55447, 592 m, 10 Jan. 2008, W. MacKay \#22879, 1 worker (WEMC: USNMENT00757737).

1875 BRAZIL: Bahia: Boa Vista do Tupim, 06 Dec. 2010, V.M.S. Cameiro \& J.J. Resende, 1 worker 1876 (CEPLAC: USNMENT00757887); Mato Grosso do Sul: 70 km E Corumbá, Faz. Maria 1877 Bonita, -19.16666 -57.16666, 22 Aug. 1998, A. L. Wild \#AW0657, 1 worker (ALWC:

1878 USNMENT00759025); 10 km Posto Chapadao, 18 Oct. 1989, S. Porter, 3 workers (WEMC:

1879 USNMENT00758994); 3 km Anastácio, 17 Oct. 1989, W. MacKay \#12605, 3 workers (WEMC: 1880 USNMENT00757652); Passo da Lontra, -19.53333 -57.01667, 80 m, 08 Sep. 1996, P.S. Ward $1881 \# 13222,1$ worker, 1 male (MCZC: CMOS000020); Para: Santarem, Taperinha, -2.9 -54.3, July 1882 1975, R.L. Jeanne, 440, 4 workers (MCZC: CMOS000015, CMOS000016); Rio Grande do 1883 Norte: Ceará, Mirim, W.M. Mann, 10 workers (MCZC: CMOS000124, CMOS000125); 
1884 Rondonia: Ji Parana, 27 Aug. 1984, W. Overal, 2 workers (MPEG: USNMENT00757583, 1885 00757964); Ouro Preto do Oeste, 25 Mar. 1985, W. França, Res INPA 0050, 3 workers (MPEG: USNMENT00757984, 00758043); São Paulo: Aguas de São Pedro, May-June 1985, S. Silva, 1 worker (ICN: USNMENT00757670); Caraguatatuba, Res. Florest rain for, 40-80 m 18-22 May 1971, W.L. \& D.E. Brown, 6 workers (MCZC: CMOS000017, CMOS000019, CMOS000021); José Bonifacio, 17 Nov. 1970, J. Diniz, 2 workers, 1 queen (MZUSP: USNMENT00757582).

1890 COLOMBIA: Caqueta: Florencia, 2 workers (ICN: LEV127); Huila: 17 km NW, La Plata, 03 Jan. 1984, W. \& E. MacKay \#7138, 2 workers (WEMC: USNMENT00757673); Meta: 65 km E Puerto Lopez, 30 Jan. 1973, W.P. MacKay \#7365, 3 workers (WEMC: USNMENT00757636); Villavicencio, 17 Dec. 1975, W. \& E. MacKay, 2 workers (WEMC: USNMENT00757648);

1894 Vista Hermosa, 25 Dec. 1975, W. \& E. MacKay \#75812, \#815, 7 workers, 1 queen, 1 male 1895 (WEMC: USNMENT00757653, 00757675, 00757985). COSTA RICA: Limón: Guapiles, R.

1896 Toro Amarillo vic., 15 Feb.-09 Mar. 1966, W.L. Brown, 3 workers (MCZC:

USNMENT00757647); Puntarenas: 8 km WNW Potrero Grande, 9.03 -85.26, 200 m, 01 Aug. 1985, P.S. Ward \#7791, 3 workers (PSWC: USNMENT00757877). CUBA: Guantanamo: Baracoa, 20.35 -74.5, 20 m, 26 Aug. 2001, P.S. Ward \#14462-14, 3 workers (PSWC: -75.99786, 11 Sep. 1992, P.S. Ward \#11757, 1 worker, 1 queen (PSWC: USNMENT00758016). ECUADOR: Loja: Estación San Francisco, 2200 m, 11 \& 14 Sep. 2011, F. Fernandez, 46 1904 workers (ICN: USNMENT00759034, 00759036, 00759037); Napo: near Dureno, 0.07778 1905 76.73056, 287 m, 20 July 2005, W. \& E. MacKay \#21273 \#21277, 4 workers (WEMC: 1906 USNMENT00757581, 00757637); Pichincha: Mitad del Mundo, 00.00 -78.45, 2483 m, 07 Dec. 
SALVADOR: La Libertad: Quezaltepeque, 500 m, 19 June 1963, D.Q. Cavagnaro \& M.E.

Irwin, ANTC 10258, 1 worker (CASENT: CASENT0196000). GUATEMALA: Suchitepéquez: \#20782, 3 workers (WEMC: USNMENT00758045, 00758046). GUYANA: Kartabo, July-Aug. 1920, W.M. Wheeler, 16 workers (MCZC: CMOS000022-000027). MEXICO: Morelos: Cuernavaca, 25 May 1989, W. MacKay \#11418, 2 workers (WEMC: USNMENT00757981); (WEMC: USNMENT00758032, 00757649); Veracruz: Los Tuxtlas, 10 June 1994, L. Quiroz, 2 workers (ICN: USNMENT00757661). NEW CALEDONIA: Kuto Penin. Ile des Pins, -22.6666 167.4333, 5 m, 11 May 1980, P.S. Ward \#4294-9, 3 workers (PSWC: USNMENT00757882);

1918 Noumea, 0-100 m, N.L.H. Krauss, 1 worker (CASENT: CASENT0196015). PARAGUAY:

1919 Central: Guarambaré, -25.48 -57.45, 25 Apr. 1997, A. Wild \#AW0514, 1 worker (ALWC:

1920 USNMENT00757645); Guairá: Roque Gonzalez, -25.88333 -57.28333, 14 Jan. 1995, B.

1921 Garcete \#AW0457, 1 worker (ALWC: USNMENT00759028). PERU: Madre de Dios:

1922 Tambopata, Cuzco Amazónico, 15 km NE Puerto Maldonado, June 1989, S.P. Cover \& J.E.

1923 Tobin, CA-275, 6 workers, 1 queen (MCZC: USNMENT00757276-00757279); San Martin:

1924 Con. Mun. Zona Barreal 23 km S Picota, -7.09111 -76.31361, 335 m, 06-15 Mar. 2005, M.E.

1925 Irwin \& J.D. Vasquez, ANTC1447, 1 worker (CASENT: CASENT0066404). SEYCHELLES:

1926 La Dique Island, 1 m, 09 Nov 1993, Alpert et al., 2 workers (MCZC: USNMENT00757245).

1927 SOLOMON ISLAND: Guadalcanal, Honiara, 0-100 m, Mar 1986, N.L.H. Krauss, ANTC 1928 10277, 1 worker (CASENT: CASENT0196019). SURINAME: Dirkshoop, May 1959, I. V. d. 1929 Drift, 3 workers (MPEG: USNMENT00757580). USA: Arizona: Pima Co. Tucson, 32.23417 1930 110.96666, A.L. Wild \#AW2826 (ALWC: USNMENT00757958). VANUATU: Tafea, Tanna, 01931100 m, Dec. 1985, N.L.H. Krauss, ANTC 10270, 10271, 2 workers (CASENT: 
1932 CASENT0196012, 0196013). VENEZUELA: Lara: Barquisimeto, to Carora km 19, 29 June

1933 1971, W.L.\& D.E. Brown, 2 workers (MCZC: USNMENT00757884); Miranda: D.F Inst Estud.

1934 Avan. Caracas, 10 Oct 1988, W. MacKay \#11144-2 \#11146-6, 4 workers (WEMC:

1935 USNMENT00757654, 00757744).

1936

1937 Diagnosis. Brachymyrmex cordemoyi strongly resembles B. obscurior and to some extent also $B$.

1938 patagonicus. All these species have scapes that reach or surpass the posterior cephalic margin,

1939 but by less than the maximal diameter of the eye; their mesonotum does not bulge dorsally above

1940 the pronotum in lateral view, and the metanotal groove is absent or narrower than the diameter of

1941 methathoracic spiracles. In general, B. cordemoyi has a longer pronotum and mesonotum than $B$.

1942 obscurior and B. patagonicus, but these characters show important intraspecific variation.

1943 Furthermore, it differs from B. patagonicus by having considerably denser pubescence on the

1944 gaster, and from B. obscurior by having a larger head, more ommatidia along the maximal

1945 diameter of the eye, and lighter-colored pubescence which is denser on the dorsum of the entire

1946 body and appressed on the gaster instead of decumbent in B. obscurior.

1947

1948

Additional material examined measurements $(\mathrm{mm})(\mathrm{n}=20)$. $\mathrm{HL}_{1}$ 0.39-0.62; $\mathrm{HL}_{2}$ 0.27-0.41; $\mathrm{HL}_{3}$

1949

0.10-0.16; HW 0.33-0.59; SL 0.27-0.53; EL 0.08-0.16; WL 0.37-0.60; PnL 0.10-0.20; PnW 0.23-

1950

0.39; ML 0.08-0.18; MW 0.16-0.29; Indices CI 84.38-96.78; SI 1 82.35-106.38; $\mathrm{SI}_{2}$ 100.00-

1951 142.86; $\mathrm{OI}_{1} 23.33-34.69 ; \mathrm{OI}_{2} 20.00-29.63$.

1952

1953

Description. Head. Slightly longer than wide in full face view; posterior cephalic margin slightly

1954 concave. Dorsal hairs dense and appressed. Clypeus with a rounded anterior margin and five

1955 long, erect hairs of which a single, usually conspicuous hair is near the anterior margin, two hairs 
1956 are in mediolateral position and two more near the toruli; other hairs on the clypeus are markedly

1957 shorter and appressed or decumbent. Toruli surpassing the posterior clypeal margin in oblique

1958 anterodorsal view. Scapes reach the posterior cephalic margin or surpass it by a length up to the

1959 maximal diameter of the eye; they have appressed hairs. Three inconspicuous ocelli are usually

1960 present. Eyes are positioned on the cephalic midline and have 10-12 ommatidia along their

1961 maximal diameter.

1962 Mesosoma. Typically with two erect hairs on the pronotum and two on the mesonotum;

1963 sometimes with additional suberect hairs, mainly on the pronotum. The mesonotum is not inflated

1964 and does not bulge dorsally above the pronotum in lateral view. Metanotal groove absent or

1965 narrower than the diameter of the metathoracic spiracles. Metathoracic spiracles in dorsolateral

1966 position, not protruding, and typically touching the mesometanotal and propodeal sutures.

1967 Dorsum of the propodeum slightly convex and shorter than the posterior slope. Propodeal

1968 spiracles circular, positioned on the posterior propodeal margin, slightly posterior of the middle

1969 of the propodeal slope. Legs with appressed hairs. Petiole short and inclined forward.

1970 Gaster. With dense yellowish pubescence and several scattered and sub-erect hairs, mainly but

1971 not exclusively along the edges of the segments.

1972 Color and sculpture. Body smooth, shiny, and brownish in color.

1974 Distribution (Supplementary material Fig. S13). Brachymyrmex cordemoyi is widespread and

1975 known from Argentina, Brazil, Colombia, the Dominican Republic, Ecuador, El Salvador,

1976 Guatemala, Guyana, Mexico, Paraguay, Peru, Suriname, the United States, Venezuela and it has

1977 been introduced in New Caledonia, Seychelles, Vanuatu, Solomon Island, Saudi Arabia (Sharaf

1978 et al., 2016), Europe and Asia (Ortiz-Sepulveda, pers. obs.). 
Manuscript submitted to: Organisms Diversity \& Evolution

Published version available; DOI: 10.1007/s13127-019-00406-2

1980 Biology. Some specimens were collected from under stones (PSWC: USNMENT00757877, 1981 00757881; MCZC: CMOS000020), or on cacti (WEMC: USNMENT00757981).

1983 Remarks. We refrain from designating a lectotype because we did not come across the type series of B. cordemoyi at the MHNG. However, we studied the original description and the type series of its varieties (i.e. distincta, nigricans) (Santschi 1916; Santschi 1923a). Hence, the taxonomic decisions made here are based on these data together with the overall morphological framework we developed for the genus.

1988 The type series of B. cordemoyi was collected in Reunion, and Forel (1895a) already suggested 1989 that it represents an introduction from the Neotropics. Forel (1895a) indicated that B. cordemoyi 1990 resembles B. patagonicus, and originally described it as a variety of the latter species that has more pubescence. Such dense pubescence is also observed in B. patagonicus var.

1992 brevicornoeides. Forel (1914) did not provide diagnostic features to distinguish B. patagonicus

1993 var. brevicornoeides and typical B. patagonicus. However, he suggested that the scapes in $B$.

1994 patagonicus var. brevicornoeides resemble those of $B$. brevicornis, but are slenderer, and that $B$. 1995 patagonicus var. brevicornoeides has somewhat larger eyes than B. brevicornis. Before, Emery 1996 (1906) had suggested that B. brevicornis is closely related to B. cordemoyi because they have 1997 similar integument and pubescence, although the integument is slightly more lucid in $B$. 1998 brevicornis. Furthermore, the head and antennal funiculi of B. brevicornis are somewhat longer 1999 than those of B. cordemoyi, the clypeus slightly more prominent, and the eyes smaller. However, 2000 many of these differences could represent geographic variation rather than specific differences. It 2001 is noteworthy that B. cordemoyi is variable in most of these features, and therefore we 2002 synonymize B. patagonicus var. brevicornoeides and B. brevicornis to it here. Quirán (2005) 2003 redescribed B. brevicornis but did not compare or relate it to other Brachymyrmex species. 
Manuscript submitted to: Organisms Diversity \& Evolution

Published version available; DOI: 10.1007/s13127-019-00406-2

2004 Another example of the variability within B. cordemoyi represents Brachymyrmex cordemoyi var.

2005 distinta, which was obtained from various places in Argentina, and which has somewhat shorter

2006 scapes than specimens of the typical B. cordemoyi (Santschi 1923a). Beyond this feature, the only

2007 difference that Santschi (1923a) remarked is the body color of queens. Santschi (1923a) also

2008 synonymized B. patagonicus var. brevicornoeides with B. nigricans, which he previously

2009 (Santschi 1916) considered a variety of B. cordemoyi. Studying the type material of B. nigricans

2010 we agree with this taxonomic decision, but brevicornoeides has taxonomic priority over nigricans

2011 (Bolton 1995: 81), so that B. nigricans is also synonymized to B. cordemoyi here.

2012 The type specimens of B. laevis var. fuscula are morphologically more similar to B. cordemoyi

2013 than they are to B. laevis, and the only difference Emery (1906) described between B. laevis and

2014 B. laevis var. fuscula is body color, however, from our observations both differ also in other

2015 traits, notably the pubescence of the gaster, resulting in their synonymization to B. patagonicus

2016 and B. cordemoyi, respectively.

2017 In summary, B. cordemoyi has several diagnostic features, however, we also observed

2018 considerable intraspecific variation in various traits. This variation may hint to a potential species

2019 complex. Brachymyrmex cordemoyi is very widespread and a more comprehensive study of the

2020 variation within and between its populations would be required to fully resolve the taxonomic

2021 status of this species.

2022

2023 
2026 Brachymyrmex coactus subs. degener Emery, 1906: 177 (w.). Lectotype worker (MCSN:

2027 USNMENT00757208) and paralectotype workers (MCSN: USNMENT 00757207, MCZC:

2028 M.C.Z. Cotype 01435; here designated): 4 workers [examined]. BRAZIL: Matto Grosso:

2029 Cuiaba. Raised to species: Santschi (1923a: 670).

2030 = Brachymyrmex admotus r. niger Forel, 1912a: 62 (w.). (MHNG: USNMENT00757162,

2031 00757163, 00758155): 7 workers [examined]. BRAZIL: Ceara. Assigned as B. degener st. niger 2032 by Santschi (1923a: 671). n. syn.

2033 = Brachymyrmex incisus Forel, 1912a: 63 (w.m.). (MHNG: USNMENT00758134 -00758139, 2034 00757141-00757143; NHMB: USNMENT00758096): 24 workers, 1 male [examined].

2035 COLOMBIA: Naranjo. n. syn.

2036 = Brachymyrmex luederwaldti Santschi, 1923a: 672, Figs. 36, 66 (w.). (NHMG:

2037

USNMENT00758140; NHMB: USNMENT00758097, 00758098): 6 workers [examined].

BRAZIL: São Paulo: Alcatrazes. n. syn.

2039

Additional material examined. BRAZIL: Bahia: Canavieiras, -15.69028 -39.00722, 17 July 1998, J.C.S. Carmo \& J.R.M. Santos, 4 workers (CEPLAC: USNMENT00757566); Para: Serra 2042 Norte, Serraría, -6.08276-50.16666, 22 Oct. 1984 (MPEG: MPEG_HYM11506088).

2043 COLOMBIA: Caldas: Aguadas, Cañón del Río Arma, 5.61472 -75.45972, 1995, C. Sarmiento 2044 CES096, 3 workers (IAvH: USNMENT00757575); Guajira: Quebrada Guacoche, nr. Don 2045 Diego, forest, 10.72305 -72.96972, 10 m, 22 July 1976, W.L. Brown \& R.C. Kugler, 8 workers 2046 (MCZC: USNMENT00757565, CMOS000094-CMOS000096); Huila: 4 km NE Rivera, 30 Dec. 2047 1986, W. MacKay \#9023, 3 workers (WEMC: USNMENT00758026); Tolima: Cunday, vereda 2048 “El Eden”, 4.08333 -74.66667, 450 m, 01 Oct. 1999, Mejia et al., 2 workers (ICN:

2049 MPUJ_ENT0000416); Valle del Cauca: 08 Jan. 1976, W. \& E. MacKay, 2 workers (WEMC: 
19 Nov. 2003, A.L. Wild \#AW2121, 2 workers (ALWC: USNMENT00757576). FRENCH

GUIANA: Basse Vie-foret, 04 July 1999, S. Durou, 2 workers, 1 queen (CEPLAC:

USNMENT00757568); Petit Saut, May 2003, J. Orivel \& J. Le Breton, 3 workers (CEPLAC:

E.S. McCluskey, 3 workers (MCZC: USNMENT00758033). PARAGUAY: Amambay: Parque

Nacional Cerro Corá, -22.65 -56.05, 13 May 1997, A. Wild \#AW0576, 3 workers (ALWC:

Oct. 2002, T. Delsinne, 2 workers (RBINS: Coll.RIScNB SID SPM_ID11523); Enciso N.P.

(Southern side), -21.20609 -61.65748, 01-02 Oct. 2002, M. Leponce, 1 worker (RBINS:

Coll.RIScNB SID SPM_ID31985); Estancia Maria Vicenta, -20.92130 -61.39321, T. Delsinne, 1 worker (RBINS: Coll.RIScNB SID SPM_ID26822); Canindeyú: Residencias, 6 km N Ygatimi, 24.06667 -55.63333, 21 Feb. 1997, A. Wild \#AW0451, 1 worker (AWLC: USNMENT00757577). TRINIDAD AND TOBAGO: Cumuto, 24 Apr. 1929, Darlinhton, 1 worker (MCZC: USNMENT00757578).

Diagnosis. Brachymyrmex degener morphologically resembles B. coactus as both species have scapes that surpass the posterior margin of the head, they have faint sculpture on the mesosoma, a mesonotum that is inflated and that bulges dorsally above the pronotum in lateral view, a wide 2069 metanotal groove, metathoracic spiracles that are slightly protruding dorsally, and their gasters 2070 have sparse pubescence. However, B. degener has a uniformly brownish body, whereas the gaster 2071 is conspicuously darker than the rest of the body in B. coactus. 
Manuscript submitted to: Organisms Diversity \& Evolution

Published version available; DOI: 10.1007/s13127-019-00406-2

2073

2074

2075

2076

2077

2078

2079

2080

2081

2082

2083

2084

2085

2086

2087

2088

2089

2090

2091

2092

2093

2094

2095

2096

Lectotype and paralectotypes measurements $(\mathrm{mm})(\mathrm{n}=3)$. HL $10.51-0.55 ; \mathrm{HL}_{2}$ 0.35-0.41; HL 3

0.16; HW 0.49-0.55; SL 0.37-0.53; EL 0.12-0.14; WL 0.55-0.68; PnL 0.16-0.20; PnW 0.31-0.37;

ML 0.12-0.16; MW 0.20-0.23; Indices CI 96.15-100.00; $\mathrm{SI}_{1}$ 76.00-96.43; $\mathrm{SI}_{2}$ 105.56-135.00; OI

21.43-25.93; $\mathrm{OI}_{2} 28.57-30.77$.

Additional material examined measurements (mm) $(\mathrm{n}=24)$. HL $10.53-0.70 ; \mathrm{HL}_{2}$ 0.29-0.49; HL3

0.12-0.20; HW 0.51-0.73; SL 0.55-0.68; EL 0.12-0.20; WL 0.60-0.79; PnL 0.14-0.23; PnW 0.33-

0.50; ML 0.12-0.21; MW 0.20-0.31; Indices CI 87.50-112.50; $\mathrm{SI}_{1} 82.22-117.86$; $\mathrm{SI}_{2} 137.04-$

233.33; $\mathrm{OI}_{1} 20.00-30.30 ; \mathrm{OI}_{2} 22.22-33.33$.

Description. Head. Slightly longer than wide in full face view; posterior cephalic margin slightly concave. Dorsum of the head has scattered appressed hairs. Clypeus with a rounded anterior margin and five long, erect hairs of which a single, usually conspicuous hair is near the anterior margin, two hairs are in mediolateral position and two more near the toruli; other hairs on the clypeus are markedly shorter and appressed or decumbent. Toruli surpassing the posterior clypeal margin in oblique anterodorsal view. The scapes surpass the posterior cephalic margin by a length smaller or equal to the maximal diameter of the eye, and they bear appressed and decumbent hairs. Three ocelli are present. The eyes are positioned on the cephalic midline and have 8-14 ommatidia along their maximal diameter.

Mesosoma. Typically with two erect hairs on the pronotum and two on the mesonotum; sometimes with additional suberect hairs, mainly on the pronotum. The mesonotum is inflated and bulges dorsally above the pronotum in lateral view. Metanotal groove wider than the diameter of the metathoracic spiracles. Metathoracic spiracles in dorsolateral position, slightly protruding, and not touching any sutures. Dorsum of the propodeum strongly convex and shorter 
Manuscript submitted to: Organisms Diversity \& Evolution

Published version available; DOI: 10.1007/s13127-019-00406-2

than the posterior slope. Propodeal spiracles conspicuous and circular, positioned on the propodeal margin or just dorsal of it, at the anterior margin of the propodeal slope. Legs with appressed hairs. Petiole short and inclined forward.

Gaster. With scattered pubescence and several scattered long erect hairs.

Color and sculpture. Body shiny and uniformly brownish in color. Head and gaster smooth whereas the dorsum of the mesosoma usually bears imbricate sculpture.

\section{Distribution (supplementary material Fig. S14). Brachymyrmex degener occurs in Brazil,} Colombia, Guatemala, French Guiana, Trinidad and Tobago.

\section{Biology. Unknown.}

Remarks. The lectotype of $B$. degener is the top specimen on pin USNMENT00758155, whereas the others on that pin are paralectotypes.

Brachymyrmex degener was first described as a subspecies of B. coactus by Emery (1906) and Santschi (1923a) subsequently raised it to species. Brachymyrmex degener indeed resembles $B$. coactus closely, and in retrospect we are uncertain that it represents a separate species. However, the issue of $B$. degener and $B$. coactus is taxonomically very complex and involves several other previously described species and subspecies that warrant synonymization too. Perhaps this process is best performed incrementally, which is the approach taken here.

One of these other taxa involved is B. admotus $\mathrm{r}$ niger which was described by Forel (1912a) with the following diagnostic traits: the metanotal groove is deep, the mesonotum bulges out dorsally above the pronotum (in lateral view), the body is shiny and the head and gaster smooth whereas faint sculpture is present on the mesosoma. Upon examination, the type specimens of $B$. 
Manuscript submitted to: Organisms Diversity \& Evolution

Published version available; DOI: 10.1007/s13127-019-00406-2

2121 admotus $\mathrm{r}$ niger have the diagnostic traits of B. degener, but lack some of those for B. admotus,

2122 such as the presence of a pair of thin erect hairs between the methathoracic spiracles, which are

2123 positioned fully dorsal instead of dorsolaterally, and the absence of sculpture on the mesosoma.

2124 These criteria that motivated Santschi (1923a) to reclassify the race as B. degener st. niger, and

2125 whereas we agree with this reclassification, we do not consider there to be sufficient differences

2126 to prevent synonymization of niger to B. degener.

2127 In the description of B. incisus Forel (1912a) likewise indicated similarities to B. coactus and B.

2128 admotus, but again some of the diagnostic traits of $B$. admotus are absent. Moreover, whereas the

2129 specimens resemble $B$. coactus closely they do not have a gaster that is conspicuously darker in

2130 color than the head and mesosoma, and hence B. incisus is here synonymized to B. degener.

2131 As to B. luederwaldti, Santschi (1923a) indicated similarities to B. coactus, and even more so to

2132 B. admotus r. niger (Forel 1912a), from which he distinguished B. luederwaldti mainly by its

2133 fainter propodeal suture. We consider this variation to be intraspecific here and consequently also

2134 synonymize $B$. luederwaldti to $B$. degener.

2135 Upon describing degener as a variety of B. coactus, Emery (1906) indicated that this variety

2136 differs from typical B. coactus mainly in body and eye size, which are traits with a lot of

2137 intraspecific variation as we already indicated in the remarks of B. coactus. We did not find

2138 consistent differences in body size, nor in the number of ommatidia along the maximal diameter

2139 of the eye between both taxa. Emery (1906) further emphasized that the medial antenomeres are

2140 somewhat longer than wide in B. degener, and vice versa in B. coactus. However, we cannot

2141 confirm this putative difference from the type material of both species. Although some putatively

2142 diagnostic differences between $B$. coactus and $B$. degener are indicated in the diagnosis, the

2143 taxonomic importance of these differences remains to be examined. Our morphometric

2144 measurements confirm the difficulty to establish consistent differences between both taxa, and 
2145 furthermore our phylogenetic analyses (see below) recovered $B$. degener nested within $B$.

2146 coactus. However, a deep phylogenetic branch separates B. degener from B. coactus as is also

2147 recognized by in the ABGD analysis (see below), and given the taxonomic complexity

2148 surrounding B. coactus it is possible that the one specimen identified as B. coactus that renders

2149 the species paraphyletic in fact belongs to a distinct taxon. With the sampling that is currently

2150 available, this issue cannot be resolved and therefore we do not further synonymize B. coactus

2151 and B. degener here.

\section{Brachymyrmex delabiei Ortiz \& Fernández}

(Fig. 26, supplementary material Fig. S15)

Brachymyrmex delabiei Ortiz and Fernández, 2014: 24, Figs. 22, 23, 24 (w). Holotype worker

(MZSP: USNMENT00757718) and paratype workers (CPDC: USNMENT00757719, ICN:

USNMENT00757720, USNM: USNMENT00757721): 4 workers. BRAZIL: São Paulo:

2162 Santos \& J.C.S. Carmo, 1 worker (CPDC: USNMENT00757610); A61 Camacan, 27 Aug. 1999, 2163 -15.60111 -39.52111, col. J.R.M. dos Santos, 1 worker (CPDC: USNMENT00757837); Santa

2164 Catharina: Palhoça, PE Serra do Tabuleiro, 02-10 Nov. 2003, -27.74111 -48.69722, R.R. Silva, 2165 B.H. Dietz and A. Tavares, 1 worker (MZSP: USNMENT00757725); São Paulo: São Bernardo 2166 do Campo, 01 June 1971, W.L. \& D.E. Brown, 1 worker (MCZC: USNMENT00757835). 
2168 Diagnosis. Brachymyrmex delabiei is most similar in morphology to B. brasiliensis and B.

2169 feitosai, because they all have tumuliform metathoracic spiracles, however, it differs from $B$.

2170 brasiliensis by its entirely smooth and shiny body, and from B. feitosai by the presence of two

2171 erect hairs on the pronotum and two on the mesonotum, the lack of dense pubescence on the first

2172 segment of the gaster and the yellowish body.

2173

2174 Description. See Ortiz and Fernández (2014).

2175

2176

2177

2178

2180

2181

2182

2183

2184

2185

2186

2187

\section{Brachymyrmex depilis Emery}

\section{(Fig. 27, supplementary material Fig. S16)}

Brachymyrmex heeri subsp. depilis Emery, 1893: 635 (w.q.). Lectotype worker (MCSN:

USNMENT00757228) and paralectotype workers, queen, male (MCSN: USNMENT00757225

- 00757232; here designated): 37 workers, 1 queen, 10 males [examined]. USA: District of

Columbia: Georgetown College, 10 Aug. 1885, leg. Pergrande. Wheeler and Wheeler (1953:

139) (1.). Raised to species: Santschi (1923a: 663).

= Brachymyrmex nanellus Wheeler, 1903: 102, Fig. 7b (w.m.). (MCZC: MCZ Cotype 22939): 5

workers [examined]. USA: Texas: Austin, 25 May 1901. Synonymy by Creighton (1950: 359).

= Brachymyrmex depilis subsp. flavescens Grundmann, 1952: 117 (w.). (USNM:

USNMENT00529204): 3 workers [examined]. USA: Utah: near Salt Lake City. Lower portion of Big Cottonwood Canyon, 24 June 1947. Synonymy by Cole (1953: 266). 
Additional material examined. CANADA: Nova Scotia: Halifax, 15 m, 44.63333 -63.61667,

25 Oct. 1996, P.S. Ward \#13234, 2 workers, 1 queen (PSWC: USNMENT00757818). MEXICO:

Tamaulipas: Gomez Parias, 25 Sep. 1987, W. MacKay \#10073, 2 workers (WEMC:

2193 USNMENT00757816); Veracruz: Las Hamacas, 17 km. N Santiago Tuxtla, 26-28 Aug. 1953, 2194 E.O. Wilson, 5 workers, 1 queen (MCZC: CMOS000114 - 000115); Los Tuxtlas, 10 km NNW

2195 Sontecomapan, 18.58333 -95.08333, 200 m, 20 Mar. 1985, P.S. Ward \#7333-55, 3 workers

2196 (PSWC: USNMENT00757815). UNITED STATES: Alabama: Marshall Co. JCT 4207 km S

2197 Morgna city, 34.41111 -86.52361, 09 June 1998, MacKay fam. \#188203, 2 workers (WEMC:

2198 USNMENT00757813); Arkansas: Cross Co. Village Cr. St. Pk. 14 Aug. 1988, R. Anderson, 3

2199 workers (WEMC: USNMENT00757805 - 00757807); California: 8 km S, Brans. Wiask, 10 Feb.

2200 1943, W.S. Ross, ANTC10266, 4 workers (CASENT: CASENT0196008); Santa Barbara Co,

Figueroa Crk., Sedgwick Ranch, 34.71667 -120.03333, 350 m, 02 Mar. 1996, P.S. Ward \#12963, 1948, F. Bonet \#1718, 3 workers (MZUSP: USNMENT00757798). Florida: Highlands Co. Archbold Biol. Station, 22 Aug. 1995, A. Wild, 5 workers (ALWC: USNMENT00757817);

Kentucky: Floyd Co. Jennie Wiley St. Pk., 07 July 1968, S. Peck Ber \#134, 1 worker (MCZC: 89.95488, 08 Sep. 2000, A.M. Pranschke, 2 workers (CEPLAC: USNMENT00757801); New Mexico: Sandoval Co, Bandelier, Nat. Mon, 21 Aug. 1986, W. \& E. MacKay \#8784, 2 workers (WEMC: USNMENT00757814); New York: Newark, Morris Farm, U. Delaware, (ALWC: USNMENT00757799); Ontario Co. Gannet Hill, 42.7 -77.4, 640 m, 10 Sep. 1995, A.L. 
2214 Feb. 1942, E.S. Ross, ANTC10267, 3 workers (CASENT: CASENT0196009); Houston Co. Big 2215 Stough Wild Area, 09 May 1988, R. Anderson \#12760, 4 workers (WEMC:

2216 USNMENT00757811 - 00757812, 00758040); Sabino Co. 14.5 K E Nerwphill, 11 May 1988, R. 2217 Anderson \#12763, \#12763, 6 workers (WEMC: USNMENT00757808 - 00757810); Vermont:

2218 Nr. Burlington, Temperate Forest, Nov 2001, R. Blatrix, 9 workers (CEPLAC:

2219 USNMENT00757802 - 00757804).

Diagnosis. Brachymyrmex depilis resembles B. heeri and B. giardi as all three taxa have the mesonotum bulging dorsally above the pronotum in lateral view, and a gaster with dense hairs on the mesosoma, and from B. giardi by its smaller eyes, its appressed hairs on the dorsum of the mesosoma, its yellowish color and its Nearctic distribution, i.e from the South of Canada to 2226 the North of Mexico.

0.10-0.18; HW 0.39-0.45; SL 0.35-0.41; EL 0.08-0.12; WL 0.39-0.51; PnL 0.12-0.20; PnW 0.27117.65; $\mathrm{OI}_{1} 18.18-30.00 ; \mathrm{OI}_{1} 20.00-36.00$. 0.05-0.14; HW 0.29-0.46; SL 0.27-0.42; EL 0.08-0.10; WL 0.31-0.46; PnL 0.08-0.18; PnW 0.22OI 1 19.57-30.30; $\mathrm{OI}_{2}$ 17.14-30.00. 
2238 Description. Head. Slightly longer than wide in full face view; posterior cephalic margin slightly

2239 concave. Clypeus with a rounded anterior margin and five long, erect hairs of which a single,

2240 usually conspicuous hair is near the anterior margin, two hairs are in mediolateral position and

2241 two more near the toruli; other hairs on the clypeus are markedly shorter and appressed or

2242 decumbent. Toruli surpassing the posterior clypeal margin in oblique anterodorsal view. The

2243 scapes are short, usually barely reaching the posterior margin of the head, and never surpassing it

2244 by a length that equals the maximal diameter of the eye. Ocelli are absent. Eyes are small and

2245 positioned on the cephalic midline; they have 6-8 ommatidia along their maximal diameter.

2246 Mesosoma. Not bearing any erect hairs. The mesonotum is inflated and bulges dorsally above the

2247 pronotum in lateral view. Metanotal groove absent or narrower than the diameter of the

2248 metathoracic spiracles. Metathoracic spiracles are small, in dorsolateral position, not protruding,

2249 but touching the propodeal suture. Dorsum of the propodeum is weakly convex and much shorter

2250 than the propodeal slope. Propodeal spiracles are circular, positioned on the posterior propodeal

2251 margin at the middle of the propodeal slope. Legs with appressed hairs. Petiole short and inclined

2252 forward.

2253 Gaster. With dense pubescence and scattered long erect hairs at the edges of the segments.

2254 Color and sculpture. Body opaque with inconspicuous sculpture. Body yellowish, sometimes

2255 with the gaster a bit darker than the mesosoma.

Distribution (supplementary material Fig. S16). Brachymyrmex depilis is known from Canada, 2258 México, and the United States.

2260 Biology. Grundmann (1952) collected a nest of B. depilis subsp. flavescens from among the roots 2261 of the scrub oak Quercus gambelii and suggested that this species is subterraneous and tends 
Manuscript submitted to: Organisms Diversity \& Evolution

Published version available; DOI: 10.1007/s13127-019-00406-2

2262 aphids and coccids on the roots of plants. This association was also highlighted by Yensen et al.

2263 (1980) and Wheeler and Wheeler (1986). Small colonies of B. depilis were found in the soil

2264 under stones or in rotting wood in a wide variety of habitats: open forest, dense moist forest,

2265 grass lands, and dry fields (Wheeler and Wheeler 1986). Surprisingly, Yensen et al. (1980)

2266 reported B. depilis from an intertidal halophyte-covered mud flat in the Gulf of California in

2267 Mexico, where colonies are regularly inundated by sea water. The authors suggest that the

2268 mechanisms that allow the species to survive heavy rains elsewhere may have preadapted their

2269 survival in this unusual habitat. Page (1982) reported on copulatory behavior and observed a

2270 queen of B. depilis with attached to her abdomen three motionless males, thatshe dragged around.

2271 As such he suggested that B. depilis seems to have multiple copulations but whether insemination

2272 occurs by several partners is unknown.

2273

2274 Remarks. The lectotype is designated here as the worker on pin USNMENT00757229 and the

2275 other specimens are paralectotypes.

2276 Brachymyrmex depilis was originally described as a subspecies of B. heeri by Emery (1893), and

2277 he distinguished it from typical B. heeri because B. depilis lacks erect hairs on the mesosoma.

2278 Santschi (1923a) raised the subspecies to species but did not provide criteria to support his

2279 decision. Nevertheless, we consider this decision justified given the differences we mention here

2280 in the diagnosis.

2281 In the original description of B. nanellus Wheeler (1903) reported a comparison of his material to

2282 alleged specimens of $B$. depilis, and he described a series of differences to support the status of $B$.

2283 nanellus as a separate species. Santschi (1923a) accepted this taxonomic decision, but as

2284 Creighton (1950) pointed out the comparative material unlikely belonged to B. depilis, and after a 
2285 further comparison of both taxa he synonymized B. nanellus with B. depilis, which we support 2286 here after re-examining the material.

2287 Brachymyrmex depilis subsp. flavescens was originally distinguished from B. depilis by having a 2288 lighter body color, smaller eyes, an opaquer body due to its shriveled integument, scarcer 2289 pubescence and hairs (Grundmann 1952). However, after examining this material we agree with 2290 the conclusion of Cole (1953) that these specimens appear to be part of an incipient colony, 2291 which adequately explains all these morphological differences outlined by Grundmann (1952).

2292 Fisher and Cover (2007) suggested that B. depilis may constitute a complex of several species. 2293 The material studied here is perhaps to limited to accurately comment on this issue, however, we 2294 did not find consistent morphological differences between samples, except perhaps in body size.

\section{Brachymyrmex donisthorpei Santschi}

Brachymyrmex donisthorpei Santschi, 1939: 320, Figs. 4, 5 (w.). Lectotype worker (NHMB:

USNMENT00757183) and paralectotype workers (NHMB: USNMENT00757184-00757185;

Additional material examined. BRAZIL: Bahia: Vargito, -15.40 -39.55, 22 Mar. 1999, J.R.M.

2304 dos Santos, 1 worker (CEPLAC: USNMENT00757839); São Paulo: Iguape, E.E. Jureia-Itatins, 2305 Nucleo Rio verde, -24.54417 -47.23556, 5-14 Mar. 2001, A.A. Tavares, 1 worker (ICN:

2306 MZSP158). COLOMBIA: Magdalena: El Campano, 11.12 -74.10, 1300 m, 13 Aug. 1985. P.S. 2307 Ward \#7891-23, 2 workers, 1 queen (PSWC: USNMENT00757840); Nariño: territorio Kofan, 
Manuscript submitted to: Organisms Diversity \& Evolution

Published version available; DOI: 10.1007/s13127-019-00406-2

0.47481 -77.17913, 1000 m, 28 Sep. 1998, 1 worker (IAvH). ECUADOR: Zamora-Chinchipe:

2309

2310

2311

2312

2313

2314

2315

2316

2317

2318

2319

2320

2321

2322

2323

2324

2325

2326

2327

2328

2329

2330
Copalinga, -4.09122 -78.96069, 17-19 Oct. 2009, Jacquemin, 1 worker (RBIN: Coll.RIScNB SID

SPM_ID3753921). PARAGUAY: Boquerón: Enciso N.P. (Southern side), -21.20298 -

61.65909, 04-06 Nov. 2001, M. Leponce.

Diagnosis. Brachymyrmex donisthorpei morphologically resembles B. modestus and B. myops because they all have dense, short pubescence over the entire body, scapes with short suberect hears, eyes that are positioned below the cephalic midline, a metanotal groove that is either absent or narrower than the diameter of the metathoracic spiracles, and yellowish body color. Brachymyrmex donisthorpei differs from B. modestus and B. myops by its short scapes that approximately reach the posterior margin of the head or surpass it by less than the maximal diameter of the eye.

Lectotype and paralectotype measurements $(\mathrm{mm})(\mathrm{n}=2)$. HL $10.39-0.41 ; \mathrm{HL}_{2}$ 0.25-0.27; HL 3 0.08; HW 0.33-0.35; SL 0.27-0.29; EL 0.05; WL 0.39; PnL 0.10; PnW 0.27-0.29; ML 0.10; MW 0.20; Indices CI 85.00-85.71; SI 1 82.35-83.33; SI $107.14-107.69 ; \mathrm{OI}_{1} 13.89-14.71$; $\mathrm{OI}_{2}$ 19.0520.00 .

Additional material examined measurements (mm) $(\mathrm{n}=4)$. HL $10.32-0.38 ; \mathrm{HL}_{2}$ 0.22-0.29; HL 3 0.07-0.09; HW 0.26-0.33; SL 0.24-0.29; EL 0.04; WL 0.27-0.38; PnL 0.11-0.12; PnW 0.20-0.23; ML 0.06-0.09; MW 0.13-0.16; Indices CI 80.55-86.05; SI 1 86.49-96.55; SI 26.97-112.00; OI 13.51-16.67; OI 1 22.22-23.26. 
2331 Description. Head. Substantially longer than wide in full face view; posterior cephalic margin

2332 slightly concave. Clypeus with a rounded anterior margin and five long, erect hairs of which a

2333 single, usually conspicuous hair is near the anterior margin, two hairs are in mediolateral position

2334 and two more near the toruli; other hairs on the clypeus are markedly shorter and appressed or

2335 decumbent. Toruli surpassing the posterior clypeal margin in oblique anterodorsal view. Dorsum

2336 of the head has conspicuous appressed pubescence and several suberect hairs. The scapes

2337 approximately reach the posterior margin of the head or surpass it by a length smaller than the

2338 maximal diameter of the eye, and they have appressed and decumbent hairs. Ocelli absent. The

2339 eyes are positioned below the cephalic midline and have only 3-4 ommatidia along their maximal

2340 diameter.

2341 Mesosoma. With several short appressed and sub-erect hairs. The mesonotum is not inflated and 2342 does not bulge dorsally above the pronotum in lateral view. Metanotal groove absent or narrower 2343 than the diameter of the metathoracic spiracles. Metathoracic spiracles dorsolateral in position, 2344 not protruding, and touching the propodeal suture. Dorsum of the propodeum flat and much 2345 shorter than propodeal declivity. Propodeal spiracles circular, small and inconspicuous, 2346 positioned on the posterior propodeal margin, slightly posterior of the middle of the propodeal 2347 slope. Legs with appressed and sub-erect hairs. Petiole short and inclined forward.

2348 Gaster. With appressed dense pubescence and some sub-erect hairs near the edges of the 2349 segments.

2350 Color and sculpture. Body yellowish, with imbricate sculpture on the dorsum of the mesosoma. 
Manuscript submitted to: Organisms Diversity \& Evolution

Published version available; DOI: 10.1007/s13127-019-00406-2

Biology. Unknown.

Remarks. No specific geographic information is available on the type material beyond

2358 Colombia.

\section{Brachymyrmex feitosai Ortiz \& Fernández}

(Figs. 29, supplementary material Fig. S18)

Brachymyrmex feitosai Ortiz and Fernández, 2014: 27, Figs. 25, 26, 27 (w). Holotype worker and paratype workers (MZSP: USNMENT00757694): 3 workers. BRAZIL: Rio de Janeiro:

2365 Floresta de Tijuca, D. Federal. 16 Dec. 1959, C.A: Campos Seabra.

Additional material examined. BRAZIL: Minas Gerais: Lavras, Ijaci e Perdões, -21.24528 -

44.99972, Fragmento, 06 Dec. 2002, M.S. Santos \& N.S. Dias, 4 workers (CPDC:

USNMENT00757836, 00759008); São Paulo: Piedade, Floresta Atlantica "Theomar", -23.73846

$2370-47.38957,16$ Nov. 2008, G. Bieber, 3 workers (ICN: USNMENT00759038); Sete Barras, PE

2371 Carlos Botelho, 600 m, -24.20833 -47.97056, 11-15 May 2009, armadilha subterrânea \#18, F.

2372 Esteves et al., 1 worker (MZSP: ANTWEB CASENT0217326).

2374 Diagnosis. Brachymyrmex feitosai resembles B. brasiliensis and B. delabiei because they all have

2375 tumuliform metathoracic spiracles. However, B. feitosai differs from B. brasiliensis by its entirely smooth and shiny body, that is more brownish, and by the dense yellowish pubescence 
on the first gastral segment. It differs from $B$. delabiei by the presence of many suberect hairs on the pronotum and mesonotum and its dense yellowish pubescence on the first gastral segment.

Description. See Ortiz and Fernández (2014).

$2389=$ Brachymyrmex fiebrigi var. funicularis Santschi, 1922: 260 (w.). (NHMB:

2392 = Brachymyrmex fiebrigi var. fumida Santschi, 1923a: 661 (w.). (MHNB: USNMENT00757704, 2393 00758157): 4 workers [examined]. ARGENTINA: Buenos Aires: Cerro "Ruinas"; (MHNB: USNMENT00758093, NHMG: USNMENT00758153): 3 workers [examined]. ARGENTINA:

2395 Cordoba: La Cabana. n. syn. 
2400 Baixio, -12.11444 -37.69694, June-Oct. 2010, M.L.O. Travassos, \#5644, 1 worker (CEPLAC: 2401 USNMENT00757545). Minas Gerais: Lavras, 06-12 2002, M.S. Santos, N.S. Dias, 2 workers 2402 (CEPLAC: USNMENT00759008). São Paulo: Iguape, EE Jureia-Itatins, Nucleo Rio verde, 240324.54417 -47.23556, 05-14 Mar. 2001, A.A. Tavares, 1 worker (ICN: MZSP158). COSTA 2404 RICA: Heredia: Cantarrana, 11 km ESE La Virgen, 10.33516 -84.04856, 300 m, 26 Feb. 2007, 2405 Marcos-Deimer-Joel, 1 worker (JTLC: INBIO0003646597); Limón: Casa Verde, Tortuguero, 240610.58333 -83.51667, 5 m, 24 June 1988, J. Longino \#2154, 3 workers (JTLC: 85.25, 200 m, 01 Aug. 1985, P.S. Ward \#7792, 3 workers (PSWC: USNMENT00757549); La Pita, rd. To Monteverde 10.16667 -84.91667, 120 m, 13 July 1984, J. Longino, 1 worker (JTLC: 2410 JTLC000005902). CUBA: Viñales: Pinar del Rio, 14 June 1953, E.O. Wilson \#10, 2 workers, 1 male (MCZC: USNMENT00757546). MEXICO: Quintana Roo: Municipio Leona Vicario, 2412 Reserva Ecológica "El Edén", 21.21667 -87.18333, 03 July 1997, G.M. Daniel, 1 worker (ICN: USNMENT00757626); PARAGUAY: Boquerón: Garrapatal, -21.44306 -61.87500, 04-06 Nov. 2001, M. Leponce, 1 worker (RBIN: Coll.RIScNB SID SPM_ID14544); Garrapatal, -21.43965 2415 61.48899, 05-06 Nov. 2001, M. Leponce, 1 worker (RBIN: Coll.RIScNB SID SPM_ID25159); 2416 Enciso, -21.20 -61.67, 03-06 Nov. 2001, M. Leponce \& T. Delsinne \#4123-9/3, 3 workers 2417 (ALWC: ANTWEB CASENT0173481); Enciso N.P. (Southern side), -21.19978 -61.66084, 17241818 Sep. 2003, T. Delsinne, 1 worker (RBIN: Coll.RIScNB SID SPM_ID31851); Enciso N.P. 2419 (Southern side), -21.19978 -61.66084, 04-06 Nov. 2003, M. Leponce, 1 worker (RBIN: 2420 Coll.RIScNB SID SPM_ID32154); Fortín Mayor Infante Rivarola, -21.67146 -62.41312, 02-06 2421 Nov. 2001, M. Leponce, 1 worker (RBIN: Coll.RIScNB SID SPM_ID30618); Mister Long, 242220.60386 -62.05053, 05-06 Nov. 2001, M. Leponce, 1 worker (RBIN: Coll.RIScNB SID 2423 SPM_ID25477); Mister Long, -20.60386 -62.05053, 17-18 Sep. 2003, T. Delsinne, 2 workers 

\#ibn 197, 1 worker (ALWC: USNMENT00757544); Itapúa: Isla Yacyretá E Melgarejo, -22.42 56.50, 11 Nov. 1997, B. Barrios \#ibn 217, 2 workers (ALWC: USNMENT00757891).

SURINAME: Paramaribo, Apr. 1959, I.v.d. Drif, 3 workers (MZUSP: USNMENT00757547).

Diagnosis. Brachymyrmex fiebrigi morphologically resembles B. depilis, because they both have short scapes that do not or just reach the posterior margin of the head, a gaster with dense

2434 pubescence, a yellowish body and eyes that are positioned on the cephalic midline.

2435 Brachymyrmex fiebrigi differs from B. depilis by its mesosoma, which usually bears several erect 2436 hairs, two on the pronotum and two on the mesonotum and by its geographic distribution, which 2437 ranges from the South of Mexico until Paraguay, including Cuba.

Lectotype and paralectotypes measurements $(\mathrm{mm})(\mathrm{n}=3) . \mathrm{HL}_{1} 0.35-0.37$; $\mathrm{HL}_{2}$ 0.23; HL 3 0.08$\mathrm{OI}_{2} 21.05-27.78$.

Additional material examined measurements $(\mathrm{mm})(\mathrm{n}=12) . \mathrm{HL}_{1}$ 0.32-0.46; HL 2 0.22-0.34; HL 3 
Manuscript submitted to: Organisms Diversity \& Evolution

Published version available; DOI: 10.1007/s13127-019-00406-2

Description. Head. Slightly longer than wide in full face view; posterior cephalic margin flat.

2450 Dorsum of the head with appressed hairs. Clypeus with a rounded anterior margin and five long,

2451 erect hairs of which a single, usually conspicuous hair is near the anterior margin, two hairs are in

2452 mediolateral position and two more near the toruli; other hairs on the clypeus are markedly

2453 shorter and appressed or decumbent. Toruli surpassing the posterior clypeal margin in oblique

2454 anterodorsal view. The scapes are short, usually approximately reaching the posterior margin of

2455 the head, and they bear appressed and decumbent hairs. Ocelli apparently absent. Eyes are

2456 positioned on the cephalic midline and have 6-9 ommatidia along their maximal diameter.

2457 Mesosoma. Typically with two erect hairs on the pronotum and two on the mesonotum. The

2458 mesonotum is not inflated and does not bulge dorsally above the pronotum in lateral view.

2459 Metanotal groove absent or narrower than the diameter of the metathoracic spiracles.

2460 Metathoracic spiracles dorsolateral in position, not protruding, and touching the propodeal suture.

2461 Dorsum of the propodeum flat and much shorter than the posterior slope. Propodeal spiracles

2462 circular, small and inconspicuous, positioned on the posterior propodeal margin slightly posterior

2463 of the middle of the propodeal slope. Legs with appressed hairs. Petiole short and inclined

2464 forward.

2465 Gaster. With dense pubescence and scattered suberect hairs at the eges of the segments.

2466 Color and sculpture. Body usually smooth, shiny and yellowish.

Distribution (supplementary material Fig. S19). Brachymyrmex fiebrigi is known from 
Manuscript submitted to: Organisms Diversity \& Evolution

Published version available; DOI: 10.1007/s13127-019-00406-2

2471 Biology. Some specimens have been collected from below stones (PSWC:

2472 USNMENT00757549); Forel (1908) suggested that this species nests in dry branches of bushes.

2474 Remarks. The lectotype is the second ant from the top on pin USNMENT00757164, whereas the

2475 other specimens on that pin are paralectotypes. Santschi (1922) considered B. fiebrigi var.

2476 funicularis as a variety of B. fiebrigi mainly based on its darker-colored funiculus and posterior

2477 segments of the gaster, but otherwise the type specimens of this variety are very similar in

2478 measurements, head shape, and gastric pubescence compared to the type material of B. fiebrigi.

2479 Overall, we consider these differences to represent intraspecific variation.

2480 Santschi (1923a) considered B. fiebrigi var. fumida as a variety that only differs from the typical

2481 B. fiebrigi by its somewhat darker body color, and the overall light yellowish scapes and tibia. As

2482 for B. fiebrigi var. funicularis we consider these differences to represent intraspecific variation

2483 and both varieties are synonymized here.

\section{Brachymyrmex flavidulus (Roger)}

Plagiolepis flavidula Roger, 1863: 162 (w.). Lectotype worker (MfNB: 19185: GBIF-

D/FoCol2900; GBIF-D/FoCol2910; here designated): 1 worker [examined]. CUBA. Attributed to Brachymyrmex by Smith (1955: 99). 
Manuscript submitted to: Organisms Diversity \& Evolution

Published version available; DOI: 10.1007/s13127-019-00406-2 2517 inclined forward.

2518 Gaster. With dense pubescence.

worker, 1 queen (JTLC: JTLC0000005251). JAMAICA: Trelawny: 5 km N Quick Step, 18.26667 -77.71667, 360 m, A.L. Wild \#AW1382, 1 worker (ALWC: USNMENT00757658).

Diagnosis. Brachymyrmex flavidulus resembles B. fiebrigi, B. giardi and B. depilis in that they all have short scapes that approximately reach the posterior margin of the head or surpass it by less than one maximal diameter of the eye, their gaster bears dense pubescence, their eyes are located on the cephalic midline and their bodies are yellowish. Brachymyrmex flavidulus differs from $B$. depilis and B. giardi by its mesonotum that does not bulge dorsally above the pronotum in lateral view, and from $B$. fiebrigi by the absence of erect hairs on the pronotum and mesonotum.

Description. Head. Slightly longer than wide in full face view; posterior cephalic margin slightly convex. Clypeus with a rounded anterior margin and five long, erect hairs of which a single, usually conspicuous hair is near the anterior margin, two hairs are in mediolateral position and two more near the toruli; other hairs on the clypeus are markedly shorter and appressed or decumbent. Toruli surpassing the posterior clypeal margin in oblique anterodorsal view. The scapes are short and barely reach the posterior margin of the head. Ocelli apparently absent. Eyes are positioned on the cephalic midline and have 7-9 ommatidia along their maximal diameter.

Mesosoma. Without erect hairs. The mesonotum does not bulge dorsally above the pronotum in lateral view. Metanotal groove absent. Metathoracic spiracles dorsolateral in position, not protruding, and touching the propodeal suture. Dorsum of the propodeum shorter than posterior slope. Propodeal spiracles circular, positioned on the posterior propodeal margin, slightly posterior of the middle of the propodeal slope. Legs with appressed hairs. Petiole short and 
Manuscript submitted to: Organisms Diversity \& Evolution

Published version available; DOI: 10.1007/s13127-019-00406-2

Color and sculpture. Body usually smooth, shiny and yellowish.

Distribution (Supplementary material Fig. S20). This species is known from Colombia, Costa

2522 Rica, Cuba and Jamaica.

2524 Biology. Unknown.

Remarks. Brachymyrmex flavidulus is a problematic species for several reasons. It was described by Roger (1863) as a species of Plagiolepis. Smith (1955) transferred it to Brachymyrmex,

2528 seemingly based in geographic reasons, i.e. that Plagiolepis is not native to the neotropics. We 2529 agree with the attribution to Brachymyrmex because the type of Brachymyrmex flavidulus has 9 2530 antennal segments, which is a diagnostic trait of Brachymyrmex, whereas Plagiolepis has 11 2531 antennal segments (Bolton 2003). The type series consist of a single individual of which the 2532 mesosoma and gaster are mounted on a pin, and the head is prepared on a microscope slide. This preservation hampers us to document the arrangement of hairs on scapes, head, and clypeus as

2534 well as the number of ommatidia in the maximal diameter of the eye.

2535 The worker on pin JTLC0000005251 is unusual in comparison to the other specimes of $B$.

2536 flavidulus in having sparser gastral pubescence and somewhat longer scapes. Additional material 2537 from Costa Rica would be required to adequately characterise the morphological variation in 2538 these populations, and to verify its species attribution.

2539 This species is morphologically very similar to B. fiebrigi. Brachymyrmex flavidulus lacks the 2540 erect hairs on the mesosoma that are present in B. fiebrigi, but as the number of specimens 2541 available of $B$. flavidulus is very limited we cannot currently comment on the consistency of this 
2542 difference. An in-depth comparison with B. fiebrigi is required when more specimens of $B$.

2543 flavidulus become available, especially from Cuba, where both species occur.

Brachymyrmex gagates Wheeler, 1934: 206 (w.). Lectotype worker (USNM:

Additional material examined. PANAMA: Colon: San Lorenzo Forest, 9.28333 -79.97194, J.

Schmidt \& J. Bail, fogging, 2 workers (ICN: USNMENT00759031).

Diagnosis. Brachymyrmex gagates resembles B. degener and B. gaucho in morphology, because they all have smooth, shiny, and dark brown or black bodies, scapes that surpass the posterior margin of the head, and a gaster with scarce pubescence. Brachymyrmex gagates differs from $B$.

2559 degener by its darker body and by having a mesonotum that is almost circular in dorsal view and 2560 that does not bulge above the pronotum in lateral view. It differs from B. gaucho by having a 2561 slightly concave posterior cephalic margin, scapes with decumbent hairs, a second segment of the 2562 antennal funiculus that is conspicuously shorter than the first antennal segment, and its almost 2563 circular mesonotum in dorsal view that does not bulge above the pronotum in lateral view. 
Manuscript submitted to: Organisms Diversity \& Evolution

Published version available; DOI: 10.1007/s13127-019-00406-2

Lectotype measurements (mm). HL $10.59 ; \mathrm{HL}_{2} 0.39 ; \mathrm{HL}_{3} 0.18$; HW 0.55; SL 0.51; EL 0.16; WL

0.59; PnL 0.18; PnW 0.39; ML 0.16; MW 0.20; Indices CI 93.33; SI 1 92.86; $\mathrm{SI}_{2}$ 130.00; OI

$28.57 ; \mathrm{OI}_{2} 30.00$.

Description. Head. Slightly longer than wide in full face view; posterior cephalic border slightly concave. Dorsum of the head with scattered appresed hairs. Clypeus with a rounded anterior margin and five long, erect hairs of which a single, usually conspicuous hair is near the anterior margin, two hairs are in mediolateral position and two more near the toruli; other hairs on the clypeus are markedly shorter and appressed or decumbent. Toruli surpassing the posterior clypeal margin in oblique anterodorsal view. The scapes bear decumbent hairs and surpass the posterior margin of the head by a length smaller than the maximal diameter of the eye. Three ocelli present. Eyes are positioned slightly posteriorly to the cephalic midline and have 10-12 ommatidia along their maximal diameter.

Mesosoma. Typically bearing two erect hairs on the pronotum and two on the mesonotum, sometimes with some additional appressed hairs on the dorsum of the mesonotum. The mesonotum is inflated but does not bulge dorsally above the pronotum in lateral view; it is almost circular in dorsal view. Metanotal groove wider than the diameter of the metathoracic spiracles. Metathoracic spiracles in dorsolateral position, protruding slightly, and either just or just not touching the propodeal suture. Dorsum of the propodeum convex and somewhat shorter than the posterior declivity. Propodeal spiracles circular, positioned on the posterior propodeal margin, anterior of the middle of the propodeal slope. Legs have appressed hairs. Petiole short and inclined forward.

Gaster. With scattered pubescence and several scattered long erect hairs. 
Manuscript submitted to: Organisms Diversity \& Evolution

Published version available; DOI: 10.1007/s13127-019-00406-2

2588 Color and sculpture. Head and gaster are smooth and shiny, whereas the dorsum of the

2589 mesosoma is slightly imbricate. Body uniformely dark brown, apart from the terminal segments

2590 of the tarsus and the hairs, which are lighter.

2591

2592 Distribution (Supplementary material Fig. S21). Brachymyrmex gagates is known from

2593 Mexico and Panama.

2594

2595

Biology. The type specimens were collected from an epiphytic bromelia (Tillandsia

2596 streptophylla) (Wheeler 1934).

Remarks. The lectotype is the ant at the top of pin USNM: USNMENT00529454, whereas the others on that pin are paralectotypes. Wheeler (1934) pointed out that B. gagates is similar to but nevertheless different from $B$. incisus (which is here synonymized to $B$. degener) of which he had specimens from Panama in his collection. He reported that B. gagates has a wider head, a much more prominent mesonotum, a more distinct and impressed promesonotal suture, longer funicular

2603 joints and darker body color. We are uncertain as to what he exactly implied about the 2604 promesonotal suture, because it is very distinctive in all Brachymyrmex species, and the 2605 mesonotum bulges dorsally above the pronotum in lateral view in $B$. degener whereas it does not 2606 in B. gagates (see diagnosis). We agree that generally B. incisus (and thus B. degener) generally have much lighter body color than B. gagates, but as mentioned in the remarks of B. degener and 2608 B. coactus the variation in body color in these species requires more detailed documentation. 
Manuscript submitted to: Organisms Diversity \& Evolution

Published version available; DOI: 10.1007/s13127-019-00406-2

\section{Brachymyrmex gaucho Santschi}

(Fig. 33, supplementary material Fig. S22)

Brachymyrmex gaucho Santschi, 1917: 283 (w.). (NHMB) [examined, but the type is severely damaged]. ARGENTINA: Córdoba: Unquillo, M. Birabén. Combination in Brachymyrmex (Bryscha) by Santschi (1923a: 674). See also: Quirán (2005: 767).

Diagnosis. Brachymyrmex gaucho is morphologically similar to B. antennatus because both have legs and antennae with erect hairs and a second segment of the antennal funiculus that is as long as or longer than the first. However, B. gaucho differs from B. antennatus by having a flat posterior cephalic margin, a dark brown body, erect hairs on the scape and the dorsum of the head, a mesonotum that bulges dorsally above the pronotum, and a gaster with scarce pubescence.

Description. Head. Almost equally wide as long in full face view; the posterior cephalic margin is flat and the posterior side of the head is wider than the anterior side. Dorsum of the head bears scattered erect hairs. Clypeus with a rounded anterior margin and five long, erect hairs of which a single, usually conspicuous hair is near the anterior margin, two hairs are in mediolateral position and two more near the toruli; other hairs on the clypeus are clearly shorter and decumbent. Toruli surpassing the posterior clypeal margin in oblique anterodorsal view. The scapes surpass the posterior cephalic margin by a length smaller than $1.5 \times$ the maximal diameter of the eye and have erect hairs. The second segment of the antennal funiculus is as long as or longer than the first. Three ocelli are present. Eyes are positioned on the cephalic midline and have 13-14 ommatidia along their maximal diameter. 
Mesosoma. With several thin, erect hairs. The mesonotum is inflated, anteroposteriorly inclined and bulges dorsally above the pronotum in lateral view. Metanotal groove usually absent, but when present narrower than the diameter of the metathoracic spiracles. Metathoracic spiracles in

\section{7} dorsolateral position, slightly protruding, and near the propodeal suture. Dorsum of the propodeum flat and equal in length to the propodeal slope. Propodeal spiracles circular, positioned just dorsally of the posterior propodeal margin and slightly posterior of the middle of the propodeal slope. Legs have suberect and erect hairs. Petiole short and inclined forward.

Gaster. With scattered pubescence and several scattered long erect hairs.

Color and sculpture. Head and gaster are smooth and shiny, whereas the dorsum of the mesosoma is imbricate. Body uniformly dark brown.

Distribution (Supplementary material Fig. S22). Brachymyrmex gaucho is currently only known from Argentina.

\section{Biology. Unknown.}

Remarks. The type specimen in the NHMB is damaged but Quirán deposited 3 workers belonging to this species from Argentina, Córdoba II-2001, E. Quirán, leg. at the NHMB, which we also examined. These specimens come from the same state as the type material, but they are no types. We studied these specimens, one of which is illustrated in Fig. 33. More type material would exist at the MACN (5 workers) and the MLP (1 worker) (Quirán 2005), but it is not studied here. 
Manuscript submitted to: Organisms Diversity \& Evolution

Published version available; DOI: 10.1007/s13127-019-00406-2

\section{Brachymyrmex giardi Emery}

(Fig. 34, supplementary material Fig. S23)

Brachymyrmex giardi Emery, 1895: 215 (w.q.). Lectotype worker (MSNG:

USNMENT00757220) and paralectotype workers, putative worker-queen intercaste, queen, male (MSNG: USNMENT00757218 - 00757220, MHNG: USNMENT00758105-00758109;

here designated): 6 workers, 9 putative worker-queen intercastes, 1 queen, 1 male [examined].

CHILE: Santiago de Chile. Emery (1906: 178) (m.).

= Brachymyrmex melensis De Zolessi et al., 1978: 26 (w.q.1.). URUGUAY: Cerro Largo: Melo. [not examined]. n. syn.

Additional material examined. CHILE: Valparaiso, 2 workers (MCZC: M.C.Z. Cotype22940).

Diagnosis. Brachymyrmex giardi resembles B. depilis and B. heeri as these species have a mesonotum that bulges dorsally above the pronotum in lateral view, and a gaster with dense pubescence. Additionally, B. giardi and B. depilis have bodies without erect hairs; they can be distinguished because B. giardi has dense decumbent pubescence on the head and mesosoma, usually a dark brownish body, and it is geographically restricted to Chile and Uruguay.

Furthermore, B. giardi differs from B. heeri by having short scapes, and no erect hairs on the pronotum or mesonotum.

Lectotype and paralectotype measurements $(\mathrm{mm})(\mathrm{n}=8)$. $\mathrm{HL}_{1}$ 0.45-0.68; $\mathrm{HL}_{2}$ 0.29-0.42; HL 3 0.10-0.32; HW 0.35-0.68; SL 0.33-0.59; EL 0.10-0.18; WL 0.39-0.89; PnL 0.10-0.21; PnW 0.250.57; ML 0.08-0.35; MW 0.16-0.52; Indices CI 78.26-105.00; SL1 84.85-100.00; SL2 113.33142.86; $\mathrm{OI}_{1} 23.53-33.33 ; \mathrm{OI}_{2} 21.74-50.00$. 
Manuscript submitted to: Organisms Diversity \& Evolution

Published version available; DOI: 10.1007/s13127-019-00406-2

2683 Worker description. Head. Slightly longer than wide in full face view; posterior cephalic

2684 margin is flat. Dorsum of the head has dense appressed hairs. Clypeus with a rounded anterior 2685 margin and five long, erect hairs of which a single, usually conspicuous hair is near the anterior 2686 margin, two hairs are in mediolateral position and two more near the toruli; other hairs on the 2687 clypeus are clearly shorter and appressed or decumbent. Toruli surpassing the posterior clypeal margin in oblique anterodorsal oblique view. The scapes surpass the posterior cephalic margin by

2689 a length smaller than the maximal diameter of the eye and have decumbent hairs. Three ocelli 2690 appear to be present. Eyes are positioned on the cephalic midline and have 7-9 ommatidia along 2691 their maximal diameter.

2692 Mesosoma. Without erect hairs. The mesonotum is inflated and bulges dorsally above the 2693 pronotum in lateral view. Metanotal groove usually absent, or narrower than the diameter of the 2694 metathoracic spiracles. Metathoracic spiracles in dorsolateral position, not protruding, and touching the propodeal suture. Dorsum of the propodeum slightly convex and shorter than the posterior propodeal margin. Propodeal spiracles circular, positioned on the posterior propodeal 2697 margin slightly posterior of the middle of the propodeal slope. Legs with appressed hairs. Petiole 2698 short and inclined forward.

2699 Gaster. With dense pubescence and scattered long erect hairs along the edges of the segments. 2700 Some specimens have the same morphology as a regular worker as to the head and mesosoma, 2701 but have a gaster that is somewhat expanded, i.e. they are somewhat physogastric.

2702 Color and sculpture. Body smooth and shiny, usually dark brownish with yellowish legs and 2703 pubescence. 
Manuscript submitted to: Organisms Diversity \& Evolution

Published version available; DOI: 10.1007/s13127-019-00406-2

2705 Intercaste description. The morphology of the putative worker-queen intercaste differs from

2706 that of the worker by its larger size, the eyes that have around 9 ommatidia along their maximal

2707 diameter, the pronotum that bears several semi-erect hairs, the enlargened mesonotum that does

2708 not bulge dorsally above the pronotum in lateral view, and that does not bear erect but several

2709 subdecumbent hairs, the sharper posterior ending of the mesonotum in dorsal view, the deep

2710 metanotal groove that is wider than the metathoracic spiracles, the almost laterally positioned

2711 metathoracic spiracles, that do not protrude and do not touch any suture, and the uniform

2712 yellowish body color (albeit with lighter-colored legs).

2713

2714 Distribution (Supplementary material Fig. S23). Brachymyrmex giardi is known to occur in

2715 Chile and Uruguay.

2717 Biology. The biology of B. giardi has not recently been studied, however Emery (1895) indicated 2718 that Prof. Giard observed an association between B. giardi and the coccid Margadores vitium. As 2719 to the biology of B. melensis, which we synonymize here with B. giardi, De Zolessi et al. (1978:

272039 ) provided detailed habitat information including specifications on the landscape, soil and 2721 vegetation. Their nest was subterranean, with several chambers between 15 and $50 \mathrm{~cm}$ deep, each 2722 chamber being about $3 \mathrm{~cm}$ high and 3 to $5 \mathrm{~cm}$ long and wide. Some repletes were found hanging 2723 from the roof together with normal workers as is observed in Mymecocystus hortideorum.

2725 Remarks. The second ant from the top in pin MSNG: USNMENT00757220 is designated here as 2726 lectotype, whereas the other specimens are paralectotypes. In the original description of $B$. giardi 2727 Emery (1895: 215) described a worker, a replete and a queen, and the replete is what we consider 2728 here as a putative worker-queen intercaste, because a regular queen was also reported by Emery 
2729 (1895). Note that this queen was indicated to be wingless, however, after studying the material

2730 we confirm that it represents a real queen rather than an ergatoid, and the replete has, as

2731 mentioned above, a hybrid morphology between queen and worker. Upon dissection of the

2732 abdomen of the replete Emery (1895: 215) reported that the crop is full of honey-like liquid, but

2733 also that the ovaries are more developed than in normal workers, and that these repletes likely

2734 have a reproductive function. Nevertheless, he considered nourishment their primary function, as

2735 is confirmed by De Zolessi et al. (1978). In summary, the exact affinity of these repletes is

2736 uncertain: if it were ergatoid queens we would not expect a regular queen to be present (Peeters

2737 1991), which points to an intercaste, because intercastes co-exist with a regular queen. However,

2738 intercastes do not usually participate in reproduction (Peeters 1991). Given all the available data,

2739 we consider these specimens for now to be a putative worker-queen intercaste, as mentioned

2740 before, but the intriguing issue of the repletes in B. giardi requires further study.

2741 We have not been able to locate the type material of B. melensis and have therefore studied it

2742 from the detailed work of De Zolessi et al. (1978). These authors subdivided the putative worker-

2743 queen intercaste into two categories: the first for specimens that resemble normal workers but

2744 have the gaster somewhat expanded, and the second for the putative intercaste, which displays a

2745 strongly enlargened gaster with the ability to store liquids. De Zolessi et al. (1978) indicate that

2746 B. melensis resembles B. physogaster Kusnezov (1960) most, a species here synonymized to $B$.

2747 heeri, but that both differ in size and in the number of ocelli (see additional differences in the

2748 diagnosis above). These authors did not compare B. melensis and B. giardi, but upon doing so we

2749 did not find any trait that allows distinguishing these taxa and hence we synonymize B. melensis

2750 here. Brachymyrmex giardi and B. heeri are indeed quite similar, not in the least by the presence

2751 of a putative worker-queen intercaste, and further in-depth study of both species is required. 
2752 Brachymyrmex giardi var. nitida was previously suggested to be a junior synonym of B. giardi 2753 (Snelling and Hunt 1975), but in our opinion, it is a junior synonym of B. bruchi (see above).

2754 Brachymyrmex giardi var. cordobensis on the other hand appears to be a junior synonym of $B$. 2755 heeri (see below).

2756

2757

2758 2759

\section{Brachymyrmex heeri Forel}

(Figs. 35, 36, supplementary material Fig. S24)

Brachymyrmex heeri Forel, 1874: 91, Figs. 16, 20 (w.). Lectotype worker (MHNG:

USNMENT00757169) and paralectotype workers, males, queen (MHNG:

USNMENT00757167-00757171, USNMENT00758116-00758120); here designated): 15 workers, 3 males, 1 queen [examined]. SWITZERLAND: Zurich: Serra des orchidiées. Forel (1876: 52) (q.m.). See also: Santschi (1923a: 664).

= Brachymyrmex goeldii Forel, 1912a: 65 (w.). (MHNG: USNMENT00757166): 1 worker

[examined]. BRAZIL: São Paulo: Botucatu. n. syn.

= Brachymyrmex giardi var. cordobensis Santschi, 1929: 309 (w.). (NHMB:

USNMENT00757698, 00757699, CASENT0911600): 23 workers [examined]. ARGENTINA: Cordoba: Alta Gracia. n. syn.

= Brachymyrmex physogaster Kusnezov, 1960: 382, Figs.1-4 (w.). (INSUE): 7 workers [examined]. ARGENTINA: Salta: National park Estancia El Rey. n. syn.

Additional material examined. ARGENTINA: Misiones: Loreto, C. Bruch, 1 worker (NHMB: USNMENT00758095). BOLIVIA: Santa Cruz: 10 km NW Terevinto, -17.67 -63.45, 380 m, 09 Dec. 1993, P.S. Ward \#12314-61, 2 workers (MCZC: USNMENT00757940); Buena Vista, - 
2779 Campo Limpo, faz conceição, -16.33083 -49.16367, 01-07 July 2005, R.R. Silva \& R.M. Feitosa, 27808 workers (ICN: MZSP120, 121); Minas Gerais: Serra Caraça, 1380 m, Oct. 1961, Martins \& 2781 Silva, 2 workers, 3 putative worker-queen intercastes (MZSP: USNMENT00757603); Serra 2782 Caraca, Kloss, Lenko, Nov. 1961, Martins \& Silva, 3 workers, 1 putative worker-queen intercaste (MCZC: USNMENT00757598); Pará: Melgaço, Caixiuanã, ECFPn, -1.77803 -51.42694, 27

2784 Nov.- 03 Dec. 2001, 2 workers (MPEG: USNMENT00757592, 00757550); Melgaço, Caixiuanã, 2785 ECFPn, -1.70661 -51.45909, 25-27 Oct. 2005, Equipe A.Y. Harada, 11 workers (MPEG: 2786 AYH057); Melgaço, Caixiuanã, ECFPn, -1.75444 -51.52241, 24-26 Jan. 2006, Equipe A.Y. Harada, 5 workers (MPEG: AYH023); Melgaço, Caixiuanã, ECFPn, -1.75444 -51.52241, 28 Oct. 2003, A.Y. Harada, E.P. Fagundes, C.J.M. Ribeiro, C.E.D. Sanhudo, C.A.R. Moura, J.L.P. Souza, C. Renato, 8 workers (MPEG: AYH083); Santa Catarina: São Bento do Sul, APA Rio Vermelho, -26.36417 -49.27111, 30 Mar.-04 Apr. 2001, R.R. Silva \& Everhardt, 2 workers (ICN: MZSP043); São Paulo: Barueri, K. Lenko, 4 workers, 1 queen (MZSP: USNMENT00757602); 2792 Caraguatatuba, Reserva Florestal, 13 July 1965, Exp. Dep. Zool. 3487, 4 workers, 1 queen 2793 (MZSP: USNMENT00757597); Cunha, PE Serra do Mar, Nucleo Cunha-Indara, -23.25083 45.00722, 21-22 Apr. 2001, A.A. Tavares \& R.R. Silva, 15 workers (ICN: MZSP151). 75.48947, 1837 m, 06-08 Aug. 2003, L.E. Franco \& J. Cruz, 2 workers (IAvH: IAvH27322); Aranzazu, Vereda La Guaira, Finca Alto Bonito, 5.27883 -75.48461, 2056 m, 25-26 July 2003, 2798 L.E. Franco \& J. Cruz, 1 worker (IAvH: IAvH27303); Aranzazu, Vereda Sabana Larga, Finca 2799 Las Colinas de Zega, 5.31713 -75.47556, 2000 m, 25-27 July 2003, L.E. Franco \& J. Cruz, 5 
workers, 1 queen (IAvH: IAvH25458, 25459); Salamina, Vereda El Cedrito, Finca El Cedrito, 5.33117 -75.46744, 1960 m, 27-29 Aug. 2002, L.E. Franco \& J. Cruz, 1 worker (IAvH:

Sanda \#22, 2 workers (ICN: USNMENT00757633); Quindio: Calarcá, Vereda Pradera Baja,

Finca La Holanda, 4.55694 -75.63917, 1575 m, 29 Nov. 1999, E. Gonzalez \& J. Sossa, 1 worker workers (IAvH: IAvH27228); Génova, Vereda El Cedral, Finca Buenos Aires, 4.235 -75.77556, 1600 m, 26 Oct. 1999, E. Gonzalez \& J. Sossa, 2 workers (IAvH: IAvH-E74166, 74167);

Risaralda: Apia, La María, Cafetal de sol (S-III), 3.13 -75.95, 1405 m, 28 Jan. 2002, L. Rivera, 1 worker (IAvH: IAvH-E74175); Pereira Vereda La Suiza, SFF Otún Quimbaya, 4.72800 intercaste (IAvH: IAvH27279); Pereira, Vereda La Suiza, Finca Pez Fresco, 1890 m, 22-24 Nov. 2002, E. Jimenez \& M.F. Reina, 1 worker (IAvH: IAvH27285); Valle del Cauca: Cairo, Vereda Llano Grande, Finca Encanto, 4.73603 -76.21698, 1650 m, 03 Apr. 2003, J. Henao, 1 worker (IAvH: IAvH25147); Medio Calima Campamento DR., C.H.M. Aldana, 1 worker (ICN: m, 09 Feb. 1989, J. Longino \#2342, 1 worker (INBIOCRI001280503); Heredia: 16 km N Vol. 

\#3578-s, 1 worker (JTLC: INBIO CRI001282749); 4 km S San Vito, 8.783 -82.967, 1200 m, 30 June 1995, J. longino \#3702-s, 1 worker (JTLC: INBIOCRI001280752); Sirena, Parque Nacional Corcovado, 8.467 -83.583, 0-100 m, 23 Sep. 1982, J. Longino, 1 worker (JTLC: workers, 1 queen (PSWC: USNMENT00757596); Zamora-Chinchipe: Copalinga, -4.09122 78.96069, 1000 m, 01-03 Oct. 2009, Delsinne \& Arias. FRENCH GUIANA: Basse Vie (Petit Saut), Aug. 1999, S. Dorou, 3 workers, 2 males (CPDC: USNMENT00757952).

GUATEMALA: El Progreso, 20 km N Estancia de la Virgen, 1800-1900 m, 08 June 1991, R.S. Anderson, 1 worker (JTLC: CASENT0601427); Sololá, 1 km N San Andrés, Semetabaj, 14.75 91.13, 1840 m, 16 Nov. 2003, A.L. Wild \#AW2059, A.L. Wild \#AW 2059, 3 workers (ALWC:

USNMENT00757942). MEXICO: Chiapas : 15.1 km N.W. Bochil, 17.09120 -92.99138, 1930 m, 24 Sep. 1992, R.S. Anderson, 1 worker (JTLC: CASENT0603200); 29 km E La Trinitaria, 16.106 -91.772, 1520 m, 21 July 2007, J. Longino \#6100, 1 worker (JTLC: JTLC000010323); 3.8 km ESE Custepec, 15.71205 -92.93387, 1900 m, 18 July 2007, J. Longino \#6072-2, 2 workers, 1 queen, 1 male (JTLC: JTLC000010342, 000010343); Jalisco: 6.76 km SW Mazamitla, 19.89222 $2845-103.07722,1997$ m, 22 June 2000, W. \& E. MacKay, 1 worker, 1 male (WEMC: 2846 USNMENT00757739); Nuevo León: nr Monterrey, Mesa de Chipinque, 1365 m, 16-18 July 2847 1965, 2 workers, 1 queen (MCZC: USNMENT00757666); Veracruz: 2.7 km N Teocelo, 1128 
Coscomatepec, 05 June 1988, W. MacKay \#10844, 2 workers, 1 male (WEMC:

PANAMA: Canal zone: 3 km NW Gamboa, 9.13333 -79.71667, 40 m, 10 Dec. 1983, P.S. Ward 1997, A. Wild \#AW0477, \#AW0478, 3 workers, 1 queen (ALWC: USNMENT00757543, 
Manuscript submitted to: Organisms Diversity \& Evolution

Published version available; DOI: 10.1007/s13127-019-00406-2

2871

2872

2873

2874

2875

2876

2877

2878

2879

2880

2881

2882

2883

2884

2885

2886

2887

2888

2889

2890

2891

2892

2893

2894

dense pubescence. However, B. heeri differs from B. depilis and B. giardi by having scapes that surpass the posterior margin of the head.

Lectotype and paralectotypes measurements $(\mathrm{mm})(\mathrm{n}=5) . \mathrm{HL}_{1}$ 0.39-0.43; HL 2 0.27-0.30; HL 3

0.10; HW 0.35-0.41; SL 0.37-0.39; EL 0.10-0.11; WL 0.39-0.45; PnL 0.10; PnW 0.25-0.31; ML

0.08-0.12; MW 0.16-0.20; Indices CI 90.00-100.00; SI 1 90.48-111.11; SI2 126.67-142.86; OI1

23.81-27.78; $\mathrm{OI}_{2} 22.72-25.00$.

Additional material examined measurements $(\mathrm{mm})(\mathrm{n}=5)$. HL 1 0.41-0.60; HL 2 0.27-0.39; HL 3

0.10-0.13; HW 0.40-0.66; SL 0.36-0.52; EL 0.09-0.19; WL 0.35-0.68; PnL 0.11-0.16; PnW 0.27-

0.45; ML 0.09-0.21; MW 0.18-0.35; Indices CI 93.75-110.81; SI1 78.05-93.62; SI2 114.29-

135.71; $\mathrm{OI}_{1} 21.74-29.27 ; \mathrm{OI}_{2}$ 16.22-28.00.

Description. Head. Slightly longer than wide in full face view; posterior cephalic margin slightly concave. Clypeus with a rounded anterior margin and five long, erect hairs of which a single, usually conspicuous hair is near the anterior margin, two hairs are in mediolateral position and two more near the toruli; other hairs on the clypeus are markedly shorter and appressed or decumbent. Toruli surpassing the posterior clypeal margin in oblique anterodorsal view. The scapes surpass the posterior margin of the head by a length smaller than the maximal diameter of the eye; they bear decumbent hairs. Ocelli absent. Eyes are positioned on the cephalic midline and have 6-7 ommatidia along their maximal diameter.

Mesosoma. With several decumbent hairs and usually two erect hairs on the pronotum and two on the mesonotum, but sometimes those on the mesonotum or on both are absent. The mesonotum is inflated and bulges dorsally above the pronotum in lateral view. Metanotal groove 
Manuscript submitted to: Organisms Diversity \& Evolution

Published version available; DOI: 10.1007/s13127-019-00406-2

absent or narrower than the diameter of the metanotal spiracles. Metathoracic spiracles in

dorsolateral position, not protruding, and touching the propodeal suture. Dorsum of the

propodeum convex and shorter than the propodeal slope. Propodeal spiracles circular, positioned

on the posterior propodeal margin, slightly posterior of the middle of the propodeal slope. Legs

with appressed hairs. Petiole short and inclined forward.

2900 Gaster. With dense pubescence and scattered long erect hairs at the edges of the segments. Some specimens of $B$. heeri resemble the regular worker in head and mesosoma, but they have a strongly expanded gaster (physogastry).

Color and sculpture. Head and gaster smooth, dorsum of the mesosoma with imbricate sculpture, body opaque and yellowish, sometimes with a somewhat darker gaster.

Distribution (Supplementary material Fig. S24). We have studied B. heeri from localities in Argentina, Bolivia, Brazil, Colombia, Costa Rica, Ecuador, French Guiana, Guatemala, Mexico, Nicaragua, Panama, Paraguay, Uruguay, Venezuela and from populations that were introduced in Switzerland. Santschi (1923a) also reported this species from Puerto Rico, Jamaica, Haiti and

2910 Guyana, but we have not studied this material.

2912 Biology. Brachymyrmex heeri was originally described from specimens collected in a tropical 2913 orchid greenhouse in Switzerland (Forel 1874). The species was found climbing on various

2914 plants, and was associated with aphids, but the nest was not located. Santschi (1929) reported that 2915 the nest of the type specimens of B. giardi var. cordobensis was found at the base of a tree, and $B$ 2916 physogaster was collected in the heavily humic, finely loamy soil in the shadow of trees, where 2917 both excessive moisture and eventual drought are unlikely (Kusnezov 1960). 
Manuscript submitted to: Organisms Diversity \& Evolution

Published version available; DOI: 10.1007/s13127-019-00406-2

2919 Remarks. The lectotype is designated here as the ant in the middle of their holder MHNG:

2920 USNMENT00757169, whereas the other specimens are paralectotypes. Forel (1874) described

2921 the worker of B. heeri, but did not indicate physogastry in his description, and Santschi (1923a)

2922 did not comment on this issue neither. In the description of B. giardi var. cordobensis (which is

2923 here synonymized under B. heeri) Santschi (1929) refered to physogastric specimens, and also to

2924 'worker-queens' with a strongly expanded gaster. He does not provide any additional description

2925 of these worker-queen specimens, but upon examination of this material and other samples of $B$.

2926 heeri we exclusively found worker-like specimens with a normal or robust mesosoma and an

2927 expanded gaster. These specimens do not have morphological features reminiscent of a queen,

2928 but rather differ from regular workers by having a larger body size, a subquadrate head, with the

2929 posterior cephalic margin slightly concave to almost flat, scapes that barely reach the posterior

2930 margin of the head, three ocelli, eyes that have approximately 11 ommatidia along their maximal

2931 diameter, a deep metanotal groove that is wider than the diameter of the metathoracic spiracles,

2932 and as already mentioned, a strongly expanded gaster. To exclude the possibility that the museum

2933 samples we studied reflect a mixture of two species, we sequenced specimens of both morphs,

2934 and found them to be genetically very similar. In summary, B. heeri either has dimorphic

2935 workers, or a putative worker-queen intercaste, and whereas we consider the first scenario more

2936 likely (because we did not find specimens with a hybrid worker-queen morphology), the issue

2937 requires more study. These observations also apply to $B$. physogaster, and this species and $B$.

2938 giardi var. cordobensis are synonymized here with $B$. heeri because they contain all its

2939 morphological features. Forel (1912a) distinguised B. goeldii from other Brachymyrmex species

2940 principally based on the form of the head, and he mainly compared it with B. bruchi, however,

2941 this material appears to belong to a 'robust worker' of B. heeri. Interestingly, as for B. heeri

2942 before, Forel (1912a) does not mention physogastry. 
Manuscript submitted to: Organisms Diversity \& Evolution

Published version available; DOI: 10.1007/s13127-019-00406-2

2943 Two varieties have been assigned to B. heeri, namely B. heeri var. fallax, and B. heeri var.

2944 basalis. As indicated before, B. heeri var. fallax is attributed here to B. aphidicola, and B. heeri

2945 var. basalis is synonymized under B. pictus (see below) here.

2946 It is noteworthy that $B$. heeri has a wide geographic distribution and a study of the morphological

2947 variation within the species in a molecular and geographic context would be required. Likewise,

2948 it would be interesting to study the biology of the various morphs within a colony, including the

2949 underlying developmental processes and their distribution and behavior within the colony.

2950 Indeed, some colleagues (Kusnezov 1960) have labeled physogastric specimens here assigned to

2951 B. heeri as honey pot workers and have observed them hanging from the ceiling of the chambers

2952 of the nest, as in Myrmecocystus, and B. melensis (see B. giardi above). However, why

2953 physogastry is present in some Brachymyrmex species, but not in others remains unclear.

2954 Kusnezov (1960) suggested that it may relate to a trophobiotic lifestyle, whereas others suggested

2955 it is an adaptation to periodically arid conditions or food scarcity (Forel 1902; Wheeler 1910).

2956 However, Creighton (1950), argued exactly the opposite by suggesting that physogastry may

2957 develop when a xerophyte species encounters and adapts to less arid and more resource-rich

2958 habitats. Clearly, more work on this issue is required, but as mentioned above, the habitat from

2959 which B. physogaster was reported by Kusnezov (1960) does not appear to confirm the 'scarcity

2960 hypothesis'. This future work should perhaps also consider potential intrinsic causes of

2961 physogastry beyond the putative environmental drivers discussed above. 
2966 Holotype worker (MZSP: USNMENT00757758) and paratype workers (MZSP:

2967 USNMENT00757757): 5 workers. BRAZIL: Santa Catharina, Chapecó, July 1960, F.

2968 Plaumann 9878.

Additional material examined. ARGENTINA: Misiones: Parque Nacional Iguazú, -25.71847 -

2971 54.43319, 23 Sep. 1999, Leponce, Roisin \& Theunis, 1 worker (MACN: MACN_En 18283,

2972 MACN_En 18201, MACN_En 18242); Parque Nacional Iguazú, 1 worker (RBINS: Coll.

2973 RIScNB SID SPM_ID01612). BRAZIL: Parana: Londrina, Nov. 2004, D.T. Lopes, 1 worker

2974 (CPDC: USNMENT00757755); Santa Catharina: Teutônia, June 1961, F. Plaumann, 8219, 3

2975 workers (MZSP: USNMENT00757756).

2977 Etymology: The epithet iridescens refers to the conspicuous iridescent appearance of this species 2978 under stereoscope illumination.

Diagnosis. Brachymyrmex iridescens morphologically resembles B. santschii, because both have conspicuous, strongly alveolate sculpture on the head and mesosoma. However, they differ from one another because $B$. iridescens has a metanotal groove that is narrower than the diameter of 2983 the metathoracic spiracles, scapes that approximately reach the posterior margin of the head, and 2984 a gaster with dense pubescence.

Holotype and paratype measurements $(\mathrm{mm})(\mathrm{n}=2) . \mathrm{HL}_{1}$ 0.40-0.43; $\mathrm{HL}_{2} 0.29-0.30 ; \mathrm{HL}_{3} 0.09$;

$2988 \quad$ - 0.11; MW 0.13-0.16; Indices CI 85.42-86.67; SI180.95-82.5; SI 2 100.00; OI 1 23.81-25.00; OI 2 
Manuscript submitted to: Organisms Diversity \& Evolution

Published version available; DOI: 10.1007/s13127-019-00406-2

2990

2991 Additional material examined measurements $(\mathrm{mm})(\mathrm{n}=2) . \mathrm{HL}_{1}$ 0.37-0.42; HL $0.26-0.30$; HL 3

2992 0.07-0.11; HW 0.29-0.38; SL 0.28-0.30; EL 0.09; WL 0.39-0.42; PnL 0.12 - 0.13; PnW 0.22-

2993 0.22; ML 0.09-0.11; MW 0.13-0.18; Indices CI 78.57-89.36; SI 1 80.95-93.94; SI 100.00-106.90;

$2994 \quad \mathrm{OI}_{1} 23.81-30.30 ; \mathrm{OI}_{2}$ 19.05-25.53.

2995

2996 Description. Head. Slightly longer than wide in full face view; posterior cephalic margin slightly

2997 concave or flat. Dorsum of the head with decumbent hairs. Clypeus with a rounded anterior

2998 margin and five long, erect hairs of which a single, usually conspicuous hair is near the anterior

2999 margin, two hairs are in mediolateral position and two more near the toruli; other hairs on the

3000 clypeus are markedly shorter and appressed or decumbent. Toruli surpassing the posterior clypeal

3001 margin in oblique anterodorsal view. The scapes are short and approximately reach the posterior

3002 margin of the head; they have decumbent and suberect hairs. Three ocelli are present. Eyes are

3003 positioned on the cephalic midline and have 8-9 ommatidia along their maximal diameter.

3004 Mesosoma. With several decumbent hairs, and on the pronotum some suberect hairs. The

3005 mesonotum is inflated and bulges dorsally above the pronotum. The metanotal groove is

3006 narrower than the diameter of the metathoracic spiracles. Metathoracic spiracles dorsal, slightly

3007 protruding, and not touching the mesonotal nor propodeal suture. Dorsum of the propodeum

3008 slightly convex and shorter than the propodeal slope. Propodeal spiracles circular, positioned on

3009 the posterior propodeal margin at the middle of the propodeal slope. Legs with appressed hairs.

$3010 \quad$ Petiole short and inclined forward.

3011 Gaster. With decumbent, dense pubescence and several scattered long erect hairs.

3012 Color and sculpture. Head and thorax finely alveolate, gaster smooth and shiny. The body is 3013 uniformly brownish. 
Distribution (supplementary material Fig. S25). Brachymyrmex iridescens is known from Argentina and Brazil.

Biology. Unknown.

Remarks. Brachymyrmex iridescens resembles B. santschii, but their distributions are strongly

\section{Brachymyrmex micromegas Emery}

Brachymyrmex (Bryscha) micromegas Emery in Santschi, 1923a: 675, Figs. 30, 32 (w.).

major workers (MCSN: USNMENT00757222-00757223; MZSP: USNMENT00758145-

Magalhães, L.T.F.M. Kulman, 1 minor worker (MZSP: USNMENT00757834). 
3038 Diagnosis. Brachymyrmex micromegas morphologically resembles B. pilipes because both species have a dimorphic worker caste, a clypeus with a row of long thick hairs near the anterior

3040 margin, toruli that touch the posterior clypeal margin, but never surpass it in oblique anterodorsal 3041 view, and tumuliform metathoracic spiracles. However, B. micromegas differs from B. pilipes by 3042 having a smooth and shiny body, with very fine longitudinal striations restricted to the 3043 metapleura.

3044

Description. See Ortiz and Fernández (2014).

Brachymyrmex minutus Forel

(Fig. 39, supplementary material Fig. S27)

Brachymyrmex minutus Forel, 1893: 346 (w.q.). Lectotype worker (MHNG:

ANTILLES: Saint Vincent. See also: Santschi (1923a: 667).

Additional material examined. BOLIVIA: Santa Cruz: Aserradero Moira, -14.57 -61.20, 180 (MCZC: USNMENT00757305); 10 km NW Terevinto, -17.67 -63.45, 380 m, 09 Dec. 1993, P.S. Ward \#12314-62, \#12314-63, 2 workers (PSWC: USNMENT00757870), 5 workers (MCZC: USNMENT00757303-00757304); 35 km SSE Flor de Oro, -13.833 -60.867, 450 m, 29 Nov. 1993, P.S. Ward \#12199-73, 7 workers (MCZC: USNMENT00757301 - 00757302); Las Gamas,

3060 Parque Natural Noel Kempff Mercado, -14.80 -60.38, 700 m, 03 Dec. 1993, P.S. Ward \#12266- 
3062

3063

3064

3065

3066

3067

3068

3069

3070

3071

3072

3073

3074

3075

3076

3077

3078

3079

3080

3081

3082

3083

3084

3085

Kempff Mercado P, -14.80 -60.38, 700 m, 04 Dec. 1993, P.S. Ward \#12266-45, 6 workers

(MCZC: USNMENT00757297-00757298). BRAZIL: Ceará: Guaramiranga (Pq. Tr.), -4.267 -

38.933, 900 m, 22 Feb. 2002, Y. Quinet, 1 worker (CPDC: USNMENT00757874); Goias:

Campo Limpo, faz conceição, -16.33083 -49.16367, 20-24 Jan. 2005, R.R. Silva, 9 workers

(ICN: MZSP071); Campo Limpo, faz conceição, -16.33083 -49.16367, 01-07 July 2005, R.R.

Silva \& R.M. Feitosa, 15 workers (ICN: MZSP120 - MZSP121); Pará: Belem, 07 Aug. 1962,

P.F. Doulington. B.F. 14, 1 worker (MCZC: USNMENT00757256); Melgaço, Caxiuanã ECFPn,

-1.70661 -51.45909, 10-12 Oct. 2006, Equipe A.Y. Harada, 1 worker (MPEG: AYH018); 10-11

Oct. 2006, 1 worker (MPEG: AYH019); 10-12 Oct. 2005, 7 workers (MPEG: AYH041); 24-26

Jan. 2007, 6 workers (MPEG: AYH003, 069, 115, 122, 124); 28-30 Jan. 2006, 5 workers

(MPEG: AYH001, 007); 23-25 Apr. 2007, 1 worker (MPEG: AYH005); A.Y. Harada, E.P.

Fagundes, C.J.M. Ribeiro, C.E.D. Sanhudo, C.A.R. Moura, J.L.P. Souza, C. Renato, 3 workers

(MPEG: AYH076); -1.72484 -51.42979, 26 Oct. 2006, A.Y. Harada, E.P. Fagundes, C.J.M.

Ribeiro, C.E.D. Sanhudo, C.A.R. Moura, J.L.P. Souza, C. Renato, 45 workers 1 Queen (MPEG:

AYH005, 016, 032, 052, 053, 068, 070, 078, 087, 093, 097, 100, 102, 106, 113, 136); 12-14 Oct.

2006, Equipe A.Y. Harada, 1 worker (MPEG: AYH045); 20-22 July 2006, 2 workers (MPEG:

AYH095); 20-22 Oct. 2005, 2 workers (MPEG: AYH082, 105); 21-23 Oct. 2005, 1 workers

(MPEG: AYH006); 22-24 Apr. 2005, 2 workers (MPEG: AYH082, 105); 23-25 Feb. 2006, 1

worker (MPEG: AYH033); 24-26 July 2003, 10 workers (MPEG: AYH066, 084, 108, 119, 133,

135); 26-28 Nov. 2003, A.Y. Harada, E.P. Fagundes, C. Renato, 1 worker (MPEG: AYH117);

07-09 Feb. 2003, 1 worker (MPEG: AYH060); Melgaço, Caxiuanã ECFPn, -1.73360 -51.51054,

27 Oct. 2003, Equipe A.Y. Harada, 3 workers (MPEG: AYH014, 061); Melgaço, Caxiuanã

ECFPn, -1.73360 -51.51053, 27 Oct. 2003, A.Y. Harada, E.P. Fagundes, C.J.M. Ribeiro, C.E.D.

Sanhudo, C.A.R. Moura, J.L.P. Souza, C. Renato, 3 workers (MPEG: AYH101, 035, 050); 14-16 

2006, 1 worker (MPEG: AYH104); 12-14 Oct. 2006, Equipe A.Y. Harada, 3 workers (MPEG: AYH051); Melgaço, Caxiuanã ECFPn, -1.73584 -51.48762, 30 Oct. 2003, A.Y. Harada, E.P. Fagundes, C.J.M. Ribeiro, C.E.D. Sanhudo, C.A.R. Moura, J.L.P. Souza, C. Renato, 1 worker (MPEG: AYH091); 13-15 Oct. 2005, Equipe A.Y. Harada, 5 workers (MPEG: AYH031, 056); 15-17 Jan. 2006, 1 worker (MPEG: AYH132); 21 Apr. 2006, 1 worker (MPEG: AYH080); 22-24 July 2006, 1 worker (MPEG: AYH121); 23-25 Oct. 2005, 3 workers (MPEG: AYH017, 027, 030); 23-28 Oct. 2005, 1 worker (MPEG: AYH022); 25-27 Jan. 2006, 1 worker (MPEG: AYH128); 26-28 Jan. 2007, 2 workers (MPEG: AYH075); -1.75444 -51.52241, 28 Jan. 2003, AY Harada, E.P. Fagundes, C.J.M. Ribeiro, C.E.D. Sanhudo, C.A.R. Moura, J.L.P. Souza, C. Renato, 1 worker (MPEG: AYH011); 28 Oct. 2003, 10 workers (MPEG: AYH028, 079, 089, 092, 118); 01-03 Nov. 2004, Equipe A.Y. Harada, 1 worker (MPEG: AYH020); 01-05 Nov. 2004, 1 worker (MPEG: AYH004); 19-21 Oct. 2007, 1 worker (MPEG: AYH026); 20-22 July 2007, 3 workers (MPEG: AYH025, 065); 22-24 Oct. 2003, 1 worker (MPEG: AYH085); 22-24

3100 Oct. 2005, 2 workers (MPEG: AYH110, 123); 24-26 Oct. 2006, 1 worker (MPEG: AYH040); 3101 Melgaço, Caxiuanã ECFPn, -1.78155 -51.59197, 24-26 Oct. 2007, 1 worker (MPEG: AYH009); 310230 July-01 Aug. 2003, 2 workers (MPEG: AYH010); 02 Oct. 2006, A.Y. Harada, E.P. Fagundes, 3103 C.J.M. Ribeiro, C.E.D. Sanhudo, C.A.R. Moura, J.L.P. Souza, C. Renato, 2 workers (MPEG: AYH077); 30 Oct. 2003, 2 workers (MPEG: AYH125, 130); 02 Nov. 2003, 1 worker (MPEG: AYH120); 12-14 Oct. 2006, Equipe A.Y. Harada, 1 worker (MPEG: AYH054); 14-16 Oct. 2006, 31061 worker (MPEG: AYH043); 15-17 Oct. 2006, 1 worker (MPEG: AYH055); 15-17 Oct. 2010,16 3107 workers (MPEG: AYH013, 024); 23-25 Apr. 2003, 1 worker (MPEG: AYH096); 23-25 July 3108 2007, 6 workers (MPEG: AYH002, 042, 072); 23-25 May 2003, 1 worker (MPEG: AYH114); 3109 24-26 July 2006, 2 workers (MPEG: AYH015); 25-27 Jan. 2007, 2 workers (MPEG: AYH064, 
090); 25-27 June 2007, 1 worker (MPEG: AYH012); 30 July-01 Aug. 2003, 3 workers (MPEG:

AYH103, 131); 30 July-01 Aug. 2003, A.Y. Harada, E.P. Fagundes, C. Renato, 2 workers N0388, 2 workers (MPEG: USNMENT00757865, 00757866); São Paulo, Jundiai, Serra Do Japi, Jan. 2009, S. Diniz, 3 workers (ICN: USNMENT00759044); São Paulo: Tapirai, -24.03208

3115 -47.46556, 08-14 Jan. 2001, R.R. Silva \& Everhardt, 1 worker, 2 males (ICN: MZSP172).

3116 COLOMBIA: Amazonas: Leticia, 1 worker (ICN); Parque Nacional Natural Amacayacu,

3117 Matamata, -3.68 -70.25, 150 m, 23 Oct. 2000, 1 worker (ICN); Cundinamarca: La Vega, 3118 Reserva Natural Natautá, 5.00 -74.33, 1040 m, 10 Nov. 2010, F. Fernández, 1 worker (ICN:

3119 USNMENT00757873); Magdalena: 4 km N San Pedro, 10.95 -74.05, 550 m, 14 Aug. 1985, P.S. 3120 Ward \#7912-35, 3 workers (PSWC: USNMENT00757863); Norte de Santander: 2 km N 3121 Barrancabermeja, Dec. 1962, leafmodd Berles. J. Archer; Quindio: Buenavista, Vereda El 3122 infierno, Finca Guadalajara, 4.37667 -75.76944, 1160 m, 16 Nov. 1999, E. Gonzalez, 3 workers 3123 (IAvH: IAvH-E74164); Calarca, Vereda Santo Domingo, Finca Santa Librada, 4.55694 3124 75.63917, 1575 m, 16 Jan. 2000, J. Sosa, 5 workers, 1 queen (IAvH: IAvH-E74163, 74157); 3125 Circasia, Vereda Buenavista, Finca Calamar, 4.59806 -75.69861, 1450 m, 12 Oct. 1999, E. 3126 Gonzalez, 2 workers (IAvH: IAvH-E74168); Risaralda: La Celia, 5.00361 -76.00444, 1900 m, 312727 Jan. 2011, Gustavo Zabala, 2 workers (ICN); Valle del Cauca: Cairo, Vereda Vallecitos, 3128 Finca El Maladero, 4.75803 -76.22732, 1850 m, 29 Mar. 2003, J. Henao, 1 worker (IAvH:

3129 IAvH25152); Vichada: Cumaribo, Corregimiento Santa Rita, PNN El Tuparro, 5.3075 -67.9500, 3130135 m, 14-16 Feb. 2004, I. Quintero \& E. Gonzalez, 1 worker (IAvH: USNMENT00759055).

3131 COSTA RICA: Heredia: Estación Biológica La Selva, 10.43691 -84.01374, 50 m, 19 Mar. 93, 3132 J. Longino, 1 worker (JTLC: JTLC000007845); La Selva, 12 June 1991, L.E. Tennant, 2 workers 3133 (MCZC: USNMENT00757284, 00757285); Puntarenas: Estación Biológica Los Llanos, 

1980, J. Longino, 1 worker (MCZC: USNMENT00757289); Parque Natural Corcovado, Sirena, 8.48333 -83.60000, 10 m, 27 June 1982, J. Longino, 1 worker (JTLC: JTLC000005929); San José: San Jose, 9.933 -84.083, 1100 m, 14 June 1999, J. Longino \#4040-s, 1 worker (JTLC:

3139 LACM ENT 143521). CUBA: Holguín: 2 km N La Melba, 20.467 -74.817, 400 m, 22 Aug. 2001, P.S. Ward \#14424-16, 3 workers (PSWC: USNMENT00757862); Manicaragua: Trinidad

3141 Mts, 01 Aug. 1953, E. O. Wilson \#65, 3 workers, 1 queen (MCZC: USNMENT00757295).

3142 DOMINICAN REPUBLIC: 16 km ENE Pedernales, 18.1167 -71.6167, 800 m, 10 Sep. 1992, 3143 P.S. Ward \#11751-16, 3 workers (PSWC: USNMENT00757872). ECUADOR: Pichincha:

3144 Reserva Forestal ENDESA, 0.083 -79.033, 25 Jan. 1994, L.E. Tennant, 3 workers MCZC: 3145 USNMENT00757293, 00757869); Reserva Forestal ENDESA, 0.13 -79.05, 600 m, 05 Dec. 3146 2003, A. L. Wild \#AW2195, 1 worker (ALWC: USNMENT00757861); Zamora-Chinchipe: 3147 Copalinga, -4.09122 -78.96069, 1000 m, 28-30 Sep. 2009, Delsinne/Arias, col id 35155, 35161, 314815 workers (RBINS: Coll.RIScNB SID SPM_ID3515505, 3516111); 30 Sep.- 02 Oct. 2009, 3149 Delsinne/Arias, col id 34651, 39654, 3 workers (RBINS: Coll.RIScNB SID SPM_ID3465109, 3150 3465404); 01-03 Oct. 2009, Delsinne/Arias, col id34663, 34671, 34673, 14 workers (RBINS: 3151 Coll.RIScNB SID SPM_ID3466304, 3467107, 3467305); 07 Oct. 2009, Delsinne/Arias, col Id 3152 34715, 34733, 29 workers (RBINS: Coll.RIScNB SID SPM_ID3471501, 3473311); 04-06 Oct. 3153 2009, Delsinne/Arias, col id34695, 34703-34705, 34709), 19 workers (RBINS: Coll.RIScNB SID 3154 SPM_ID3469506, 3470305, 3470405, 3470504, 3470909); 05-07 Oct. 2009, Delsinne/Arias, col 3155 id34746, 34751, 34753, 5 workers (RBINS: Coll.RIScNB SID SPM_ID3474605, 3475106, 3156 3475305). FRENCH GUIANA: Araguez, Inselbery forest, Sara Groc, 3 workers (ICN:

3157 USNMENT00757864); Kaw Mountains, Oct. 2008, Sara Groc, 2 workers (ICN: 
3159 GUATEMALA: Zacapa: 8.5 km NE Tuculután, 15.058717 -89.67638, 1100 m, 06 July 2001, J.

3160 Longino \#6016-s, 1 worker (JTLC: JTLC000009864). MEXICO: Oaxaca: 7.2 km S Valle

3161 Nacional, 490 m, 11-18 Aug. 1973, A. Newton, 2 workers (MCZC: USNMENT00757286,

3162 00757287); Veracruz: Los Tuxtlas, 10 km NNW Sontecomapan, 18.583 -95.083, 500 m, 21

3163 Mar. 1995, P.S. Ward \#1369-39, 2 workers (PSWC: USNMENT00757871); Sa. Teoviscocla, nr.

3164 Cuichapa to 1600 m trop. For w. coffe, 04 Aug. 1965, Cornell Univ. Mexico Field Party, 6

3165 workers, 1 queen (MCZC: USNMENT00757290, 00757291, 00757296). PANAMA: Barro

3166 Colorado I., Canal Zone, Jan. 1960, m-16 Strays, W.L. Brown, E.S. McCluskey, 1 worker

3167 (MCZC: USNMENT00757288); PARAGUAY: Canindeyú: Reserva Natural del Bosque,

3168 Mbacarayù, Jejuimi, -24.1 -55.5, 02 May 1996, A. Wild \#0132, 3 workers, 1 queen (ALWC:

3169 USNMENT00757601); 11 Feb. 1997, A. Wild \#AW 0409, 1 worker (ALWC:

3170 USNMENT00757860). PERU: Madre de Dios: Reserva Nacional Tambopata, Centro

3171 Sachavacayoc, -12.85583 -69.36194, 19-31 July 2012, curso de hormigas, 7 workers (ICN:

3172 JSC120726-LS01). SURINAME: Tambahredjo, June 1959, I. V. d. Drift, 1 worker (MPEG:

3173 USNMENT00757876). VENEZUELA: Aragua: Parque Nac. Henri Pittier, La Toma, 10.34924

$3174-67.68251,1169$ m, 09-19 Aug. 2008, Ant Course, 3 workers, 1 queen (ICN:

3175 USNMENT00757600, 00758023); Rancho Grande, 1100 m, 23-27 June 1967, W.L. Brown, 1

3176 worker (MCZC: USNMENT00757294); 12 Aug. 1967, R.W. Poole, 3 workers (MCZC:

3177 USNMENT00757875).

3178

3179 Diagnosis. Brachymyrmex minutus morphologically resembles B. australis, B. aphidicola and B.

3180 termitophilus, because all these species have eyes located on the cephalic midline, a mesonotum

3181 that does not bulge dorsally above the pronotum in lateral view, and yellowish body color. 
Manuscript submitted to: Organisms Diversity \& Evolution

Published version available; DOI: 10.1007/s13127-019-00406-2

3182 Brachymyrmex minutus differs from the three other species, or any other Brachymyrmex species

3183 for that matter, by having a very inconspicuous mesometanotal suture, giving the impression that

3184 the mesonotum and metanotum are fused. Additionally, B. minutus differs from B. termitophilus

3185 by having scattered pubescence on the gaster, from B. aphidicola by the presence of only two

3186 erect hairs on the pronotum and from B. australis by having scapes that surpass the posterior

3187 margin of the head by a length that is smaller than the maximal diameter of the eye.

3189 Lectotype and paralectotypes worker measurements $(\mathrm{mm})(\mathrm{n}=4) . \mathrm{HL}_{1}$ 0.37-0.40; $\mathrm{HL}_{2}$ 0.25-0.31;

3190 HL $30.07-0.10$; HW 0.32-0.36; SL 0.32-0.36; EL 0.08-0.11; WL n.a.; PnL n.a.; PnW 0.20-0.24;

3191 ML 0.06-0.07; MW 0.14-0.15; Indices CI 85.88-89.29; SI 1 92.59-108.00; SI 2 107.14-126.67; OI

$3192 \quad 26.03-29.63 ; \mathrm{OI}_{2} 20.00-25.27$.

3194 Description. Head. Slightly longer than wide in full face view; posterior cephalic margin weakly

3195 convex. Dorsum of the head with sparse hairs. Clypeus with a rounded anterior margin and five

3196 long, erect hairs of which a single, usually conspicuous hair is near the anterior margin, two hairs

3197 are in mediolateral position and two more near the toruli; other hairs on the clypeus are markedly

3198 shorter and appressed or decumbent. Toruli surpassing the posterior clypeal margin in oblique

3199 anterodorsal oblique view. The scapes surpass the posterior margin of the head by a length that is

3200 smaller than the maximal diameter of the eye; they have appresed pubescence. Ocelli absent.

3201 Eyes are positioned on the cephalic midline and have 8-9 ommatidia along their maximal

3202 diameter.

3203 Mesosoma. Typically with two erect hairs on the pronotum and without erect hairs on the

3204 mesonotum. The mesonotum is not inflated and does not bulge dorsally above the pronotum in

3205 lateral view. Mesometanotal suture inconspicuous, giving the impression that the mesonotum and 
metanotum are fused. Metanotal groove absent or narrower than the diameter of the metathoracic spiracles. Metathoracic spiracles in dorsolateral position, not protruding, and touching the propodeal suture. Dorsum of the propodeum slightly convex and shorter than the propodeal slope.

3209 Propodeal spiracles circular, positioned on the posterior propodeal margin, just dorsally at the 3210 middle of the propodeal slope. Legs with appressed and scattered hairs. Petiole short and inclined 3211 forward.

3212 Gaster. With scarce pubescence and several scattered long suberect hairs.

3213 Color and sculpture. Body smooth, or finely granulated and shiny, sometimes with some 3214 imbricate sculpture on the dorsum of the mesosoma. Body usually yellowish, but sometimes 3215 reddish.

3217 Distribution (Supplementary material Fig. S27). Brachymyrmex minutus is known to occur in

3218 Bolivia, Brazil, Colombia, Costa Rica, Cuba, the Dominican Republic, Ecuador, French Guiana, 3219 Guatemala, Mexico, Panama, Paraguay, Peru, Suriname and Venezuela.

Biology. Forel (1893) found several colonies subterraneous at the roots of sod, usually where it

3222 overgrows rocks, typically within the forest and/or nearby streams. The nest of $B$. minutus

3223 consists of large tunnels with small chambers at intervals. Colonies contain $\sim 50$ to 100

3224 individuals, with a single queen.

3225

3226 Remarks. The lectotype is designated here as the second ant counting from the top of pin

3227 MHNG: USNMENT00757150, whereas the other specimens on that pin are paralectotypes. 
Forel (1893) admitted having confused this species for B. heeri before but provided several morphological differences. However, B. minutus is morphologically more similar to the species 3230 indicated here in the diagnosis.

3231

3232

3233

3234

3235

3236

3237

3238

3239

3240

3241

3242

3243

3244

3245

3246

3247

3248

3249

3250

3251

\section{Brachymyrmex modestus Santschi}

(Fig. 40, supplementary material Fig. S28)

Brachymyrmex modestus Santschi, 1923b: 271 (w.). Lectotype worker (NHMB:

USNMENT00758099) and paralectotype workers (NHMB: USNMENT00758099, 00758100;

here designated): 3 workers [examined]. BRAZIL: Santa Catarina: Blumerau, A.

Reinchensperguer leg.

Additional material examined. BRAZIL: Santa Catarina: Palhoça, PE Serra do Tabuleiro, 27.74111 -48.69722, 02-10 June 2003, R.R. Silva, B.H. Dietz \& A. Tavares, 1 worker (ICN: MZSP033); São Bento do Sul, APA Rio Vermelho, -26.36417 -49.27111, 30 Mar.-04 Apr. 2004, R. Silva \& Eberhardt, 8 workers (ICN: MZSP138); São Paulo: Cunha, PE Serra do Mar, Nucleo Cunha-Indara, -23.25083 -45.00722, 21-22 Apr. 2001, A.A. Tavares \& R.R. Silva, 12 workers (ICN: MZSP149); Praia grande, PE Serra do Mar, nucleo pilhões-Cubatão, -23.9753 -46.5400, 26-27 May 2001, A.A. Tavares \& R.R. Silva, 5 workers (ICN: MZSP165). COLOMBIA:

Amazonas: Leticia, Reserva Forestal del Rio Calderón, Estación Biológica El Zafre, -4.00583, 69.89861, 150 m, 02-04 Dec. 2007, L.E. Franco \& S. Florez, 2 workers (IAvH); Caldas: Aranzazu, Vereda Chambery, Finca Los Planes, 5.29231 -75.47283, 1910 m, 01-03 Aug. 2003, L.E. Franco \& Cruz, 1 worker (IAvH: IAvH27307); Finca maranduba, 5.30731 -75.47250, 2050 m, 30 July-01 Aug. 2003), L.E. Franco \& Cruz, 2 workers (IAvH: IAvH27288); Vereda La Guiaira, Finca Villa Ofelia, 5.286 -75.465, 1965 m, 01-03 Aug. 2003, L.E. Franco \& Cruz, 1 

75.47281, 1920 m, 31 July-02 Aug. 2003, L.E. Franco \& Cruz, 3 workers (IAvH: IAvH55442);

3254 Quindio: Circasia, Finca Calamar, 4.60 -75.70, 1450 m, 12 Oct. 1999, E. Gonzalez, 1 worker 3255 (IAvH: IAvH 74169); Filandia, Vereda Cruces, Finca Aranjuez, 4.70826 -75.64679, 1750 m, 13 325615 July 2002, E. Jiménez \& L.E. Franco, 2 workers (IAvH: IAvH27261); Finca La Cha, 4.70468 $3257-75.60982,1920$ m, 28-30 Aug. 2002, E. Jiménez \& L.E. Franco, 1 worker, 1 queen (IAvH: IAvH27233); 4.69617 -75.61056, 1920 m, 28-30 Aug. 2002, E. Jiménez \& L.E. Franco, 2 workers (IAvH: IAvH27239); Risaralda: Pereira, Vereda El Manzano, Finca Santa Isabel, 4.70515 -75.62377, 1860 m, 15-17 July 2002, E. Jiménez \& L.E. Franco, 3 workers (IAvH: IAvH27234); Vereda La Suiza, Finca El Amparo de Niños, 4.74624 -75.59830, 1810 m, 28-30 Nov. 2002, L.E. Franco, 3 workers (IAvH: IAvH27273); 4.75013 -75.60278, 1780 m, 26-28 Nov. 2002, L.E. Franco \& E. Londoño, 2 workers (IAvH: IAvH27281); Finca Pez Fresco, 4.73838 75.58016, 1910 m, 22-24 Nov. 2002, E. Jiménez \& M.F. Reina, 1 worker, 1 queen (IAvH: IAvH27275); Finca Tesorito, 4.72141 -75.56186, 1940 m, 27-29 Nov. 2002, E. Jiménez, L.E.

3266 Franco \& E. Londoño, 2 workers, 1 queen (IAvH: IAvH27280); Santuario, 26 Feb. 2003, 1 3267 worker (IAvH: IAvH27286). ECUADOR: Pichincha: Maquipucuna, 5 km, ESE Nanegal, 32680.11667 -78.63333, 1500 m, 17 Aug. 1991, P.S. Ward \#11503-19, 5 workers (MCZC:

3269 USNMENT00757255, 00757283).

Diagnosis. Brachymyrmex modestus morphologically resembles B. donisthorpei and B. myops 3272 because these species have short dense hairs on the head and the mesosoma, short suberect hairs 3273 on the scapes, eyes below the cephalic midline of the head, the metanotal groove is either absent 3274 or narrower than the diameter of the metathoracic spiracles, their gaster bears dense pubescence, 3275 and their bodies are yellowish. Brachymyrmex modestus differs from B. donisthorpei by having 
Manuscript submitted to: Organisms Diversity \& Evolution

Published version available; DOI: 10.1007/s13127-019-00406-2

3276 scapes that surpass the posterior margin of the head, and from B. myops by having a mesonotum that bulges dorsally above the pronotum in lateral view.

Lectotype and paralectotypes measurements $(\mathrm{mm})(\mathrm{n}=3) \mathrm{HL}_{1}$ 0.49-0.51; HL 2 n.a.; HL 3 0.14-0.16; HW 0.45; SL 0.43; EL 0.08-0.09; WL 0.49-0.55; PnL 0.10-0.14; PnW 0.29-0.39; ML 0.08-0.16; MW 0.20-0.25; Indices CI 88.46 - 92.00; SI1 95.65; SI2 n.a.; OI1 17.39-19.57; OI2 20.00-25.27. 133.33; $\mathrm{OI}_{1} 15.56-18.61 ; \mathrm{OI}_{2} 23.53-27.66$.

Description. Head. Slightly longer than wide in full face view; posterior cephalic margin flat. Dorsum of the head with appresed and several suberect hairs. Clypeus with a rounded anterior margin and five long, erect hairs of which a single, usually conspicuous hair is near the anterior margin, two hairs are in mediolateral position and two more near the toruli; other hairs on the clypeus are markedly shorter and appressed or decumbent. Toruli surpassing the posterior clypeal margin in oblique anterodorsal view. The scapes surpass the posterior margin of the head by a length approximately equal to the maximal diameter of the eye and bear decumbent hairs. Ocelli appear to be absent. Eyes are positioned below the cephalic midline and have 3-4 ommatidia 3296 along their maximal diameter. Mesosoma. Usually with two erect hairs on the pronotum and two on the mesonotum; sometimes 3298 additional decumbent hairs are present, mainly on the pronotum. The mesonotum is inflated, 3299 somewhat anteriorly inclined, and bulges dorsally above the pronotum in lateral view. Metanotal 
3300 groove usually absent or narrower than the diameter of the metathoracic spiracles. Metathoracic

3301 spiracles small and in dorsolateral position, not protruding, and touching the proprodeal suture.

3302 Dorsum of the propodeum convex and shorter than the propodeal slope. Propodeal spiracles

3303 circular and positioned on the posterior propodeal margin, ventrally and slightly posterior of the

3304 middle of the propodeal slope. Legs with appressed hairs. Petiole short and inclined forward.

3305 Gaster. With dense pubescence and some long erect hairs at the edges of the segments.

3306 Color and sculpture. Head and gaster smooth and shiny, dorsum of the mesosoma slightly

3307 imbricate. Body yellowish, with the gaster sometimes being darker in color.

3309 Distribution (Supplementary material Fig. S28). Brachymyrmex modestus is known from

3310 Brazil, Colombia and Ecuador.

3312 Biology. The type material of B. modestus was collected in association with termites (Santschi 3313 1923b).

3315 Remarks. The here designated lectotype is the specimen without expanded gaster on pin NHMB:

3316 USNMENT00758099, whereas the other specimen is one of the paralectotypes.

3317 Santschi (1923b) mentioned the presence of physogastric workers in B. modestus, and we also 3318 observed some physogastric individuals in other samples (ICN: MZSP138, 149). These

3319 specimens are characterized by having a larger body in comparison to regular workers, and they 3320 have shorter scapes that barely reach the posterior margin of the head. 
Brachymyrmex tristis r. musculus Forel, 1899: 124 (w.). Lectotype worker (MHNG: 135). See also: Santschi (1923a: 673).

3334 (CASC: CASENT0196018). COLOMBIA: Quindio: Filandia, Vereda Cruces, Finca Los Micos, 4.70239 -75.64665, 1800 m, 12-14 July 2002, E. Jimenez \& L.E. Franco, 1 worker (IAvH: IAvH27235). COSTA RICA: Puntarenas: Monteverde, 10.301 -84.806, 1500 m, 27 June 1984, J. Longino, 2 workers, 1 queen (JTLC: JTLC000005951, JTLC000005953). MEXICO: Mexico, 6.5 km E Chalma, 26 May 1988, W.P. MacKay \#10386, 1 worker, 2 males, 33391 queen (WEMC: USNMENT00759016). PARAGUAY: Amambay: Pedro Juan Caballero, 3340 22.567 -55.617, 20 Aug. 1998, A. Wild \#AW0642, 1 worker (ALWC: USNMENT00757965). 3341 VENEZUELA: Lara: 9 km SE Barbacoas, 9.77 -71.06, 2000 m, 22 Aug. 1987, P.S. Ward $3342 \quad$ \#8923, 3 workers (PSWC: USNMENT00757589).

Diagnosis. Brachymyrmex musculus morphologically resembles B. bruchi, B. patagonicus and B.

3345 oculatus, because all four species have scapes that surpass the posterior margin of the head, a 3346 mesonotum that does not bulge dorsally above the pronotum in lateral view, a gaster with 3347 scattered pubescence and a brownish body. However, B. musculus differs from the three other 
Manuscript submitted to: Organisms Diversity \& Evolution

Published version available; DOI: 10.1007/s13127-019-00406-2

3348 species by having a metanotal groove that is wider than the diameter of the metathoracic

3349 spiracles.

3350

3351 Lectotype and paralectotype measurements $(\mathrm{mm})(\mathrm{n}=5) . \mathrm{HL}_{1}$ 0.43-0.48; HL $20.30-0.33 ; \mathrm{HL}_{3}$

3352 0.10-0.11; HW 0.39-0.42; SL 0.39-0.42; EL 0.10-0.12; WL 0.42-0.46; PnL 0.11; PnW 0.25-0.29;

3353 ML 0.08-0.10; MW 0.18-0.20; Indices CI 87.16-91.26; $\mathrm{SI}_{1}$ 98.92-100.00; $\mathrm{SI}_{2}$ 117.65-136.76; OI

$3354 \quad 23.16-30.00 ; \mathrm{OI}_{2} 21.10-23.81$.

3355

3356

Additional material examined measurements (mm) (n=3) HL $10.48-0.51$; $\mathrm{HL}_{2}$ 0.33-0.37; HL 3

3357

0.10-0.12; HW 0.44-0.47; SL 0.43-0.47; EL 0.12-0.14; WL 0.35-0.51; PnL 0.10-0.14; PnW 0.30-

3358

3359

0.32; ML 0.10-0.12; MW 0.19-0.20; Indices CI 89.09-92.59; SI1 97.87-102.04; SI2 125.00-

131.58; $\mathrm{OI}_{1} 26.00-30.61 ; \mathrm{OI}_{2} 21.15-24.07$.

3360

3361

Description. Head. Slightly longer than wide in full face view; posterior cephalic margin slightly

concave. Dorsum of the head has sparse appressed hairs. Clypeus with the medial anterior margin somewhat forming a lip and five long, erect hairs of which a single, usually conspicuous hair is near the anterior margin, two hairs are in mediolateral position and two more are near the toruli; other hairs on the clypeus are markedly shorter and appressed or decumbent. Toruli surpassing the posterior clypeal margin in oblique anterodorsal view. The scapes surpass the posterior cephalic margin with a length up to the maximal diameter of the eye; with appressed hairs. Three ocelli are present but inconspicuous. Eyes are positioned on the cephalic midline with 9-11 ommatidia along their maximal diameter.

3370 Mesosoma. Typically with two erect hairs on the pronotum and two on the mesonotum; 3371 sometimes with additional suberect hairs mainly on the pronotum. The mesonotum is not inflated 
3372 and does not bulge dorsally above the pronotum in lateral view. Metanotal groove wider than the

3373 diameter of the metathoracic spiracles. Metathoracic spiracles in dorsolateral position, not

3374 protruding, and close to the propodeal suture. Dorsum of the propodeum convex and shorter than

3375 the posterior propodeal slope. Propodeal spiracles circular, positioned on the posterior propodeal

3376 margin at the middle of the propodeal slope. Legs with appressed hairs. Petiole short and inclined

3377 forward.

3378 Gaster. With scattered pubescence and several scattered long erect hairs.

3379 Color and sculpture. Body overall smooth and shiny, except for the sometimes slightly imbricate 3380 sculpture on the dorsum of the mesosoma. Body typically brownish, however, the bulbi of the 3381 antennae are whitish, and the antenna and legs, especially the tarsi, are somewhat lighter in color 3382 than the body.

3384 Distribution (Supplementary material Fig. S29). Brachymyrmex musculus is known from 3385 Argentina, Colombia, Costa Rica, Mexico, Paraguay and Venezuela.

Biology. Unknown.

3389 Remarks. The lectotype is here designated as the ant at the top of pin MHNG:

3390 USNMENT00757155, whereas the other specimens in the pin are paralectotypes.

3391 Forel (1899) originally described B. musculus as a race of B. tristis, but later indicated that the 3392 difference in size urged him to elevate it to a separate species (Forel 1901a). We agree with this

3393 decision, because B. tristis differs from B. musculus by having dense decumbent hairs on the 3394 head and the dorsum of the mesosoma, a mesonotum that bulges dorsally above the pronotum, 3395 and metathoracic spiracles that protrude slightly. 

60.867, 450 m, 29 Nov. 1993, P.S. Ward \#12199-74, 5 workers (MCZ: USNMENT00757254, 00757892), 3 workers (PSWC: USNMENT00758027); BRAZIL: Amazonia: Rondonia, Jerau, R.M. Feitosa, 5 workers (ICN: MZSP178); Pará: Belém, 07 Aug. 1962, P.F. Doulington. B.F. 14, 1 worker (MCZC: USNMENT00757257); 14 Aug. 1962, P.F. Doulington. B.F. 19, 2 workers 3410 (MCZC: USNMENT00757258); 14 Aug. 1962, P.F. Doulington. B.F. 19, 1 worker (MCZC: 3411 USNMENT00757259); Melgaço, Caxiuanã ECFPn, -1.70661 -51.45909, 01 Nov. 2003, A.Y. 3412 Harada, E.P. Fagundes, C.J.M. Ribeiro, C.E.D. Sanhudo, C.A.R. Moura, J.L.P. Souza, C. Renato, 34131 worker (MPEG: AYH094); 10-12 Oct. 2006, Equipe A.Y. Harada, 1 worker (MPEG:

3414 AYH046); 10-12 Oct. 2007, Equipe A.Y. Harada, 2 workers (MPEG: AYH038); 20-22 Oct. 3415 2006, Equipe A.Y. Harada, 8 workers (MPEG: AYH058); 20-22 Oct. 2007, Equipe A.Y. Harada, 34164 workers (MPEG: AYH021, 047, 059); 25-27 Oct. 2007, Equipe A.Y. Harada, 3 workers 3417 (MPEG: AYH039, 048, 099); -1.73584 -51.48762, 13-15 Oct. 2005, Equipe A.Y. Harada, 5 3418 workers (MPEG: AYH037); 25-27 Jan. 2007, Equipe A.Y. Harada, 1 worker (MPEG: AYH111); $3419-1.78155$-51.59753, 15-17 Oct. 2007, Equipe A.Y. Harada, 3 workers (MPEG: AYH013, 044); 

24-26 Oct. 2007, Equipe A.Y. Harada, 1 worker (MPEG: AYH029); 25-27 Jan. 2007, Equipe

3421 A.Y. Harada, 1 worker (MPEG: AYH062); 27-29 Jan. 2006, Equipe A.Y. Harada, 5 workers

3422 (MPEG: AYH034); 30 July-01 Aug. 2003, Equipe A.Y. Harada, 13 workers (MPEG: AYH134);

3423 A.Y. Harada, E.P. Fagundes, C. Renato, 3 workers (MPEG: AYH129). COLOMBIA: Cauca:

3424 PNN Gorgona, Mancora, 2.967 -78.183, 60 m, 02 Feb. 2000, D. Campos, 16 workers (IAvH). 3425

3426 Diagnosis. Brachymyrmex myops morphologically resembles B. donisthorpei and B. modestus 3427 because all three species have dense short hairs on the head and mesosoma, scapes with short 3428 suberect hairs, eyes that are positioned below the cephalic midline of the head, a metanotal 3429 groove that is absent or narrower than the diameter of the metathoracic spiracles, a gaster with 3430 dense pubescence, and yellowish body color. However, B. myops differs from B. donisthorpei by 3431 having scapes that surpass the posterior margin of the head and from $B$. modestus by having a 3432 mesonotum that does not bulge dorsally above the pronotum.

Lectotype measurements (mm) HL $\mathrm{HL}_{1}$ 0.41; $\mathrm{HL}_{2}$ 0.29; HL 3 0.12; HW 0.37; SL 0.35; EL 0.06; WL 0.41; PnL 0.14; PnW 0.25; ML 0.12; MW 0.20; Indices CI 90.48; SI 1 94.74; $\mathrm{SI}_{2}$ 120.00; OI 1 15.79; $\mathrm{OI}_{2} 28.57$.

n.a.; HW 0.33-0.34; SL 0.34-0.36; EL 0.05-0.06; WL 0.36; PnL 0.09-0.10; PnW 0.22-0.23; ML 
3443 Description. Head. Slightly longer than wide in full face view; posterior cephalic margin slightly 3444 concave. Dorsum of the head with appressed and several suberect hairs. Clypeus with a rounded 3445 anterior margin and five long, erect hairs of which a single, usually conspicuous hair is near the 3446 anterior margin, two hairs are in mediolateral position and two more are near the toruli; other 3447 hairs on the clypeus are markedly shorter and appressed or decumbent. Toruli surpassing the 3448 posterior clypeal margin in oblique anterodorsal view. The scapes surpass the posterior margin of 3449 the head by a length approximately equal to the maximal diameter of the eye and have decumbent 3450 and suberect hairs. Ocelli absent. Eyes are positioned below the cephalic midline and have 3-4 3451 ommatidia along their maximal diameter.

3452 Mesosoma. Usually two erect hairs on the pronotum and two on the mesonotum; sometimes 3453 decumbent hairs are present, mainly on the pronotum. The mesonotum is somewhat inflated, but 3454 it does not bulge dorsally above the pronotum in lateral view. Metanotal groove absent or 3455 narrower than the diameter of the metathoracic spiracles. Metathoracic spiracles inconspicuous, 3456 in dorsolateral position, not protruding, and not touching any suture. Dorsum of the propodeum 3457 weakly convex and much shorter than the propodeal slope. Propodeal spiracles circular but 3458 inconspicuous, positioned on the posterior propodeal margin, slightly posterior of the middle of 3459 the propodeal slope. Legs with appressed hairs. Petiole short and inclined forward.

3460 Gaster. With dense pubescence and several long erect hairs, mainly along the edges of the 3461 segments.

3462 Color and sculpture. Head and gaster smooth and shiny, dorsum of the mesosoma slightly 3463 imbricate. Body usually uniformly yellowish, but sometimes with a darker gaster

3465 Distribution (Supplementary material Fig. S30). Brachymyrmex myops is known from Bolivia, 3466 Brazil and Colombia. 
Manuscript submitted to: Organisms Diversity \& Evolution

Published version available; DOI: 10.1007/s13127-019-00406-2

3468 Biology. Emery (1906) described B. myops from specimens that were collected in the nest of the 3469 termite Anoplotermes ater.

Remarks. The worker on pin NHMB: USNMENT00757221 is designated here as the lectotype.

3472 Brachymyrmex myops has been described from one worker and a male, which makes it currently 3473 impossible to determine the intraspecific variation. Brachymyrmex modestus has also been

3474 collected from termite nests, has a very similar geographic distribution as B. myops, and both 3475 species resemble one another morphologically (see diagnosis). They differ in whether the 3476 mesonotum bulges dorsally above the pronotum in lateral view, which is a trait of diagnostic 3477 value to delimit several Brachymyrmex species, however, the conditions in B. myops and B. 3478 modestus are not strongly different, and both species may be conspecific.

3479

3480

3481

3482

3483

3484

3485

3486

3487

3488 3489

\section{Brachymyrmex nebulosus LaPolla \& Longino}

(Fig. 43, supplementary material Fig. S31)

Brachymyrmex nebulosus LaPolla and Longino, 2006: 299, Fig. 1 (w.). COSTA RICA:

Puntarenas: $6 \mathrm{~km}$ south of Monteverde, 10.25 -84.82, 800 m, 22 June 1999, J. Longino \#4050, LACM ENT 143550 (INBC).

Paratype examined. COSTA RICA: Puntarenas: Ojo de agua, rd to Monteverde, 800 m, 05 July 1991, J. Longino, leg. (JTLC \#2965), 2 workers (INBIO). 
Manuscript submitted to: Organisms Diversity \& Evolution

Published version available; DOI: 10.1007/s13127-019-00406-2

3490

3491

3492

3493

3494

3495

3496

3497

3498

3499

3500

3501

3502

3503

3504

3505

3506

3507

3508

3509

3510

3511

3512

3513

Additional material examined. MEXICO: Chiapas: Sierra Morena, 16.15427 -93.58961, 1150

m, 11 May 2008, J. Longino \#6218-s, 2 workers (JTLC: JTLC0000007379; CASENT0609689).

Diagnosis. Brachymyrmex nebulosus differs from other Brachymyrmex species in having a

clypeus with its medial portion forming a conspicuous "lip", its hour-glass shaped mesosoma and it has portions of the head and mesosoma that bear alveolate sculpture. Brachymyrmex musculus is the only other Brachymyrmex species known to date that has a clypeus with a somewhat developed medial lip, but it is less conspicuous than in B. nebulosus.

Paratype measurements (mm). HL1 0.67; HL2 0.40; HL 30.24 ; HW 0.63; SL 0.62; EL 0.18; WL 0.80; PnL 0.29; PnW 0.45; ML 0.26; MW 0.23; Indices CI 94.67; SI 1 97.18; SI2 153.33; OI 28.17; $\mathrm{OI}_{2} 36.00$.

Additional material examined measurements (mm) $(\mathrm{n}=1)$. $\mathrm{HL}_{1} 0.80 ; \mathrm{HL}_{2} 0.49 ; \mathrm{HL}_{3} 0.23$; HW 0.73; SL 0.72; EL 0.20; WL 0.92; PnL 0.31; PnW 0.50; ML 0.12; MW 0.27; Indices CI 91.11; SI1 98.78; SI $111.76 ; \mathrm{OI}_{1} 15.79 ; \mathrm{OI}_{2}$ n.a.

Description. See LaPolla and Longino (2006).

Distribution (supplementary material Fig. S31). This species is known from Costa Rica and Mexico.

Biology. Brachymyrmex nebulosus was collected from sites at about $800 \mathrm{~m}$ elevation in moist forest at the transition between lowland dry forest and cloud forest. All collected workers were 
3514 obtained from open scrubby vegetation. In the field, these ants look and behave remarkably like

3515 Crematogaster (LaPolla and Longino 2006).

Remarks. Brachymyrmex nebulosus has been originally described from Costa Rica, but during our studies we came across two specimens from Mexico that very strongly resemble this species.

3519 The only differences are that the Mexican specimens have a more squared head, and stronger alveolate sculpture on the head and the dorsum of the mesosoma. Considering these differences and the geographical distribution, these Mexican specimens may be a variety of B. nebulosus, or potentially a different species, although more material and further study would be required to resolve this issue.

Brachymyrmex heeri var. obscurior Forel, 1893: 345 (w.q.m.). Lectotype worker (MHNG:

Additional material examined. ARGENTINA: Chubut: $3 \mathrm{~km} \mathrm{~N}$. Puerto Lobos, 20 m, 14 Dec. 
workers, 1 queen (MCZC: USNMENT00757659); Itirapina, cerrado, Dec. 2008, D.P. Silva, 3 workers (ICN: USNMENT00759042); Ubatuba, Picinguaba, July 2011, 2 workers (ICN: (IAvH); Huila: 17 km NW La Plata, 03 Jan. 1984, W.P. MacKay \#7133, 1 worker (WEMC: USNMENT00759021); 17km N La Plata, 03 Jan. 1984, W.P. MacKay \#7139, 1 worker 1 queen 11.33 -74.03, 30 m, 18-20 Aug. 2002, M. Sharkey, P. Arias \& E. Torres, 7 workers (IAvH);

Valle del Cauca: Cairo, vereda Llano Grande, Finca Encanto, 4.73620 -76.21698, 1550 m, 31 km NW Bonao, 19.03333 -70.48333, 890 m, 31 Aug. 2001, A.L. Wild \#AW1324, 2 workers \#AW1339, 1 worker (ALWC: USNMENT00757657); Casabito For. El Rio - Bona Km 8, 07 Feb. 1975, W.L.\& D.E. Brown, 2 workers (MCZC: USNMENT00757664). FRENCH GUIANA: 20 km Sinnamary, 12 Feb 1994, A. Dejean \#17025, 2 workers (ICN: USNMENT00757660). GUATEMALA: El Progreso: 5 km El Rancho, 14.9167 -90.0667, 400 m, 17 Nov. 2003, P.S. Ward \#15076-3, 3 workers (PSWC: USNMENT00757667); Escuintla: Escuintla, 30 Dec. 1911, W.M. Wheeler, 3 workers (MCZC: USNMENT00759001). JAMAICA: Manchester, Gourie 3557 Forest Res., 18.20 -77.52, 860 m, 10 Sep. 2001, A.L. Wild \#AW1375, 1 worker (ALWC: 3558 USNMENT00757669). MEXICO: Chiapas: Custepec, 15.72196 -92.95037, 1530 m, 19 May 3559 2008, J. Longino \#6280, 1 worker, 1 queen (JTLC: JTLC000007437, JTLC 000007438); Jalisco: 35607 km SW Tamazula, 19.68056 -103.32194, 992 m, 22 June 2000, W. \& E. Mackay, 2 workers 3561 (WEMC: USNMENT00757729). NEW CALEDONIA: Road to My. Koghi, Dec. 1985, N.L.H. 
Manuscript submitted to: Organisms Diversity \& Evolution

Published version available; DOI: 10.1007/s13127-019-00406-2

3562

3563

3564

3565

3566

3567

3568

3569

3570

3571

3572

3573

3574

3575

3576

3577

3578

3579

3580

3581

3582

3583

3584

3585

Krauss, ANTC10279, 1 worker (CASC: CASENT0196021). UNITED STATES: Florida:

Sarasota Co. Longino Ranch. T38S, R22E Sect, 27.15 -82.12, 20 m, 07 June 1981, J. Longino, 2

workers (JTLC: JTLC0000005943); Texas: Del Mar, 26.01167 -97.31861, 26 Sep. 1972, W.S.

Ross, ANTC 10263 10264, 2 workers (CASC: CASENT0196005, 0196006).

Diagnosis. Brachymyrmex obscurior morphologically resembles B. cordemoyi and $B$.

patagonicus because all three species have a metanotal groove that is absent or narrower than the diameter of metathoracic spiracles, their mesonotum does not bulge dorsally above the pronotum, their scapes usually surpass the posterior margin of the head, and their bodies are brownish.

Brachymyrmex obscurior and B. cordemoyi differ from B. patagonicus, however, because they have dense pubescence on the gaster. Brachymyrmex obscurior differs from B. cordemoyi by having less conspicuous dense pubescence on the dorsum of the head and the mesosoma, dense decumbent pubescence on the gaster, and eyes with fewer ommatidia along their maximal diameter (on average 9 instead of 10-12).

Lectotype and paralectotypes workers measurements $(\mathrm{mm})(\mathrm{n}=8)$. HL $10.39-0.47$; $\mathrm{HL}_{2}$ 0.27-0.35; HL3 0.10-0.12; HW 0.35-0.48; SL 0.35-0.45; EL 0.10-0.15; WL 0.31-0.53; PnL 0.09-0.15; PnW 0.23-0.30; ML 0.06-0.14; MW 0.15-0.23; Indices CI 79.17-106.67; SI $196.59-115.79$; $\mathrm{SI}_{2}$ 125.711146.67; $\mathrm{OI}_{1}$ 25.00-31.25.

Additional material examined measurements (mm) $(\mathrm{n}=2)$. HL $10.44-0.47$; HL $20.30-0.32$; $\mathrm{HL}_{3}$

0.11-0.12; HW 0.37-0.42; SL 0.38-0.41; EL 0.11-0.12; WL 0.42-0.47; PnL 0.11-0.13; PnW 0.260.30; ML 0.11; MW 0.18-0.19; Indices CI 84.34-88.89; SI 1 96.25-102.86; $\mathrm{SI}_{2}$ 126.32-128.33; $\mathrm{OI}_{1}$ 28.57-28.75; $\mathrm{OI}_{2} 24.10-24.44$. 
Manuscript submitted to: Organisms Diversity \& Evolution

Published version available; DOI: 10.1007/s13127-019-00406-2

Description. Head. Slightly longer than wide in full face view; posterior cephalic margin slightly concave. Dorsum of the head with sparse appressed hairs. Clypeus with a rounded anterior margin and five long, erect hairs of which a single, usually conspicuous hair is near the anterior margin, two hairs are in mediolateral position and two more near the toruli; other hairs on the

3591 clypeus are clearly shorter and appressed or decumbent. Toruli surpassing the posterior clypeal margin in oblique anterodorsal view. The scapes surpass the posterior cephalic margin by a length up to the maximal diameter of the eye, and they have appressed hairs. Ocelli absent. Eyes

3594 are positioned on the cephalic midline and have 8-10 ommatidia along their maximal diameter. Mesosoma. Typically with two erect hairs on the pronotum and two on the mesonotum. The mesonotum is not inflated and does not bulge dorsally above the pronotum in lateral view. Metanotal groove absent or narrower than the diameter of the metathoracic spiracles.

3598 Metathoracic spiracles in dorsolateral position, not protruding, and typically touching the mesometanotal and propodeal sutures. Dorsum of the propodeum convex and shorter than the 3600 propodeal slope. Propodeal spiracles circular and positioned on the posterior propodeal margin, slightly anterior of the middle of the propodeal slope. Legs with appressed hairs. Petiole short and 3602 inclined forward.

3603 Gaster. With decumbent dense pubescence and several scattered long erect hairs.

3604 Color and sculpture. Body smooth and shiny, except for the dorsum of the mesosoma which is 3605 sometimes slightly imbricate. Body uniformely brownish, but with slightly lighter antenna and 3606 legs.

3608 Distribution (supplementary material Fig. S32). Brachymyrmex obscurior is widespread and 3609 known from the Antilles, Argentina, Brazil, Chile, Colombia, the Dominican Republic, French 
3610 Guiana, Guatemala, Hawaii, Jamaica and Mexico. It has also been introduced in New Caledonia,

3611 the United States and other colleagues have reported it from Samoa and Hawaii (Wilson and

3612 Taylor, 1967), but we did not examine this material.

3614 Biology. In the original description, Forel (1893) mentioned that this species forms colonies of a

3615 few hundred individuals. Nests are usually constructed on open ground, typically under a stone,

3616 or at the roots of grass and weeds. The nest consists of only one or two simple chambers that are

3617 connected with a short passage. Forel (1893) indicated that B. obscurior occurs from sea level up 3618 to $800 \mathrm{~m}$ of altitude, but here we report new records from localities above $800 \mathrm{~m}$.

3620 Remarks. The specimen at the top of pin MHNG: USNMENT00757132 is designated here as the 3621 lectotype, whereas the other ants are paralectotypes. Forel (1893) described B. obscurior as a 3622 variety of $B$. heeri and indicated that it differs from typical B. heeri by having a brownish instead 3623 of yellowish body and slightly denser pubescence on the gaster. We observed that both species 3624 can readily be distinguished as to whether or not the mesonotum bulges dorsally above the 3625 pronotum in lateral view. Forel (1893) also reported that B. obscurior resembles B. patagonicus

3626 but that both taxa differ as to the presence or absence of ocelli, in body size, as to pubescence and 3627 the length of the scapes. He further considered B. obscurior to be a difficult "form" that 3628 represents a morphological transition between B. patagonicus and B. heeri (Forel 1912a). We 3629 agree that B. obscurior and B. patagonicus are morphologically very similar (see diagnosis), and 3630 molecular studies of both taxa will be required to examine whether they are distinct species. 3631 Wilson and Taylor (1967) recognized B. heeri var. obscurior as a distinct species as a provisional 3632 measure in anticipation of a full-scale revision of the genus. We agree with this decision, based 3633 on the morphological differences indicated above, but we cannot for now comment on their 
3634 proposed synonymization of B. heeri var. aphidicola Wheeler, 1934 to B. obscurior, as this 3635 material from Hawaii was not available to us.

3636

3637

3638

3639

3640

3641

3642

3643

3644

3645

3646

3647

3648

3649

3650

3651

3652

3653

3654

3655 3656

\section{Brachymyrmex oculatus Santschi}

(Fig. 42, supplementary material Fig. S33)

Brachymyrmex oculatus Santschi, 1919: 55 (w.). Lectotype worker (NHMB:

USNMENT00758101) and paralectotype workers (NHMB: USNMENT00758101; here

designated): 6 workers [examined]. ARGENTINA: Buenos Aires: Sierra de las Ventanas, Bruch leg. Quirán et al. (2004: 282) (m).

Additional material examined. ARGENTINA: Entre Ríos: Vilcaguay, Bruchi, 3 workers (MZSP: USNMENT00757776); Santa Fé: Fives Lilles, Wiser, 6 workers (MCZC: USNMENT00757250).

Diagnosis. Brachymyrmex oculatus morphologically resembles B. bruchi and B. patagonicus, because all three species have scapes that surpass the posterior margin of the head, they usually have two erect hairs on the mesonotum, their mesonotum does not bulge dorsally above the pronotum in lateral view, a metanotal groove is absent or narrower than the diameter of the metathoracic spiracles, their gaster has scarce pubescence and several scattered long erect hairs and their body is brownish. Brachymyrmex oculatus differs from B. bruchi and B. patagonicus, however, by having larger eyes, with a maximal diameter that approximates a third of the length of the head $\left(\mathrm{HL}_{1}\right)$. They usually have more than 14 ommatidia along their maximal diameter. 
Manuscript submitted to: Organisms Diversity \& Evolution

Published version available; DOI: 10.1007/s13127-019-00406-2

Lectotype and paralectotypes worker measurements $(\mathrm{mm})(\mathrm{n}=4)$. HL 1 0.45-0.50; HL2 0.35-0.41;

$\mathrm{HL}_{3}$ 0.11-0.14; HW 0.48-0.58; SL 0.45-0.50; EL 0.15-0.18; WL 0.53-0.61; PnL 0.15-0.17; PnW

0.30-0.39; ML 0.14-0.20; MW 0.23-0.27; Indices CI 106.67-115.15; $\mathrm{SI}_{1}$ 86.84-93.75; $\mathrm{SI}_{2}$ 122.22-

133.33; $\mathrm{OI}_{1}$ 31.25-34.29; $\mathrm{OI}_{2} 21.88-27.27$.

Description. Head. Slightly longer than wide in full face view; posterior cephalic border flat.

Dorsum of the head with sparse appressed hairs. Clypeus with a rounded anterior margin and five long, erect hairs of which a single, usually conspicuous hair is near the anterior margin, two hairs are in mediolateral position and two more near the toruli; other hairs on the clypeus are markedly shorter and appressed or decumbent. Toruli surpassing the posterior clypeal margin in oblique anterodorsal view. The scapes surpass the posterior cephalic margin by a length that is shorter than the maximal diameter of the eye; they have appressed hairs. Ocelli absent. Eyes are positioned on the cephalic midline and usually have more than 14 ommatidia along their maximal diameter.

Mesosoma. Dorsum of the mesosoma with sparse appressed hairs, and typically with two erect hairs on the pronotum and two on the mesonotum; sometimes with additional suberect hairs, mainly on pronotum. The mesonotum is not inflated and does not bulge dorsally above the pronotum in lateral view. Metanotal groove absent or narrower than the diameter of the metathoracic spiracles. Metathoracic spiracles in dorsolateral position, not protruding, and touching the propodeal suture. Dorsum of the propodeum slightly convex and shorter than the propodeal slope. Propodeal spiracles circular, positioned on the posterior propodeal margin, at the middle of the propodeal slope. Legs with scattered appressed hairs. Petiole short and inclined forward. 
3680 Gaster. With scattered pubescence and several scattered long erect hairs, mainly at the edges of 3681 the segments.

3682 Color and sculpture. Body overall smooth and shiny, with the dorsum of the mesosoma slightly 3683 imbricate. Body uniformely brownish.

Distribution (Supplementary material Fig. S33). Brachymyrmex oculatus is exclusively known from Argentina. Quirán et al. (2004) examined material from additional localities throughout the country.

Biology. Unkown.

Remarks. The specimen at the top of pin NHMB: USNMENT00757132 is here designated as

3692 lectotype, whereas the other ants in that pin are paralectotypes. Santschi (1919) suggested that $B$.

3694 is also very similar, and as mentioned in the diagnosis B. oculatus differs mainly from these

3695 species by its larger eyes. Whereas B. patagonicus has two erect hairs on the pronotum and $B$.

3696 bruchi usually more than two, the number of erect hairs on the pronotum is variable in $B$.

3697 oculatus.

3698 Quirán et al. (2004) designated a male to be the lectotype of B. oculatus, because it was labelled

3699 as "typus", and the associated workers were designated to be paralectotypes. However, the

3700 original description by Santschi (1919) exclusively described the worker morphology, and

3701 therefore logic dictates that the lectotype should be a worker. As such, we redesignated a worker 3702 of Santschi (1919) type series as lectotype here. 
Manuscript submitted to: Organisms Diversity \& Evolution

Published version available; DOI: 10.1007/s13127-019-00406-2

3704

3705

3706

3707

3708

3709

3710

3711

3712

3713

3714

3715

3716

3717

3718

3719

3720

3721

3722

3723

3724

3725

3726

3727

\section{Brachymyrmex patagonicus Mayr}

(Figs. 46, 47, supplementary material Fig. S34)

Brachymyrmex patagonicus Mayr, 1868: 164 (w.m.). (NHMW), Emery (1906: 178) (q.).

ARGENTINA: Buenos Aires: Rio Negro. See also: Santschi (1923a: 657).

= Brachymyrmex patagonicus var. atratula Santschi, 1923a: 657, Fig. 3 (w.). (NHMB:

USNMENT00757695): 2 workers [examined] ARGENTINA: Jujuy: Alfarito; synonym proposed by Quirán et al. (2004: 275). See also: Santschi (1923a: 657).

= Brachymyrmex laevis Emery, 1895: 216 (w.). (MSNG: USNMENT00757205, 00757206;

MHNG: USNMENT00758130): 4 workers [examined] CHILE: Valdivia. See also: Forel (1908: 400); Forel (1912a: 62); Santschi (1923a: 659). n. syn.

Additional material examined. ARGENTINA: Entre Rios: 8.63 km W Concordia,-31.42303 58.11672, 16 m, 26 Dec. 2007, W. MacKay \#22667, 1 worker (WEMC: USNMENT00758002);

Las Heras: Agua de las zorras, Paramillo de Uspallata, $13 \mathrm{~km} \mathrm{NW}$ of Villavicencio, -32.48011 69.16467, 2750 m, 3 workers 1 queen (MCZC: USNMENT00759011); Mendoza: $22.81 \mathrm{~km} \mathrm{~W}$ Villa Seca, -33.58515 -69.41708, 1835 m, 06 Jan. 2008, W. MacKay, 4 workers, 1 queen (WEMC: USNMENT 00757968, 00757973, 00759018, 00759020); Santiago del Estero: 2 workers (ICN: USNMENT00759047). BRAZIL: Pará: Melgaço, Caxiuanã ECFPn, -1.73584 51.48762, 23-25 Oct. 2005, Equipe A.Y. Harada, 5 workers (MPEG: AYH036); -1.72484 51.42979, 26 Oct. 2003, A.Y. Harada, E.P. Fagundes, C.J.M. Ribeiro, C.E.D. Sanhudo, C.A.R. Moura, J.L.P. Souza, C. Renato, 2 workers (MPEG: AYH053); Santarem, Taperinha, -2.90 54.33, July 1975, R. L. Jeannne, 3 workers (MCZC: USNMENT00757990); São Paulo: 
Cananéia, P.E. Ilha Do Cardoso, -22.30 -47.88, 02 Nov. 2007, C. Bottcher \& E.R. Pereira, 1 worker (ICN: USNMENT00757730); Itirapina: 11 Feb. 2009, S. Sendoya, 23 workers (ICN:

J. Cruz, 2 workers (IAvH: IAvH25467, 25468); Vereda Buenavista, Naranjal Finca Bizerta, queen (IAvH: IAvH27267); Finca La Herradura, 5.27936 -75.49744, 2020 m, 5-7 Aug. 2003, Guayacanes, 5.29606 -75.49428, 1984 m, 26 July 2003, L.E. Franco \& J. Cruz, 1 worker, 1 male (IAvH: IAvH27294); Vereda San José, Finca Casa Roja 5.33348 -75.48892, 1777 m, 07-09 Aug. 2003, L.E. Franco \& J. Cruz, 2 workers (IAvH: IAvH25462, 25463); Salamina, Vereda E1 Cedrito, Finca El Cedrito, 5.33197 -75.46785, 1960 m, 27-28 July 2003, L.E. Franco \& J. Cruz, 3 workers (IAvH: IAvH25470, 25472); Córdoba: Monteria, 29 June 2009, Juan C. Abadia, 3 workers (ICN); Cundinamarca: Villeta, Conjunto Residencial Las Acacias, 5.01361 -74.47306, 11 Jan. 2010, C.M. Ortiz, 8 workers (ICN); Quindio: Filandia, Vereda Cruces, Finca Los Micos, 4.70452 -75.64665, 1800 m, 12-14 July 2002, E. Jimenez \& L.E. Franco, 2 workers (IAvH: IAvH27227, 27240); Valle del Cauca: bosque Yotoco, 1575 m, 23 June 1989, W.P.MacKay $3750 \quad \# 11720,1$ worker (WEMC: USNMENT00757995); Medio Calima, 24 June 1989, E. MacKay 3751 \#11744, 3 workers, 1 queen (WEMC: USNMENT00759012, 00759013). COSTA RICA: 
Alajuela: Juan Santa Maria airport, 9.98 -84.20, 900 m, 09 Jan. 1999, J. Longino \#3958-s, 1

3753

3754

3755

3756

3757

3758

3759

3760

3761

3762

3763

3764

3765

3766

3767

3768

3769

3770

3771

3772

3773

3774

3775

worker (JTLC: LACM ENT 142311); Heredia: Estación Biológica la Selva, 10.433 -84.017,

May 1994, J. Longino \#3625, 1 worker (JTLC: INBIOCRI001260979); 10.423 -84.001, 50 m, 04

Aug. 2004, W. \& E. Mackay \#20890, 1 worker (WEMC: USNMENT00758039); 06 Aug. 2004,

W. \& E. Mackay \#20917, 1 worker (WEMC: USNMENT00757982); Limon: 3 km SSE Cahuita,

9.71667 -82.83333, 70 m, 24 Dec. 1983, P.S. Ward \#6530-40, 3 workers (PSWC:

USNMENT00758007); Puntarenas: Estación Biológica Los Llanos, 10.30487 -84.83735, 1150

m, 28 Feb. 2004, J. Longino, 1 worker (JTLC: JTLC000005287); 6 km S Monteverde, 10.25 -

84.82, 800 m, 22 June 1999, J. Longino, 1 worker, 1 queen (JTLC: LACM ENT 143543).

ECUADOR: Chimborazo: Huigra, -2.29417 -78.98861, 1200 m, 18 Feb. 2004, Roger Vila I-

457, 2 workers (ICN: USNMENT00758037). GUATEMALA: El Progreso: 3.8 km E. San

Cristobal, 14.91850 -90.04075, 302 m, 19 July 2004, W. \& E. MacKay \#20586,3 workers

(WEMC: USNMENT00759006); Santa Rosa: 5 km SW Cuilapa, 14.23333 -90.33333, 575 m,

14 Nov. 2003, A.L. Wild \#AW2030, 1 worker (ALWC: USNMENT00758009); Suchitepéquez:

Finca Tarrales, 12.3 km N Patulul, 14.52256 -91.13642, 740 m, 30 July 2004, W. \& E. Mackay

\#20782, 2 workers (WEMC: USNMENT00757688, 00757983). HONDURAS: La Lima, 23 Jan.

1960, C. Evers, UFC-217-35 (6871), 5 workers, 1 male (MZSP: USNMENT00757621,

00757622). JAPAN: Hyogo, Kob, Port Island, 34.67 135.20, 18 Sep. 2007, M. Yoshimura, 1

worker (ICN: MY1862-12). MEXICO: Federal: Mexico City, 6.5 km E Chalma, 26 May 1998,

W. MacKay \#10386, 1 worker, 2 males (WEMC: USNMENT00757993); Guanajuato: Highway

57, km 306, Rancho Jardin, 21.14224 -100.95341, 10 Aug. 1965, Cornell University, 1 worker

(MCZC: USNMENT00759002); Jalisco: 6 km N El Tuito, 20.3667 -105.3167, 730 m, 31 Dec.

1987, P.S. Ward \#9327-11, 2 workers (PSWC: USNMENT00757679); Nuevo Leon: 8 km W.

Iturbide, 09 Nov. 1946, W.S. Ross, ANTC10261, 2 workers (CPDC: CASENT0196003); 
3776

3777

3778

3779

3780

3781

3782

3783

3784

3785

3786

3787

3788

3789

3790

3791

3792

3793

3794

3795

3796

3797

Nayarit: 19.3 km S Rosamorada, 21.94389 -105.20639, 51 m, 19 June 2000, W. \& E. MacKay

\#19126, 2 workers (WEMC: USNMENT00757983); Oaxaca: 148 km NE Oaxaca Rt175,

17.02647 -96.71947, 1210 m, 04 June 1988, W. MacKay \#10825, 3 workers (WEMC:

USNMENT00757732); 1.6 km E Reforma, near Tuxtepec, 18.08078 -96.13677, 12-15 Aug.

1973, A. Newton, 1 worker (MCZC: USNMENT00757680); Puebla: 6.5 km W Izucar

Matamoros, 1220 m, 26 May 1988, W. MacKay, 1 worker, 1 male (WEMC:

USNMENT00757991); San Luis de Potosi: 10 km S San Luis Potosi, 21 May 1988, W.P.

MacKay \#10307 \#10308, 6 workers, 2 males, 1 queen (WEMC: USNMENT00757685,

00759015, 00759017); 16 km S San Luis Potosi, 21 May 1988, W.P. MacKay \#10307, 2

workers, 1 male (WEMC: USNMENT00758006); 11 km N Cardenas, 1720 m, 09 June 1988, W.

MacKay \#1095, 1 worker, 2 males (WEMC: USNMENT00759027); Tamaulipas: 32.3 km SE

Ciudad Victoria, 23.49161 -96.97775, 289 m, 24 Mar. 2008, W. \& E. MacKay \#22930, 2 workers

(WEMC: USNMENT00757681, 00757687); Gomez Farias, 25 Sep. 1987, A. Rebeles \#10096, 1

worker (WEMC: USNMENT00757994); Veracruz: Los Tuxlas, July 2001, A. Pezon, 1 worker

(CPDC: USNMENT00757989); Xalapa, V. Rico Gray \#17209, 4 workers (MCZC:

USNMENT00759026, 00758044). PARAGUAY: Canindeyú: Reserva Natural Bosque

Mbaracayú, Aguara Ñu, -24.18333 -55.28333, 240 m, 16 Nov. 2002, A. L. Wild, 1 worker

(ALWC: USNMENT00757971); Itapúa: Isla Yacyretá, -27.41667 -56.75417, 25 Sep. 1997, B.

Barrios \#ibn 216, 1 worker (ALWC: USNMENT00757683); Presidente Hayes: 5 km SSE Pozo

Colorado, -23.55 -58.77, 140 m, 05 Dec. 2002, A.L. Wild \#AW1764, 1 worker (ALWC:

USNMENT00758010). URUGUAY: Salta: Salta, Parque Municipal Benito Solari, 25 Dec.

2007, W. \& E. MacKay \#22634, 1 worker (WEMC: USNMENT00757731). 
Manuscript submitted to: Organisms Diversity \& Evolution

Published version available; DOI: 10.1007/s13127-019-00406-2

3799 Diagnosis. Brachymyrmex patagonicus morphologically resembles B. bruchi and B. oculatus,

3800 because all three species have scapes that surpass the posterior margin of the head by a length

3801 approximately equal to the maximum diameter of the eye or less, they usually have two erect

3802 hairs on the mesonotum, which does not bulge dorsally above the pronotum in lateral view, the

3803 metanotal groove is absent or narrower than the diameter of the metathoracic spiracles, their

3804 gaster has scarce pubescence and several scattered long erect hairs, the body is uniformly

3805 brownish. Brachymyrmex patagonicus differs from B. bruchi, however, by usually having two

3806 erect hairs on the pronotum and two on the mesonotum and from B. oculatus by having smaller

3807 eyes, with a maximal diameter of approximately $1 / 4^{\text {th }}$ of the length of the head $\left(\mathrm{HL}_{1}\right)$ and usually

3808 with less than 14 ommatidia along their maximal diameter.

3809

3810

Types measurements $(\mathrm{mm})(\mathrm{n}=2)$. $\mathrm{HL}_{1}$ 0.45-0.53; $\mathrm{HL}_{2} 0.33-0.37$; $\mathrm{HL}_{3} 0.10-0.13$; HW 0.38-0.49;

3811 SL 0.40-0.48; EL 0.14-0.17; WL 0.38-0.51; PnL 0.11-0.15; PnW 0.26-0.33; ML 0.07-0.11; MW

3812 0.17-0.24; Indices CI 85.29-92.50; SI $197.30-103.45 ; \mathrm{SI}_{2}$ 120.00-128.57; $\mathrm{OI}_{1} 33.78-36.21 ; \mathrm{OI}_{2}$

$3813 \quad 22.06-25.00$.

3814

3815 Additional material examined measurements $(\mathrm{mm})(\mathrm{n}=13)$. $\mathrm{HL}_{1}$ 0.40-0.59; $\mathrm{HL}_{2}$ 0.28-0.39; $\mathrm{HL}_{3}$

3816 0.07-0.16; HW 0.33-0.51; SL 0.35-0.49; EL 0.09-0.14; WL 0.35-0.55; PnL 0.09-0.20; PnW 0.23-

3817 0.35; ML 0.07-0.14; MW 0.15-0.23; Indices CI 81.40-93.33; SI 1 92.00-128.95; SI 2 116.22-

$3818 \quad 163.33 ; \mathrm{OI}_{1} 22.22-32.5 ; \mathrm{OI}_{2}$ 18.18-28.57.

3819

3820 Description. Head. Slightly longer than wide in full face view; posterior cephalic margin slightly

3821 concave. Dorsum of head with sparse appressed hairs. Clypeus with a rounded anterior margin

3822 and five long, erect hairs of which a single, usually conspicuous hair is near the anterior margin, 
Manuscript submitted to: Organisms Diversity \& Evolution

Published version available; DOI: 10.1007/s13127-019-00406-2

two hairs are in mediolateral position and two more near the toruli; other hairs on the clypeus are markedly shorter and appressed or decumbent. Toruli surpassing the posterior clypeal margin in oblique anterodorsal view. The scapes surpass the posterior cephalic margin by a length that is shorter than the maximal diameter of the eye; they have appressed hairs. At least one central ocellus is present. Eyes are positioned on the cephalic midline and have 8-12 ommatidia along

3828 their maximal diameter.

Mesosoma. Dorsum of the mesosoma with sparse appressed hairs, typically with two erect hairs on the pronotum and two on the mesonotum. The mesonotum is not inflated and does not bulge dorsally above the pronotum. Metanotal groove absent or narrower than the diameter of the metathoracic spiracles. Metathoracic spiracles in dorsolateral position, not protruding, and

3833 touching the propodeal suture. Dorsum of the propodeum slightly convex and shorter than the 3834 propodeal slope. Propodeal spiracles circular, situated on the posterior propodeal margin, at the 3835 middle of the propodeal slope. Legs with appressed and scattered hairs. Petiole short and inclined 3836 forward.

3837 Gaster. With scattered pubescence and several scattered long erect hairs, mainly at the edges of 3838 the segments.

3839 Color and sculpture. Body overall smooth and shiny, except for the sometimes slightly imbricate 3840 sculpture on the dorsum of the mesosoma, and typically uniformly brownish. 
Manuscript submitted to: Organisms Diversity \& Evolution

Published version available; DOI: 10.1007/s13127-019-00406-2

3847

3848

3849

3850

3851

3852

3853

3854

3855

3856

3857

3858

3859

3860

3861

3862

3863

3864

Biology. MacGown et al. (2007) indicated that B. patagonicus nests in a variety of habitats, both natural and disturbed, ranging from pine forests over mixed forest and prairie to urban environments. Colonies may contain many hundreds of workers packed into a small sheltered area. Where this species is found, colonies are often abundant and within a few centimeters from one another. Nests can be found in loose tree bark, at the base of plants, in soil, dead wood and organic litter, or below natural and man-made objects. The species is considered a nuisance pest, as both alates and foraging workers may enter man-made structures to forage and/or nest (MacGown et al. 2007).

Remarks. As Quirán et al. (2004) already indicated Mayr (1868) described B. patagonicus based on specimens from Argentina. However, the specimens in the NHMW: USNMENT0075720100757204 that were examined and identified as types by Mayr are from Chile. Either the locality indicated in the original description may be wrong, or specimens from Argentina may be lacking from the collection, and as such we do not designate a lectotype here.

Emery (1895), upon describing B. laevis (which is sometimes misspelled as B. levis, e.g. Emery (1906: 178); Santschi (1923a: 659)), indicated that it is closely related to B. patagonicus and to the dark forms of $B$. heeri, but he considered B. laevis distinct by having a smooth and shiny tegument of the head. However a description of the species is not provided, and after examining the type material of $B$. laevis we have not identified any consistent morphological differences compared to B. patagonicus so that we synonymize the species here.

Brachymyrmex patagonicus displays variation in color from light to dark brown; B. patagonicus var. atratula was described by Santschi (1923a) as a variety with darker, almost black tegument, and a smooth and shiny body. Evaluating these morphological differences Quirán et al. (2004) 
3870 suggested that $B$. patagonicus var. atratula is a junior synonym of B. patagonicus, and we agree 3871 with this decision.

3872 Guénard (2018) reports the first record of B. patagonicus from continental Asia (Hong Kong), 3873 however, the specimen illustrated in the paper does not display the diagnostic features of this 3874 species, but rather those of $B$. cordemoyi. It is noteworthy that B. patagonicus is very abundant 3875 and geographically widespread, but its morphological variation and genetic diversity as well as 3876 other biological features remain poorly studied. An in-depth study of these features in a 3877 geographic context would be required to determine if $B$. patagonicus is a distinct species, a 3878 species complex, or conspecific with some other taxa, e.g. B. bruchi and B. obscurior.

\section{Brachymyrmex pictus Mayr} designated): 3 workers [examined]. BRAZIL: Santa Catharina.

$3886=$ B. heeri var. basalis Wheeler, 1921: 166 (w.). [not examined]. GUYANA: Kartabo, Puruni 3887 trail. n. syn.

$3888=$ B. pictus subsp. balboae Wheeler, 1942: 253 (w.q.m.). (MCZC: M.C.Z. Cotype 1-3, 4-6, 7-9, 3889 21438): 2 workers, 8 queens, 2 males [examined]. PANAMA: Balboa. n. syn. 
3894 CMOS000002); Aleixo nr. Manaus, 11 Sep. 1962, W. L. Brown, 8 workers, 2 males, 6 queens 3895 (MCZC: CMOS000004, CMOS000006, CMOS000009-0000011); Peredão Rd. S. of Manaus, 02 3896 Sep. 1962; W. L. Brown, 12 workers (MCZC; CMOS000003, CMOS000005, CMOS000007, 3897 CMOS000008); Bahia: Ilheus, 27 Mar. 1997, C.S.F. Mariano, 4 workers (CPDC: USNMENT00757794); Espiritu Santo: Nov. 1977, M. Alvarenga, 4 workers (MZSP: USNMENT00757785); São Paulo: Caraguatatuba, Reserva Florestal, 40 m, 22 May-01 June 1962, Exp. Dep. Zool. 2056, 8 workers (MZSP: USNMENT00757676, 00757783); Ilha dos Pescadores (Ilha da Vitoria), 24 Mar. 1964, 2 workers, 2 queens (MZSP: USNMENT00757604); Ubatuba, Picinguaba, July 2011, 9 workers (ICN: USNMENT00759053). COLOMBIA: Cauca: Isla Gorgona, 11 Sep. 1989, M. Baena \#GQA-05, 3 workers (WEMC: USNMENT00757796, 00757797); Magdalena: 2 km ESE Minca, 11.13 -74.10, 780 m, 13 Aug. 1985, P.S. ward \#7895, 2 workers, 1 queen (PSWC: USNMENT00757792); Putumayo: Parque Nacional Natural La Paya, Cabaña La Paya, -0.03, -75.20, 330 m, 15-30 Sep. 2002, A. Morales, 1 worker (IAvH). COSTA RICA: Puntarenas: Parque Natural Corcovado, Sirena, 8.483 -83.583; 23 Apr. 1981, J. 3908 Longino, 1 worker, 1 queen (JTLC000005913, 000005914); 14 June 1982, J. Longino, 2 workers 3909 (MCZC: USNMENT00757793); Reserva Biologica Carara, 9.78 -84.60, 30 m, 24 July 1985, P.S. 3910 Ward \#7615, 2 workers, 1 queen (PSWC: USNMENT00757784); Reserva Biologica Carara, 3911 Estación Quebrada Bonita, 9.78 -84.60, 30 m, 24 July 1985, J. Longino \#0562, 1 worker, 1 queen 3912 (JTLC: JTLC000006051). ECUADOR: Esmeraldas: 6.1 km E Rio Verde, 1.07694, -79.41389, 391313 July 2005, W. \& E. MacKay \#21098, 1 worker (WEMC: USNMENT00757791); Manabí: 20 3914 km NE Chone, 300 m, 1976, S. \& J. Peck, 2 workers (MCZC: CMOS000014); Pichincha: 3915 Cotopaxi, 19 km ENE La Maná, -0.88 -79.05, 1100 m, 10 Aug. 1991, P.S. Ward \#11418-23, 1 3916 worker (MCZC: USNMENT00758017). FRENCH GUIANA: Saint Elie-K, 4.82261, -53.27649, 3917 Apr. 2002, J. Orivel \& J. Le Breton, 6 workers, 1 queen (CPDC: USNMENT00757786, 
3921 J. Longino, 1 worker (JTLC: JTLC000005918). JAMAICA: Saint Andrew: Cinchona, 18.067 -

3922 76.650, 1450 m, 19 Mar. 1984, 1 worker (JTLC: JTLC000005924). PANAMA: Gamboa,

3923 Parque, 9.11722 -79.69972, 24 Apr. 1988, D. Quintero \#1, 2 workers (WEMC:

USNMENT00757795). PERU: Madre de Dios: Tambopata, 15 km NE Puerto Maldonado, June 1989, S.P. Cover \& J.E. Tobin, JT 219 CA-740, 2 workers (MCZC: CMOS000032).

VENEZUELA: Bolìvar: Canaima, Orchid Is., 14 Oct. 1988, W. MacKay \#11165, 8 workers, 3 males, 1 queen (WEMC: USNMENT0075778800757790, 00757960, 00758997).

Diagnosis. The unique feature for $B$. pictus is a conspicuous color difference between the head and thorax, which are yellow and the gaster, which is black, or yellow with (a) black spot(s). 0.38; SL 0.38; EL 0.11; WL 0.44; PnL n.a.; PnW n.a.; ML 0.09; MW 0.18; Indices CI 89.58; SI 1 100.00; $\mathrm{SI}_{2}$ n.a.; $\mathrm{OI}_{1} 26.83 ; \mathrm{OI}_{2} 28.57$.

Description. Head. Slightly longer than wide in full face view; posterior cephalic margin flat. Dorsum of the head has sparse appressed hairs. Clypeus with a rounded anterior margin and five 3938 long, erect hairs of which a single, usually conspicuous hair is near the anterior margin, two hairs 3939 are in mediolateral position and two more near the toruli; other hairs on the clypeus are markedly 3940 shorter and appressed or decumbent. Toruli surpassing the posterior clypeal margin in oblique 3941 anterodorsal view. The scapes surpass the posterior cephalic margin by a length that is smaller 
3942 than the maximal diameter of the eye; they have appressed hairs. Three ocelli present. Eyes are

3943 positioned on the cephalic midline and have 7-10 omatidia along their maximal diameter.

3944 Mesosoma. Typically with two erect hairs on the pronotum and two on the mesonotum. The 3945 mesonotum is not inflated and does not bulge dorsally above the pronotum in lateral view. The 3946 mesometanotal suture is directly visible, however, there is no marked constriction between the 3947 mesonotum and metanotum, and as a result the metanotal groove is absent. Metathoracic 3948 spiracles widely separated in dorsolateral position, not protruding, and touching the propodeal 3949 suture. Dorsum of the propodeum flat and shorter than the propodeal slope. Propodeal spiracles 3950 circular, situated slightly ventral to the posterior propodeal margin, and slightly posterior of the 3951 middle of the propodeal slope. Legs with appressed and scattered hairs. Petiole short and inclined 3952 forward.

3953 Gaster. With scattered pubescence and several scattered long erect hairs.

3954 Color and sculpture. Body smooth and shiny. The head and thorax are yellowish whereas the 3955 gaster is either totally black or yellowish with one or more black spots.

Distribution (Supplementary material Fig. S35). Brachymyrmex pictus is known to occur in Bolivia, Brazil, Colombia, Ecuador, French Guiana, Guatemala, Guyana, Jamaica, Panama, Peru and Venezuela.

Biology. The colony of B. heeri var. basalis reported by Wheeler (1921) and Wheeler (1942) was

3962 small but nevertheless contained brood. It was found in hollow petioles of a small Tachigalia

3963 paniculata tree on the Puruni trail at Kartabi, Guyana. Several colonies of B. pictus subsp.

3964 balboae were found to be nesting in hollow twigs of Tripalis americana at Balboa, Panama 
Manuscript submitted to: Organisms Diversity \& Evolution

Published version available; DOI: 10.1007/s13127-019-00406-2

3965 (Wheeler 1942). No biological information exists on typical B. pictus, but it seems this species is 3966 arboreal.

3968 Remarks. One of the specimens determined as a syntype of B pictus (NHMW:

3969 CASENT0915734) displays the diagnostic features of B. admotus. Given that both species were 3970 described by Mayr (1887) in the same publication from the same type locality, we consider the identification of this specimen to be a labeling mistake. Upon describing B. pictus, Mayr (1887) did not provide any information on the diagnostic features he considered relevant to distinguish 3973 B. pictus from other Brachymyrmex species. Wheeler (1921) described B. heeri var. basalis, but 3974 he did not provide any morphological description for his typical B. heeri specimens nor for the 3975 variety. The only feature described for B. heeri var. basalis is its yellow body with a black first 3976 segment of the gaster (which to our knowledge only fits with the characters of B. pictus). Other 3977 complications are that the material has not been illustrated, that both the typical form and the 3978 variety were found on the same tree species and the same locality, and that we have not been able 3979 to locate the material. Later, Wheeler (1942) continued to consider his specimens of B. heeri and 3980 B. heeri var. basalis to be distinct of B. pictus. Given the information available we consider it 3981 likely that $B$. heeri var. basalis belongs to B. pictus, but we cannot comment on the taxonomic 3982 status of his typical B. heeri specimens for now.

3983 Fortunately, Wheeler (1942) provided a description of B. pictus subsp. balboae, which indicates 3984 that it differs from the typical B. pictus only by being smaller. It is indeed somewhat smaller (1.0$39851.2 \mathrm{~mm})$ than the typical form described by Mayr (1887; 1.3-1.6 mm), however, after studying 3986 the material we consider this difference to likely represent geographic variation, and we 3987 synonymize this subspecies here, although a better characterization of the variation in B. pictus is 3988 required. 
3994 queen, male (NHMW): 2 queens, 1 male [examined]. BRAZIL: Santa Catharina. Santschi 3995 (1929: 310) (w.). (NHMB): 2 major workers, 2 minor workers, 1 queen [examined]. BRAZIL:

3996 Parana: Río Negro. Combination in Brachymyrmex (Bryscha): Santschi (1923a: 674). See also: 3997 Ortiz and Fernández (2014: 19, Figs. 7-12).

Diagnosis. Brachymyrmex pilipes morphologically resembles B. micromegas because both 4000 species have a dimorphic worker caste, tumuliform metathoracic spiracles, toruli that touch the 4001 posterior clypeal margin, but never surpass it (best observed in oblique anterodorsal view) and a 4002 clypeus with a row of long thick hairs near the anterior margin. However, B. pilipes differs from B. micromegas by the fine, longitudinal striations on most of the mesosoma, and by usually 4004 having a gaster of darker color than the rest of the body.

Description. See Ortiz and Fernández (2014).

4011 Brachymyrmex santschii Menozzi, 1927: 338, Fig. 5 (w.). [not examined]. COSTA RICA: San 4012 José. 
4014 Additional material examined. COSTA RICA: Cartago: 2 km N Cervantes, 1600 m, Jan.

4015 1973, W.L. Brown, 4 workers, 2 putative worker-queen intercastes (MCZC: CMOS000098, 4016 USNMENT00757750-00757751); Guanacaste: Rincon de la Vieja, Las Pailas 7676, 10.77556 4017 85.34528, 1400 m, 18 Feb. 1996, R. Anderson, 2 workers (WEMC: USNMENT00757753, 4018 00757754); Puntarenas: Monteverde, 10.30 -84.83, 1400 m, Apr.-May 1987, S. Little, 1 worker 4019 (JTLC: JTLC000005243); Monteverde, 10.2964 -84.7831, 1550 m, 18 Jan. 2003, L.A.

4020 Schonberg, 1 worker (JTLC: JTLC000005055); San José: Cerros de Escazu, 2 km S Antonio, 40211650 m, 13 June 1997, R. Anderson \#186880C, 1 worker (WEMC: USNMENT00757593).

4022 PANAMA: Chiriqui: Volcan Hartman`s, Finca \#17815, 1450 m, 14 June 1996, R.S. Anderson, 40231 worker (WEMC: USNMENT00757752).

Diagnosis. Brachymyrmex santschii morphologically resembles B. iridescens, because both species have the head and the mesosoma with strongly alveolate sculpture. However, they can be distinguished from one another because $B$. santschii has a metanotal groove that is wider than the 4028 diameter of the metathoracic spiracles, scapes that surpass the posterior margin of the head, and a 4029 gaster with scattered pubescence.

4030

4031 Additional material examined measurements $(\mathrm{mm})(\mathrm{n}=4) . \mathrm{HL}_{1}$ 0.40-0.44; HL $20.29-0.30 ; \mathrm{HL}_{3}$

4032 0.08-0.10; HW 0.37-0.40; SL 0.39-0.42; EL 0.09-0.11; PnL 0.11-0.13; PnW 0.24-0.28; ML 0.09; 4033 MW 0.13-0.17; Indices CI 89.80-91.82; SI 102.27-109.76; SI 2 136.36-138.24; OI 1 24.39-26.84;

$4034 \quad \mathrm{OI}_{2} 20.00-24.44$. 
Manuscript submitted to: Organisms Diversity \& Evolution

Published version available; DOI: 10.1007/s13127-019-00406-2

4036

4037

4038

4039

4040

4041

4042

4043

4044

4045

4046

4047

4048

4049

4050

4051

4052

4053

4054

4055

4056

4057

4058

4059

Worker description. Head. Longer than wide in full face view; posterior cephalic margin flat or slightly concave. Dorsum of the head with subdecumbent hairs. Clypeus with a rounded anterior margin and five long, erect hairs of which a single, usually conspicuous hair is near the anterior margin, two hairs are in mediolateral position and two more near the toruli; other hairs on the clypeus are markedly shorter and appressed or decumbent. Toruli surpassing the posterior clypeal margin in oblique anterodorsal view. The scapes surpass the posterior margin of the head by a length approximately equal to the maximal diameter of the eye; they bear appressed hairs. Three conspicuous ocelli are present. Eyes are positioned on the cephalic midline and have 8-9 ommatidia along their maximal diameter.

Mesosoma. Dorsum subsinusoidal in lateral view. Without erect hairs, but with decumbent hairs on the promesonotum. The mesonotum is variable, typically not or weakly inflated, and not or slightly bulging dorsally above the pronotum in lateral view. Metanotal groove wider than the diameter of the metathoracic spiracles. Metathoracic spiracles in dorsal position, not protruding and not touching any sutures. Dorsum of the propodeum slightly convex and shorter than the propodeal slope. Propodeal spiracles circular, positioned on the posterior propodeal margin, at the middle of the propodeal slope. Legs with appressed hairs. Petiole short and inclined forward.

Gaster. With scattered pubescence and long erect hairs at the edges of the segments.

Color and sculpture. Head and dorsum of the mesosoma finely alveolate, those parts that are not sculptured, including the gaster, are smooth and shiny. The body is brownish, but sometimes the antennae, tarsi, and articulations of the legs are more yellowish.

Intercaste description. The morphology of the putative worker-queen intercaste differs from that of the worker by its larger body size, the eyes that have around 10 ommatidia along their maximal diameter, its strongly expanded mesonotum, the absence of a metanotal groove, the 
4060 dorsolateral position of the metathoracic spiracles, the less convex dorsum of the propodeum, and 4061 a markedly expanded gaster with dense pubescence.

Distribution (Supplementary material Fig. S37). Brachymyrmex santschii is known from 4064 Costa Rica and Panama.

Biology. Unknown.

Remarks. Menozzi (1927) considered B. santschii to differ from any other Brachymyrmex species by its sculpture and pubescence. He described the sculpture as strongly punctuatereticulate, however, following the terminology of Harris (1979) we consider it rather alveolate.

4071 We do not designate a lectotype here, as we have not studied the type series, which would be 4072 deposited at the German Entomological Institute in Berlin-Dahlem.

\section{Brachymyrmex sosai NEW SPECIES}

Holotype worker (UNMSM: USNMENT00757760) and paratype workers (USNM: 71.60556, 2825 m, Andean Forest, J. Sosa-Calvo, JSC040920-04. 
Manuscript submitted to: Organisms Diversity \& Evolution

Published version available; DOI: 10.1007/s13127-019-00406-2

4086

4087

4088

4089

4090

4091

4092

4093

4094

4095

4096

4097

4098

4099

4100

4101

4102

4103

4104

4105

4106
USNMENT00759024); PERU: Lima: Zárate forest, 2850 m, N. Valencia, I. Frank, 16 workers

(MCZC: USNMENT00757314-00757320).

Etymology: In honor of Dr. Jeffrey Sosa-Calvo, the collector, for his unconditional support and friendship.

Diagnosis. Brachymyrmex sosai n. sp. does not have a specific unique feature but rather a unique combination of features that render it distinct: its scapes surpass the posterior margin of the head by a length approximately equal to the maximal diameter of the eye, the dorsum of the mesosoma does not have conspicuous sculpture, a metanotal groove is present, the metathoracic spiracles are in dorsal position, and the dorsal margin of the mesonotum is strongly antero-posteriorly inclined. Some features of this species are reminiscent of $B$. antennatus, however, $B$. sosai differs from this species in body color, the color of the hairs, the length of the scapes, and in having an antennal funiculus with the second segment shorter than the first.

Holotype measurements (mm) HL 10.57 ; $\mathrm{HL}_{2}$ 0.35; HL 3 0.16; HW 0.53; SL 0.59; EL 0.14; WL 0.68; PnL 0.21; PnW 0.33; ML 0.16; MW 0.21; Indices CI 93.10; SI 1 111.11; SI 2 166.67; OI $25.93 ; \mathrm{OI}_{2} 27.59$.

Paratypes measurements ( $\mathrm{n}=3$ ) HL $\mathrm{HL}_{1} 0.60-0.62 ; \mathrm{HL}_{2}$ 0.41-0.43; HL 3 0.16-0.20; HW 0.57-0.60; SL 0.59-0.62; EL 0.14-0.16; WL 0.68-0.72; PnL 0.20-0.23; PnW 0.41; ML 0.18-0.20; MW 0.140.27; Indices CI 93.55-96.88; SI 103.23-103.45; SI2 142.86-145.45; OI $122.58-27.59$; OI2 25.8131.25 
Description. Head. Slightly longer than wide in full face view; posterior cephalic margin flat or

4109 slightly concave. Dorsum of the head with scattered appressed hairs. Clypeus with a rounded

4110 anterior margin and five long, erect hairs of which a single, usually conspicuous hair is near the

4111 anterior margin, two hairs are in mediolateral position and two more near the toruli; other hairs

4112 on the clypeus are markedly shorter and appressed or decumbent. Toruli surpassing the posterior

4113 clypeal margin in oblique anterodorsal view. The scapes surpass the posterior margin of the head

4114 by a length that exceeds the maximal diameter of the eye. Ocelli typically appear to be absent but

4115 some workers have a central ocellus. Eyes are positioned on the cephalic midline and have 9-10

4116 ommatidia along their maximal diameter.

4117 Mesosoma. With several semi-erect hairs on the pronotum and scattered decumbent hairs on the

4118 promesonotum. The mesonotum is slightly inflated, antero-posteriorly inclined, and it bulges

4119 dorsally above the pronotum in lateral view. Metanotal groove present and wider than the

4120 diameter of the metathoracic spiracles. Metathoracic spiracles in fully dorsal position, not

4121 protruding, and not touching any sutures. Dorsum of the propodeum weakly convex and shorter

4122 than the propodeal slope. Propodeal spiracles circular, positioned slightly ventral of the posterior

4123 propodeal margin; they are posterior of the middle of the propodeal slope. Legs with appressed

4124 hairs. Petiole short and inclined forward.

4125 Gaster. With dense pubescence and scattered long hairs at the edges of the segments.

4126 Color and sculpture. Body smooth and shiny, and usually dark brown, but with conspicuously

4127 lighter hairs. Additionally, the bulbi of the antennae, the terminal funiculus, the tarsi and the

4128 articulations of the legs are conspicuously yellowish. 
4130 Distribution (Supplementary material Fig. S38). Brachymyrmex sosai is known from Bolivia 4131 and Peru.

Biology. This species was collected from sandy soil, from below a rock.

Remarks. The single specimen of B. sosai known from Bolivia (WEMC: USNMENT00759024) differs in color from the specimens from Peru: its head and thorax are more yellowish than brown and the gaster is darker than the rest of the body. We consider it to be part of $B$. sosai as all other traits match. Currently B. sosai is only known from three localities, and more specimens from additional localities will be required to characterize the intraspecific variation in body color. USNMENT00757137) and paralectotype workers, queen (MHNG: USNMENT00757136-

4147 workers, 1 queen [examined]. BRAZIL: Rio Grande do Sul: San Leopoldo, col. Wasmann.

$4148 \quad$ Raised to species: Wild (2007: 44).

Additional material examined. BRAZIL: São Paulo: Tapirai, -24.03208 -47.46556, 08-14 Jan.

4152 Parque Nacional Natural Tamá, Vereda El Diamante, Alto Herrera, 7.12278 -72.23472, 1000 m, 415326 Nov. 1999, 1 worker (IAvH: USNMENT00759060). COSTA RICA: Guanacaste: Maritza 
4154 field Station, 10.95694 -85.49389, 03 May 1995, R. Anderson \#17716, 3 workers (WEMC:

4155 USNMENT00757632); DOMINICAN REPUBLIC: Pedemales: Parque Nacional Sierra

4156 Baoruco, "Las Abejas", 18.15 -71.62, 1320 m, 02 Sep. 2001, A.L. Wild \#AW1359, 1 worker, 1 4157 male, 1 queen (ALWC: USNMENT00757918). MEXICO: Puebla: 17 km NE Tezlutlán, 1940 4158 m, 07 June 1988, W. MacKay \#10879, 1 worker, 1 queen (WEMC: USNMENT00758036).

4159 PARAGUAY: Itapúa: San Miguel Potrero, c/Villa Yacyreta, -27.03 -56.20, 17 Jan. 1996, N.E. 4160 Lopez \#ibn 227, 1 worker (ALWC: USNMENT00757662). UNITED STATES: Texas: Sabino 4161 Co., 14.5 km E Nemphil, 11 May 1988, R. Anderson \#12763, 1 worker (WEMC: 4162 USNMENT00758031).

4164 Diagnosis. Brachymyrmex termitophilus morphologically resembles B. aphidicola, B. australis, 4165 B. cordemoyi and B. obscurior because these species have scapes that are usually surpassing the 4166 posterior cephalic margin, their eyes are positioned on the cephalic midline, they have two erect 4167 hairs on the pronotum and two on the mesonotum, and their mesonotum does not bulge dorsally 4168 above the pronotum in lateral view. Brachymyrmex termitophilus differs from B. australis and B. 4169 aphidicola, however, by having dense pubescence on the gaster, and from B. cordemoyi and $B$. 4170 obscurior by having a yellowish body instead of brownish. Brachymyrmex termitophilus also 4171 resembles B. bahamensis somewhat, but B. termitophilus typically bears two erect hairs on the 4172 pronotum whereas B. bahamensis approximately six that are moreover much longer.

4174 Lectotype and paralectotype measurements $(\mathrm{mm})(\mathrm{n}=2) . \mathrm{HL}_{1} 0.45 ; \mathrm{HL}_{2} 0.29-0.31 ; \mathrm{HL}_{3} 0.10$ -

4175 0.12; HW 0.39; SL 0.41-0.43; EL 0.10; Pnl 0.12; PnW 0.25-0.27; ML 0.08; MW 0.18; Indices CI 4176 89.96; SI1 105.00-110.00; SI2 131.25-146.67; OI $125.00 ; \mathrm{OI}_{2} 21.74-26.09$. 
Manuscript submitted to: Organisms Diversity \& Evolution

Published version available; DOI: 10.1007/s13127-019-00406-2 4198 forward.

4199 4200

Additional material examined measurements $(\mathrm{mm})(\mathrm{n}=2)$. HL $\mathrm{L}_{1}$ 0.43-0.44; $\mathrm{HL}_{2}$ 0.30; HL 3 0.10;

HW 0.38-0.39; SL 0.33-0.40; EL 0.10; WL 0.42; PnL 0.12; PnW 0.25-0.27; ML 0.08-0.09; MW

0.16-0.18; Indices CI 89.80-90.00; $\mathrm{SI}_{1}$ 85.23-101.11; $\mathrm{SI}_{2}$ 110.29-133.82; $\mathrm{OI}_{1}$ 25.56-26.14; $\mathrm{OI}_{2}$ 22.00-22.45.

Description. Head. Slightly longer than wide in full face view; posterior cephalic margin flat. Dorsum of the head with sparse appressed hairs. Clypeus with a rounded anterior margin and five long, erect hairs of which a single, usually conspicuous hair is near the anterior margin, two hairs are in mediolateral position and two more near the toruli; other hairs on the clypeus are markedly shorter and appressed or decumbent. Toruli surpassing the posterior clypeal margin in oblique anterodorsal view. The scapes surpass the posterior margin of the head by a length equal to the maximal diameter of the eye or less; they have appressed hairs. Ocelli inconspicuous. Eyes are positioned on the cephalic midline and have 7-9 ommatidia along their maximal diameter.

Mesosoma. Typically with two erect hairs on the pronotum and two on the mesonotum. The mesonotum is not inflated and does not bulge dorsally above the pronotum in lateral view.

Metanotal groove absent or narrower than the diameter of the metathoracic spiracles.

Metathoracic spiracles in dorsolateral position, not protruding, and usually touching the propodeal sutures. Dorsum of the propodeum is convex and shorter than the propodeal slope.

Propodeal spiracles circular, positioned slightly ventral of the posterior propodeal margin, at the middle of the propodeal slope. Legs with appressed and scattered hairs. Petiole short and inclined

Gaster. Usually with dense pubescence, and scattered long erect hairs, among others at the edges of the segments.

Color and sculpture. Body smooth, shiny and yellowish. 
Distribution (Supplementary material Fig. S39). Brachymyrmex termitophilus is known from

Biology. Forel (1895b) indicated that this species was collected in association with termites.

Remarks. The type material of B. termitophilus at the MHNG is somewhat problematic and may have caused confusion as to the diagnostic traits of the species (see below). This material consists of specimens mounted on three pins of which one (USNMENT00757136) holds an undescribed queen; the second (USNMENT00757137) holds a brownish worker with dense pubescence on

4212 the gaster, which is here designated as lectotype, and the gaster of another worker of which the 4213 rest of the body is missing; the third pin (USNMENT00757138) holds two workers with

4214 yellowish heads and mesosoma, and a darker gaster which bears scarce pubescence.

4215 Originally, Forel (1895b) described B. termitophilus as a variety of B. heeri that is slightly

4216 smaller than the typical form, that has longer scapes, and a somewhat sparser pubescence but 4217 denser, thicker erect hairs, mainly on the gaster. Wild (2007) subsequently elevated $B$.

4218 termitophilus to species level reporting two differences with $B$. heeri, i.e. the length of the scapes 4219 and the lateral morphology of the mesosoma. The first trait is suspect, however, as he reports the 4220 scapes of $B$. termitophilus to bearly reach the posterior margin of the head, which contrasts 4221 strongly with the original statement by Forel (1895b). We believe that this error caused Wild 4222 (2007) to suggest that B. termitophilus may be conspecific with $B$. fiebrigi. The latter species has 4223 indeed scapes that do not reach the posterior margin of the head. Rather than B. fiebrigi, $B$. 4224 termitophilus resembles the species here mentioned in the diagnosis. The status of $B$. 4225 termitophilus is unclear: Several of the specimens in the type series of B. termitophilus 
morphologically resemble $B$. australis and B. aphidicola in having scarce pubescence on the gaster. Additionally, Santschi (1923a) mentioned that B. termitophilus and B. australis are both found in association with termites. As mentioned in the diagnosis also the differences with $B$. cordemoyi and B. obscurior are limited, and B. termitophilus may be conspecific with one or several of these four species mentioned in the diagnosis. We tentatively preserve the current 4231 status of $B$. termitophilus awaiting more material and study.

Brachymyrmex tristis Mayr

CASENT0915737; here designated): 1 worker [examined]. COLOMBIA: Santafé de Bogotá. See also: Santschi (1923a: 673).

Additional material examined. COLOMBIA: Boyacá: Chinquinquirá, 07 Dec. 1975, W. \& E. MacKay \#572, 2 workers (WEMC: USNMENT00757574); Cundinamarca: Mosquera to La

4243 Mesa, km 8, >2600 m, arid slope, under rock, 30 June 1976, W.L. \& D.E. Brown, 18 workers, 2 queens, 3 males (MCZC: USNMENT00757280-00757282, 00757306-00757311).

Diagnosis. Brachymyrmex tristis morphologically resembles B. degener and B. coactus, because all three species have scapes that surpass the posterior margin of the head, they have faint sculpture on the mesosoma, their mesonotum bulges dorsally above the pronotum in lateral view, 4249 their metanotal groove is wider than the diameter of the metathoracic spiracles, the metathoracic 
4250 spiracles slightly protrude, and the gaster has sparse pubescence. Brachymyrmex tristis differs

4251 from B. coactus by having a uniform body color and dense decumbent hairs on the head. It differs

4252 from B. degener by having many decumbent hairs on the head.

4254 Lectotype worker measurements (mm). $\mathrm{HL}_{1} 0.61 ; \mathrm{HL}_{2} 0.38 ; \mathrm{HL}_{3} 0.15 ; \mathrm{HW} 0.56$; SL 0.61; EL

4255 0.15; WL 0.70; PnL 0.17; PnW 0.39; ML 0.17; MW 0.30; Indices CI 92.50; SI1108.11; SI 2

$4256 \quad 160.00 ; \mathrm{OI}_{1} 27.03 ; \mathrm{OI}_{2} 25.00$.

Description. Head. Slightly longer than wide in full face view; posterior cephalic margin slightly concave. Dorsum of the head with dense decumbent pubescence. Clypeus with a rounded anterior margin and five long, erect hairs of which a single, usually conspicuous hair is near the anterior margin, two hairs are in mediolateral position and two more near the toruli; other hairs on the clypeus are markedly shorter and appressed or decumbent. Toruli surpassing the posterior clypeal margin in oblique anterodorsal view. The scapes surpass the posterior margin of the head by a length up to $1.5 \times$ the maximal diameter of the eye; they have appressed hairs. Three ocelli are present. Eyes are positioned on the cephalic midline and have 10-12 ommatidia along their maximal diameter.

Mesosoma. With two erect hairs on the pronotum and usually also two on the mesonotum. The mesonotum is slightly inflated and bulges dorsally above the pronotum in lateral view. Metanotal groove wider than the diameter of the metathoracic spiracles. Metathoracic spiracles in

4270 dorsolateral position, slightly protruding, and not touching any sutures. Dorsum of the 4271 propodeum slightly convex and shorter than propodeal slope. Propodeal spiracles circular, 4272 positioned ventral of the posterior propodeal margin, at the middle of the propodeal slope. Legs 4273 with appressed hairs. Petiole short and inclined forward. 
Manuscript submitted to: Organisms Diversity \& Evolution

Published version available; DOI: 10.1007/s13127-019-00406-2

4274 Gaster. With scattered pubescence and several scattered long erect hairs.

4275 Color and sculpture. Head and gaster are smooth and shiny, whereas the mesosoma has faint 4276 sculpture; body uniformly dark brown apart from the tarsi of the legs which are lighter in color.

4278 Distribution (supplementary material Fig. S40). Brachymyrmex tristis is only known from 4279 Colombia.

Biology. Unknown.

Remarks. Brachymyrmex tristis is as mentioned morphologically very similar to B. degener and conspecific. For now, we follow previous authors in maintaining them as separate species.

Forel (1899) initially considered B. musculus to be a race of B. tristis, however, we agree with his later decision to consider B. musculus distinct (Forel 1901a). Santschi (1923a) also considers B. musculus to be closely related to $B$. tristis, however, the first species has a mesonotum that does not bulge dorsally above the pronotum in lateral view, and its metathoracic spiracles are not 4290 protruding.

\section{Additional taxonomic remarks.}

4293 We could not include information on B. longicornis var. pullus Santschi, 1933 in the above 4294 because the type series consists of a single, destroyed worker (NHMB). As such, we could only 4295 re-examine the morphological descriptions of Santschi (1933), from which we conclude that $B$. 4296 longicornis var. pullus seems to be morphologically similar to B. patagonicus and B. bruchi. 4297 Brachymyrmex longicornis var. pullus has a shiny body that is black or dark brownish, the scapes 
Manuscript submitted to: Organisms Diversity \& Evolution

Published version available; DOI: 10.1007/s13127-019-00406-2

4298 surpass the posterior margin of the head, it has large eyes that occupy a third of the sides of the

4299 head, and the thorax would have been similar to that of B. longicornis wich indicates that the

4300 mesonotum did not bulge dorsally above the pronotum in lateral view. Santschi (1933) did not

4301 describe the pubescence on the gaster, and so in the above we consider the pubescence to be

4302 similar to that of typical B. longicornis (here synonymized to B. australis), B. longicornis var.

4303 hemiops (here synonymized to B. aphidicola) and B. longicornis var. immunis (here synonymized

4304 to B. admotus). If this assumption were not true B. longicornis var. pullus would resemble B.

4305 cordemoyi and B. obscurior more than B. bruchi and B. patagonicus.

4306

4307 Morphometric measurements.

4308 Although the abovementioned identifications mention morphometric measurements, indices and

4309 count data, our identification system and the key were constructed before analysis of quantitative

4310 data, and thus somewhat independent from the quantitative comparison that follows. Here, we

4311 examine how well measurements corroborate the established identification system.

4312 The morphospace occupation of the various species is displayed in Fig. 54. The stress associated

4313 with nmMDS is small (5.70), indicating that this ordination is reliable and the risk of drawing

4314 false inferences very limited. The contribution of the individual morphometric variables

4315 (measurements, indices and counts) to the morphospace is indicated with a biplot. Permutation

4316 tests revealed that all variables contributed significantly to the morphospace occupation of taxa,

4317 apart from $\mathrm{OI}_{1}$, and therefore we excluded this index from further statistical tests. Overall, many

4318 of the 38 species included occupy very similar regions of the morphospace, which testifies to the

4319 cryptic nature of morphological differences among these taxa, and therefore to the legacy of

4320 difficulties with species identifications that have plagued workers of Brachymyrmex (see Wheeler 

genus is overall characterized by a large degree of morphological conservatism. However, upon more detailed examination we also perceive that most taxa occupy rather restricted regions of the morphospace, despite measurements typically deriving from specimens obtained from distant

4326 localities. For example, even widespread species, such as B. patagonicus occupy a rather restricted region of the morphospace. One notable exception is B. bruchi, which displays large variation on both nmMDS1 and 2, and which is difficult to characterize morphologically

4329 (although molecular analyses suggest our identification system works well for this species too 4330 [see below]). Beyond the measured traits, the first nmMDS axis also reflects general differences

4331 in body size, with small species (B. depilis, donisthorpei, fiebrigi, iridescens, and feitosai) 4332 plotting along the most negative and large species (B. admotus, cavernicola, and degener) along 4333 the most positive values. The overall restricted morphospace occupation of individual species 4334 testifies to the possibility to distinguish many species in one-on-one comparisons, and we examine this issue for univariate variables, because such univariate comparisons may be more 4336 helpful than multivariate comparisons for colleagues aiming to identify specimens directly in the 4337 field. Boxplots (Figs. 55, 56) highlight similarities and differences among 20 Brachymyrmex species 4340 for the 16 univariate variable (after exclusion of $\mathrm{OI}_{1}$ ) with statistical pairwise comparisons. Here we will not exhaustively compare all these species for each of the variables, as this would lead to 43423040 pairwise comparisons. Rather, we will focus on comparing five species pairs that are 4343 difficult to distinguish, i.e. aphidicola-australis, bruchi-patagonicus, coactus-degener, 4344 cordemoyi-obscurior and donisthorpei-modestus, with the aim to find additional criteria that may 
Manuscript submitted to: Organisms Diversity \& Evolution

Published version available; DOI: 10.1007/s13127-019-00406-2

4345 allow differentiating these taxa. Brachymyrmex aphidicola-australis differ significantly in $\mathrm{SI}_{1}$

4346 and $\mathrm{SI}_{2}$, but not in other variables. Brachymyrmex bruchi-patagonicus display significant

4347 differences in $\mathrm{HL}_{1}, \mathrm{HL}_{2}, \mathrm{HW}, \mathrm{SL}, \mathrm{EL}, \mathrm{WL}, \mathrm{PnL}$, and $\mathrm{PnW}$ suggesting that the main difficulty

4348 differentiating these taxa relates to the very variable nature of B. bruchi, as already highlighted

4349 above. Brachymyrmex coactus and B. degener are effectively very difficult to distinguish as the

4350 only significant difference we found is in $\mathrm{OI}_{2}$, which was admittedly very variable for $B$. degener.

4351 Although B. cordemoyi and B. obscurior overlapped strongly in morphospace occupation, they

4352 can nevertheless be distinguished based on $\mathrm{HL}_{1}, \mathrm{HL}_{2}, \mathrm{HL}_{3}$, HW, EL, PnL, PnW, MI, MW, $\mathrm{SI}_{1}$,

4353 and the number of ommatidia. For several of these variables, B. obscurior showed limited

4354 variation, despite the inclusion of 10 specimens from 4 different countries, which may have

4355 driven statistical significance. Finally, B. donisthorpei and B. modestus differed significantly in

$4356 \mathrm{HL}_{1}, \mathrm{HL}_{3}, \mathrm{HW}, \mathrm{SL}, \mathrm{WL}, \mathrm{MW}, \mathrm{CI}$, and $\mathrm{OI}_{2}$. In summary, the morphometric variables confirm

4357 significant morphological differences for all five species pairs. Intrestingly, as we will document

4358 in the next section, the two species pairs with the most limited number of differences, i.e.

4359 aphidicola-australis and especially coactus-degener are phylogenetically closely related (see 4360 below).

4361

4362 Phylogenetic inference.

4363 Our phylogenetic analyses with maximum parsimony (MP), maximum likelihood (ML) and

4364 Bayesian Inference (BI) on five gene fragments (three nuclear, two mitochondrial) for 19

4365 Brachymyrmex species, 5 species of its sister clade Myrmelachista and outgroups retrieved

4366 Brachymyrmex and Myrmelachista as a well-supported monophyletic clade (MP $=98, \mathrm{ML}=100$,

4367 BPP=1.00; Fig.57). This finding agrees with recent studies of the deep phylogenetic relationships

4368 within the subfamily Formicinae based on UCEs (ultraconserved elements: Blaimer et al. 2015; 
Ward et al. 2016), however, this previous study contained only two Brachymyrmex and one

Myrmelachista species. Under expanded taxon sampling Brachymyrmex and Myrmelachista were

4371

4372

4373

4374

4375

4376

4377

4378

4379

4380

4381

4382

4383

4384

4385

4386

4387

4388

4389

4390

4391

4392

found to be reciprocally monophyletic, with high support for each genus ( $\mathrm{MP}=98, \mathrm{ML}=100$, $\mathrm{BPP}=1.00$ and $\mathrm{MP}=96, \mathrm{ML}=82, \mathrm{BPP}=1.00$, respectively). This finding suggests that the morphological criteria currently used to delimit these genera are unambiguous autapomorphies.

Examining Brachymyrmex in more detail, many of the nodes of intermediate depth are poorly supported, indicating that more markers are required, or at least more complete sampling of markers across taxa, to reveal the phylogenetic relationships between individual Brachymyrmex species. Given that our analysis includes half of the currently recognized Brachymyrmex species, increased taxon sampling may also help to resolve phylogenetic relationships among the species.

Despite ambiguity as to interspecific relationships, species-level nodes (indicated in bold in Fig. 57) are overall well-supported, and of the14 Brachymyrmex species that were sampled with 2-15 specimens, 13 proved to be monophyletic. This finding largely confirms our assessment of intraspecific and interspecific components of morphological variation, the phylogenetic value of the morphological traits used, and thus the significance of our proposed morphological system of species delimitations. The only species that was not retrieved as monophyletic is $B$. coactus, which included the monophyletic $B$. degener. Brachymyrmex coactus and B. degener are morphologically very similar (as indicated already above in the taxonomic treatment and morphometrics), and they mainly differ in body color, which may be a trait with large intraspecific variation. Significant differences between both species were also found in $\mathrm{OI}_{2}$, although $B$. degener is very variable as to this index. On the other hand, the genetic differentiation between $B$. coactus and $B$. degener is substantial, as indicated by the branch lengths in Fig. 57, suggesting that both may be part of a larger clade with cryptic diversity, and 
that the observed bimodal distribution in body color may hint at interspecific differences.

4394 Considering the substantial genetic differentiation, we do not synonymize both species but rather postpone our assessment until more specimens become available, especially of B. coactus from Brazil. Another possible indication of cryptic species diversity relates to B. cavernicola, which contains two well-supported subclades, one with specimens from Central America, and the other

4398 clade with specimens from South America. More in-depth studies are required to test whether this split relates to different species, or rather variation between geographically-separated populations. The hypothesis of cryptic diversity is furthermore supported by the ABGD analysis 4401 (see below).

4402 For B. feitosai, B. nebulosus, B. pilipes, B. brasiliensis and B. bicolor n. sp. only a single 4403 individual per species was included in the phylogenetic analyses so that it is difficult to make 4404 conclusions on the integrity of these species, however, all these species are deeply split from 4405 other Brachymyrmex species, suggesting that they are truly distinct. It was particularly important 4406 for us to include B. pilipes, because this species has very distintive and different morphological 4407 traits (see species description) in comparison to most other Brachymyrmex species. Intrestingly, 4408 the species seems to have a basal position in our phylogeny and revealing its position in the 4409 future may yield important insights into trait evolution within the genus. Nevertheless, our 4410 phylogenetic analysis confirms that B. pilipes is part of Brachymyrmex, rather than an 4411 independent lineage.

\section{Automated species delimitation.}

4414 A total of 24 hypothetical species entities were retrieved within Brachymyrmex upon analyzing 4415 the barcoding fragment of COI (658 basepairs) with ABGD. Overall these entities are in good 4416 agreement with the morphologically-recognized species indicated in Fig. 57, and the differences 
Manuscript submitted to: Organisms Diversity \& Evolution

Published version available; DOI: 10.1007/s13127-019-00406-2

4417 are limited to the potential further subdivision of morphologically recognized species by ABGD.

4418 Within B. heeri four groups are recognized, with each group containing the specimens from one

4419 country in the phylogeny. Brachymyrmex antennatus is subdivided in two groups, with one group

4420 consisting of specimen CX81 from Peru and the other contains the additional specimens.

4421 Brachymyrmex cavernicola was subdivided in two groups also, along the main subdivision

4422 observed in Fig. 57 and discussed above, indicating that differentiation and perhaps cryptic

4423 speciation is taking place along a geographic gradient. The final difference relates to the $B$.

4424 coactus/degener clade. The ABGD analysis recognized three groups: one group containing only

4425 specimen CX37 from Brazil, the remainder of B. coactus as a second group, and the third group

4426 contains the specimens identified as B. degener. In summary, the ABGD analysis corroborates

4427 our morphological classification system. It suggests that this classification is conservative and

4428 that more cryptic diversity may exist within Brachymyrmex.

\section{CONCLUSIONS}

4431 For over a century the ant genus Brachymyrmex has been in dire need of revision, and here we 4432 present such a revision based on the morphology of workers, validated with morphometric and 4433 molecular data. Currently the strategy to focus on workers is the most effective solution to revise 4434 the genus, because other castes (queens and males) are poorly known for most Brachymyrex 4435 species. We studied 1303 samples that have been assigned to 40 species based on the established 4436 morphological identification system as represented in a dichotomous identification key, which we 4437 tested with previous and new material. Additionally, this key was tested independently by several 4438 colleagues (Fabiana Cuezzo (Argentina), John Lattke and Lívia Pires do Prado (Brazil)), and the 4439 obtained identifications were in good agreement with our own diagnoses, suggesting that it 4440 effectively allows discerning interspecific differences from intraspecific variation. Beyond these 
4441 qualitative tests we also complemented our identifications with measurements to reconstruct the 4442 distribution of species in morphospace, and we statistically analyzed individual measurements as 4443 univariate variables. These efforts suggest that even species pairs that are qualitatively difficult to 4444 discern can be separated statistically, and they illustrated that taxonomically problematic cases 4445 relate to taxa that have high intraspecific trait variance. The species pair that was most difficult to 4446 discern based on measurements proved to be B. coactus and B. degener, and interestingly, these 4447 taxa represent the only disagreement between our morphological identification system and our 4448 phylogenetic analysis based on five gene fragments. Brachymyrmex degener was nested within $B$. 4449 coactus but considering the deep phylogenetic splits in the coactus-degener clade and the results 4450 from automated species delimitation, we await more material to resolve the status of the 4451 morphospecies in this clade. In summary, 13 of the 14 morphologically-identified species that 4452 were included in molecular work with 2-15 individuals each were recovered as monophyletic, 4453 indicating the overall robustness of our proposed morphological identification system, and by 4454 extension our taxonomic revision. Finally, we have reported dimorphic workers for some 4455 Brachymyrmex species and the existence of a putative worker-queen intercaste in others. As such, 4456 the genus altogether may represent a promising system to study caste evolution in ants.

4458 ACKNOWLEDGMENTS

4459 We thank Alex Wild (ALWC), Brian Fisher (CASC), Jacques Delabie (CPDC), Claudia Medina

4460 (IAvH), John Longino (JTLC), Carlos R. F. Brandão, Rodrigo Feitosa, Flávia Esteves (MZSP), 4461 Stefan Cover (MCZC), Heraldo Vasconcelos, Renata Pacheco, Gabriela Camacho (UFUC), 4462 Maria Tavano and Roberto Poggi (MCSN), Daniel Burckhardt (NHMB), Dominique 4463 Zimmermann (NHMW), Frank Koch (MfNB), Fabiana Cuezzo (INSUE), Priscila Hanisch 4464 (MACN), Phil Ward (PSWC), Maurice Leponce and Thibaut Delsinne (RBINS), William and 
Manuscript submitted to: Organisms Diversity \& Evolution

Published version available; DOI: 10.1007/s13127-019-00406-2

4465 Emma MacKay (WEMC) for providing acces to collections and/or for the loan of critical

4466 material. David Donoso and John Longino kindly provided sequencing data. Ted Schultz, Jeffrey

4467 Sosa-Calvo, Eugenia Okonski (USNM) and Carlos Sarmiento (ICN) provided continuous support

4468 in the development of this paper. John Lattke, Fabiana Cuezzo, Lívia Pires do Prado and an

4469 anonymous referee tested the identification key and providing invaluable comments and

4470 suggestions. Comments of John Longino, an anonymous referee and the editors have strongly

4471 improved this manuscript.

4472

4473 FUNDING INFORMATION

4474 We are grateful for funding from the Division de Investigación de Bogotá (DIB), Facultad de

4475 Ciencias, Universidad Nacional de Colombia and the Colciencias program "Proyectos de

4476 Investigación Científica y Tecnológica" of 2010 (110152128319 CT 413-2011) (to CMOS and

4477 FF), for an Ernst Mayr Grant in 2011 (MCZ Harvard University), a grant from the Colciencias

4478 program "Jóvenes Investigadores e Innovadores - Virginia Gutiérrez de Pineda" in 2010-2011, a

4479 grant of the Smithsonian National Museum of Natural History installed by Cristian Samper (to

4480 CMOS), CPER CLIMIBIO funded by the Région Hauts-de-France, the French Ministry of

4481 Higher Education and Research, and the European Fund for Regional Economic Development (to

4482 CMOS and BVB), the Institut de Recherches Pluridisciplinaires en Sciences de l'Environnement

4483 (IREPSE; to BVB) and ANR-JCJC-EVOLINK of the French Agence Nationale de la Recherche

4484 (to BVB).

4485

4486 CONFLICT OF INTEREST

4487 The authors declare that they have no conflict of interest. 
Manuscript submitted to: Organisms Diversity \& Evolution

Published version available; DOI: 10.1007/s13127-019-00406-2

\section{DATA AVAILABILITY}

Sequence data is deposited in NCBI Genbank [upon acceptance of the manuscript], and Genbank accession numbers are indicated in Supplementary Table S1. Measurement data are provided as an online supplementary file.

\section{REFERENCES}

Agosti, D. (1991). Revision of the oriental ant genus Cladomyrma, with an outline of the higher classification of the Formicinae (Hymenoptera: Formicidae). Systematic Entomology, 16, 293-310.

Alayo, D. P. (1974). Introducción al estudio de los Himenopteros de Cuba. Superfamilia Formicoidea. Academia de Ciencias de Cuba, 53, 1-58.

Amante, C., \& Eakins, B. W. (2009). ETOPO1 1 Arc-Minute Global Relief Model: Procedures, Data Sources and Analysis. NOAA Technical Memorandum NESDIS NGDC-24.

Benjamini, Y., \& Hochberg, Y. (1995). Controlling the false discovery rate: a practical and powerful approach to multiple testing. Journal of the Royal Statistical Society, Series $B(57), 289-230$.

Blaimer, B. B., Brady, S. G., Schultz, T. R., Lloyd, M. W., \& Ward, P. S. (2015). Phylogenomic methods outperform traditional multi-locus approaches in resolving deep evolutionary history: a case study of formicine ants. BMC Evolutionary Biology, 15, 1-14, doi:10.1186/s12862-015-0552-5.

Bolton, B. (1994). Identification guide to the ant genera of the world. Cambridge, Massachusetts: Harvard University Press.

Bolton, B. (1995). A new general catalogue of the ants of the world. Cambridge, Massachusetts: Harvard University Press. 
Manuscript submitted to: Organisms Diversity \& Evolution

Published version available; DOI: 10.1007/s13127-019-00406-2

Bolton, B. (2003). Synopsis and classification of Formicidae. Memoirs of the American Entomological Institute, 71, 1-370.

Bolton, B. (2007). How to conduct large-scale taxonomic revisions in Formicidae. Memoirs of the American Entomological Institute, 80, 52-71.

Bolton, B. (2018). An online catalog of ants of the world. http://www.antcat.org/. Accessed December 152016.

Brady, S. G., Schultz, T. R., Fisher, B. L., \& Ward, P. S. (2006). Evaluating alternative hypotheses for the early evolution and diversification of ants. Proceedings of the National Academy of Sciences of the United States of America, 103, 18172-18177.

Brandão, C. R. F. (1991). Adendos ao catálogo abreviado das formigas da região Neotropical (Hymenoptera: Formicidae). Revista Brasileira de Entomologia, 35, 319-412.

Brownrigg, R. (2015). Mapdata: Extra Map Databases (original S code by Becker R. A. and Wilks A. R). R package, Version 2.2-5.

Brownrigg, R., Minka, T. P., \& Deckmyn, A. (2015). Maps: draw geographical maps (original S code by Becker R. A. and Wilks A. R.). R package, Version 3.0.1.

Clarke, K. R. (1993). Non-parametric multivariate analyses of changes in community structure. Australian Journal of Ecology, 18, 117-143.

Cole, A. C. J. (1953). Studies of New Mexico ants. V. The genus Pheidole with synonymy (Hymenoptera: Formicidae). Journal of the Tennessee Academy of Science, 28, 297-299.

Creighton, W. S. (1950). The ants of North America. Bulletin of the Museum of Comparative Zoology, 104, 1-585.

Da Silva, R., Peloso, P. L. V., Sturaro, M. J., Veneza, I., Sampaio, I., Schneider, H., et al. (2018). Comparative analyses of species delimitation methods with molecular data in snappers (Perciformes: Lutjaninae) Mitochondrial DNA Part A, 29, 1108-1114. 
Manuscript submitted to: Organisms Diversity \& Evolution

Published version available; DOI: 10.1007/s13127-019-00406-2

De Zolessi, L. C., Abenante, Y. P., \& González, L. A. (1978). Descripción y observaciones bioetológicas sobre una nueva especie de Brachymyrmex (Hymenoptera: Formicidae). Revista de Biología del Uruguay, 4, 21-44.

Dejean, A., Fisher, B. L., Corbara, B., Rarevohitra, R., Randrianaivo, R., Rajemison, B., et al. (2010). Spatial distribution of dominant arboreal ants in a Malagasy coastal rainforest: Gaps and presence of an invasive species. PLOS ONE, 5(2), e9319, doi:10.1371/journal. pone.0009319.

Dinno, A. (2017). dunn.test: Dunn's test of multiple comparisons using rank sums. R package version 1.3.4.

Emery, C. (1893). Beiträge zur Kenntniss der nordamerikanischen Ameisenfauna. Zoologische Jahrbücher. Abteilung für Systematik, Geographie und Biologie der Tiere, 7, 633-682.

Emery, C. (1895). Note sur les fourmis du Chili avec descriptions de deux espèces nouvelles. Actes de la Société Scientifique du Chili, 4, 213-216.

Emery, C. (1906). Studi sulle formiche della fauna Neotropica. XXVI. Bullettino della Società Entomologica Italiana, 37, 107-194.

Emery, C. (1925). Hymenoptera. Fam. Formicidae. Subfam. Formicinae. Genera Insectorum, 183, 1-302.

Fisher, B. L., \& Cover, S. P. (2007). Ants of North America. A guide to genera: Berkeley: University of California Press.

Forel, A. (1874). Les fourmis de la Suisse. Systématique, notices anatomiques et physiologiques, architecture, distribution géographique, nouvelles expériences et observations de moeurs. Neue Denkschriften der Allgemeinen Schweizerischen Gesellschaft für die Gesammten Naturwissenschaften, 26, 1-452. 
Manuscript submitted to: Organisms Diversity \& Evolution

Published version available; DOI: 10.1007/s13127-019-00406-2

4560 Forel, A. (1876). Études myrmécologiques en 1875 avec remarques sur un point de l'anatomie

4561

4562

4563

4564

4565

4566

4567

4568

4569

4570

4571

4572

4573

4574

4575

4576

4577

4578

4579

4580

4581

4582

4583

des coccides. Bulletin de la Société Vaudoise des Sciences Naturelles, 14, 33-62.

Forel, A. (1893). Formicides de l'Antille St. Vincent, récoltées par Mons. H. H. Smith. Transactions of the Entomological Society of London, 333-418.

Forel, A. (1895a). Nouvelles fourmis de diverses provenances, surtout d'Australie. Annales de la Société Entomologique de Belgique, 39, 41-49.

Forel, A. (1895b). Die Ameisen- und Termitengäste von Brasilien. Anhang. Beschreibung einiger neuer brasilianischer Ameisenarten. . Verhandlungen der Kaiserlich-Königlichen Zoologisch-Botanischen Gesellschaft in Wien, 45, 178-179.

Forel, A. (1897). Quelques Formicides de l'Antille de Grenada récoltés par M. H. H. Smith. Transactions of the Entomological Society of London, 297-300.

Forel, A. (1899). Formicidae. [part]. Biologia Centrali-Americana Hymenoptera, 3, 105-136.

Forel, A. (1901a). I. Fourmis mexicaines récoltées par M. le professeur W.-M. Wheeler. II. A propos de la classification des fourmis. Annales de la Société Entomologique de Belgique, 45, 123-141.

Forel, A. (1901b). Einige neue Ameisen aus Südbrasilien, Java, Natal und Mossamedes. Mitteilungen der Schweizerischen Entomologischen Gesellschaft, 10, 297-311.

Forel, A. (1902). Fourmis nouvelles d'Australie. . Revue Suisse de Zoologie, 10, 405-548.

Forel, A. (1907). Formiciden aus dem Naturhistorischen Museum in Hamburg. II. Teil. Neueingänge seit 1900. Mitteilungen aus dem Naturhistorischen Museum in Hamburg, $24,1-20$.

Forel, A. (1908). Ameisen aus Sao Paulo (Brasilien), Paraguay etc. gesammelt von Prof. Herm. v. Ihering, Dr. Lutz, Dr. Fiebrig, etc. Verhandlungen der Kaiserlich-Königlichen Zoologisch-Botanischen Gesellschaft in Wien, 58, 340-418. 
Manuscript submitted to: Organisms Diversity \& Evolution

Published version available; DOI: 10.1007/s13127-019-00406-2

4584 Forel, A. (1909). Ameisen aus Guatemala usw., Paraguay und Argentinien (Hym.). Deutsche Entomologische Zeitschrift, 1909, 239-269.

4586

4587

4588

4589

4590

4591

4592

4593

4594

4595

4596

4597

4598

4599

4600

4601

4602

4603

4604

4605

4606

Forel, A. (1911). Ameisen des Herrn Prof. v. Ihering aus Brasilien (Sao Paulo usw.) nebst einigen anderen aus Südamerika und Afrika (Hym.). Deutsche Entomologische Zeitschrift, 285312.

Forel, A. (1912a). Formicides néotropiques. Part VI. 5me sous-famille Camponotinae Forel. Mémoires de la Société Entomologique de Belgique, 20, 59-92.

Forel, A. (1912b). The Percy Sladen Trust Expedition to the Indian Ocean in 1905, under the leadership of Mr. J. Stanley Gardiner, M.A. Volume 4. No. XI. Fourmis des Seychelles et des Aldabras, reçues de M. Hugh Scott. Transactions of the Linnean Society of London. Zoology, 15(2), 159-167.

Forel, A. (1914). Formicides d'Afrique et d'Amérique nouveaux ou peu connus. Bulletin de la Société Vaudoise des Sciences Naturelles, 50, 211-288.

Guénard, B., Weiser, M., Gomez, K., Narula, N., \& Economo, E. P. (2017). The Global Ant Biodiversity Informatics (GABI) database: a synthesis of ant species geographic distributions. Myrmecological News 24, 83-89.

Guénard, B. (2018). First record of the emerging global pest Brachymyrmex patagonicus Mayr 1868 (Hymenoptera: Formicidae) from continental Asia. Asian Myrmecology, 10, 1-6 (doi: 10.20362/am.010012).

Grundmann, A. W. (1952). A new Brachymyrmex from northern Utah Journal of the Kansas Entomological Society, 25, 117.

Harris, R. A. (1979). A glossary of surface sculpturing. California Department of Food and Agriculture. Laboratory Services, Entomology. Occasional Papers, 28, 1-31. 
Manuscript submitted to: Organisms Diversity \& Evolution

Published version available; DOI: 10.1007/s13127-019-00406-2

Hebert, P. D. N., Cywinska, A., Ball, S. L., \& DeWaard, J. R. (2003). Biological identifications through DNA barcodes Proceedings of the Royal Society B-Biological Sciences, 270, 313321.

Janicki, J., Narula, N., Ziegler, M., Guénard, B., \& Economo, E.P. (2016). Visualizing and interacting with large-volume biodiversity data using client-server web-mapping applications: The design and implementation of antmaps.org. Ecological Informatics 32, 185-193.

Katoh, K., \& Standley, D. M. (2013). MAFFT Multiple Sequence Alignment Software Version 7: Improvements in Performance and Usability. Molecular Biology and Evolution, 30, 778780.

Kempf, W. W. (1972). Catálogo abreviado das formigas da região Neotropical. Studia Entomologica, 15, 3-344.

Kruskal, J. (1964). Multidimensional scaling by optimizing goodness of fit to a nonmetric hypothesis Psychometrika, 29, 1-27.

Kugler, C. (1994). A revision of the ant genus Rogeria with description of the sting apparatus (Hymenoptera: Formicidae). Journal of Hymenoptera Research, 3, 17-89.

Kusnezov, N. (1959). La fauna de hormigas en el oeste de la Patagonia y Tierra del Fuego. Acta Zoológica Lilloana. Tucumán. Argentina, 17, 321-401.

Kusnezov, N. (1960). Brachymyrmex physogaster n. sp. aus Argentinien und das Problem der Physogastrie bie den Ameisen. Zoologischer Anzeiger, 165, 381-388.

Lanfear, R., Calcott, B., \& Ho, S. Y. W. (2012). Guindon S PartitionFinder: combined selection of partitioning schemes and substitution models for phylogenetic analyses Molecular Biology and Evolution, 29(6), 1695-1701, doi:http://dx.doi.org/10.1093/molbev/mss020. 
Manuscript submitted to: Organisms Diversity \& Evolution

Published version available; DOI: 10.1007/s13127-019-00406-2

4630 LaPolla, J. S., Brady, S. G., \& Shattuck, S. O. (2010). Phylogeny and taxonomy of the Prenolepis genus-group of ants (Hymenoptera: Formicidae). Systematic Entomology, 35, 118-131.

4632

4633

4634

4635

4636

4637

4638

4639

4640

4641

4642

4643

4644

4645

4646

4647

4648

4649

4650

4651

LaPolla, J. S., \& Longino, J. T. (2006). An unusual new Brachymyrmex Mayr (Hymenoptera: Formicidae) from Costa Rica, with implications for the phylogeny of the Lasiine tribe group. Proceedings of the Entomological Society of Washington, 108, 297-305.

Leliaert, F., Verbruggen, H., Vanormelingen, P., Steen, F., López-Bautista, J. M., Zuccarello, G. C., et al. (2014). DNA-based species delimitation in algae European Journal of Phycology, 49, 179-196.

MacGown, J. A., Hill, J. G., \& Deyrup, M. A. (2007). Brachymyrmex patagonicus (Hymenoptera: Formicidae), an emerging pest species in the southeastern United States. Florida Entomologist, 90, 457-464.

Maddison, W. P., \& Maddison, D. R. (2017). Mesquite: a modular system for evolutionary analysis. (2.10 ed.).

Mayr, G. (1868). Formicidae novae Americanae collectae a Prof. P. de Strobel. Annuario della Società dei Naturalisti e Matematici, Modena, 3, 161-178.

Mayr, G. (1870). Formicidae novogranadenses. Sitzungsberichte der Kaiserlichen Akademie der Wissenschaften in Wien. Mathematisch-Naturwissenschaftliche Classe. Abteilung I, 61, $370-417$.

Mayr, G. (1887). Südamerikanische Formiciden. Verhandlungen der Kaiserlich-Königlichen Zoologisch-Botanischen Gesellschaft in Wien, 37, 511-632.

Menozzi, C. (1927). Formiche raccolte dal Sig. H. Schmidt nei dintorni di San José di Costa Rica (Schluss). Entomologische Mitteilungen. Berlin-Dahlem, 16, 336-345. 
Manuscript submitted to: Organisms Diversity \& Evolution

Published version available; DOI: 10.1007/s13127-019-00406-2

Miller, M. A., Pfeiffer, W., \& Schwartz, T. "Creating the CIPRES Science Gateway for inference of large phylogenetic trees". In Proceedings of the Gateway Computing Environments Workshop (GCE), New Orleans, LA, 14 Nov. 20102010 (pp. 1-8)

Moreau, C. S., Bell, C. D., Vila, R., Archibald, S. B., \& Pierce, N. E. (2006). Phylogeny of the ants: diversification in the age of angiosperms. Science, 312, 101-104.

Moretti, T. C., Quirán, E. M., Solis, D. R., Rossi, M. L., \& Thyssen, P. J. (2011). Pycnoscelus surinamensis (Linnaeus, 1758) (Blaberoidea: Blaberidae), a cockroach with a possible association with the ant Brachymyrmex cordemoyi Forel, 1895 (Hymenoptera: Formicidae) and which may be exhibiting a domiciliation trend. Symbiosis, 53, 37-39, doi:10.1007/s13199-010-0101-3.

Oksanen, J., Blanchet, F. G., Kindt, R., Legendre, P., Minchin, P. R., O’Hara, R. B., et al. (2015). vegan: Community Ecology Package. Version 2.3-0.

Ortiz, C. M., \& Fernández, F. (2014). Brachymyrmex species with tumuliform metathoracic spiracles: description of three new species and discussion of dimorphism in the genus (Hymenoptera, Formicidae). ZooKeys, 371, 13-33.

Page, R.E., Jr. (1982) Polyandry in Brachymyrmex depilis Emery (Hymenoptera: Formicidae). Pan-Pacific Entomologist, 58, 258.

Peeters, C. P. (1991). Ergatoid queens and intercast in ants: two distinct adult forms wich look morphologically intermediate between workers and winged queens. Insectes Sociaux, 38(1), 1-15, doi:doi: 10.1007/BF01242708.

Pons, J., Barraclough, T. G., Gomez-Zurita, J., Cardoso, A., Duran, D. P., Hazell, S., et al. (2006). Sequence-based species delimitation for the DNA taxonomy of undescribed insects Systematic Biology, 55, 595-609. 
Manuscript submitted to: Organisms Diversity \& Evolution

Published version available; DOI: 10.1007/s13127-019-00406-2

4675

4676

4677

4678

4679

4680

4681

4682

4683

4684

4685

4686

4687

4688

4689

4690

4691

4692

4693

4694

4695

4696

4697

4698

Puillandre, N., Lambert, A., Brouillet, S., \& Achaz, G. (2011). ABDG, Automatic Barcode Gap Discovery for primary species delimitation Molecular Ecology, 21, 1864-1877.

Quirán, E. M. (2005). El género neotropical Brachymyrmex Mayr (Hymenoptera: Formicidae) en la Argentina. II: Redescripción de las especies B. admotus Mayr, de B. brevicornis Emery y B. gaucho Santschi. Neotropical Entomology, 34, 761-768.

Quirán, E. M. (2007). El género neotropical Brachymyrmex Mayr (Hymenoptera: Formicidae) en la Argentina. III: Redescripción de las especies: B. aphidicola Forel, de B. australis Forel y B. constrictus Santschi. Neotropical Entomology, 36, 699-706.

Quirán, E. M., Martínez, J. J., \& Bachmann, A. O. (2004). The Neotropical genus Brachymyrmex Mayr, 1868 (Hymenoptera: Formicidae) in Argentina. Redescription of the type species, B. patagonicus Mayr,1868; B. bruchi Forel, 1912 and B. oculatus Santschi, 1919. Acta Zoológica Mexicana, 20, 273-285.

R Core Team (2015). R: A language and environment for statistical computing. Version 3.2.1. Vienna, Austria: R Foundation for Statistical Computing.

Rambaut, A. (2012). FigTree. Version 1.4.0.

Rambaut, A., Suchard, M. A., Xie, D., \& Drummond, A. J. (2013). Tracer. Version 1.6.

Roger, J. (1863). Die neu aufgeführten Gattungen und Arten meines Formiciden-Verzeichnisses, nebst Ergänzung einiger früher gegeben Beschreibungen. Berliner Entomologische Zeitschrift, 7, 131-214.

Ronquist, F., Teslenko, M., Van der Mark, P., Ayres, D., Darling, A., Höhna, S., et al. (2012). MrBayes 3.2: Efficient Bayesian phylogenetic inference and model choice across a large model space Systematic Biology, 61(3), 539-542.

Santschi, F. (1912). Quelques fourmis de l'Amérique australe. Revue Suisse de Zoologie, 20, 519534. 
Manuscript submitted to: Organisms Diversity \& Evolution

Published version available; DOI: 10.1007/s13127-019-00406-2

4699 Santschi, F. (1916). Formicides sudaméricains nouveaux ou peu connus. Physis (Buenos Aires), $4700 \quad 2,365-399$.

4701 Santschi, F. (1917). Description de quelques nouvelles fourmis de la République Argentine. $4702 \quad$ Anales de la Sociedad Cientifica Argentina, 84, 277-283.

4703 Santschi, F. (1919). Nouveaux formicides de la République Argentine. Anales de la Sociedad $4704 \quad$ Cientifica Argentina, 87, 37-57.

4705 Santschi, F. (1922). Description de nouvelles fourmis de l'Argentine et pays limitrophes. Anales 4706 de la Sociedad Cientifica Argentina, 94, 241-262.

4707 Santschi, F. (1923a). Revue des fourmis du genre Brachymyrmex Mayr. Anales del Museo $4708 \quad$ Nacional de Historia Natural de Buenos Aires, 31, 650-678.

4709 Santschi, F. (1923b). Solenopsis et autres fourmis néotropicales. Revue Suisse de Zoologie, 30, $4710 \quad 245-273$.

4711 Santschi, F. (1929). Nouvelles fourmis de la République Argentine et du Brésil. Anales de la $4712 \quad$ Sociedad Cientifica Argentina, 107, 273-316.

4713 Santschi, F. (1933). Fourmis de la République Argentine en particulier du territoire de Misiones. $4714 \quad$ Anales de la Sociedad Cientifica Argentina, 116, 105-124.

4715 Santschi, F. (1939). Études et descriptions de fourmis néotropiques. Revista de Entomologia (Rio 4716 de Janeiro), 10, 312-330.

4717 Sharaf, M. R., Salman, S., Aldhafer, H. M., Youysef, A. F. A., \& Aldawood, A. S. (2016). First 4718 occurrence of the ant genus Brachymyrmex Mayr, 1868 (Hymenoptera: Formicidae) from 4719 the Kingdom of Saudi Arabia. Sociobiology, 63(2), 800-803, $4720 \quad$ doi:10.13102/sociobiology.v63i2.981. 
Manuscript submitted to: Organisms Diversity \& Evolution

Published version available; DOI: 10.1007/s13127-019-00406-2

Smith, D. R. (1979). Superfamily Formicoidea. In K. V. Krombein, P. D. Hurd, D. R. Smith, \& B. D. Burks (Eds.), Catalog of Hymenoptera in America north of Mexico. Volume 2. Apocrita (Aculeata) (pp. 1323-1467). Washington, D.C.: Smithsonian Institution Press.

Smith, M. R. (1955). Ants of the genus Pheidole, subgenus Hendecapheidole (Hymenoptera, Formicidae). Proceedings of the Entomological Society of Washington, 57, 301-305.

Snelling, R. R., \& Hunt, J. H. (1975). The ants of Chile (Hymenoptera: Formicidae). Revista Chilena de Entomología, 9, 63-129.

Stamatakis, A., Hoover, P., \& Rougemont, J. (2008). A Rapid Bootstrap Algorithm for the RAxML Web-Servers. Systematic Biology, 75(5), 758-771.

Swofford, D. L. (2002). PAUP*: Phylogenetic analysis using parsimony (*and other methods). Version 4.0b: Sinauer Associates; Sunderland, Massachussetts.

Venables, W. N., \& Ripley, B. D. (2002). Modern Applied Statistics with S (4ed.). New York: Springer.

Ward, P. S. (1989). Systematic studies on pseudomyrmecine ants: revision of the Pseudomyrmex oculatus and P. subtilissimus species groups, with taxonomic comments on other species. Quaestiones Entomologicae, 25, 393-468.

Ward, P. S., Blaimer, B. B., \& Fisher, B. L. (2016). A revised phylogenetic classification of the ant subfamily Formicinae (Hymenoptera: Formicidae), with resurrection of the genera Colobopsis and Dinomyrmex. Zootaxa, 4072, 343-357.

Wheeler, G. C., \& Wheeler, J. (1953). The ant larvae of the myrmicine tribe Pheidolini (Hymenoptera, Formicidae). Proceedings of the Entomological Society of Washington, $55,49-84$.

Wheeler, G. C., \& Wheeler, J. (1978). Brachymyrmex musculus, a new ant in the United States. Entomological News, 89, 189-190. 
Manuscript submitted to: Organisms Diversity \& Evolution

Published version available; DOI: 10.1007/s13127-019-00406-2

4745 Wheeler, G. C., \& Wheeler, J. (1982). Supplementary studies on ant larvae: Formicinae

4746 (Hymenoptera: Formicidae). Psyche, 89, 175-181.

4747 Wheeler, G.C., \& Wheeler, J. (1986) The ants of Nevada. Natural History Museum of Los

$4748 \quad$ Angeles County, Los Angeles, vii +138 pp.

4749 Wheeler, W. M. (1903). A decad of Texan Formicidae. Psyche, 10, 93-111.

4750 Wheeler, W. M. (1910). Ants: their structure, development and behavior. New York: Columbia $4751 \quad$ University Press.

4752 Wheeler, W. M. (1921). The Tachigalia ants. Zoologica (New York), 3, 137-168.

4753 Wheeler, W. M. (1922). Ants of the American Museum Congo Expedition. A contribution to the Myrmecology of Africa. Bulletin of the American Museum of Natrural History, 45, 1-582.

Wheeler, W. M. (1934). Neotropical ants collected by Dr. Elisabeth Skwarra and others. Bulletin of the Museum of Comparative Zoology, 77, 157-240.

Wheeler, W. M. (1938). Ants from the caves of Yucatan. In A. S. Pearse (Ed.), Fauna of the caves of Yucatan (Vol. 491, pp. 251-304): Carnegie Institution of Washington Publication.

Wheeler, W. M. (1942). Studies of Neotropical ant-plants and their ants. Bulletin of the Museum of Comparative Zoology, 90, 1-262.

Wild, A. L. (2007). A catalogue of the ants of Paraguay (Hymenoptera: Formicidae). Zootaxa, $1622,1-55$.

Wilson, C. M., Smith-Herron, A., \& Cook, J. L. (2016). Morphology of the male genitalia of Brachymyrmex and their implications in the Formicinae phylogeny. Journal of Hymenoptera Research, 50, 81-95, doi:DOI 10.3897/JHR.50.8697. 
Manuscript submitted to: Organisms Diversity \& Evolution

Published version available; DOI: 10.1007/s13127-019-00406-2

4769 Xia, X. (2013). DAMBE5: A Comprehensive Software Package for Data Analysis in Molecular Biology and Evolution. Molecular Biology and Evolution, 30(7), 1720-1728, doi:10.1093/molbev/mst064.

4772 Yensen, N., Yensen, E. \& Yensen, D. (1980) Intertidal ants from the Gulf of California, Mexico. Annals of the Entomological Society of America, 73, 266-269. 
Manuscript submitted to: Organisms Diversity \& Evolution

Published version available; DOI: 10.1007/s13127-019-00406-2

\section{FIGURE CAPTIONS}

Fig. 1 Morphological measurements for Brachymyrmex workers. See text for details

Fig. 2 Habitus of a selection of queens of Brachymyrmex: head and lateral view of (a,b) $B$. admotus; (c,d) B. antennatus; (e,f) B. aphidicola and (g,h) B. giardi

4780 Fig. 3 Habitus of a selection of males of Brachymyrmex: head and lateral view of (a,b) $B$.

4781 coactus; (c,d) B. myops; (e,f) B. longicornis var. immunis (junior synonym of B. admotus) and

4782 (g,h) B. australis var. curta (=B. australis)

4783 Fig. 4 The native distribution range of Brachymyrmex as reconstructed from the unique 4784 georeferenced localities of the here studied material (black circles) and the Brachymyrmex 4785 records available in the Global Ant Biodiversity Informatics database (Guénard et al. 2017) as 4786 viewed in www.antmaps.org (Janicki et al. 2016; shaded area)

4787 Fig. 5 Morphological characteristics of the head of Brachymyrex. (a1) clypeus with five hairs of 4788 which a single long apical hair is positioned near the anterior margin, two in mediolateral 4789 position and two near the toruli (black arrow); (a2) clypeus with a row of long, thick hairs near 4790 the anterior margin (black arrow), toruli touching but not surpassing the posterior clypeal margin 4791 in oblique anterodorsal view (grey arrow); (a3) toruli surpassing the posterior clypeal margin in 4792 oblique anterodorsal view (grey arrow); (b1) eyes below the cephalic midline; (b2) eyes on 4793 cephalic midline; (c1) eyes with 3 or 4 ommatidia along the maximal diameter of the eye; (c2) 4794 eyes with more than 4 ommatidia along the maximal diameter of the eye; (d1) scapes short and 4795 not reaching the posterior margin of the head; (d2) scapes just reaching the posterior margin of 4796 the head; (d3) scapes long and surpassing the posterior margin of the head; the length by which 4797 the scapes surpass this margin is compared to the length of the maximal diameter of the eye; (e1) 4798 anterior clypeal margin with the medial portion forming a "lip"; (e2) anterior clypeal margin 
evenly convex without antero-medial "lip"; (f1) head with dense pilosity; (f2) head with sparse

4800 decumbent hairs; (g1) second segment of the antennal funiculus shorter than the first; (g2) second 4801 segment of the antennal funiculus as long or longer than the first

4802 Fig. 6 Morphological characteristics of the mesosoma and gaster of Brachymyrmex. (a1)

4803 metathoracic spiracles tumiliform; (a2) metathoracic spiracles not protruding; (a3) metathoracic

4804 spiracles slightly protruding, but not tumiliform; (b1) mesonotum inflated and bulging dorsally 4805 above the pronotum in lateral view; (b2) mesonotum not inflated or bulging dorsally above the 4806 pronotum in lateral view; (c) dorsal margin of the mesosoma of conspicuous sinusoidal shape; 4807 (d1) mesometanotal suture inconspicuous (dashed line); (d2) mesometanotal suture directly 4808 visible; (e1) mesonotum strongly antero-posteriorly inclined and thus elongated in lateral view; 4809 (e2) mesonotum weakly antero-posteriorly inclined in lateral view; (f1) metanotal groove deep 4810 and wider than the diameter of the metathoracic spiracles; (f2) metanotal groove shallow and 4811 narrower than the diameter of the metathoracic spiracles; (g1) gaster with scattered pubescence;

4812 (g2) gaster with dense pubescence, in both cases illustrated with long erect hairs near the edges of 4813 the segments; (h1) mesonotum laterally extended and oval in dorsal view; (h2) mesonotum 4814 almost circular in dorsal view

4815 Fig. 7 Brachymyrmex admotus: (a,c,e) head, dorsal and lateral view of the lectotype worker; 4816 (b,d,f) $=$ B. longicornis var. immunis n. syn.: head, dorsal and lateral view of a syntype worker 4817 Fig. 8 Brachymyrmex antennatus: (a,b,c) head, dorsal and lateral view of the lectotype worker 4818 Fig. 9 Brachymyrmex aphidicola: (a,d,g) head, dorsal and lateral view of the lectotype worker; $4819(\mathbf{b}, \mathbf{e}, \mathbf{h})=B$. heeri var. fallax: head, dorsal and lateral view of a syntype worker; $(\mathbf{c}, \mathbf{f})=B$.

4820 longicornis var. hemiops n. syn: head and dorsal view of a syntype worker

4821 Fig. 10 Brachymyrmex attenuatus: head, dorsal and lateral view of the lectotype worker (a,b,c) 
4822 Fig. 11 Brachymyrmex australis: (a,d,g) head, dorsal and lateral view of the lectotype worker;

$4823(\mathbf{b}, \mathbf{e}, \mathbf{h})=$ B. australis var. curta $\mathbf{n}$. syn.: head, dorsal and lateral view of a syntype worker; (c,f)

$4824=$ B. longicornis n. syn.: head and dorsal view of a syntype worker

4825 Fig. 12 Brachymyrmex bahamensis n.sp.: (a,b,c) head, dorsal and lateral view of the holotype 4826 worker

4827 Fig. 13 Brachymyrmex bicolor n. sp.: (a,c,e) head, dorsal and lateral view of a paratype worker;

4828 (b,d,f) head, dorsal and lateral view of a syntype specimen of the putative worker-queen inter-

4829 caste. (from www.AntWeb.org; photographer: Ryan Perry)

4830 Fig. 14 Brachymyrmex bonariensis n. st.: (a,b,c) head, dorsal and lateral view of the lectotype 4831 worker

4832 Fig. 15 Brachymyrmex brasiliensis: (a,b,c) head, dorsal and lateral view of the holotype worker 4833 Fig. 16 Brachymyrmex bruchi: (a,c,e) head, dorsal and lateral view of the lectotype worker;

$4834($ b,d,f) $=$ B. giardi var. nitida: head, dorsal and letral view of a syntype worker

4835 Fig. 17 Brachymyrmex bruchi: (a,c,e) $=$ B. laevis var. andina: head, dorsal and lateral view of a 4836 syntype worker; $(\mathbf{b}, \mathbf{d}, \mathbf{f})=B$. bruchi var. rufipes: head, dorsal and lateral view of a syntype worker 4837 Fig. 18 Brachymyrmex cavernicola: (a,b,c) head, dorsal and lateral view of a worker (from 4838 www.AntWeb.org; photographer: Estella Ortega)

4839 Fig. 19 Brachymyrmex coactus: (a,c,e) head, dorsal and lateral view of the lectotype worker, $4840 \quad$ (b,d,f $)=$ B. coactus var. nictitans $\mathbf{n}$. syn.: head, dorsal and lateral view of a syntype worker

Fig. 20 Brachymyrmex coactus: (a,c,e) $=$ B. constrictus $\mathbf{n}$. syn.: head, dorsal and lateral view of a syntype worker; $(\mathbf{b}, \mathbf{d}, \mathbf{f})=B$. robustus: head, dorsal and lateral view of a syntype worker 
Fig. 22 Brachymyrmex cordemoyi: (a,b,c) =B. brevicornis n. syn: head, dorsal and lateral view 4847 of a syntype worker

4848 Fig. 23 Brachymyrmex cordemoyi: (a,c,e) =B. brevicornoeides n. syn: head, dorsal and lateral 4849 view of a syntype worker (from www.AntWeb.org; photographer: Zach Lieberman); (b,d,f) $=B$. 4850 cordemoyi var. distincta n. syn: head, dorsal and lateral view of a syntype worker

4851 Fig. 24 Brachymyrmex degener: (a,c,e) head, dorsal and lateral view of the lectotype worker; 4852 (b,d,f) $=$ B. admotus r. niger n. syn. head, dorsal and lateral view of a syntype worker

Fig. 25 Brachymyrmex degener: (a,c,e) =B. incisus n. syn.: head, dorsal and lateral view of a 4854 syntype worker; (b,d,f) $=$ B. luederwaldti n. syn.: head, dorsal and lateral view of a syntype 4855 worker

4856 Fig. 26 Brachymyrmex delabiei: (a,b,c) head, dorsal and lateral view of the holotype worker 4857 Fig. 27 Brachymyrmex depilis: (a,c,e) head, dorsal and lateral view of the lectotype worker;

4858 (b,d,f) $=$ B. depilis subsp. flavescens: head, dorsal and lateral view of a syntype worker Fig. 28 Brachymyrmex donisthorpei: (a,b,c) head, dorsal and lateral view of the lectotype 4860 worker

4861 Fig. 29 Brachymyrmex feitosai: (a,b,c) head, dorsal and lateral view of a worker (from 4862 www.AntWeb.org; photographer: Erin Prado)

4863 Fig. 30 Brachymyrmex fiebrigi: (a,c,e) head, dorsal and lateral view of the lectotype worker; 4864 (b,d,f) $=$ B. fiebrigi var. fumida n. syn.: head, dorsal and lateral view of a syntype worker 4865 Fig. 31 Brachymyrmex fiebrigi: (a,b,c) =B. fiebrigi var. funicularis n. syn.: head, dorsal and 4866 lateral view of a syntype worker

4867 Fig. 32 Brachymyrmex gagates: (a,b,c) head, dorsal and lateral view of the lectotype worker 4868 Fig. 33 Brachymyrmex gaucho: (a,b,c) head, dorsal and lateral view of a worker 
4869 Fig. 34 Brachymyrmex giardi: (a,c,e) head, dorsal and lateral view of the lectotype worker;

4870 (b,d,f) head, dorsal and lateral view of a putative worker-queen intercaste

4871 Fig. 35 Brachymyrmex heeri: (a,c,e) head, dorsal and lateral view of the lectotype worker;

4872 (b,d,f) $=$ Brachymyrmex var. goeldii n. syn.: head, dorsal and lateral view of a syntype worker

4873 Fig. 36 Brachymyrmex heeri: (a,c,e) $=$ B. giardi var. cordobensis: head, dorsal and lateral view

4874 of a syntype worker; (b,d,f) head, dorsal and lateral view of a syntype of the putative worker-

4875 queen intercaste

4876 Fig. 37 Brachymyrmex iridiscens n. sp.: (a,b,c) head, dorsal and lateral view of the holotype 4877 worker

4878 Fig. 38 Brachymyrmex micromegas: (a,c,e) head, dorsal and lateral view of the lectotype 4879 worker; (b,d,f) head, dorsal and lateral view of a soldier

4880 Fig. 39 Brachymyrmex minutus: (a,b,c) head, dorsal and lateral view of the lectotype worker

4881 Fig. 40 Brachymyrmex modestus: (a,b,c) head, dorsal and lateral view of the lectotype worker

4882 Fig. 41 Brachymyrmex musculus: (a,b,c) head, dorsal and lateral view of the lectotype worker

4883 Fig. 42 Brachymyrmex myops: (a,b,c) head, dorsal and lateral view of the lectotype worker

4884 Fig. 43 Brachymyrmex nebulosus: (a,b,c) head, dorsal and lateral view of a worker (from 4885 www.AntWeb.org; photographer: Ryan Perry)

4886 Fig. 44 Brachymyrmex obscurior: (a,b,c) head, dorsal and lateral view of the lectotype worker 4887 Fig. 45 Brachymyrmex oculatus: (a,b,c) head, dorsal and lateral view of the lectotype worker 4888 Fig. 46 Brachymyrmex patagonicus: (a,c,e) head, dorsal and lateral view of the lectotype 4889 worker; $(\mathbf{b}, \mathbf{d , f})=$ B. laevis $\mathbf{n}$. syn.: head, dorsal and lateral view of a syntype worker 4890 Fig. 47 Brachymyrmex patagonicus: (a,b,c) $=$ B. patagonicus var. atratula: head, dorsal and 4891 lateral view of a syntype worker 
Fig. 48 Brachymyrmex pictus: (a,b,c) head, dorsal and lateral view of a syntype worker (from www.AntWeb.org; photographer: Zach Lieberman)

Fig. 49 Brachymyrmex pilipes: (a,c,e) head, dorsal and lateral view of the minor worker

4895 lectotype; (b,d) head, dorsal and lateral view of a major worker

Fig. 50 Brachymyrmex santschii: (a,c,e) head, dorsal and lateral view of a worker (from

4897 www.AntWeb.org; photographer: Will Ericson); (b,d,f) head, dorsal and lateral view of a 4898 putative worker-queen intercaste

4899 Fig. 51 Brachymyrmex sosai n. sp.: (a,b,c) head, dorsal and lateral view of the holotype worker 4900 Fig. 52 Brachymyrmex termitophilus: (a,b,c) head, dorsal and lateral view of the lectotype 4901 worker (from www.AntWeb.org; photographer: Zach Lieberman)

4902 Fig. 53 Brachymyrmex tristis: (a,b,c) head, dorsal and lateral view of the lectotype worker 4903 Fig. 54 Morphospace occupation of 38 of the here studied Brachymyrmex species as 4904 reconstructed with non-metric multidimensional scaling. The limited stress (5.70) indicates that 4905 the ordination is robust and the biplot displays how the various morphometric variables 4906 contribute to the morphospace occupation. $\mathrm{OI}_{1}$ is indicated in gray, as this variable did not 4907 contribute significantly to the morphospace

4908 Fig. 55 Boxplots representing intraspecific variation and interspecific differences for eight 4909 morphometric traits. Interspecific differences are tested with Benjamini-Hochberg corrected 4910 pairwise Dunn's tests, with significance levels indicated by letter codes (if species carry at least 4911 one identical letter than observed differences are insignificant, if they carry no identical letter, the 4912 observed differences for the studied trait are significant)

4913 Fig. 56 Boxplots representing intraspecific variation and interspecific differences for eight 4914 morphometric traits. Interspecific differences are tested with Benjamini-Hochberg corrected 4915 pairwise Dunn's tests, with significance levels indicated by letter codes (if species carry at least 
Manuscript submitted to: Organisms Diversity \& Evolution

Published version available; DOI: 10.1007/s13127-019-00406-2

4916 one identical letter than observed differences are insignificant, if they carry no identical letter, the

4917 observed differences for the studied trait are significant)

4918 Fig. 57 Maximum clade credibility tree of Brachymyrmex and Myrmelachista based on five gene

4919 fragments (see Supplementary material Table S1). Analyses were run under maximum parsimony

4920 (MP), maximum likelihood (ML) and Bayesian inference (BI) with bootstrap support values and

4921 Bayesian posterior probabilities indicated above nodes (MP/ML/BI). Support for species-level

4922 clades is indicated in bold; specimens were assigned to clades based on the morphological

4923 identification system, which proves to be overall in good agreement with the genealogy, apart

4924 from B. degener and B. coactus 


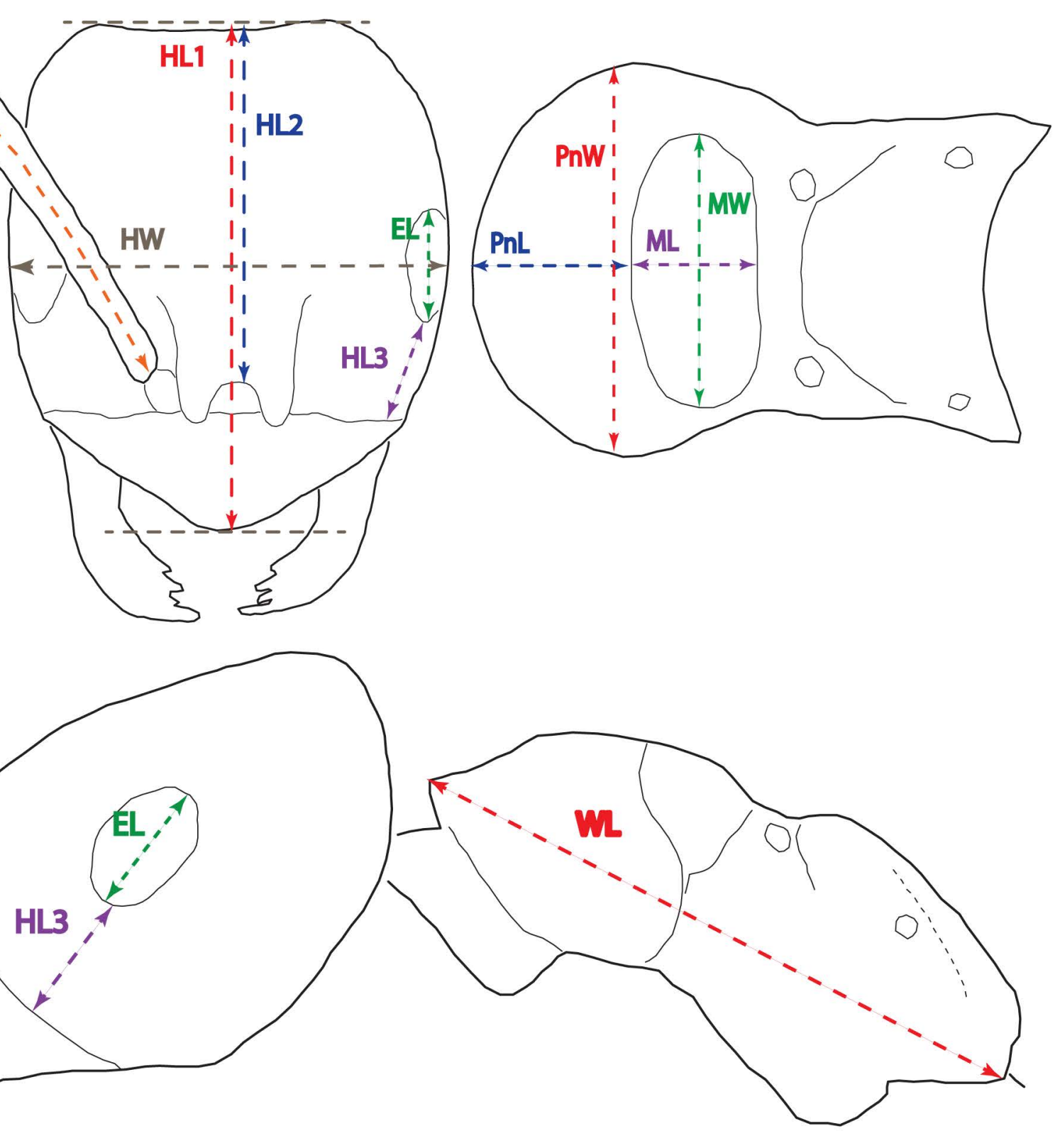

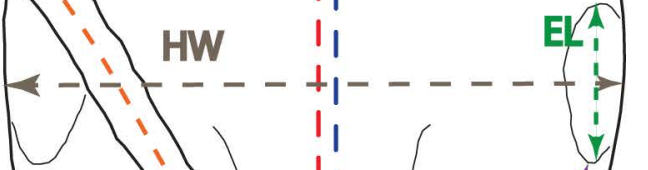
(i)
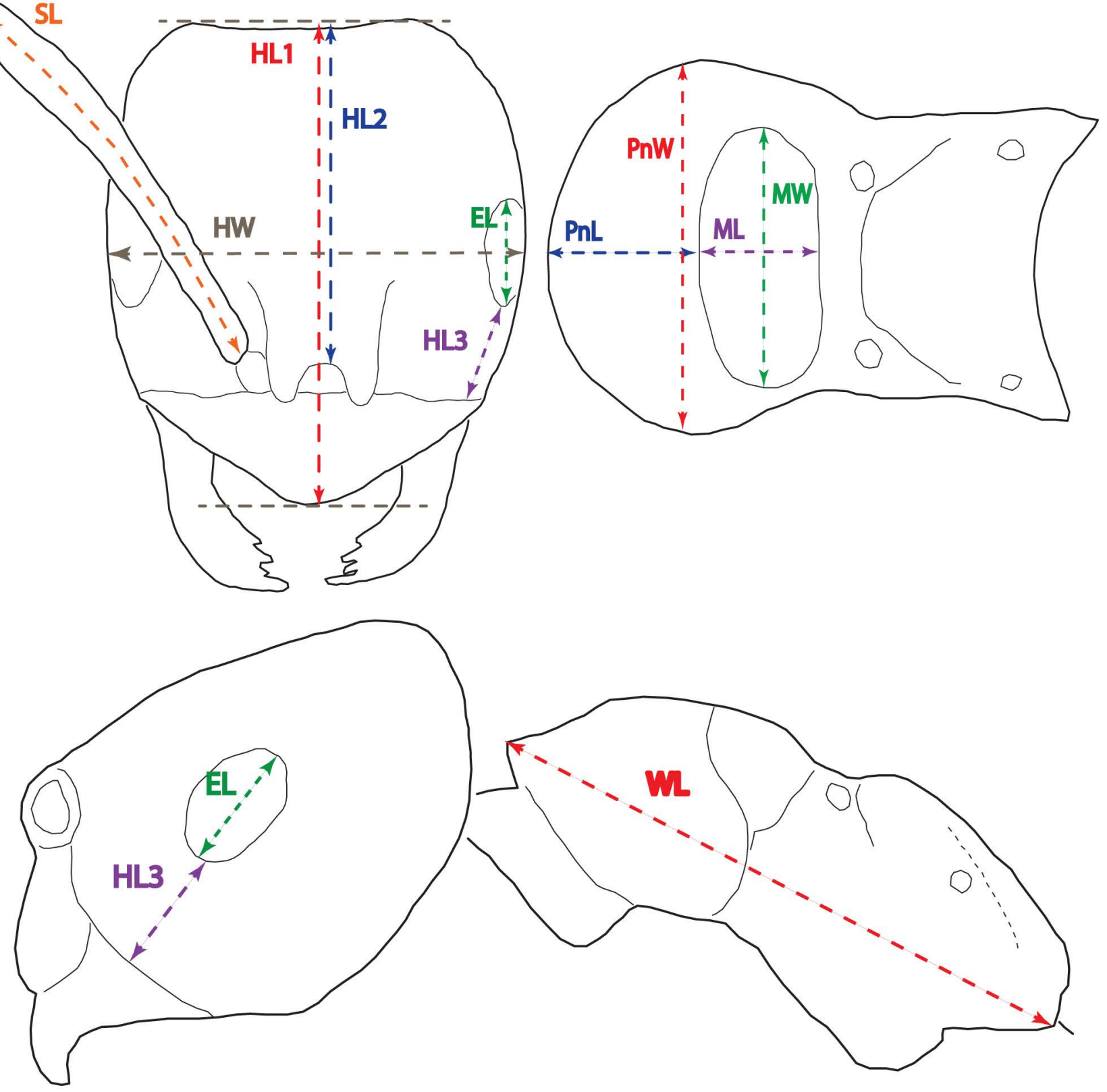


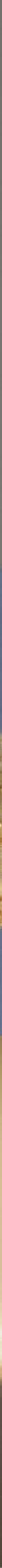

\section{a}

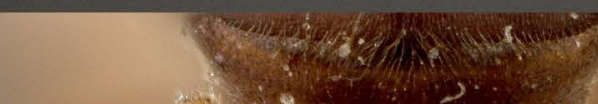

$400, x^{2}$

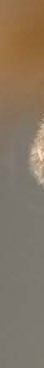

g
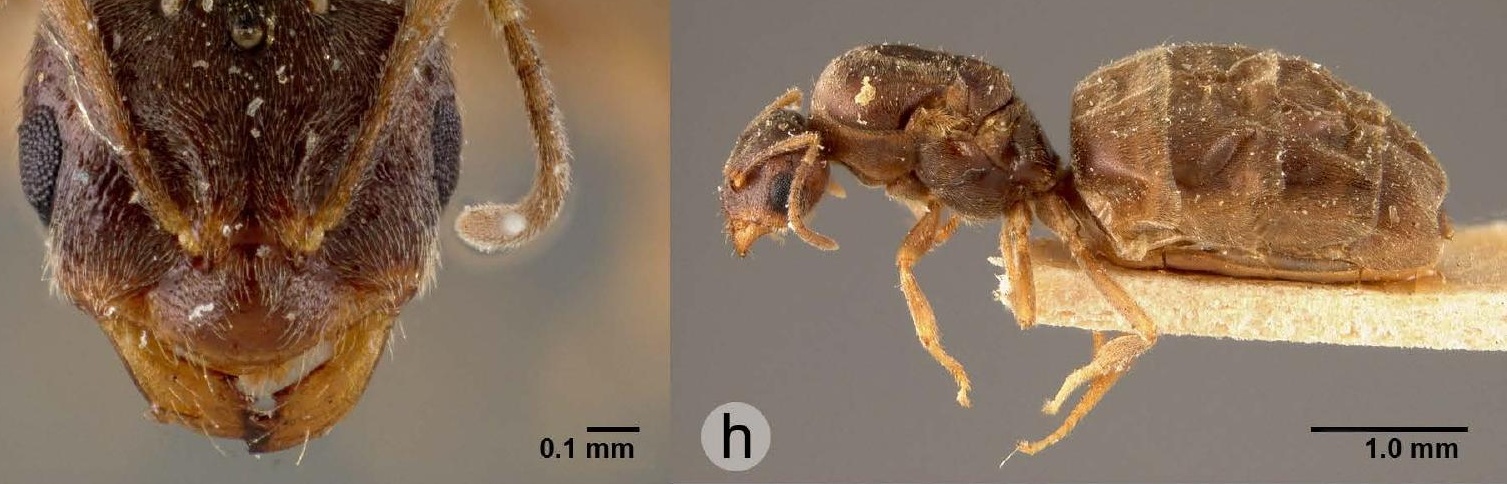


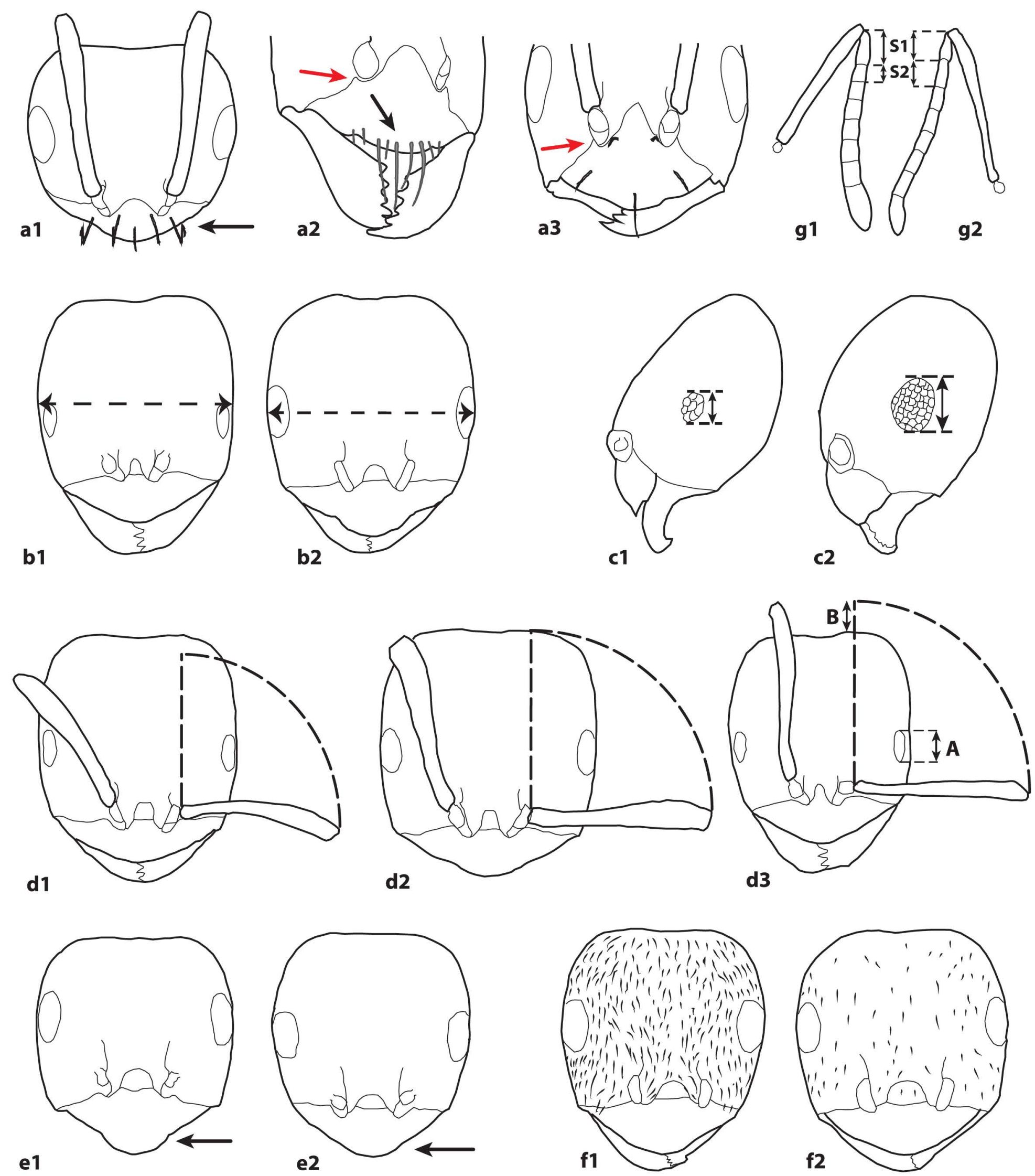


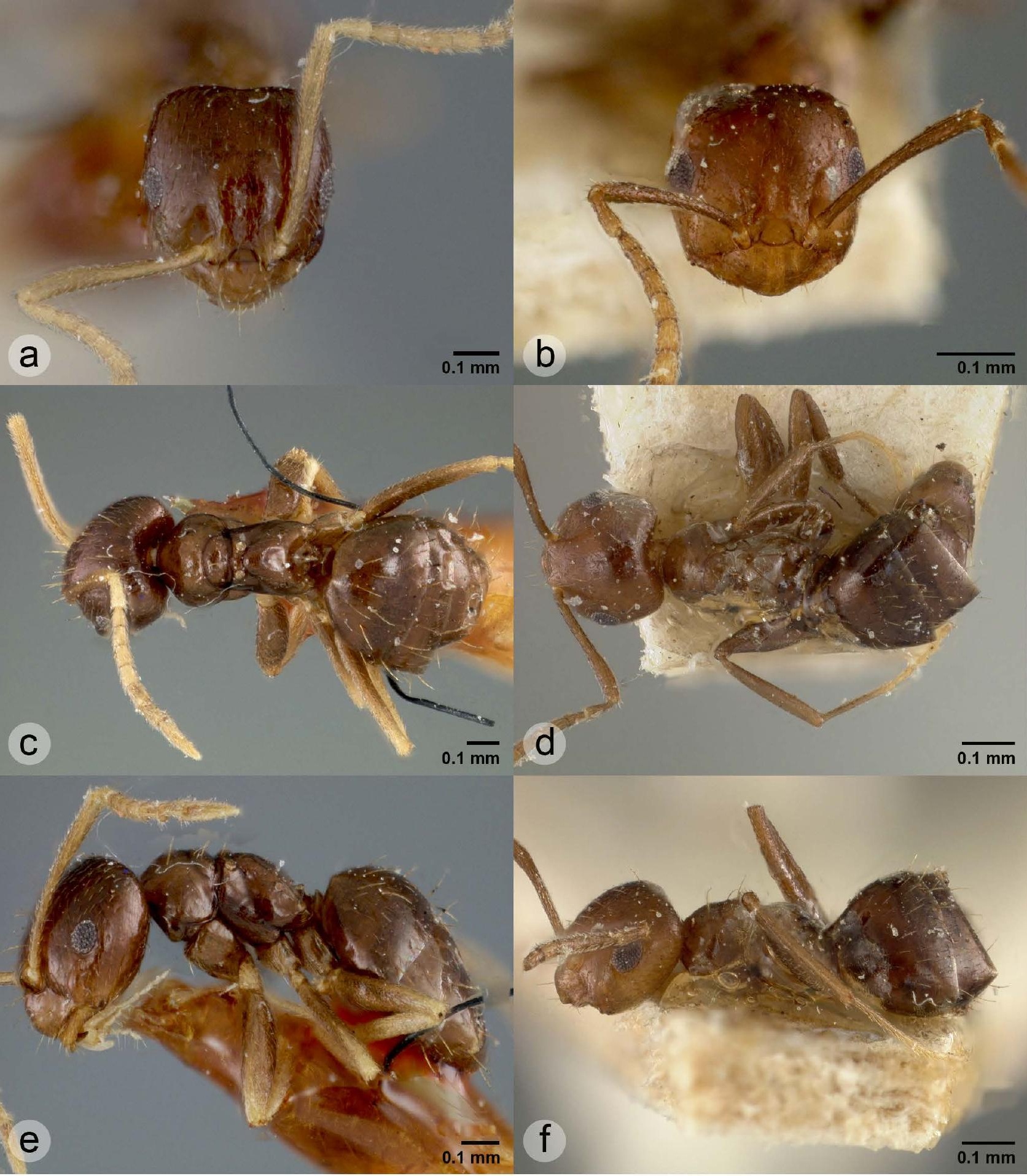





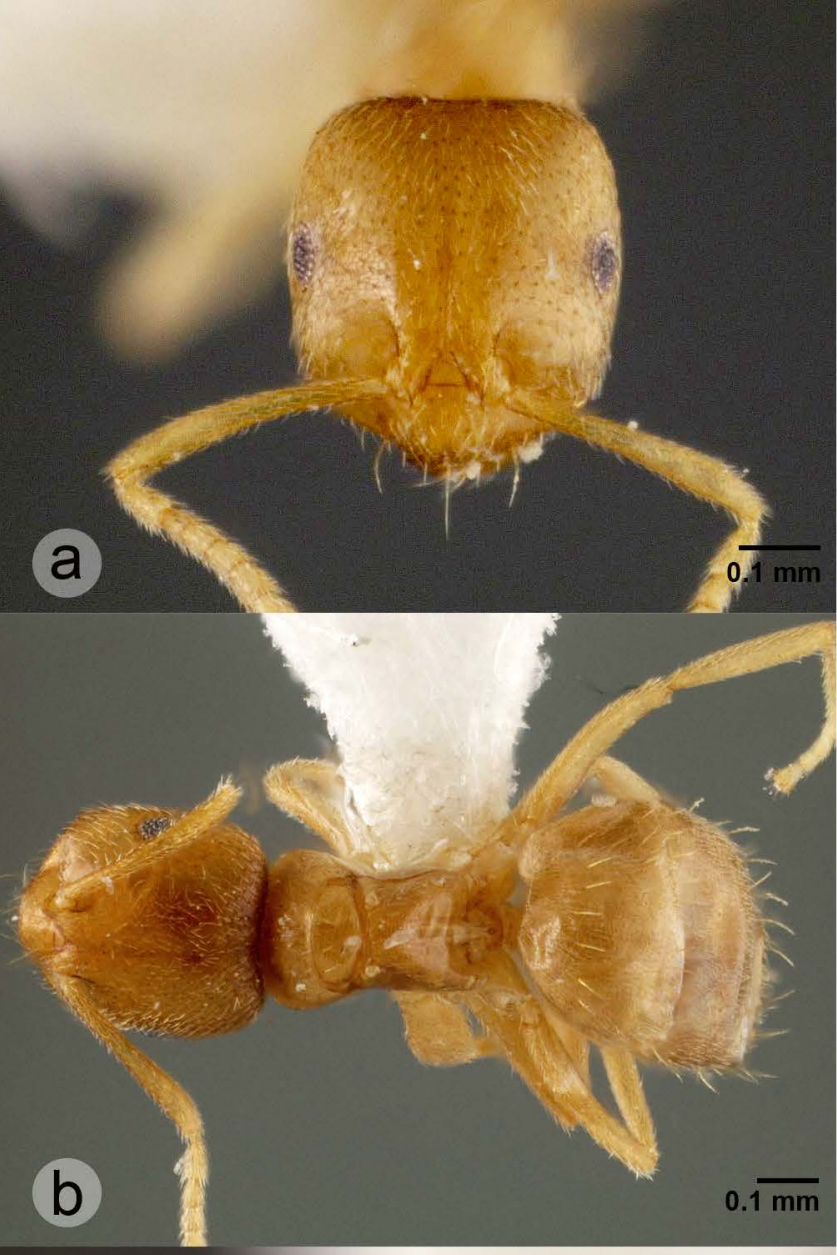




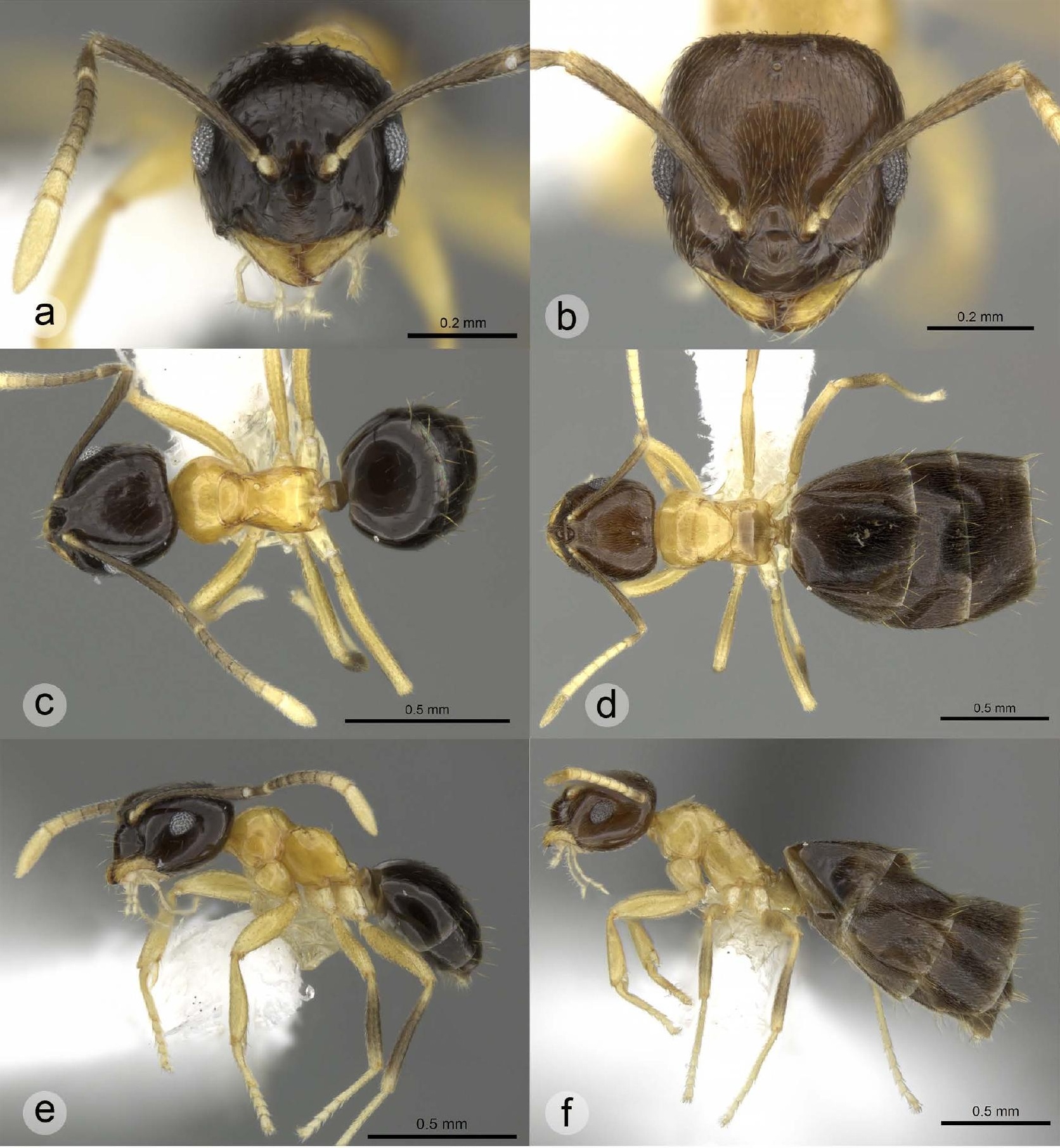




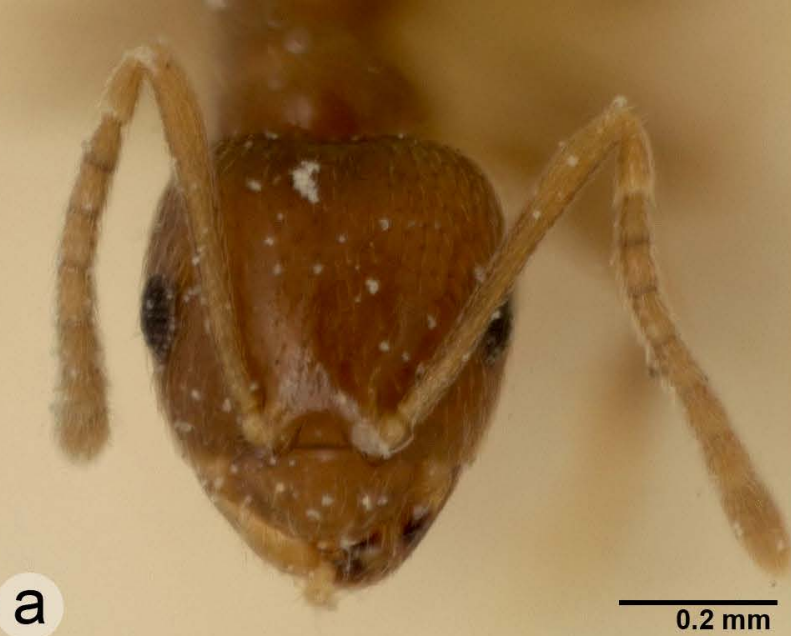

b
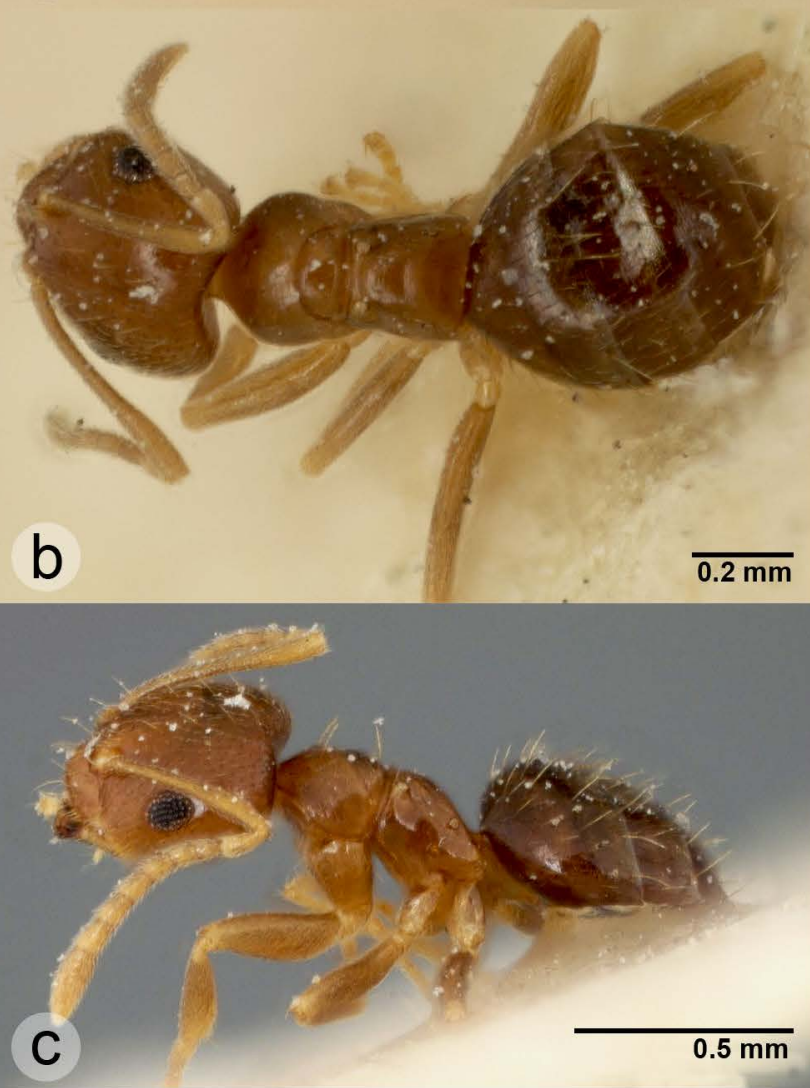

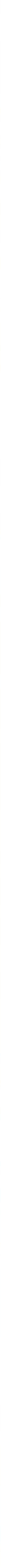


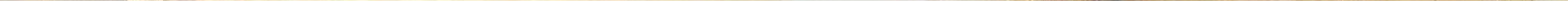




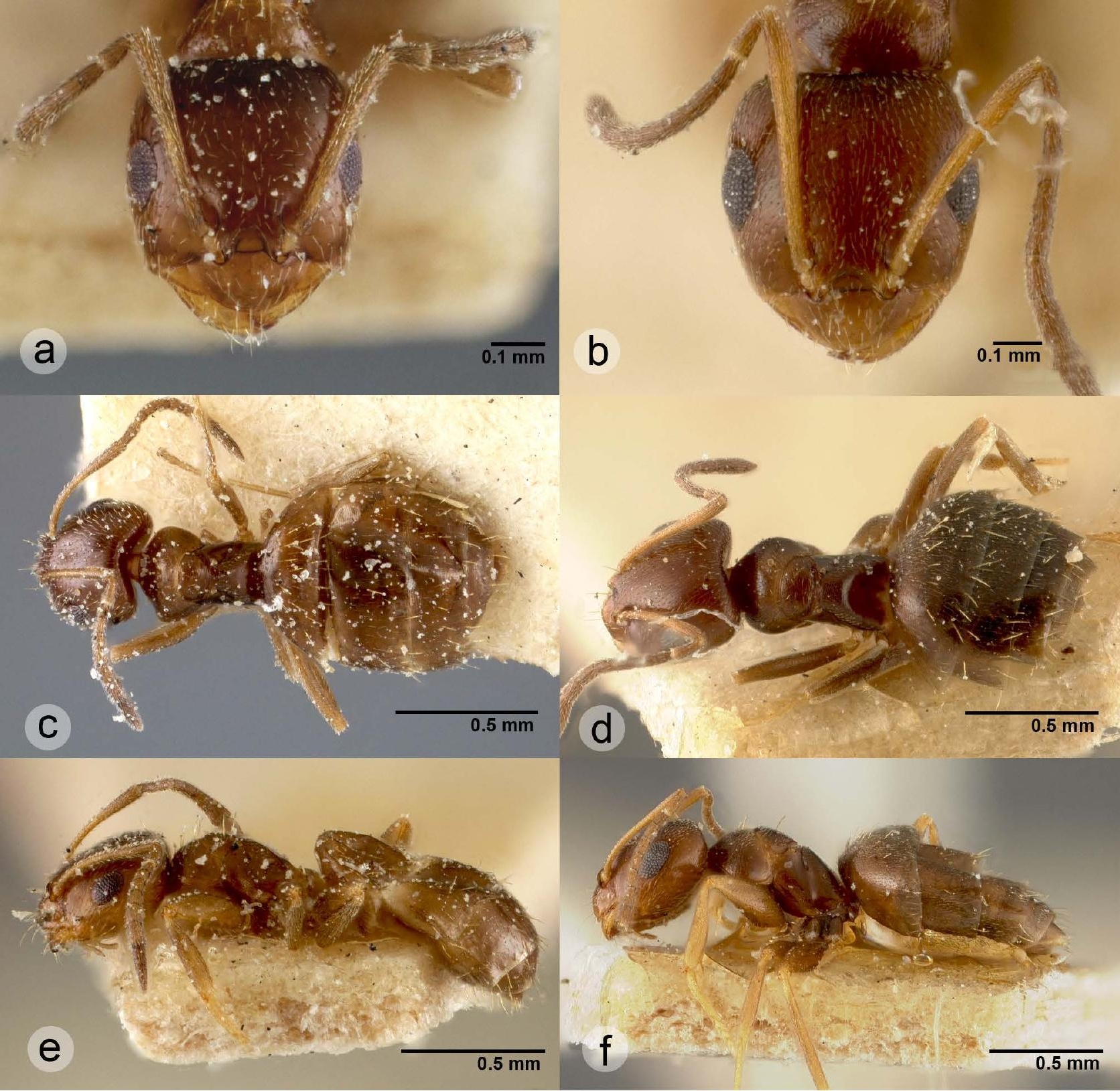




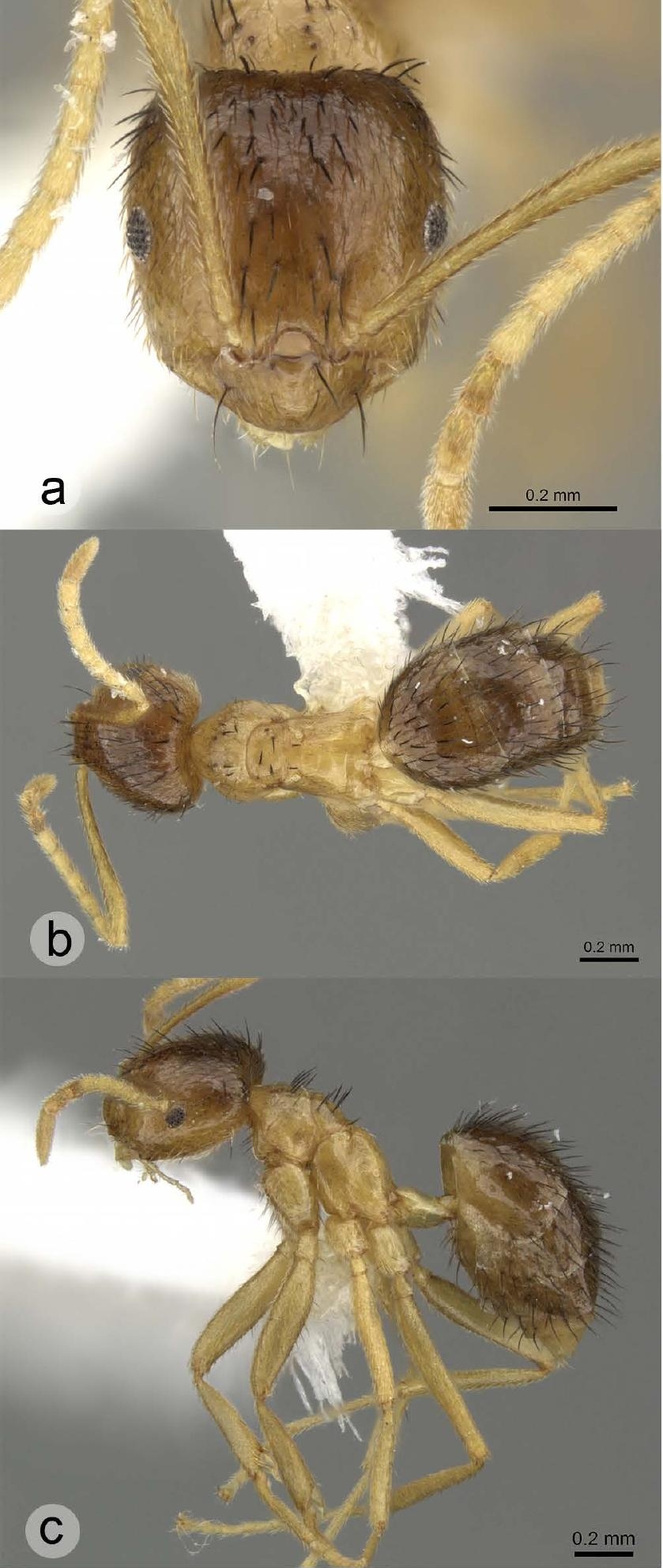




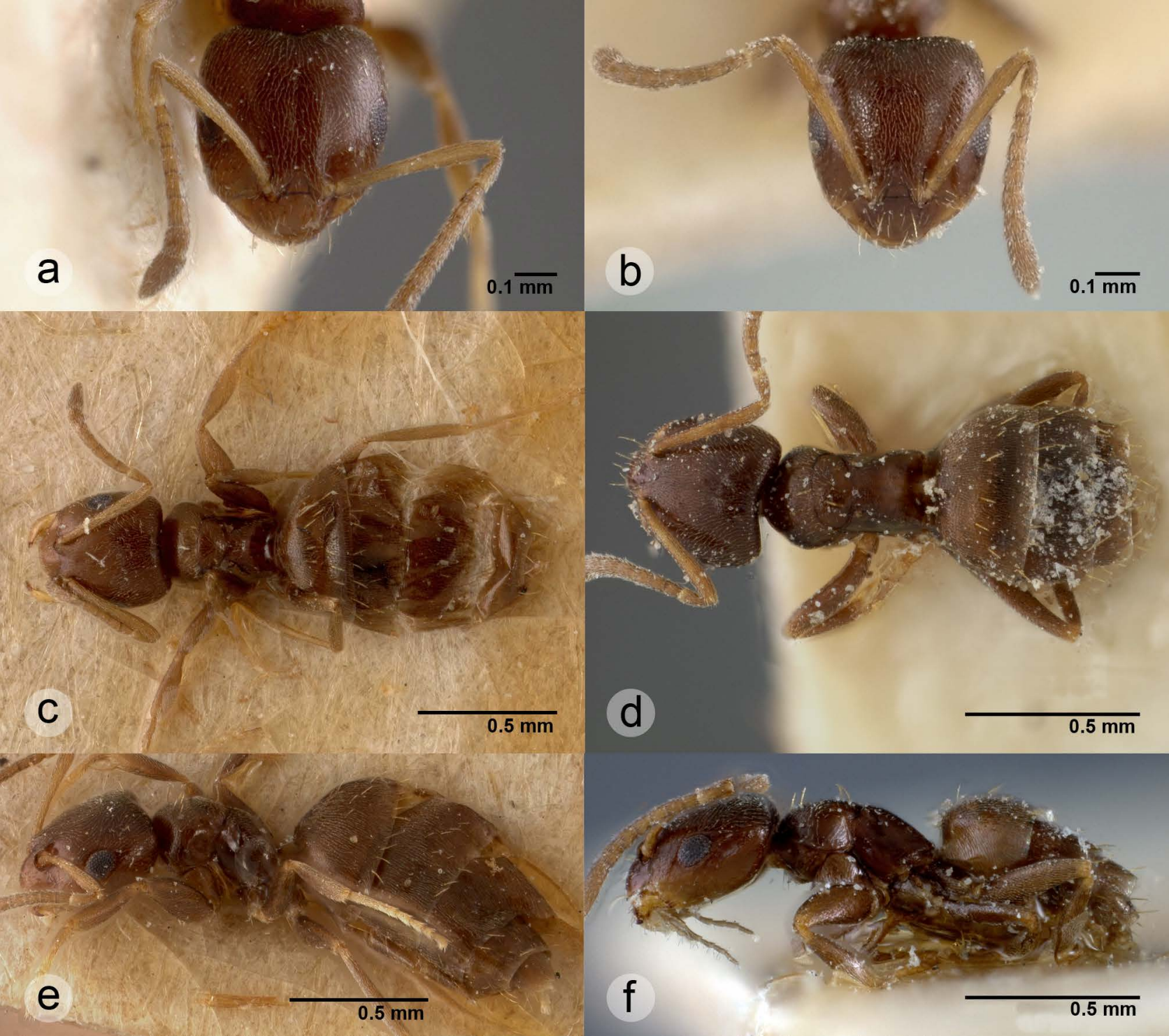


a

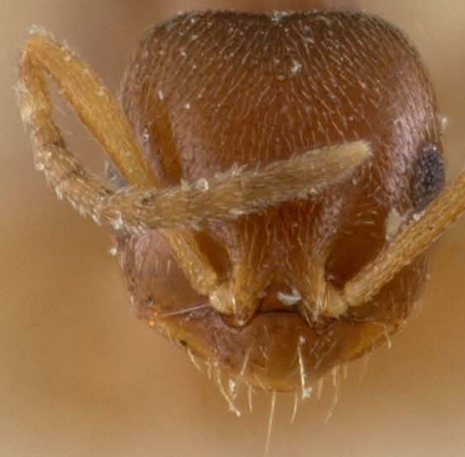

$0.1 \overline{\mathrm{mm}}$
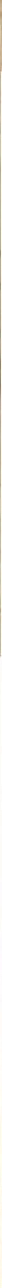


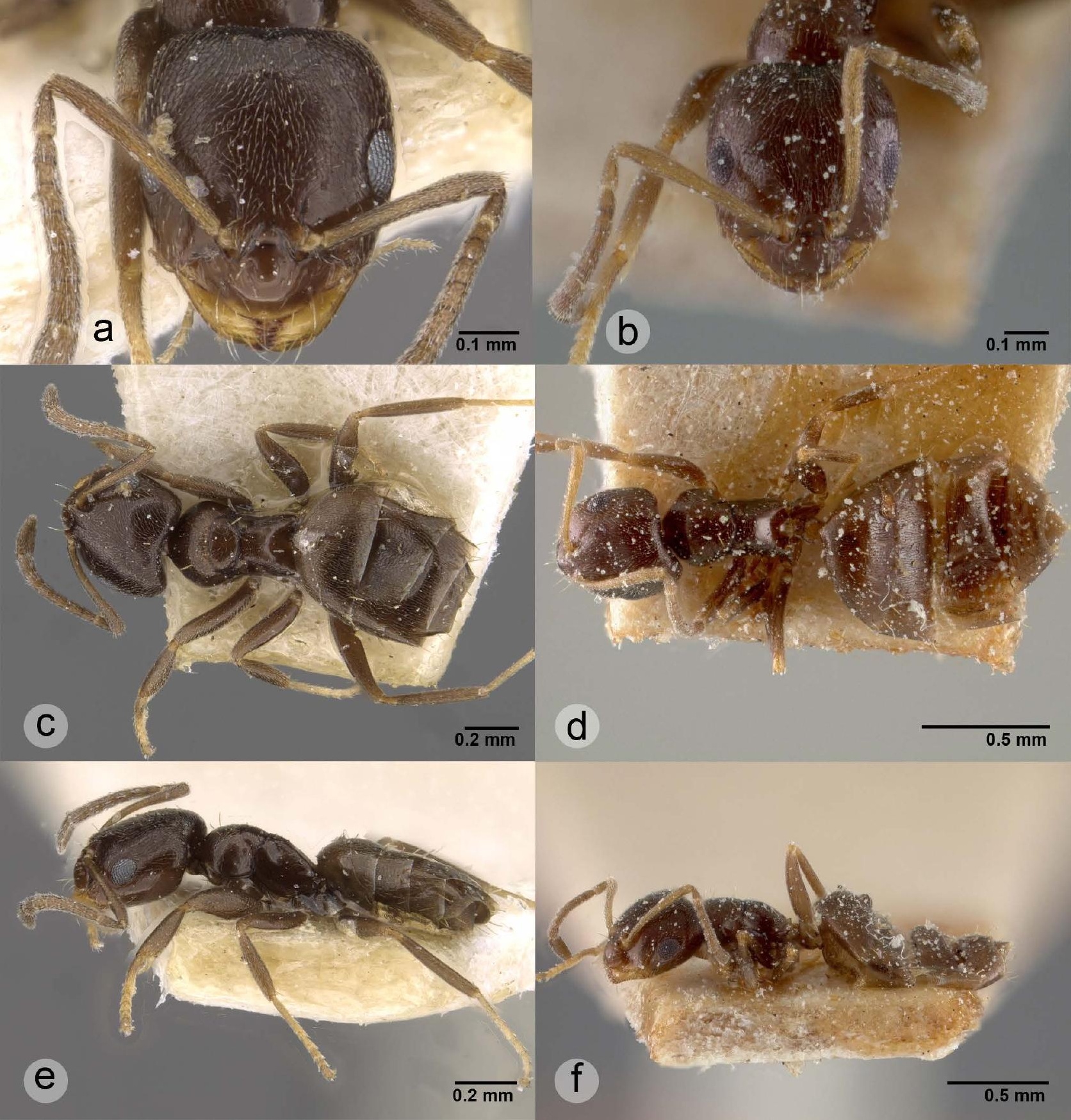



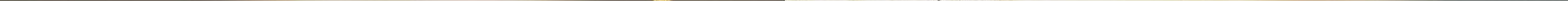


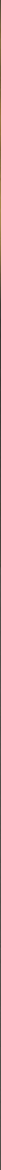





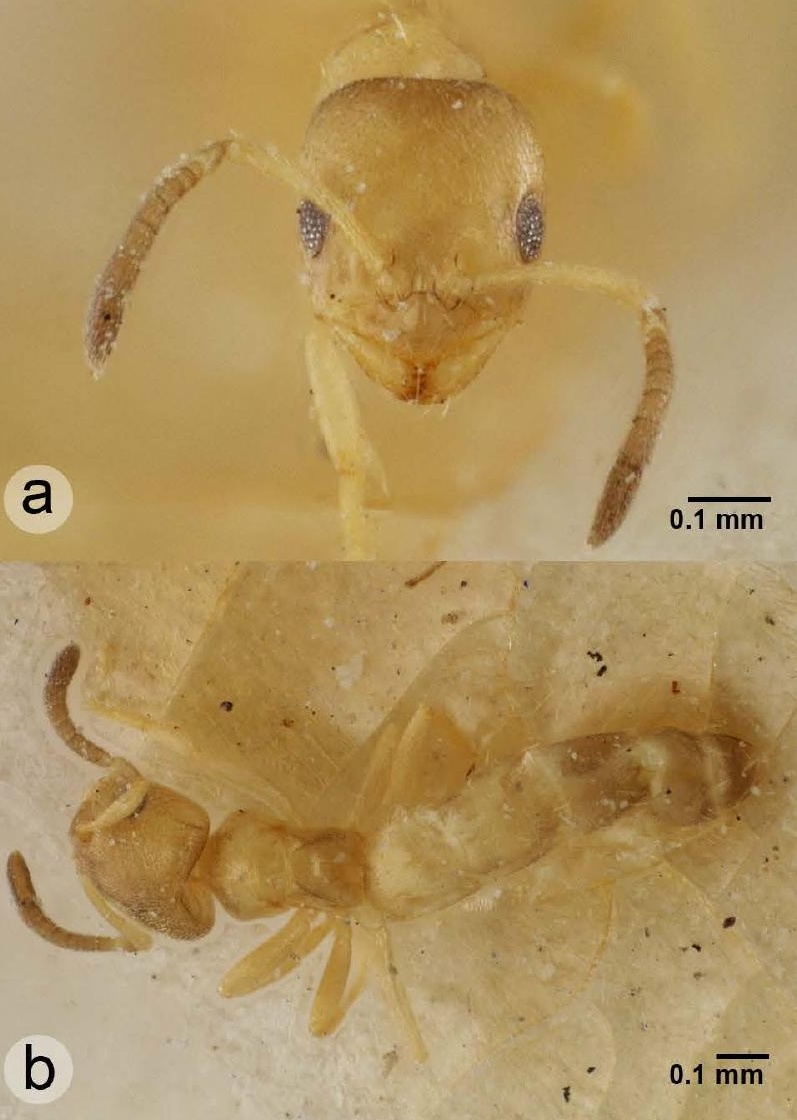




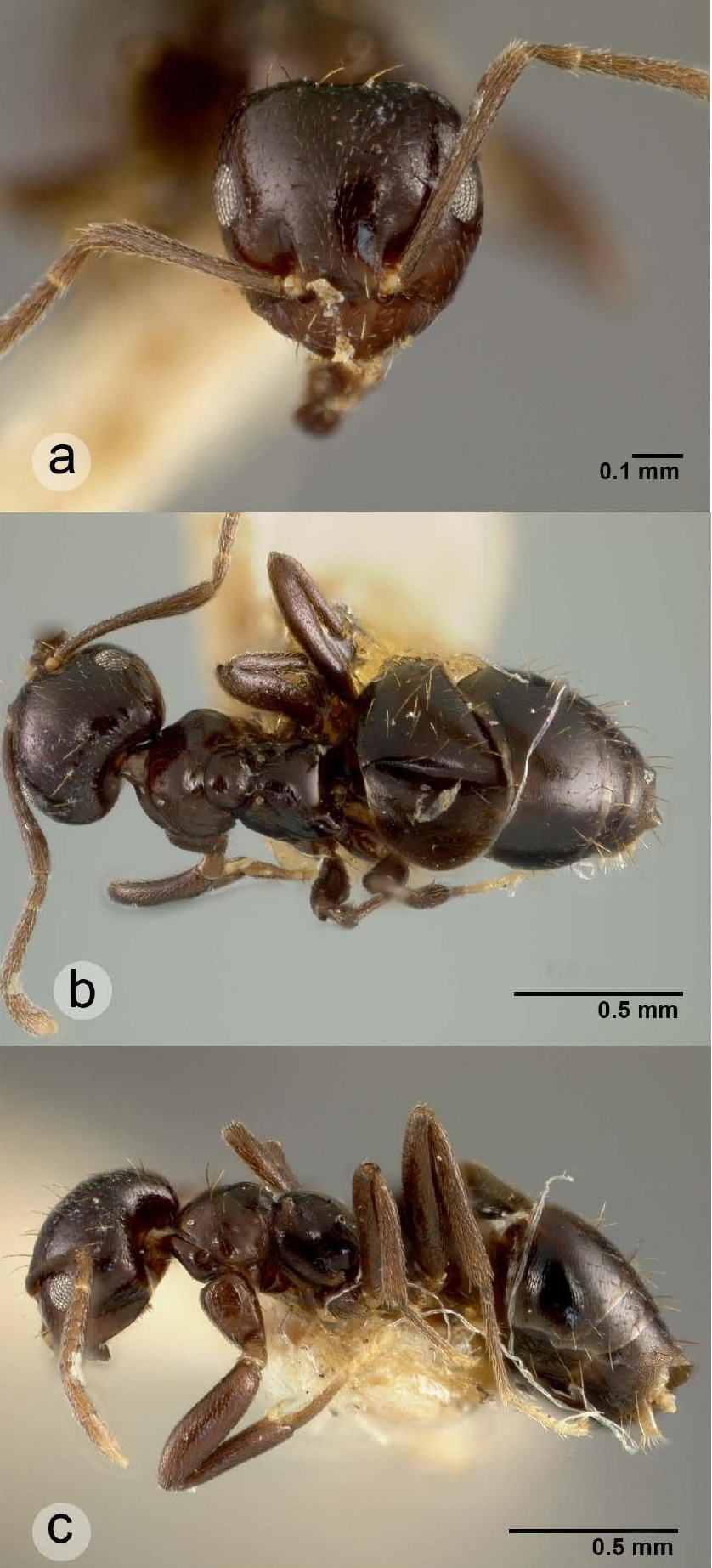




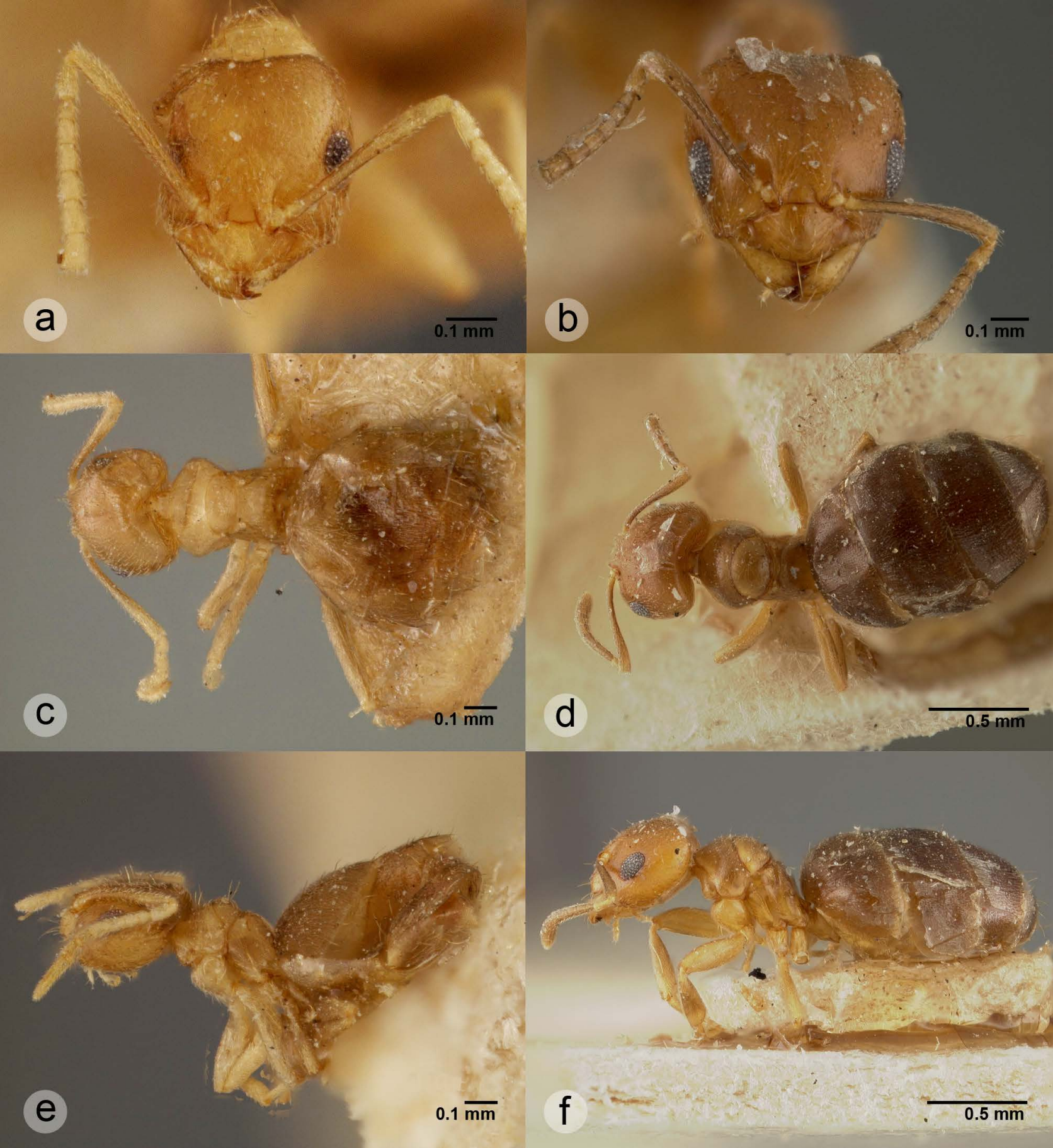


a
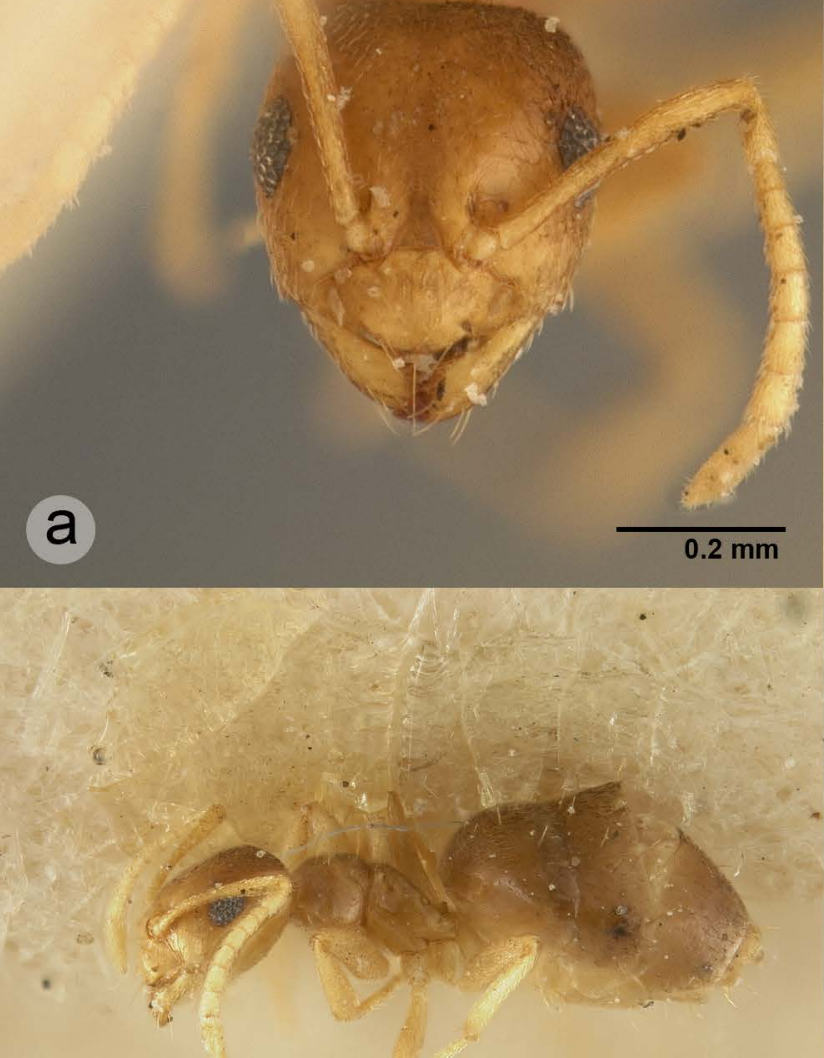

C

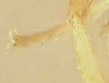

b

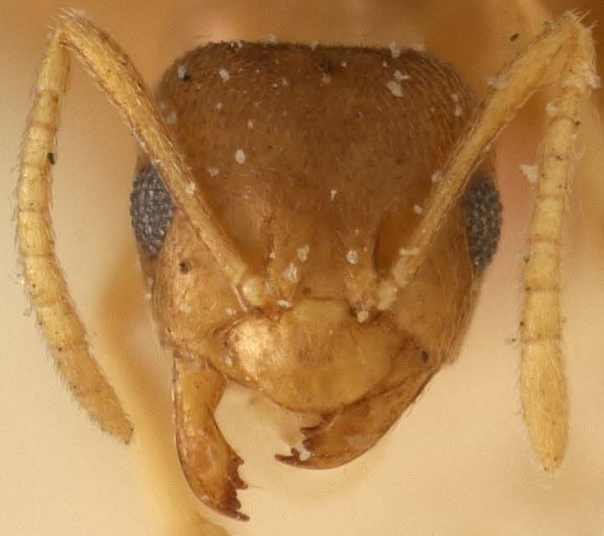

$0.2 \mathrm{~mm}$

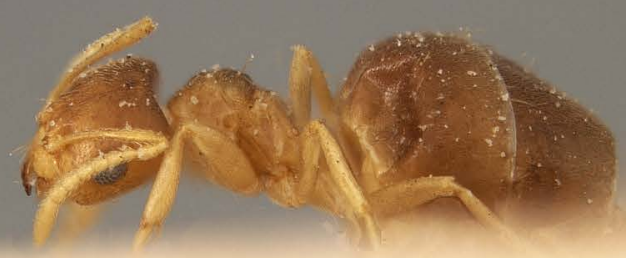

d

$0.5 \mathrm{~mm}$

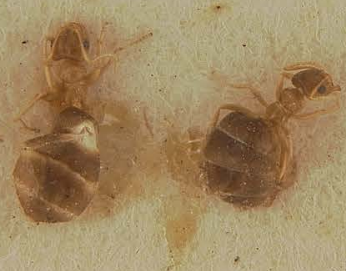

e
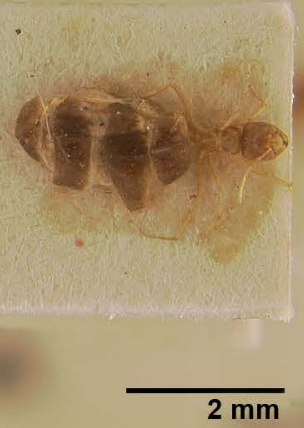

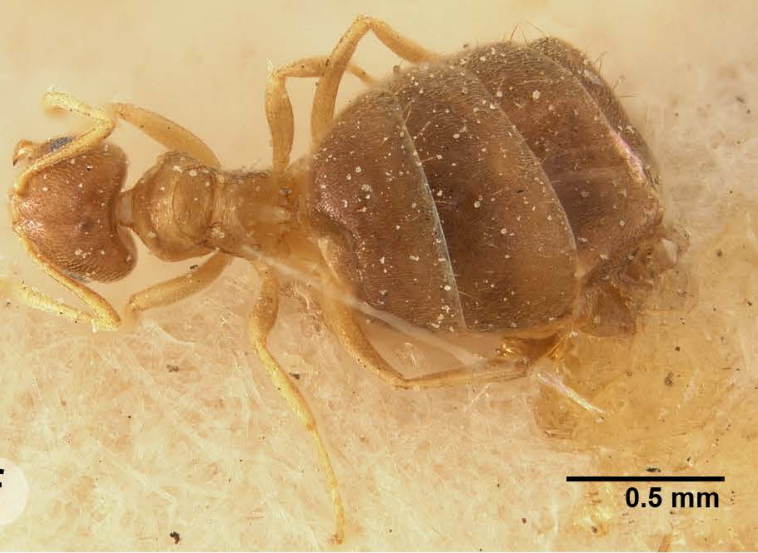




\section{a}
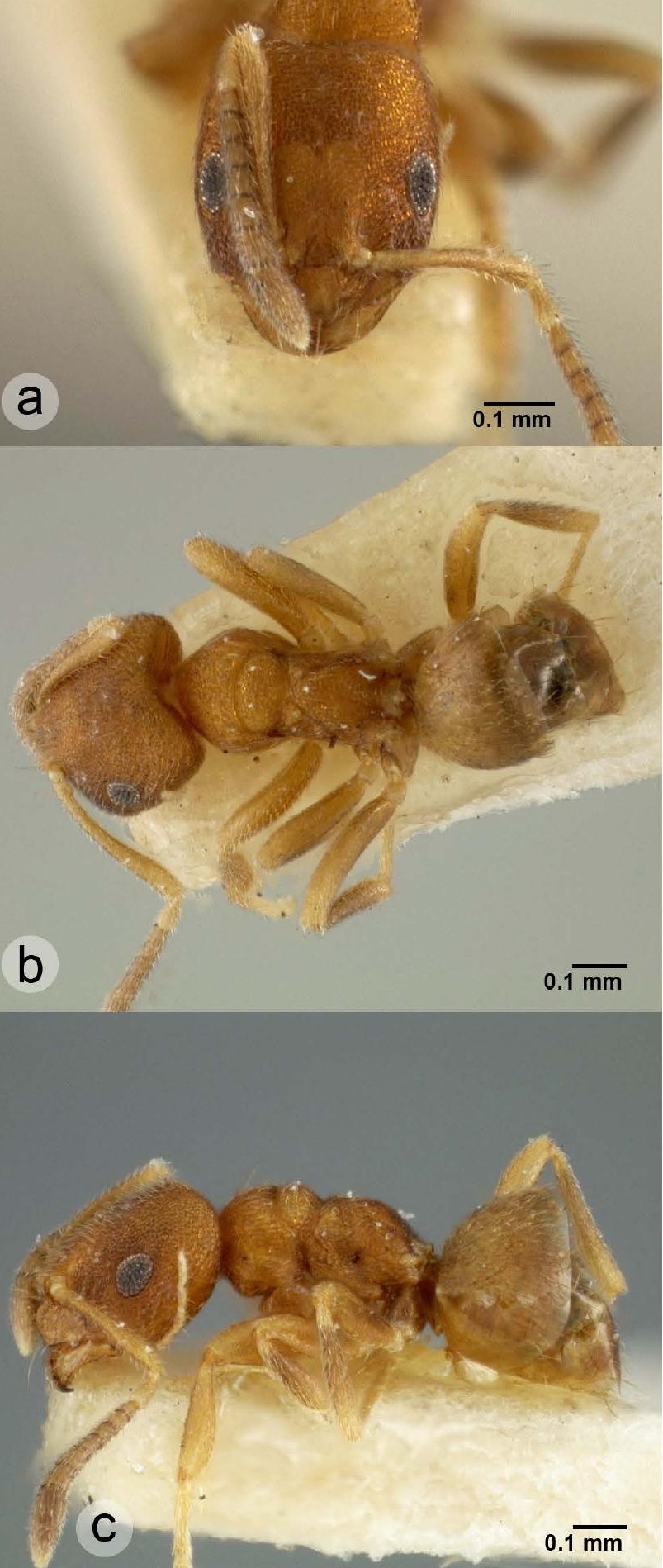

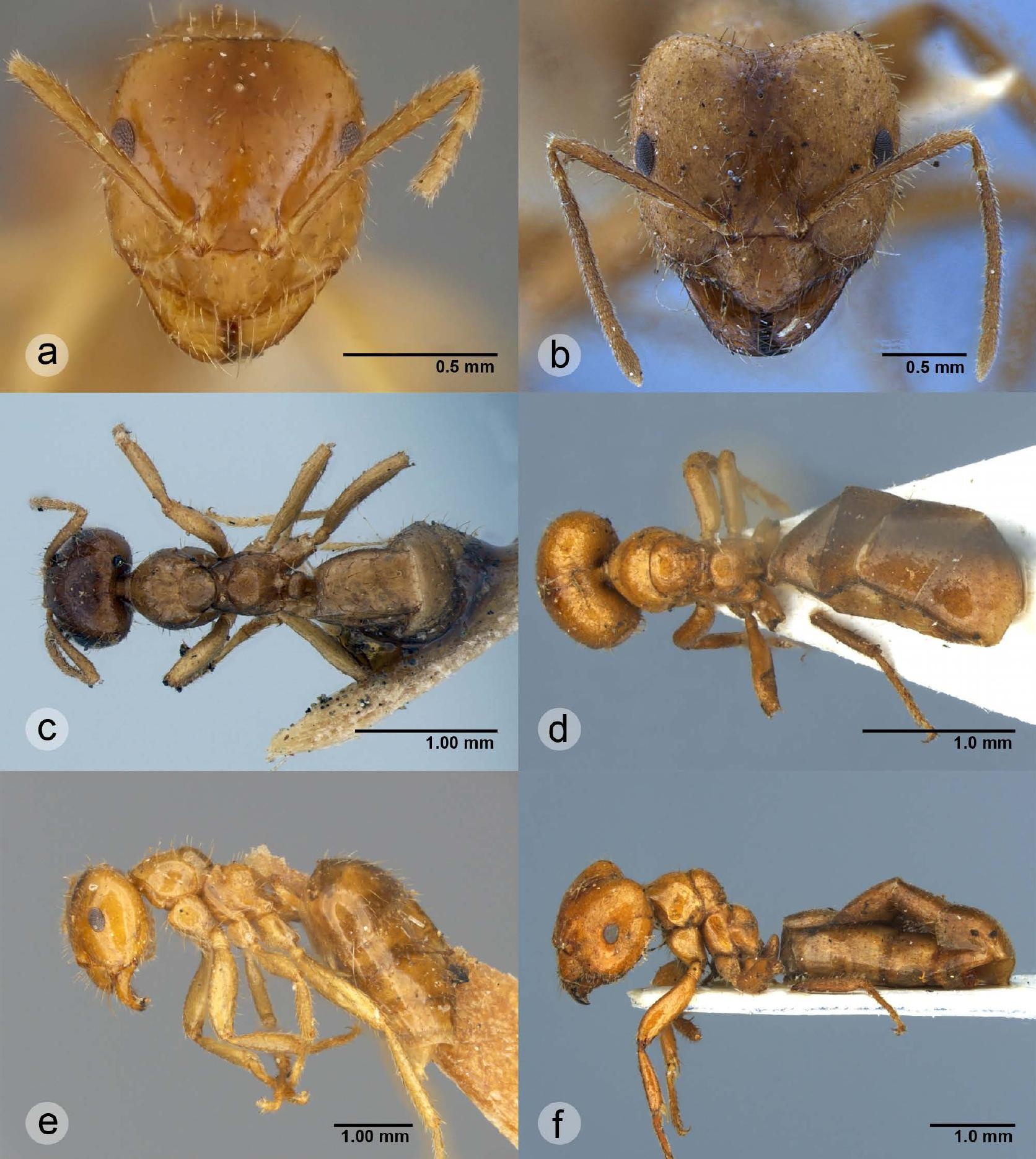
a

at?

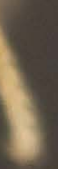

$0.1 \mathrm{~mm}$

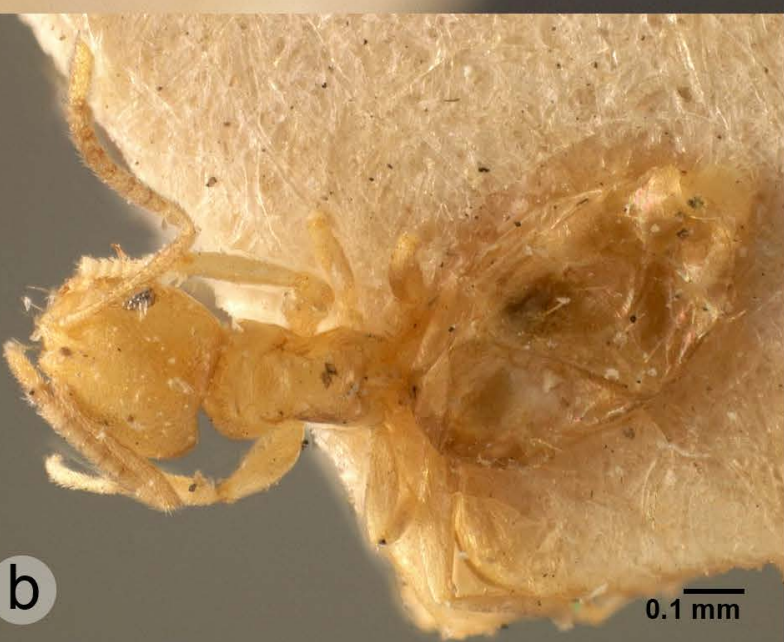

C

$0 . \overline{\mathrm{mm}}$ 

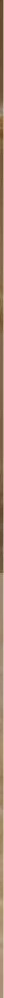

b $\quad-0.5 \mathrm{~mm}$

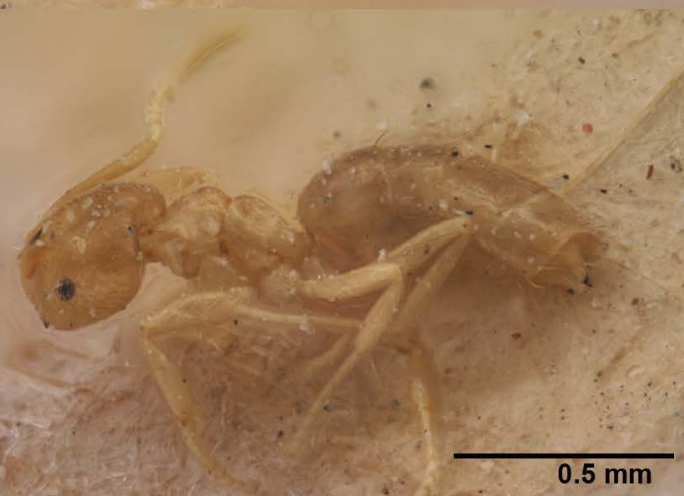



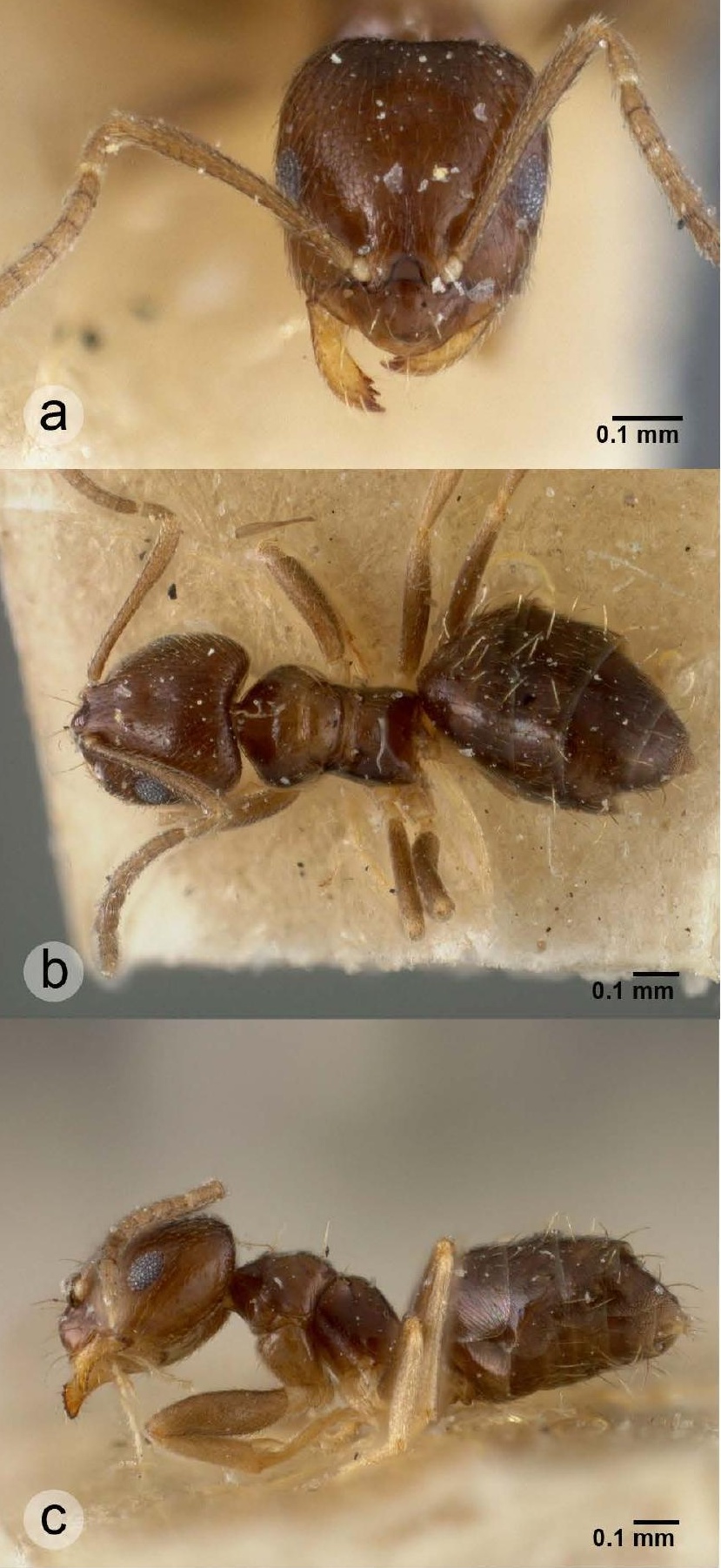
a

$0 . \overline{1 \mathrm{~mm}}$

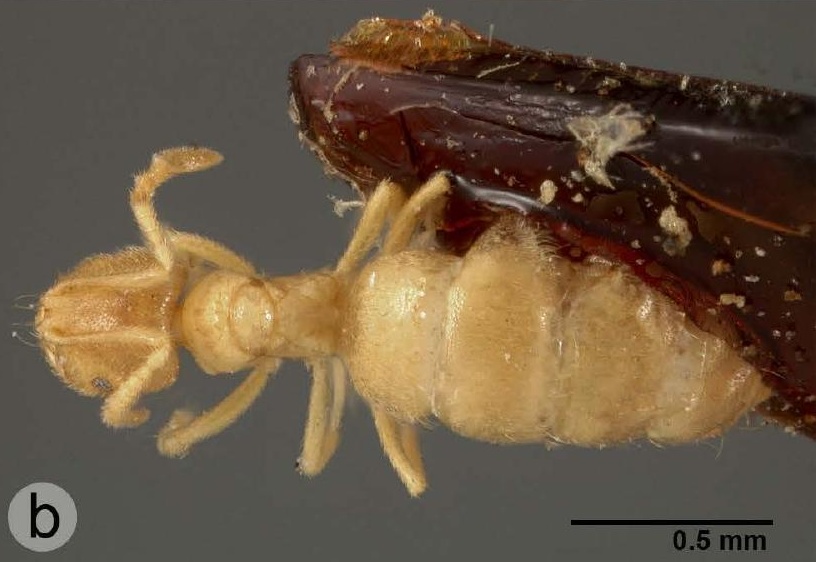

C

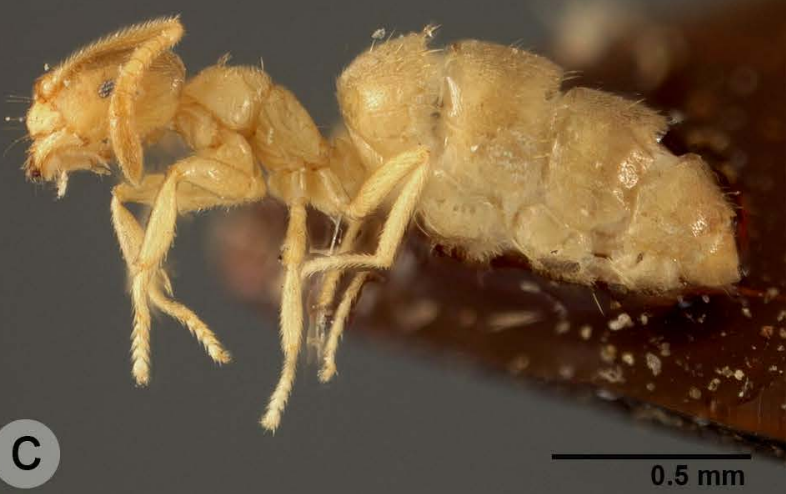




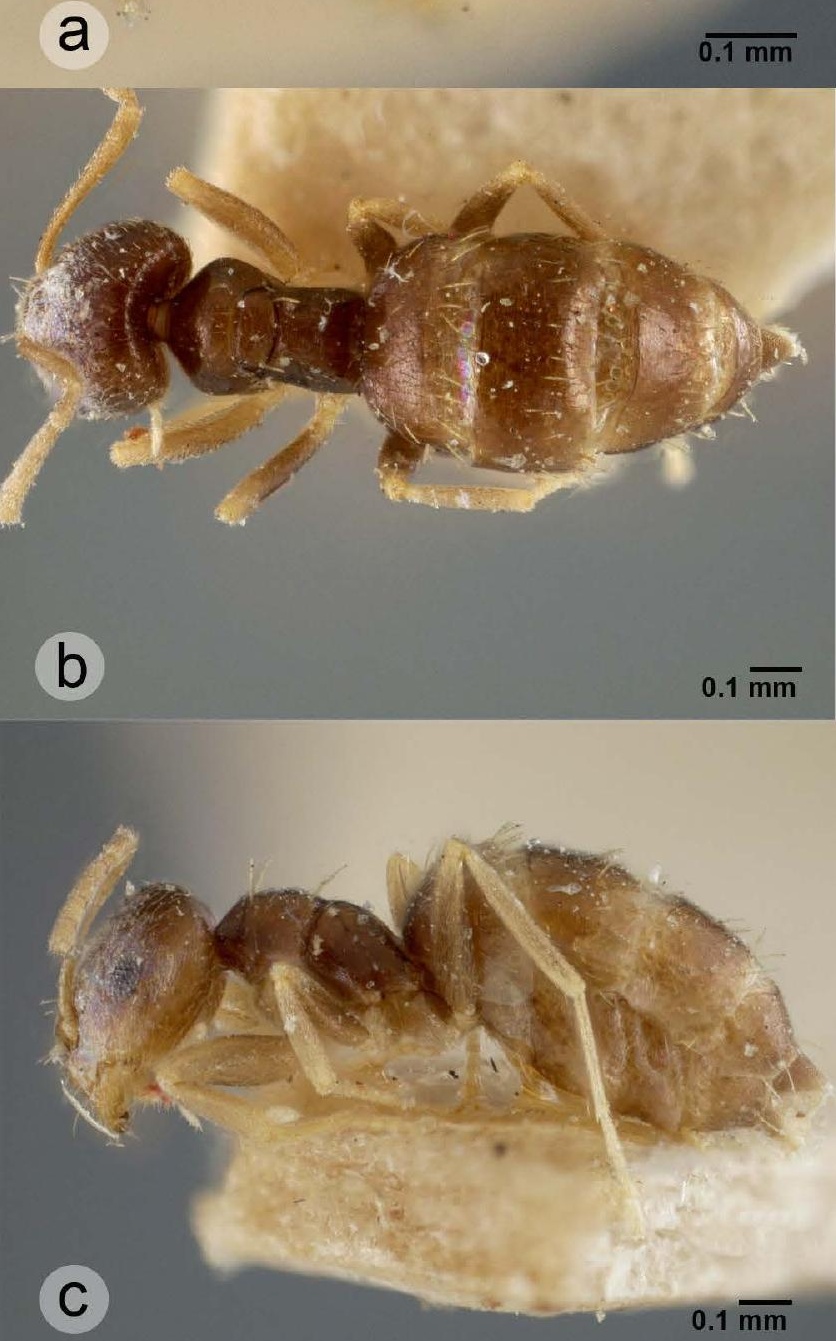



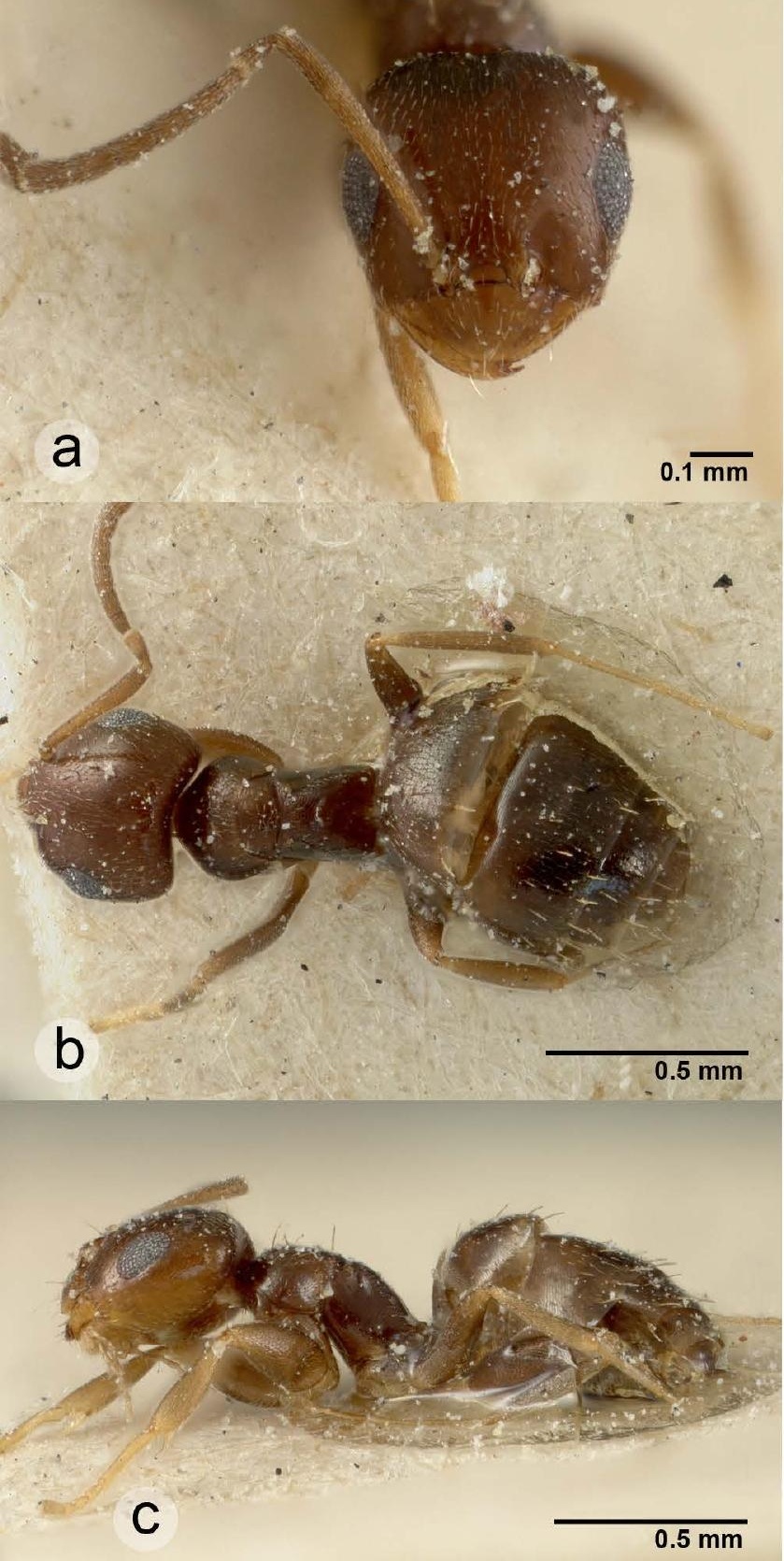


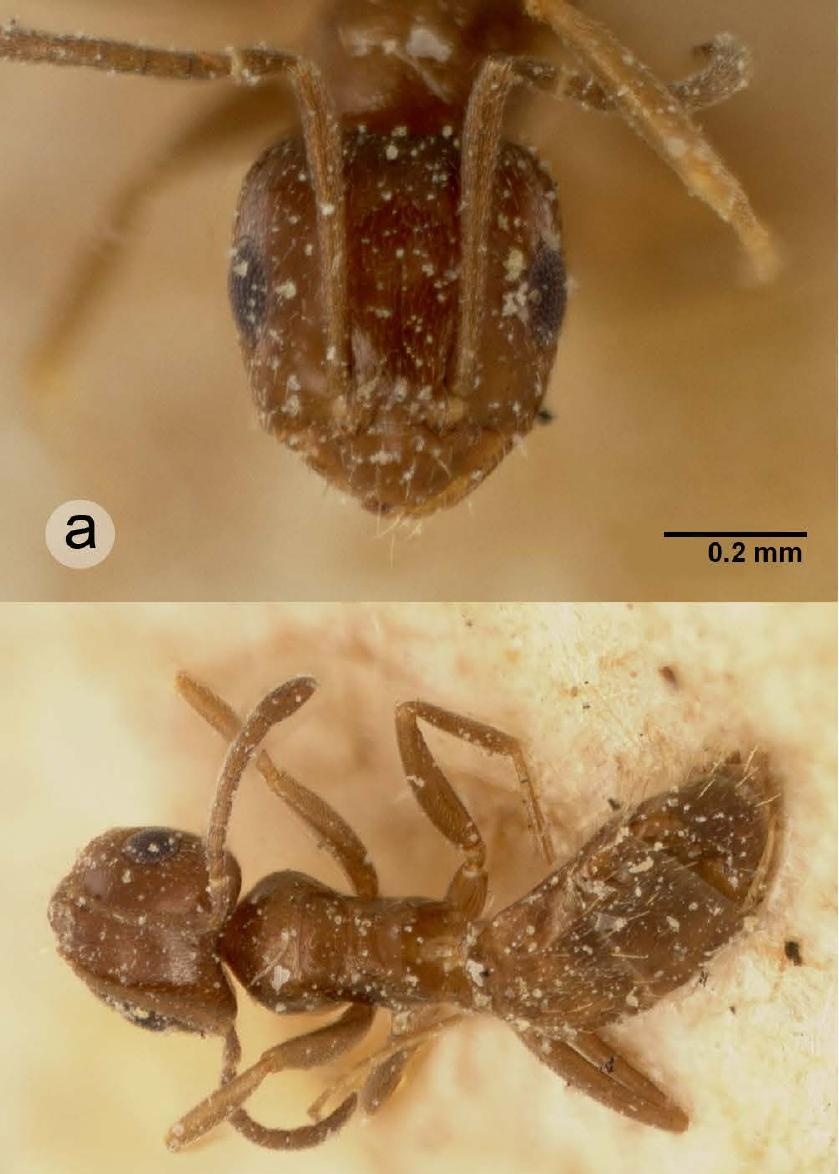

b

$0.5 \mathrm{~mm}$

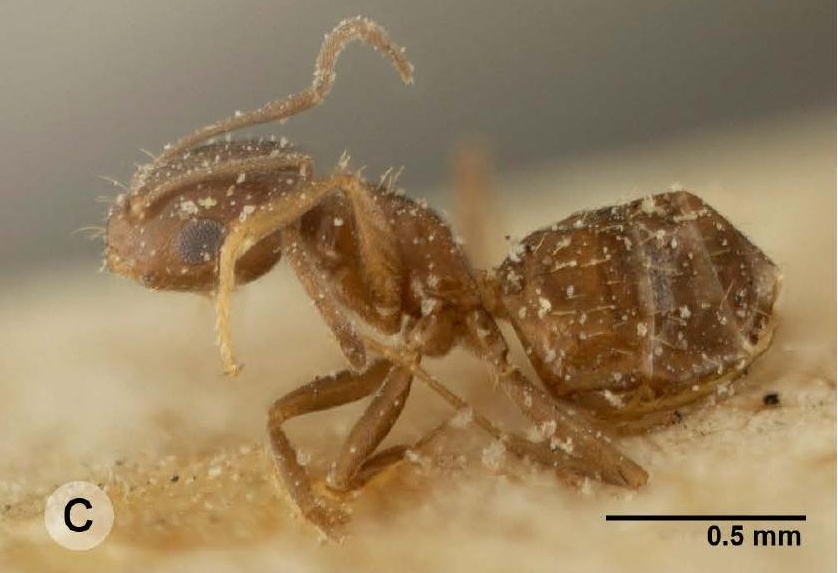




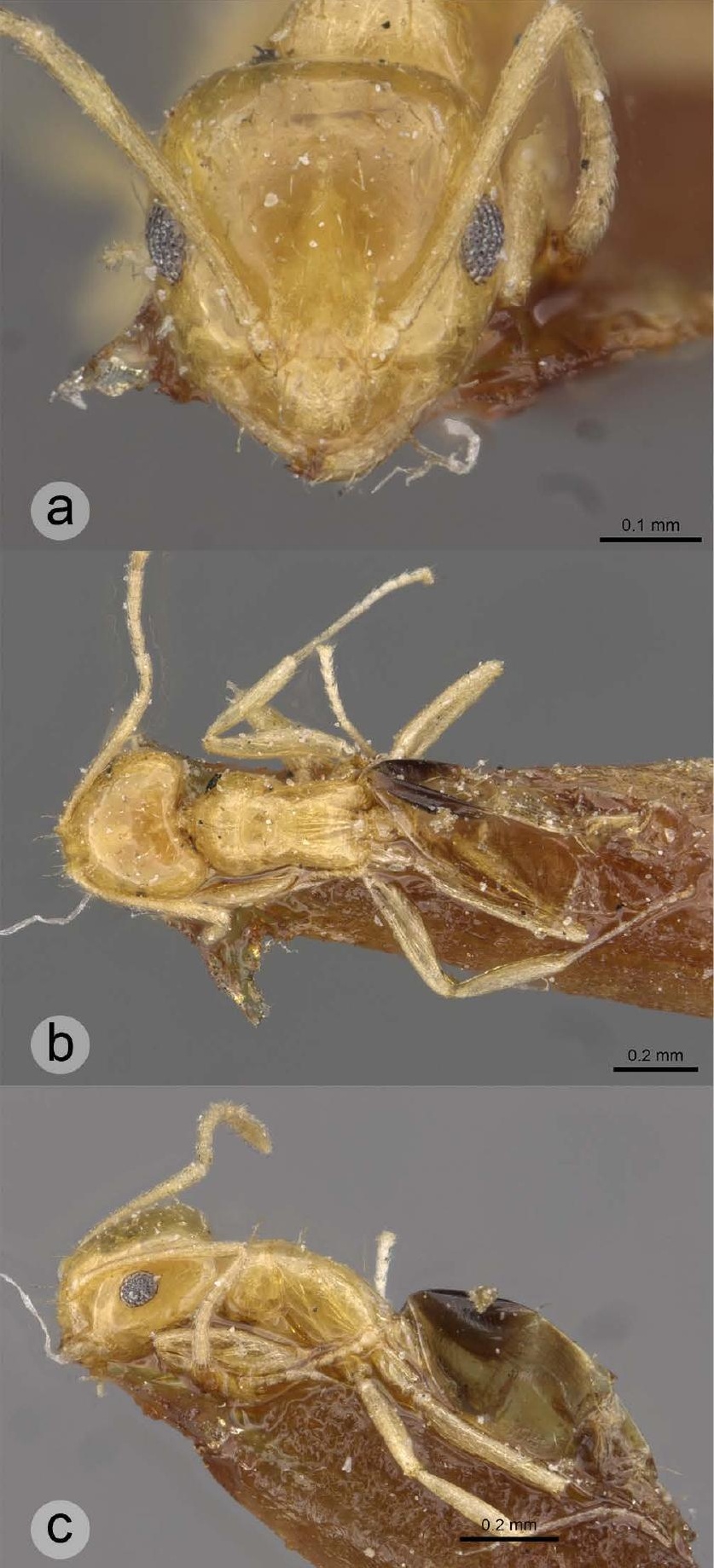



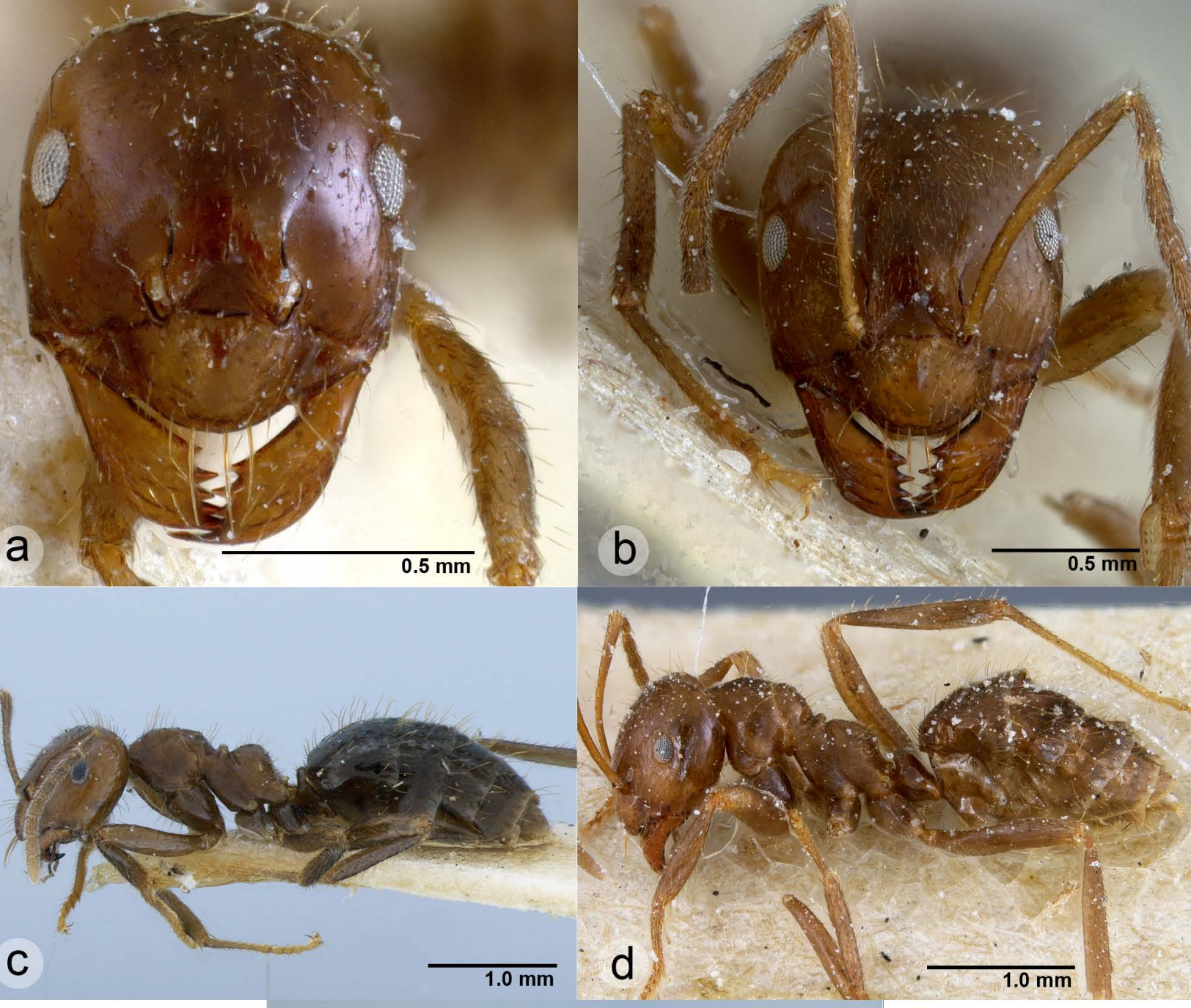


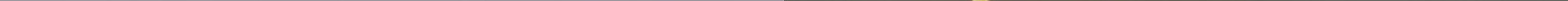



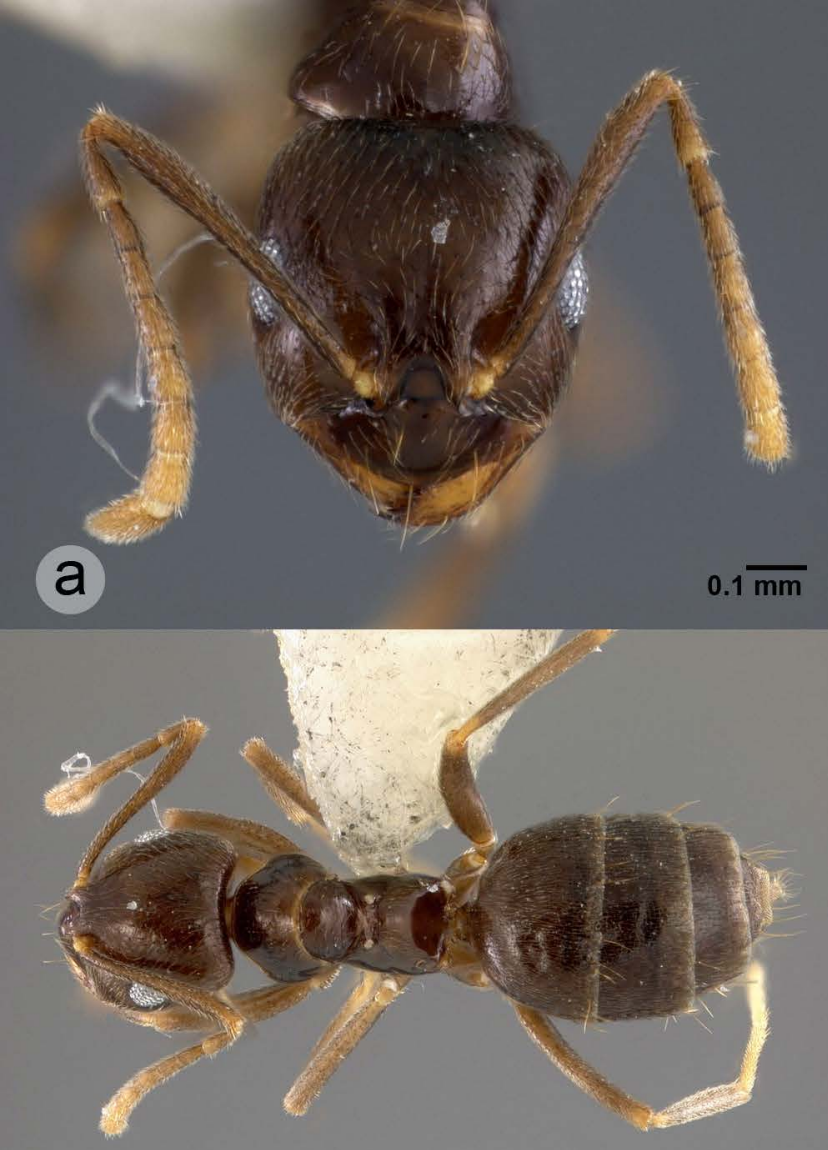

b

$0.5 \mathrm{~mm}$

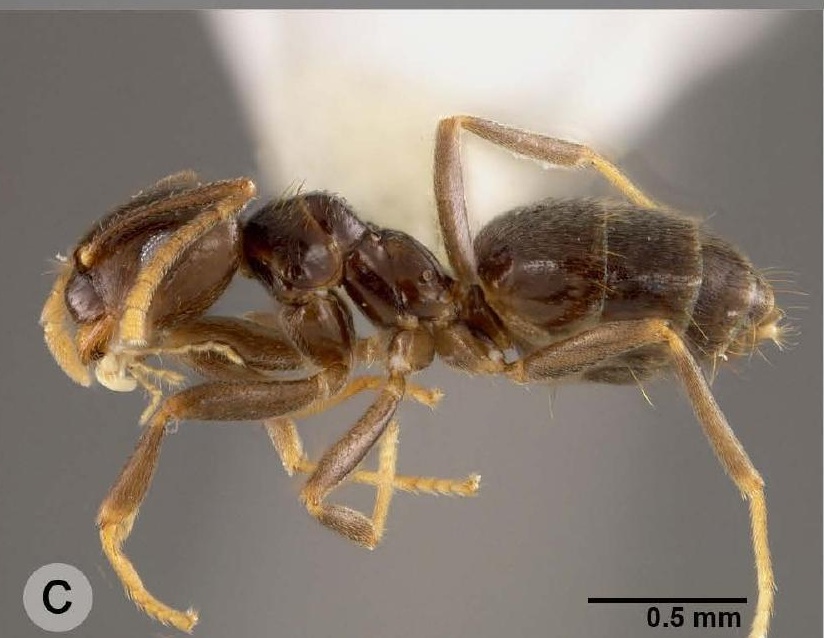



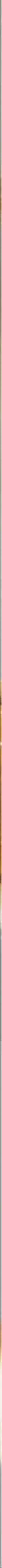


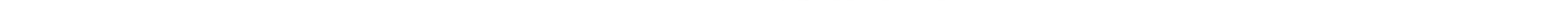




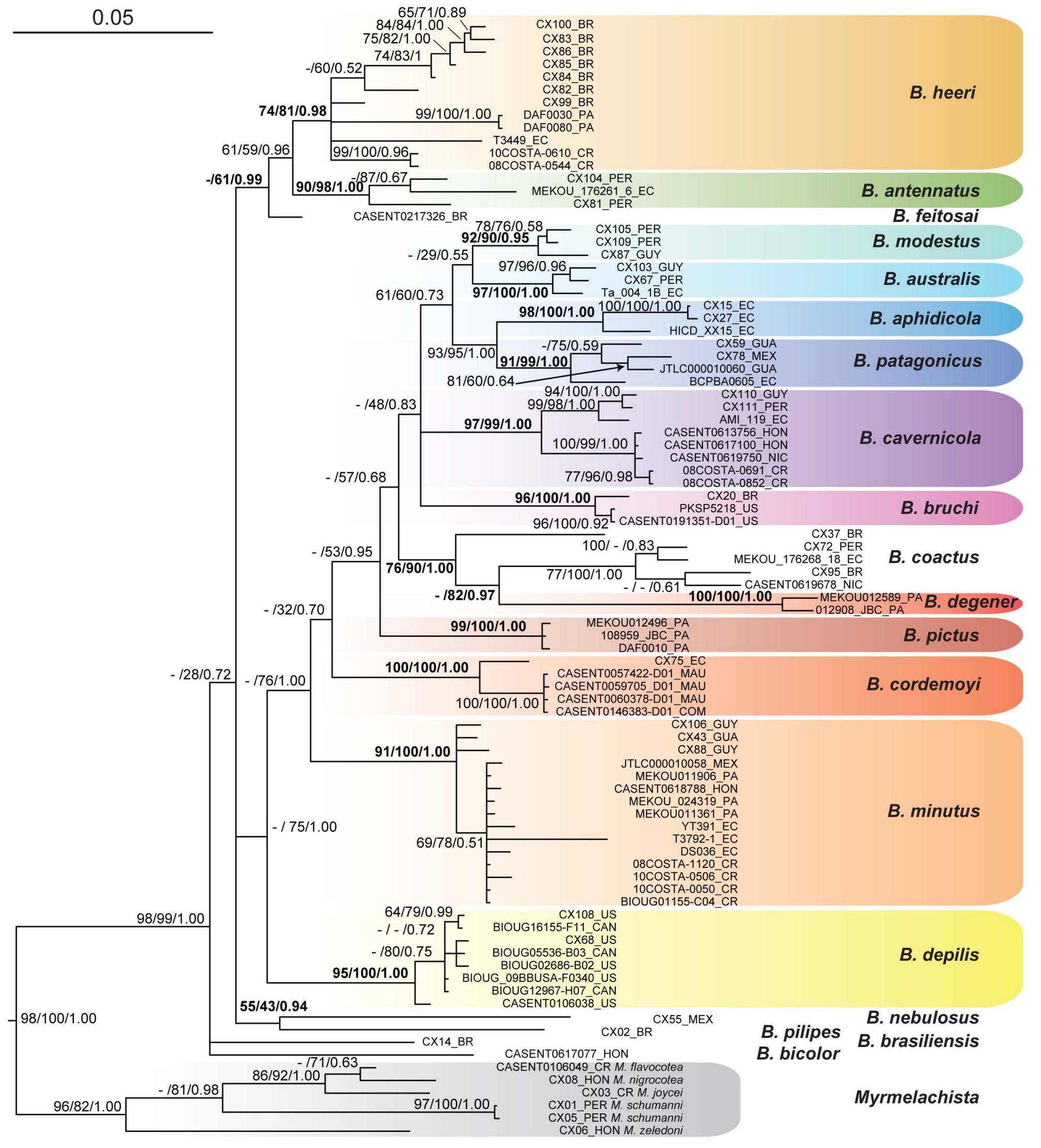

